University of Louisville ThinkIR: The University of Louisville's Institutional Repository

Electronic Theses and Dissertations

$12-2015$

\title{
Differences in the impact of a healthy relationship intervention on family cohesion, parent-child relationship and child well-being by intimate partner violence relationship type.
}

Erin E. Ness Roberts

University of Louisville

Follow this and additional works at: https://ir.library.louisville.edu/etd

Part of the Social Work Commons

\section{Recommended Citation}

Ness Roberts, Erin E., "Differences in the impact of a healthy relationship intervention on family cohesion, parent-child relationship and child well-being by intimate partner violence relationship type." (2015). Electronic Theses and Dissertations. Paper 2308.

https://doi.org/10.18297/etd/2308

This Doctoral Dissertation is brought to you for free and open access by ThinkIR: The University of Louisville's Institutional Repository. It has been accepted for inclusion in Electronic Theses and Dissertations by an authorized administrator of ThinkIR: The University of Louisville's Institutional Repository. This title appears here courtesy of the author, who has retained all other copyrights. For more information, please contact thinkir@louisville.edu. 


\title{
DIFFERENCES IN THE IMPACT OF A HEALTHY RELATIONSHIP INTERVENTION ON FAMILY COHESION, PARENT-CHILD RELATIONSHIP AND CHILD WELL-BEING BY INTIMATE PARTNER VIOLENCE RELATIONSHIP TYPE
}

\author{
By \\ Erin E. Ness Roberts \\ B.A., Dickinson College, 2004 \\ MSSW-MFT, University of Louisville, 2010
}

\begin{abstract}
A Dissertation
Submitted to the Faculty of the Raymond A. Kent School of Social Work in Partial Fulfillment of the Requirements for the Degree of
\end{abstract}

Doctor of Philosophy in Social Work
Kent School of Social Work University of Louisville Louisville, Kentucky
And
College of Social Work University of Kentucky Lexington, Kentucky

December 2015 
Copyright 2015 by Erin Ness Roberts

All rights reserved 

DIFFERENCES IN THE IMPACT OF A HEALTHY RELATIONSHIP INTERVENTION ON FAMILY COHESION, PARENT-CHILD RELATIONSHIP AND CHILD WELL-BEING BY INTIMATE PARTNER VIOLENCE RELATIONSHIP TYPE

\author{
By \\ Erin E. Ness Roberts, \\ B.A., Dickinson College, 2004 \\ MSSW-MFT, University of Louisville, 2010
}

A Dissertation Approved on

November 24, 2015

by the following Dissertation Committee:

Becky F. Antle, Ph.D.

Anita Barbee, Ph.D.

Chris Flaherty, Ph.D.

Emma Sterrett, Ph.D.

Riaan van Zyl, Ph.D. 


\section{DEDICATION}

This dissertation is dedicated to my husband

Phillip L.W. Roberts

who has provided me with support and encouragement along the way.

and

to my parents

Kim and Greg Ness

who provided me with educational opportunities and guidance

and encouraged me to keep my

Light on in the Attic. 


\section{ACKNOWLEDGEMENTS}

This dissertation would not have been possible if not for the encouragement, support and help of my Committee Chair, Dr. Becky Antle. Her encouragement and the many hours she spent helping me bring this dissertation to fruition made this come to pass. I am forever grateful for the past seven years of professional mentorship and guidance. She provided me with so many opportunities along the way, not just with my dissertation, but also life learning and personal growth, and for that I am so grateful.

Thank you also to my committee members, who read countless drafts, and have also been instrumental in giving me opportunities to grow in the academic world. Thank you to Dr. Anita Barbee who provided me with employment and research experience throughout much of the doctoral program. I will fondly remember research "brainstorms" around registration tables on CHAMPS mornings. Thank you to Dr. Emma Sterrett who included me in her coding research; you made qualitative research come alive and I truly enjoyed working with you! Thank you to Dr. Riaan van Zyl for all your help with the data analysis and asking the tough analytical questions that made this research better. And thank you to Dr. Chris Flaherty for making the trek all the way from Lexington for a student unknown to him; I aspire to have that level of commitment to students and the profession.

Thank you to my Ph.D. Cohort, the fabulous seven women who were as alike as they were different, and came together to get us through. Your support meant the world to me and I am forever grateful.

Thank you as well to my grandparents, Mary \& John Piraino and Julie \& Carl Ness and their parents who worked very hard to make sure that we had the opportunities 
that we have. A special thanks to my Nana \& Papa who were very proud at the prospect of having a "dottore" in the family. Thank you for encouraging me along the way.

Thank you to my wonderful family, my husband Phillip, my parents, Kim and Greg Ness, Molly \& John, and my Aunt Joanne Miller. You were my support team and encouragement throughout the whole process. A final thank you to my friends that are like sisters, Christy, Leah, Sue, Katie, and Bekah, for their loving support and listening ears. 


\author{
ABSTRACT \\ DIFFERENCES IN THE IMPACT OF A HEALTHY RELATIONSHIP \\ INTERVENTION ON FAMILY COHESION, PARENT-CHILD RELATIONSHIP \\ AND CHILD WELL-BEING BY INTIMATE PARTNER VIOLENCE \\ RELATIONSHIP TYPE \\ Erin E. Ness Roberts
}

November 24,2015

Intimate Partner Violence (IPV) between the parents of children living at home has shown to have a profound effect on learning outcomes, developmental milestones, pediatric development, future mental health and overall physical safety and wellbeing (Anda, Block \& Felitti, 2003). Although much research has been done on outcomes of child-witnesses and parenting in IPV relationships, some evidence suggests (Kernsmith, 2006) that the role of family dynamics amongst parents, as part of the IPV dynamic, is a critical variable. Other researchers (Johnson, 1995; Graham-Kevan \& Archer, 2003) have theorized that violence with a high degree of controlling behaviors, often called Coercive Control Violence, only comprise some of the many incidences of IPV, and that physical violence with low or without power and control dynamics, often called Situational Violence, is more common in the general population. Although previous studies have shown (Johnson, 2006; Graham Kevan \& Archer, 2003; Antle \& Ness Roberts, 2012) that these two types of violence are etiologically different and have 
dissimilar reactions to treatment, research to date has not published the effect that controlling vs. non-controlling IPV has on family cohesion, the parent-child relationship, and child well-being, or what effect relationship education has on these outcomes within the two types of violence.

This dissertation preliminarily addresses the gap in the literature by analyzing preintervention data on child well-being, family cohesion, and the parent-child relationship in Coercive Control Violent (CCV), Situational Violent (SV) and No Violence (NV) relationships using a one-way MANOVA, testing the effect of the Within My Reach healthy relationship intervention on the three outcome measures by type of violence using three Repeated Measures ANOVAs, and finally, exploring what variables may have contributed to changes in the outcome variables (change in couple communication, relationship satisfaction, reduction in physical or psychological violence) using a Multiple Regression. Utilizing the survey data from a federally-funded healthy relationship grant, Relationship Education Across Louisville (REAL) that occurred over a five-year period of time from 2005-2010, low and high control violence groups were created using a k-means cluster analysis and compared to a No Violence group on three outcome measures: the Family Adaptability and Cohesion Scale (FACES), the Parent Child Relationship Scale (PCRS) and the Child Well-Being (CWB) scales. The cluster groups were created using the same process as Graham-Kevan and Archer (2006) that clustered groups by violence types of low and high control, similar to this study, using the Conflict Tactics Scale (CTS) to measure physical violence and the Controlling Behaviors Scale (CBS) to measure power, control and psychological violence. 
The study found that CCV adversely affected family cohesion, the parent child relationship and child well-being significantly more than SV (FACES $\mathrm{p}<.001 ; \mathrm{SD}=1.3$; PCRS $\mathrm{p}<.001 ; \mathrm{SD}=.957 ; \mathrm{CWB} \mathrm{p}<.005 ; \mathrm{SD}=1.13$ ) or No Violence (FACES $\mathrm{p}<.001$; $\mathrm{SD}=1.32$; $\mathrm{PCRS} \mathrm{p}<.001, \mathrm{SD}=.97, \mathrm{CWB} \mathrm{p}<.001, \mathrm{SD}=1.14)$ and that $\mathrm{SV}$ had the next most adverse outcomes but was only significantly different than the group without violence on the Parent-Child Relationships (PCRS $p<.01, \mathrm{SD}=.74$ ). Results were also indicative of greater impact of the WMR training on CCV than SV or NV groups, though they started with significantly worse outcomes. Regression analyses indicate that the reduction of physical violence and psychological violence at six-months post intervention had a significant impact on the parent-child relationship and that there was an overall effect of improvement in couple communication, and relationship satisfaction, reduction of physical and psychological violence explaining change in family cohesion and the parentchild relationship when $\mathrm{CCV}$ and $\mathrm{NV}$ groups were combined.

The implications of this research include a more complex understanding of how Intimate Partner Violence control dynamics affect family cohesion, the parent-child relationship and child well-being as well as how each violence type is differentially affected by treatment. The evidence that each violence group clustered drastically different on the means indicates as well that we may not have the understanding of the dynamics of IPV that have been historically presented. The study points to many areas of future research and significant policy and practice implications for the field of Intimate Partner Violence. 


\section{TABLE OF CONTENTS}

ACKNOWLEDGMENTS

Problem Statement............................................................ 1

Impact of Intimate Partner Violence on Child Well-being \& Parent-Child Relationship ................................................................. 4

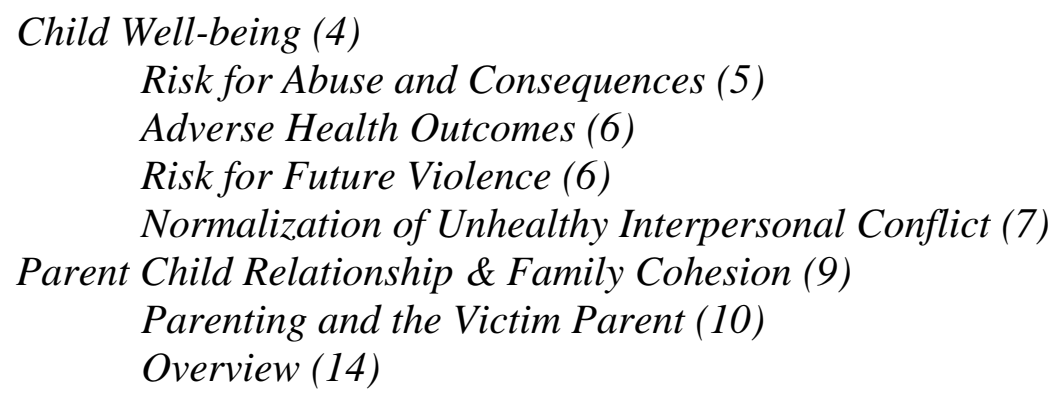

The Gap in Psychoeducation for Reducing Violence Recidivism in

Families

Perpetrator Only Treatment (15)

Dyadic Work with Couples (19)

Joint Treatment with Children (21)

PREP (25)

Love Notes (25)

Relationship Smarts (25)

Within My Reach (26)

Gap in Interventions Overview (27)

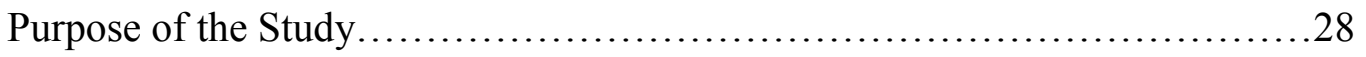

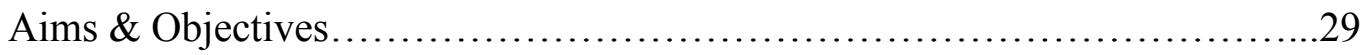

Criteria for Evaluation............................................... 30 
Topical Limitations.

Sampling Limitations (34)

Inability to Identify Perpetrator/Victim (35)

Measurement Limitations: Sexual Violence (36)

Self-Assessment Limitation (36)

Parental Mental Health (37)

Assessment on One Child (38)

Significance of Study............................................... 38

Research Questions...................................................40

Overview ........................................................ 40

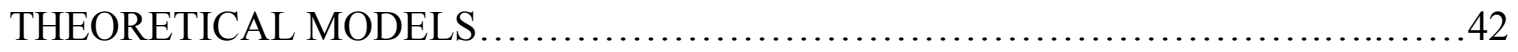

Introduction to Theoretical Models........................................43

Historical theories of Intimate Partner Violence............................44

Early History (43)

Middle Ages (44)

Early Legal History (44)

Impact of Feminism on the Duluth Model (1970s to Present) (45)

The Duluth Model.....................................................48

Michael Johnson \& Typology-based Theories.............................54

Using a Shelter Sample (59)

Theoretical Foundations of Johnson Theory (61)

Other Relationship Typology Research (62)

Relevance of Typology Research (68)

Creation of Controlling Behaviors Scale \& Use in Research (68)

Communication and Johnson Theory (71)

The Impact of IPV on Couple Communication

and Relationship Satisfaction (72)

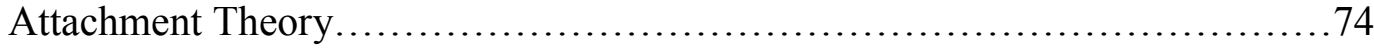

Trauma Theory................................................... 77

Social Learning \& Social Exchange Theories..............................79

Social Learning (79) 
Social Exchange (82)

Theoretical Integration to Intervention: Implications for this Study............83

Hypotheses.......................................................86

Research Question 1 (86)

Research Question 2 (87)

Research Question 3 (87)

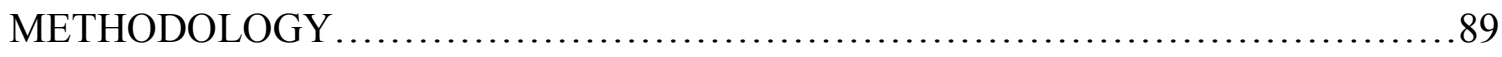

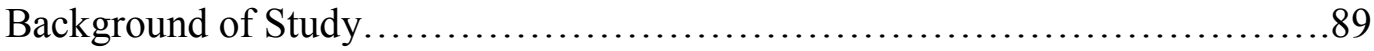

Research Design..................................................... 89

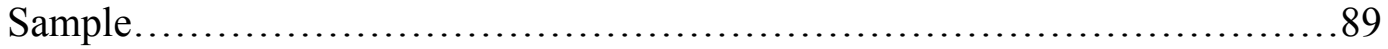

Variables and Measures............................................... 93

Presence of Physical Abuse (93)

Presence of Controlling Behaviors (94)

Family Cohesion (FACES) (94)

Parent-Child Relationship (PCRS (95)

Child Well-Being (95)

Couple Communication (RDS) (95)

Couple Relationship Quality (DAS) (96)

Recruitment and Data Collection Procedures.................................96

Recruitment (96)

Informed Consent (96)

Retention Strategies (97)

Randomization and Intervention (98)

Participant Reimbursement (100)

Pre-Treatment \& Post Treatment (101)

Data Analysis Plan. .101

Statistical Tests Used (104)

K-Means Cluster Analysis (104)

ANOVA (104)

Repeated Measures ANOVA (105)

MANOVA (105)

Multiple Regression (106)

Group Formation (107) 
Assumptions

RESULTS

111

Introduction

Process

Sample Characteristics (113)

Creation of No Violence \& Physical Violence Groups (113)

Creation of Groups based on Presence of Controlling Behaviors (115)

Overview of Data Analysis \& Research Questions Posed in Introduction......118

Research Question 1: One-way MANOVA...............................118

Baseline Differences in Violence Type

Research Question 2: Repeated Measures ANOVA

The Effect of WMR on Family Cohesion, Parent-Child Relationship \& Child Well-Being by Violence Type

Distribution Statistics (128)

Repeated Measures ANOVA for Family Cohesion (133)

Repeated Measures ANOVA for Parent-Child Relationship (139)

Repeated Measures ANOVA for Child Well-Being (145)

Research Question 3: Multiple Regression Analysis.

Exploring Potential Mediators of Change in Family Cohesion, ParentChild Relationship and Child Well-Being in CCV \& SV

Multiple Linear Regression Analysis Overview (151)

Family Cohesion (152)

Parent-Child Relationship (155)

Child Well-Being (157)

DISCUSSION 163

Overview

Summary of Findings

Baseline Differences (164)

$C C V$ at Baseline (164)

SV at Baseline (168) 
Interpretation of Results:

Family Cohesion (167)

Parent-Child Relationship (171)

Child Well-Being (172)

Potential Mediators of Change in PCRS, FACES, \& CWB (173)

Limitations 174

Sampling Limitations (174)

Response Rate at Follow-Up (175)

Potential Parents with Children Excluded (176)

Short-Comings of Methods (176)

Potential Self-Report Bias (176)

Psychologically Violent Rel. w/o Phys. Violence (177)

Data Analysis Decisions (178)

Threats to Validity (179)

Future Research

Further Definition and Exploratory Research (180)

Theoretical Approaches (182)

Future Treatment and Practice (183)

Implications of Study.

Policy Implications (184)

Court-Ordered Treatment of Perpetrators (185)

Mandated Reporting Implications (186)

Child Protective Services Implications (187)

Funding Implications (188)

Implications for First Responders (188)

Practice Implications (190)

Relationship Education for Children and Families (190)

Broader Definition of Family Violence (191)

Teaching to Students \& Practitioners (191)

Screening for Types of Violence (192)

Effective Treatment for Each Type of Violence (193)

SUMMARY AND CONCLUSIONS.

REFERENCES.

APPENDICES..

CURRICULUM VITA 


\section{LIST OF TABLES}

TABLE

PAGE

1. Definition of Key Terms ...................................................... 33

2. Conflict Theory and Related Theories.........................................50

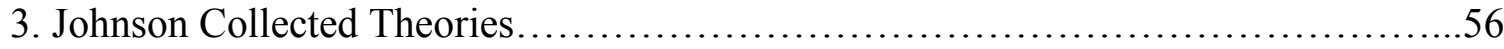

4. Intimate Partner Violence Typology Literature..........................................64

5. Participant Demographics.................................................. 92

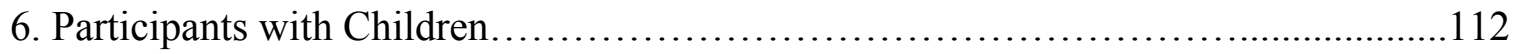

7. Number of Children in Participant's Homes..........................................113

8. Sample of Participants prior to Violence \& Non-Violence Groupings................114

9. Presence of Physical Violence Groups..........................................115

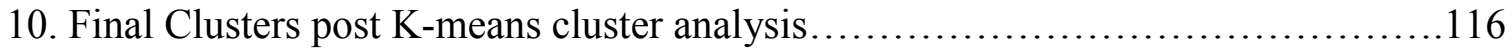

11. Iteration History for Cluster Analysis ........................................ 117

12. Final Cluster Centers for Cluster Analysis....................................117

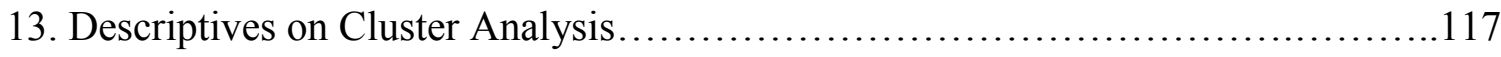

14. Differences in Mean in Cluster Analysis: ANOVA test...........................118

15. Descriptive Statistics for Baseline MANOVA...................................119

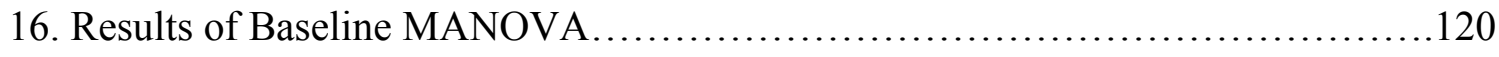

17. Test of Between-Subjects Effects for MANOVA..............................121

18. Multiple Comparison of MANOVA Using Tukey HSD ..................... 123

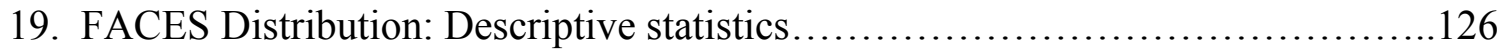


20. Parent-Child Relationship Distribution: Descriptive Statistics

21. Child Well-being Distribution: Descriptive Statistics

22. Results of Multivariate Test for Family Cohesion: RM ANOVA...................133

23. Main Effect of Time for Family Cohesion: RM ANOVA...................... 134

24. Main Effect of Group for Family Cohesion: RM ANOVA........................134

25. Main Effect of Violence Group for Family Cohesion: RM ANOVA...............135

26. Descriptive Statistics for Changes in Family Cohesion over Time by Group.......136

27. Post Hoc Analysis for Family Cohesion: RM ANOVA...........................138

28. Results of Multivariate Test for Parent-Child Relationship: RM ANOVA...........139

29. Main Effect of Time for Parent-Chile Relationships: Descriptive Statistics.........140

30. Main Effect of Group for Parent-Child Relationships: RM ANOVA................140

31. Main Effect of Violence Group for Parent-Child Relationship: RM ANOVA......141

32. Descriptive Stats for the Changes in PCRS Over Time by Group: RM ANOVA...142

33. Post Hoc Analysis for Parent-Child Relationship: RM ANOVA..................144

34. Results of Multivariate Test for Child Well-Being: RM ANOVA..................145

35. Main Effect of Time for Child Well-Being: RM ANOVA.......................146

36. Main Effect of Group for Child Well-Being: RM ANOVA......................147

37. Main Effect of Violence Group for Child Well-Being: RM ANOVA...............147

38. Descriptive Statistics for Changes in Child Well-Being over Time by Group........147

39. Post Hoc Analysis for Child Well-Being: RM ANOVA....................... 150

40. Model Summary for Family Cohesion: Multiple Regression $\ldots \ldots \ldots \ldots \ldots \ldots \ldots \ldots \ldots 2$

41. ANOVA Table for Family Cohesion: Multiple Regression ....................153

42. FACES Coefficients Table............................................. 154 
43. Collinearity Diagnostics for Family Cohesion.............................. 155

44. Model Summary for Parent Child Relationship: Multiple Regression..............156

45. ANOVA Table for Parent-Child Relationship: Multiple Regression...............156

46. Parent-Child Relationship Coefficients Table................................157

47. Collinearity Diagnostics for Parent-Child Relationship........................ 157

48. Model Summary for Child Well-Being..................................... 159

49. ANOVA Table for Child Well-Being: Multiple Regression .....................159

50. Child Well-Being Coefficients Table....................................... 161

51. Collinearity Diagnostics for Child Well-Being.............................. 163 


\section{LIST OF FIGURES}

$\begin{array}{lll}\text { FIGURE } & \text { PAGE }\end{array}$

0. Social Exchange Theory Diagram............................................. 82

1. Typologies in Theory and Potential Curriculum Pieces that Support Change...........85

2. Data Analysis Plan Diagram.................................................104

3.Formation of CCV, SV, \& NV Groups.......................................... 108

4.Results of the Cluster Analysis................................................... 108

5. Histogram of the Number of Children of Participants..............................112

6. Histogram Showing Variance in CTS Score.....................................114

7. Illustration of Difference Between DVs by Violence Type..........................119

8. Estimated Marginal Means of Family Cohesion..................................124

9. Estimated Marginal Means of Parent Child Relationship...........................124

10. Histogram for Testing Normality Family Cohesion............................128

11. Histogram for Testing Normality Parent-Child Relationship ....................131

12. Histogram for Testing Normality Child Well-Being ............................132

13. Cluster Number of Cases Family Cohesion of Time by Group....................136

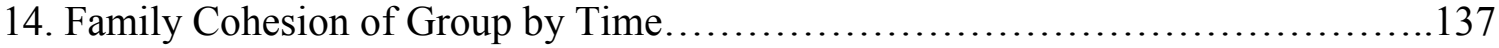

15. Parent-Child Relationship of Time by Group..................................143

16. Parent-Child Relationship Change Over Time By Group.........................143

17. Child Well-Being Of Time By Group ......................................148

18. Child Well-Being Over Time By Violence Type................................149 
19. Final Conceptual Figure for Study. 162 


\section{CHAPTER , INTRODUCTION}

\section{Problem Statement}

The impact of Intimate Partner Violence (IPV) can extend throughout generations and carry with it social, psychological and behavioral implications for individuals, families and society. Although IPV is widely researched and programs funded and implemented, the occurrence is still pervasive with $23.3 \%$ of women and $14 \%$ of men experiencing severe physical IPV and $46 \%$ of women experiencing severe psychological IPV in their lifetimes (Breiding et. al, 2011). The violence does not occur within the vacuum of the couple relationship, and it is estimated that 15.5 million children have witnessed IPV at home, with 7 million children living in a household where severe IPV occurs $^{1}$ (McDonald et al., 2006). The impact on children has shown to increase psychological maladaptation and mood dysregulation, cognitive difficulties, and relationship disturbances in adulthood. In recognizing the impact of witnessing and experiencing IPV as a child witness; relationship education, as well as psychoeducation programs for parents experiencing IPV, attempts to reduce violence in families. While

\footnotetext{
${ }^{1}$ These numbers are equivalent to the entire population of the city of Munich, Germany (7 million children) and the cities of Chicago \& New York City combined (15.5 million).
} 
many programs have limited success in reducing violence recidivism, the Relationship Education Across Louisville (REAL) grant that utilized the Within My Reach (WMR) training, reduced violence recidivism significantly across all groups ( $>>.05$; Antle et al., 2011). In meta-analyses of other programs, particularly those that attempt to reduce recidivism amongst perpetrators of IPV (Batterers Intervention Programs), "limited success" is defined as merely $5 \%$ of IPV perpetrators being less likely to re-perpetrate than those that never did the program (Babcock, Green \& Robie, 2004).

Typically these programs stem from one particular theoretical approach, which will be discussed more thoroughly in Chapter 2, however, the usage of an eclectic theoretical approach of Within My Reach may have contributed to its success in reaching families experiencing a variety of relationship violence types. This training came in part from the theoretical approach of Michael Johnson (1995), a social scientist who theorized that IPV manifested itself in multiple types, with the most prevalent types centered around the presence or absence of power and control dynamics. The violence type that contains power and control dynamics will be referred to as Coercive Control Violence $(\mathrm{CCV})$ and the violence type that does not have controlling dynamics will be referred to as Situational Violence (SV). These two types manifest themselves very differently in the relationship, but may both produce physical violence in the couple relationship, impact the child witness, and be lethal; and so in symptomology and by legal distinction they are both categorized as IPV without distinction between the two types. As a result, when treatment is recommended or court-ordered, parents in the violent relationship and their children may not receive the treatment that is most applicable for their type of violence. 
Also problematic is the gap in research on how the different types of violence may affect child well-being and the parent/child relationship. It is known that child wellbeing and the parent/child relationship is affected by relationship violence, however the effect by type of violence has not been measured by any other study to date. The WMR study collected data on child well-being and the parent child-relationship using the Child Well-being Inventory and the PCRS. The study also collected information that could distinguish violent relationship type by the two primary Johnson types of control vs. noncontrol based relationship violence. The impact of relationship education, specific to type of violence, has only been studied by Dr. Antle and colleagues as well as Dr. Gottman (Gottman et al, 2013).

This dissertation will look at the effect of violence type on family cohesion, parent-child relationship, and child well-being in Situational Violence and Coercive Control Violence before and after the Within My Reach training to see what differences control makes by violence type, and what difference the WMR training made in each violence type. The training teaches participants about both types of violence, focuses on relationship decision-making, healthy conflict management skill development, communication skills and the effects of violence on child well-being and the parent childrelationship.

Secondarily, this dissertation will also look at what in the training (change in communication, relationship satisfaction, reduction in violence, or reduction in controlling behaviors) was most impactful on child well-being, family cohesion and the parent-child relationship by violent relationship type pre to 6-mos post intervention and how that may impact future training and treatment. 


\section{Impact of IPV on Child Well-being, the Parent-Child Relationship and Family}

\section{Cohesion}

Child Well-Being. Witnessing IPV as a child impacts key features of child wellbeing, including behavioral and social functioning, mental and physical health (Rizo et al., 2011; Ireland \& Smith, 2009; Brown \& Bzostek, 2003; Silvern et al., 1995; Roustit et al., 2009; Russell, Springer \& Greenfield 2010; Graham, Bermann \& Seng, 2005; Anda, Block, Felitti, 2003). There is also an increased risk for physical and emotional abuse when there is violence in the home (Edleson, 1999; Hamby et al, 2010, Moylan et al, 2010; Rizo et al, 2011) as well as an increased risk for future health problems and relationship violence later in life (Noland et al, 2004; Kernsmith, 2006; Srofe, Egeland \& Carlson, 1999; Sover, 2005; Mitchel \& Finkelhor, 2001; Augustyn et al, 1995; Grych et al, 2002; Holden \& Richie, 199; Bowker 1988; McKibben, Devos \& Newberger, 1989;

Straus \& Gelles, 1990; Black, Susman, \& Unger, 2010; Capaldi \& Clark, 1998; Fite et al, 2008; Foo \& Margolin, 1995; Foshee, Bauman \& Linder; 1999; Foshee et al., 2011; Jouriles et al., 2012; O’Heare \& Margolin, 2000; Ritzel-Jaffe \& Wolfe, 2001; Riggs \& O’Leary; 1996; Williams et al., 2008; Wolfe et al., 1998).

Outcomes for children in homes where IPV occurs is bleak, with $63 \%$ of those children faring worse in behavioral, academic \& social functioning than a child of average functioning not exposed to IPV (Rizo, Macy, Ermentrout \& Johns, 2011). Ireland \& Smith (2009) found that exposure to severe IPV led to increased risk for antisocial behavior and relationship aggression, as well as adolescent conduct problems. Children witnessing IPV are more likely to exhibit childhood depression than children not living in homes with IPV (Brown \& Bzostek, 2003). Child witnesses are also more 
likely to experience symptoms of PTSD such as bed-wetting, nightmares and flashbacks and are also more likely than their peers to get physically ill, experience gastrointestinal issues, allergies, asthma, the flu and headaches (Graham-Bermann \& Seng, 2005). In addition, girls who have witnessed IPV between their parents are more likely to experience dating violence as an adolescent (Noland, Liller, McDermott, Couter \& Seraphine, 2004).

Risk for Abuse and Consequences. Along with the risks of witnessing IPV between parents, there is also an increased risk for childhood physical, emotional and sexual abuse and neglect in violent homes (Edleson, 1999, Hamby, Finkelhor, Turner \& Omrod, 2010, Moylan et al, 2010, Rizo, Macy Ermentrout \& Johns, 2011). In families that experience IPV, 60-70\% have children who are also abused (Bowker, 1988, McKibben, Devos \& Newberger, 1989, Straus \& Gelles, 1990) and it is estimated that $30-60 \%$ of offenders who perpetrate on their partners also abuse their children (Strauss, Gelles, and Smith, 1990). Child abuse can compound adverse developmental, social and psychological outcomes for children especially in conjunction with witnessing IPV alone. These outcomes include depression, anxiety, guilt and helplessness (for not being able to stop the abuse), behavior problems, problems at school, and issues with interpersonal relationships. Other long-term effects for children include mental health effects, including PTSD, anxiety and depression. Child victims of abuse are at a high risk for being re-victimized later in life in Intimate Partner relationships. Surveying women who are in abusive relationships as adults, $71 \%$ report an incident of physical child abuse and $53 \%$ report an incident of sexual abuse as a child (US Dept. of Justice, 2000). Kernsmith (2006) also found that $61 \%$ of batterers have been victims of childhood physical abuse 
and $71 \%$ were emotionally abused. Higher rates of conduct disorder occur in children who are abused, which is a disorder often associated with future IPV violence perpetration (Ehrensaft et al., 2003 in Stover 2005).

Adverse Health Outcomes in Adulthood. Adverse mental health outcomes of witnessing violence between parents does not end in childhood but continues through adulthood, with child witnesses experiencing higher levels of adult depression (Silvern, et al., 1995) and psychosocial maladjustment. Adults that have witnessed IPV in childhood are also at a higher risk of alcohol abuse \& child maltreatment of their own children (Roustit, et al., 2009, Russell, Springer \& Greenfield, 2010). They are also more likely to have health problems later on such as substance abuse (in particular tobacco use), obesity, cancer, heart disease and depression (Anda, Block, Felitti, 2003).

Risk for Future Violence. Children who have witnessed IPV between their parents are also more likely to either become victims or perpetrators (Ehernsaft et al, 2003; Magdo, Moffitt, Caspi \& Silva, 1998) in adult relationships (Kernsmith, 2006). Witnessing parental violence increases risk for future IPV victimization in adulthood by 158\% (Mitchell \& Finkelhor, 2001). Males were 115\% more likely, while females were $228 \%$ more likely to experience future IPV victimization (Mitchell \& Finkelhor, 2001) if they were a child witness to parental violence. Exposure to family violence is a predictive factor for future perpetration as well as difficulties sustaining peer relationships and "coordinating close friendships (Srofe, Egeland \& Carlson, 1999 in Stover, 2005, p.449)." 74\% of perpetrators of IPV have witnessed IPV in their childhood homes in a study of over 100 perpetrators of IPV (Kernsmith, 2006). Exposure to violence as a child is also associated with future psychiatric $\&$ behavioral problems 
(Augustyn, Parker, Groves \& Zuckerman, 1995, Grych, Jouriles, Swank, McDonald \& Norwood, 2002, Holden \& Richie 1991 in Stover, 2005) which can also lead to an increased risk of perpetration or victimization.

Normalization of Unhealthy Interpersonal Conflict. Additionally, Kernsmith (2006) found that the relationship between childhood experience of witnessing IPV between parents and risk for future relationship violence was mediated by the normalization of attributes of power and control within the relationship, not due to witnessing the actual acts of physical violence. When the subjects were surveyed, Kernsmith (2006) found that children identified that "hitting" was wrong, however were unaware of the harms of controlling behavior, stating, "Children from violent homes may be more likely to be able to find rationalizations for their physically abusive behaviors (63)." Unlike the Antle WMR study or the Gottman (2013) study, the Kernsmith study (2006) did not differentiate families that had physical violence intertwined with attributes of power and control and those who experienced physical violence alone, however, this is a related find that shows violent relationship control as an important indicator in child development.

Further study needs to determine the differentiating factors between Coercive Control Violence and Situational Violence as an important indicator of future violence for child witnesses. Kernsmith's (2006) finding speaks to the underlying psychological construction and conceptualization of relationships. The observed interaction patterns between parents can impress on a child how to get what they want in a relationship, what is acceptable, and what loving behavior looks like. Seeing systems of psychologically or physically violent behavior can impress on a child that these are normal relationship 
dynamics that can factor into their risk of being a future victim or perpetrator with their own partner.

The dynamic of control may be so rooted in a control-based violent relationship dynamic, that it can be difficult for the child of Coercive Control Violence to recognize a relationship without it. These control dynamics include Intimidation, Threats, Economic Control, Isolation, and Emotional Abuse (Pence \& Paymar, 1986). These control dynamics can ignite into physical violence in the relationship. These elements can also cause a great degree of partner blame, and the partner's acceptance of blame due to a belief that if the demands of control were met, the violence would not have occurred. In non/low-controlling relationships, children can also recognize the underlying relational dynamics that go along with Situational Violence, such as poor communication, escalation of a verbal argument into a physical argument, putting one's partner down, withdrawal from the conversation or stonewalling, or negatively interpreting what their partner is communicating (Stanley \& Markman, 2002, Gottman, Markman, Stanley, PREP, 2012).

These findings show that the relationship that the individual has with their families is a key component in contributing to one's risk for experiencing future IPV, although the exact mechanism for how that transmission occurs is still the subject of research (Black, Susman \& Unger, 2010; Capaldi \& Clark, 1998; Fite, et al., 2008; Foo \& Margolin, 1995; Foshee, Bauman, \& Linder, 1999; Foshee, et al., 2011; Jouriles et al., 2012; O'Heare \& Margolin, 2000; Reitzel-Jaffe \& Wolfe, 2001; Riggs \& O’Leary,1996; Williams et al., 2008; Wolfe et al.,1998). 
IPV Effect on the Parent-Child Relationship and Family Cohesion. IPV in a relationship can also have an effect on the parent-child relationship and although there is some evidence of this being a positive effect of creating closeness, several factors may influence the ability to parent effectively when in an IPV relationship (Levendosky \& Graham-Bermann, 2000, 2001; Margolin, Gordis, Medina \& Oliver, 2003). The majority of research on IPV has been done with victims from shelter populations and perpetrators in the court system, both of which have a higher rate of Coercive Control Violence (Johnson, 1995), the majority of literature written focuses on the effect that type of IPV has on parenting and the parent-child relationship. This section will discuss the effect of IPV on the victim as parent as well as the perpetrator as parent and how the dynamic of Coercive Control Violence can affect the parent-child relationship. Quality parenting can have a mediating effect and be a protective factor for the impact of IPV on externalizing behaviors (Levedosky \& Graham-Bermann 2001; McCloskey, Figueredo \& Koss, 1995). Levendosky et al. (2009) gave three reasons for this phenomenon:

Parenting has an important influence over a child's behavior

Parenting influences a child's attachment style

Maternal mental health has an influence on parenting.

As quality parenting is a protective factor for the child to shield them from the many effects of the violence discussed above, it is important to study as well, how victim parents are able to provide quality parenting amidst the stress of a violent relationship. Below is a brief overview of the research on how IPV affects victims as parents, both internally and in their role as parents, as well as how perpetrators of violence interact as parents. 
Parenting and Victim Parent. IPV can affect the victim parent's threshold of response for the child, as much attention is directed towards the needs of the violent partner. The 2009 research of Levondosky et al. (2009) found that past and current IPV has an influence on maternal functioning and "appeared to be associated with the mother's inability to respond warmly and sensitively to her infant; there is also increased hostility and disengagement in this relationship (549)." The victim parent often is forced to choose between the illusion of safely being with their abusive partner and giving their children the attention they need to grow and thrive. One of the components of controlbased violence is that perpetrators often must be the center of focus and often will intensely demand the victim's attention, which affects the entire family dynamic.

Due to the demanding nature of parenting, especially infants, the attention to the child may be very threatening to the offender, even if the offender is the biological parent to the child. Jealousy and possessiveness in control-based violence is cornerstone to Coercive Control Violence, and an offender may become very jealous of the attention the victim gives their child, becoming more possessive of the victim's time. In a stepfamily, where the child is not the biological child of the offender, the child may be blamed for taking the attention of the victim away from the perpetrator. The offender may go as far as to use the victim's attention of their child as a way to psychologically abuse the victim through accusations that the victim still reserves affection for the child's biological parent (Bancroft, 2002). The relationship dynamics of keeping the perpetrator as the center of attention has an effect on parenting, as the victim simply cannot keep the child as the center of focus without incurring the wrath of the perpetrator. 
IPV also has an influence on parenting in that it affects the mental health of the victim, which restricts their ability to parent fully, due to the nature of their untreated symptoms. Common mental health challenges that victims face due to IPV include depression, anxiety, Post-Traumatic Stress Disorder (PTSD) \& Substance Abuse (Warshaw, Sullivan \& Rivera, 2013).

Symptoms of major depressive disorder can include a blunted affect, feelings of extreme sadness, thoughts of suicide and attempted suicide, lack of energy and lethargy, and disengagement from normal activity (APA, 2014). These symptoms can have a great effect on parenting, and often victims are discouraged by abusive partners to seek mental health help for their depression or other condition, or are ridiculed for having the medical or mental health condition that is often caused by the abuse. Perpetrators also may coercively discourage their partner from seeking mental health services by using the threat of notifying Child Protective Services of the victim's mental health status. Lovejoy et al (2000) found that there was a strong association between current maternal depression and negative parenting behavior (Cummings \& Davis, 1994; Lyons-Ruth et al., 1990; Downey \& Coyne, 1990; Webster-Stratton \& Hammond, 1988; Conron \& Beardslee, 2009; Gelfand \& Teti, 1990; Leschied et al., 2005; Black et al., 2002; Burke, 2003).

There was also an association (although not as strong) between prior depression and current negative parenting behavior (Lovejoy et al., 2000). Parents experiencing IPV as victims are more likely to experience mental health challenges such as depression, anxiety, PTSD \& substance abuse as a result of their victimization, the symptoms of which can lead to a decrease in their normal parenting ability (Bogat, Levendosky, 
Theran, von Eye \& Davidson, 2003; Cascardi \& O’Leary, 1992; Kessler, Molnar, Feurer, \& Appelbaum, 2001; in Levendosky et al, 2009). Victimized parents suffering from psychological distress are more likely to disengage with their children and be less involved with parenting (Lyons-Ruth, Wolfe, Lyubchik \& Steingard, 2002, Pianta \& Egeand, 1990 in Levendosky et al 2009) which can lead to negative outcomes for their children. As their victimized parent experiences these mental health issues as a result of their abuse, children can take on a parentified role with other siblings, taking care of household chores or the parent in the place of the adult in the household (Chase et al., 1998; Jones and Wells, 1996; Bellow et al, 2005; Hooper, 2007; Miller et al. 2014).

Often there is a co-occurring Substance Disorder, as victims use the substance to self-medicate or temporarily escape the reality of their situation (NCDVTMH, 2012). Anxiety is also often present in the victim, where hypervigilance, a key diagnostic symptom of the disorder is also a survival mechanism in an IPV relationship. The ability to foresee potential dangers in the future, such as mood swings, violent acts and triggering situations with some consistency, produces hypervigilance and gives the victim some illusion on control, even with a partner that is unpredictable and controlling. PTSD is also common, 45-85\% prevalence, (Houskamp \& Foy, 1991; Kemp et al., 1991, 1995; Vitanza et al., 1995 in Levondosky \& Graham-Bermann, 2001) among victims, due to the trauma that the abusive relationship has incurred in their lives and the violence that victims have witnessed. Clients may have flashbacks and nightmares, and may react to situations outside of the abuse as they would in the abusive relationship, due to the trauma. 
Often, the role of IPV on the ability of the victim to parent their child is the focus; while not much has been written about the ability of the offender to parent their child. Parents that are abusive to their spouse are also more likely to physically and sexually abuse their children in the house, use children against their victimized parent, impart the abusive dynamic by using their children to divide the household against their victimized parent or other siblings, and can also be psychologically abusive to their children (Bancroft, Silverman, \& Ritchie, 2012). Children are also used to continue the dynamic of power and control even after the parents separate, and a co-parenting arrangement is implemented. Offenders may intimidate victims by threatening to take full custody of children, even threatening to use political, legal or social connections to help them take the children away from the victim in order to get what they are asking from them (Jaffe et al., 2003; Jaffe et al., 2008). According to the studies by Bancroft \& Silverman (2011), offenders often demand that the entire family cater to their moods of either joy or frustrations, by either demanding praise, quiet, physical attention or reaction, regardless of how each of the family member feels at the time. If the family member does not react according to how the abusing parent sees fit, the abusing parent may sulk or be vengeful, often blaming the abuse on the family member for not meeting their needs.

In an IPV relationship, with attributes of power and control, the victimized parent also can feel like their parenting is being watched and criticized, and so the type of parenting that the child receives is due largely to the abusive parent's point of view. The abusive parent might criticize and abuse the victim parent for giving the child too much attention (coddling, doting, etc.) even if the child is not receiving the proper attention needed and the abused parent wishes to fill that gap, but is fearful of retaliation. On the 
other hand, the abusive parent may accuse the victim parent of being a neglectful parent because they do not fulfill the high and ever-moving bar that the abusive parent sets, thus also causing a strained relationship between parent and child. The child, in this case may also not be receiving the attention needed in the right areas depending on the situation the abusive party sets up. While the bar may be set high for how the child dresses and looks while going to school, and the victim parent may be criticized and belittled for a hair out of place, or a scuff on the shoe, other areas, such as nurturing the child, emotional development, providing meals, etc. may not be emphasized as much by the abuser, so therefore, may not be in the full attention of the victim.

\section{Overview of the Effect of IPV on Child Well-being and the Parent-Child}

Relationship. Intimate Partner Violence has a profound effect on child-wellbeing that extends into the child's adult psychosocial development and relationship health.

Although much study has been done on the impact of witnessing partner violence, and the greater risk of being abused living in a house with violence, it has not been determined through research whether this is a result of witnessing arguments that get physical, such as in Situational Violence, or violence that includes controlling behaviors, as in Coercive Controlling Behaviors. From the literature it appears that there are more studies done on the effects of parenting and the parent-child relationship in an IPV relationship with controlling behaviors than those lacking controlling behaviors. This lends more importance to the study of how the absence or presence of control factors into child well-being and the parent-child relationship, which has not previously been studied. The literature does however show that experiencing IPV as a child witness does have a strong effect on child well-being and the parent-child relationship and so reducing the 
violence between parents and engaging the parents in positive communication strategies is pivotal in increasing child well-being, family cohesion, and the parent-child relationship. The next section will show some challenges in the field in implementing programs that successfully reduce violence recidivism.

\section{The gap in psychoeducation for reducing violence recidivism in families}

Interventions to reduce family violence range from individual, couple or family therapy, psychoeducational classes or intervention groups. The majority of interventions historically for IPV are based primarily in the control-based Coercive Control Violence, although some classes and groups, such as anger management may be better at addressing Situational Violence through increasing communication. The three main types of interventions that will be discussed in this section is perpetrator-only treatment, dyadic work with couples, joint treatment with children and the interventions that came out of the PREP framework, PREP, Love Notes, Relationship Smarts, and Within My Reach.

Perpetrator Only Treatment. Therapeutic approaches for perpetrator treatment often fall into two categories; Control-based violence (often called "Batterer Intervention") or Anger Management (Shamai \& Buchbinder, 2009) which are the groups that most perpetrators of Intimate Partner Violence are assigned to through the courts for treatment. These groups are generally educational and in the group format (Bannet \& Williams, 2001; Buttell \& Pike, 2003; Dobash \& Dobash, 2001; Edleson \& Tolman, 1992; Gondolf, 1997; Pence \&Paymar, 1993 in Shamai \& Buchbinder, 2009) but are not assigned based off of the type of violence (control-based violence or non-control-based) that the family is experiencing. 
Batterer Intervention generally focuses on educating perpetrators on the dynamic of male-dominance in society and in the home, and encouraging them to accept responsibility for their violent actions, and making amends for the harm that they have caused to their victims and families (in Shamai \& Buchbinder, 2009). This type of group aims to change men's cognitions, attitudes and behaviors through education of the power and control dynamic. Anger Management groups focus more on educating violent offenders of IPV on social behavior skills, such as anger management, relational skills and assertiveness (Edleson \& Tolman, 1992; Rosenbaum \& Leisring, 2001 in Shamai \& Buchbinder, 2009). This group often comes from a cognitive behavioral standpoint and emphasizes recognizing triggers to anger, and training offenders to control their violent episodes (Shamai \& Buchbinder, 2009).

One of the predominant issues is that, within the court and perpetrator-treatment system there is no assignment of groups based on Coercive Control Violence or Situational Violence. Within the greater community, more couples generally experience Situational Violence than CCV (Johnson, 1996) however, within the court-system, there is no distinction between types of Intimate Partner Violence. A judge may sentence a control-based perpetrator to an anger management group which may prove to be ineffective for that individual because it does not address his issue. On the flipside, an offender who is experiencing anger management issues or communication deficits with their partner may be overwhelmed by the power and control model and may think the class irrelevant and thus unhelpful for what he is experiencing. Another weakness with perpetrator-only treatment is that it may not address the entirety of the relationship dynamic by not engaging the entire family in processing the relationship violence. 
Some researchers have found that perpetrator treatment was not effective using a Coercive Control Violence method of confronting perpetrators on their power and control and that although this treatment has short-term effects it does not have long term effects (post three months). Shephard found that $40 \%$ of participants were arrested again for domestic assault in the next 5 years (1993). Van Wormer and Bednar (2002) found that facilitators were supposed to function solely on identifying participant's power and control tactics and were responsible for changing them or shutting them down. During this intervention, male perpetrators, who already may have some gender issues, are presented with a pro-feminist theoretical approach, which may shut them down or cause them to become hostile in a group. While this approach may be effective perhaps for some individuals in the group, this also may have a negative effect for some that may learn from their leaders on how to shut others down or challenge them on their believes. Thus they may become smarter in their controlling tactics, by being less physically violent to being more psychologically and emotionally violent. Due to the popularity and recognition of more of a controlling-type violence method, and frequent use in Batterer Treatment, this type of treatment has been researched more widely than other interventions for perpetrators, as has the impact of this type of treatment on IPV perpetration. It is also important to be mindful that not all Coercive Control Violence contains physical abuse, and that victims of these offenders may have experienced mental health symptoms such as anxiety, depression and PTSD related to IPV, but due to legal definitions of IPV as containing physical battering, the case may have not gone through the court system. Thus, those perpetrators of violence often do not receive treatment. 
There is a large gap in the literature, as found by Scott, King, McGinn \& Hosseini (2011) who did a literature review on the current knowledge of all batterer treatment programs. They found that there were only a total of 40 published studies and 5 metaanalyses, all of which showed low to moderate outcomes in treatment for perpetrators. They write that there is an acknowledgement in the field that more study needs to be done, and they brought a non-mainstream IPV treatment, Motivational Interviewing (MI) model to the research literature. They found that although a "sizable proportion of the men were considered "unsuccessful" by current standards of measuring intervention success in IPV perpetrator treatment, $(20 \%$ of clients were rated as "participating inappropriately" \& $18 \%$ did not take "accountability for their behavior in their program"), that they had a statistically significant change in attrition rate. This could be attributed to their higher completion rate in their MI group (84.2\% resistant batterer completion in MI group v. $46.5 \%$ resistant \& $61.1 \%$ non-resistant completers in standard batterer Duluth model treatment), which is also correlated in the literature with a $20 \%$ reduction in chance of re-assault (Bennett et al, 2007 and Gondolf, 2002). This study is critical in examining how we are measuring the effectiveness of IPV batterer treatment and what our purpose and ethical duty is in bringing effective treatment to practice. If it is our purpose in IPV intervention treatment to measure intervention success by appropriate participation by the perpetrator and how much accountability he takes for his actions, then we may measure a program "successful" with a high violence recidivism rate. Defining the outcomes that are critical and uniform to success is imperative to create congruency in intervention research so we avoid "cherry-picking" advantageous results. 
Dyadic Work with IPV couples. Perhaps one of the most controversial treatments for Intimate Partner Violence is IPV dyadic work with couples. Stith et al (2004) found that male violence recidivism rates were significantly lower in a multi-couple intervention (25\%) than in the comparison group (66\%) but found that those in individual couple therapy were not significantly less likely to recidivate (43\%) than those in the comparison group. Although it has shown to be only moderately effective (Eckhardt et al, 2006) Dyadic Work with couples has proven to be as effective as control-based Batterer Intervention Treatment in reducing further incidences of IPV (Fals-Stewart, Kashdan, O’Farrell \& Birchler, 2002, O’Leary, Heyman, \& Neidig, 2002 in Stith et al, 2004) However, this intervention poses some ethical dilemmas for practice. A perpetrator could be manipulating their victim as well as the therapist within the session, giving a false sense of safety to the therapist and perhaps to the victim. Also a safety issue, a victim who may be encouraged to confront her partner in the therapy session could be put at greater risk for violence once out of the session (Jacobson \& Gottman, 1998). The victim could also share something in a session that the perpetrator does not like and that the perpetrator could use against the victim at home. The practicing therapist has to tread carefully between keeping both clients safe, effectively intervening, and keeping confidentiality while reporting under the law.

The Creating Healthy Relationships Program or CHRP, is a psycho-education program that was created based off of the research of John Gottman and the Sound House Relationship Theory (Gottman, 1994). One of the key findings of research by Bradley \& Gottman (2012) which tested this program for effectiveness was that this training could safely be used with couples that were experiencing Situational Violence and that 
treatment using this method led to a decrease in the occurrence of violence. In the article, Bradley \& Gottman (2012) supported Johnson (1995)'s theory of types of violence and also acknowledged that it may be dangerous to Coercive Control Violent couples treated together because of the element of control that can start to build within the therapeutic dynamic.

Virginia Tech, through NIMH funding ran an 18-week manualized program called the Domestic Violence-Focused Couples Treatment (DVFCT) which split the couple into two groups that ran simultaneously with co-therapists which would then come together to do couples sessions, educational programs and safety planning (Stith et al., 2012). The couples were randomly assigned into either a multi-couple group or a single couple group and the result of the intervention was a significant reduction in violence (Stith \& McCollum, 2009; Stith, McCollum, \& Rosen, 2011; Stith, McCollum, Rosen, Locke, \& Goldberg, 2005; Stith, Rosen, McCollum, \& Thomsen, 2004). In this study they did not differentiate between Situational Violence and Coercive Control Violence, however, generally clinicians agree that couples experiencing Coercive Control Violence should not be treated together because of the increased safety risk to the victim (Gottman, 1993).

Recent studies by Gottman have incorporated skills-based healthy relationship group education classes for low-income couples using only situational-violence couples (Bradley \& Gottman, in press). Inclusion criteria in the study included couple involvement in a situational violence relationship that did not include drug or alcohol addiction or diagnosis of antisocial personality disorder $(n=115)$. Couples that were defined as "Characterologically Violent" (or Coercive Control Violence) were not 
included in the intervention. The article states that this decision was made due to the magnitude of the research done on programming in $\mathrm{CCV}$ and lack of research in Situational Violence. The research found that using a skills-based approach for couples rather than an attitude-changing approach (commonly used to treat $\mathrm{CCV}$ ) reduced Intimate Partner Violence through conflict management skills and attitude toward violence change. Bradley \& Gottman (in press) encourage research that correctly categorizes SV \& CCV groups and the impact of relationship interventions on each type. Although this dissertation looks at low-income individuals, like Bradley and Gottman's study, the WMR training did not treat couples together and discourages couples from taking the class due to safety concerns. However, this training's sample of individuals comprised SV and CCV relationship involvement, which has enabled us to split the sample by relationship violence type to study the effect of the training on each type.

Joint treatment with Children. In a 2011 meta-analysis of family interventions for IPV with children as the focus, or having children as a component of treatment, the authors evaluated 31 studies that looked at the effectiveness of programs that included joint treatment with children (Rizo, Macy, Ermentrout, \& Johns, 2012). Many of these studies had a small sample size $(\mathrm{n}<50)$, however some had a considerable sample size from 50-223 participants.

Twelve of the studies focused on children with children-only interventions or interventions that involved children (6 studies) and one or both of their parents (6 studies). Many of these studies (10 of 12) had less than 50 participants and all but two were quasi-experimental or non-experimental designs. Nearly all studies showed an 
improvement in behavioral regulation, knowledge of safe behaviors and relationships, and a reduction in post-traumatic stress symptoms (Rizo et al, 2011).

Rizo et al (2011) evaluated four studies that were categorized as crisis and outreach interventions. One of the strengths of this category was that two of the studies were an experimental design, the only two in the entire meta-analysis. This category of information included the delivery of case management or a referral card with safety planning information and resources. Part of the child component involved education on Intimate Partner Violence and safety planning for the child. Outcomes for these studies included improvements in child behaviors (McFarlane et al, 2005a, 2005b in Rizo et al, 2011) and an increase in child understanding of IPV, safety planning and non-self-blame (Ernst et al., 2008 in Rizo et al, 2011).

Three parenting interventions were evaluated as well by Rizo et al. (2011), one that focused on mothers (Peled, Davidson-Arad and Perel, 2010), one on fathers (Scott \& Crooks, 2007) and one on children and their caregivers (Ducharme, Atkinson \& Poulton, 2000). Each intervention had positive outcomes in different areas. The mother-focused intervention showed a reduction in parenting stress (Peled et al, 2010). The fatherfocused intervention showed a reduction in hostility and aggression, rejection of children and angry arousal to child and family situations (Scott \& Crooks, 2007); and the childbased intervention showed a reduction in problem-behavior (Ducharme et al., 2000).

Multicomponent interventions, involved treatment that combined parenting, therapy and advocacy, and the Rizo et al meta-analysis (2011) found that nearly all of the studies increased positive child behavior, positive child/parent interactions, reduced parent stress and increased parent confidence. There was also evidence that symptoms 
congruent with post-traumatic stress such as depression, anxiety, and trauma also decreased with intervention causing greater psychological functioning (Rizo et al, 2011).

Overall, these studies show a trend of improvement from multiple treatment points, meaning from a systems perspective, no matter which family member you treat, the system as a whole improves. From this meta-analysis by Rizo et al (2011) we see that treating one, two or multiple members of the family increases positive psychological wellbeing and behaviors as well as the family's knowledge of pro-social, anti-violence behaviors. In examining the Within My Reach intervention (see below) where participants were not allowed to come with a family member or intimate partner, we also see the potential impact of one family member on the entire system and what implications this could have for child well-being and relationship health.

PREP. The Prevention and Relationship Enhancement Program (PREP) training was created by Scott Stanley and Howard Markman and is the most widely researched relationship training available (Markman \& Rhodes, in press). Originally created as a marriage-enrichment program, it has since gone through many adaptations to suit the needs of diverse populations such as at-risk populations, adolescents, military families, fathers, churches, prisons, and even the workplace. In a meta-analysis of relationship education by Jakubowski, Milne, Brunner \& Miller, (2004) they found that PREP showed the most evidence for efficacy amongst all of the relationship education programs. PREP has been shown to increase marital satisfaction up to 5 years post-marriage relative to a control group in two studies (Hahlweg et al, 1998; Markman, Renick, Floyd, Stanley \& Clements, 1993). At three years post-marriage in a randomized control trial (Markman, Floyd, Stanley \& Storassli, 1988) found that relationship satisfaction and sexual 
satisfaction were higher in the PREP intervention group than in the control group and that the PREP group had lower levels of marital distress and problematic behavior. Couples who took PREP prior to marriage are much less likely to divorce over the course of five years than couples that did not take PREP (Hahlweg et al., 1998; Markman, Renick, Floyd, Stanley, \& Clements, 1993).

Interestingly, van Widenfeldt et al. (1997) found no difference between PREP and control groups after 2 years post intervention. Halford, Sanders \& Behrens (2001) hypothesized that the difference in time in the van Widenfeldt et al (1997) study accounted for the disputed data, mainly that two years may not have been sufficient time for the marital satisfaction piece to breakdown as with the passing of five years. Communication skills were also not measured in the van Widenfeldt (1997) study, and so it is unclear whether the couples also were able to attain the necessary communication skills (Halford, Sanders \& Behrens, 2001). However, the two studies that showed favorable results (Hahlweg et al, 1998; Markman, Renick, Floyd, Stanley \& Clements, 1993) were also not randomized control trials and the participants self-selected into PREP or an alternate training. This could have created self-selection bias, or it could speak more highly of the intervention, that although there was a selection bias, the participants may have worked on mastering the skills for their selected training, (including the control curriculum), thus the expected results may be a smaller difference between control and PREP.

Halford, Sanders \& Behrens (2001) created a variant of PREP called "SelfPREP," or "Self-regulatory PREP," which added self-regulation behaviors, and did a randomized control trial with both high-risk and low-risk individuals. They found that 
high-risk couples (defined by couples that experienced divorce or aggressive behaviors in their childhood families of origin) benefitted the most from PREP than low-risk couples in communication and relationship satisfaction. The results were congruent with what Antle \& Ness Roberts (2012) found in their Within My Reach communication research, that those experiencing controlling behaviors in their relationships often had more negative communication at baseline and improved more overall than those in a no-control violent relationship.

A version of PREP, "PREP Inside and Out" was used with a prison population $(n=224)$ with or without their partners present (Einhorn, Williams, Stanley, Wunderlin, Markman \& Easeman, 2008). They found significant differences pre to post on relationship satisfaction, dedication to the relationship, confidence, communication skills and friendship. Negative interactions and feelings of loneliness also significantly decreased amongst this population from pre to post.

Love Notes. Stemming from the PREP training and the Dibble Institute's Relationship Smarts Plus, Love U2 program is the adolescent training Love Notes. This training follows much of the same format as Within My Reach (see below), but is designed for a younger (12-21) audience, focusing on dating relationships and prevention of dating violence. The Love U2 program, that was the precursor to Relationship Smarts Plus, was studied by Adler-Baeder, Kerpelman, Schramm, Higginbotham, and Paulk (2007) who found that the program significantly reduced violent aggression among teens and significantly increased their knowledge and skills about relationships.

Relationship Smarts Plus by Marline Pearson, the same author as Love Notes, received the distinguished honor of placement on SAMHSA's National Registry of 
Evidence-based Programs and Practices. It received high scores in the areas of quality of research (2.75) and for readiness and dissemination (3). Love Notes is an adaptation of Relationship Smarts Plus which has already received approval as an evidence-based program, and Love Notes is currently under evaluation as an evidence-based program at the University of Louisville (Barbee, Antle, Langley, vanZyl, Sar, Christensen, Archuleta, Karem, in progress) through the CHAMPS program.

Within My Reach: The 15-hour Within My Reach training is also a subsidiary of PREP and focuses on individuals rather than couples that are currently involved in or are at risk for relationship violence. Dr. Becky Antle implemented a 5-year federally funded grant, Relationship Education Across Louisville (REAL), from 2006-2011, which created a body of evidence for the success of the training and is also the study from which this data is gathered. Antle and colleagues found that through this intervention; relationship quality, communication, relationship knowledge and conflict resolution skills in the adult participants increased significantly, and there was a trend in the reduction of violence $(p<.053)$ (Antle, Sar, Christensen, Ellers, Barbee \& vanZyl, 2013). They also found an extremely high $(\mathrm{M}=4.46 / 5)$ satisfaction rating with the training (Antle et al, 2013). A significant positive correlation with training satisfaction and number of children the participant had (Antle et al, 2013) also occurred, which could indicate positive impact on children or use of communication skills with children. Communication skills in the adult relationship also showed improvement as evidenced by a significant increase pre to post in mutual cooperation approach and conflict resolution skills and significant decrease in withdrawal behavior (Antle et al. 2013). 
The Within My Reach program also influenced relationship violence. Reduction in physical violence as measured by the Conflict Tactics Scale (CTS) also significantly decreased pre to 6-months post amongst participants in the 5-year study as well as a significant decrease in emotional abuse and isolation behaviors (Antle, Karam, Christensen, Barbee \& Sar, 2011).

The Antle et al. team at the University of Louisville, as well as the Stanley \& Markman group, have done the majority of quantitative scientific studies. The National Poverty Center in Oklahoma put out a paper in 2008 regarding their experience with Within My Reach in more of a qualitative narrative form that highlighted some participants' experiences as very positive and impactful (Sparks, 2008). Their themes echo the findings of the Antle team, of participant satisfaction with the program, increased knowledge of relationship concepts and awareness of relationship violence and decrease in the level of overall violence in their relationships.

Gap in Interventions Overview. In evaluating the research above, the major research gap in interventions aimed at reducing Intimate Partner Violence is the lack of study on the impact of interventions on the parent-child relationship, family cohesion and child well-being by violence type. In perpetrator-only research we see that the majority of study has come from populations that are experiencing control-based violence or perhaps populations that are experiencing Situational Violence that may be in an inappropriate group. There is also some evidence that work with the Dyadic Couple can be moderately effective in violence recidivism, but is only safe when implemented with Situational Violent Couples. Engaging multiple members of the family or one member of the family can be effective on the family system from the research done with integrating 
child witnesses into treatment and we can infer that positively changing one member of the violent family system can have an effect on the entire family system. Integrating the major themes above, we can suppose that an intervention that either addresses the specific type of violence that is in the family, or globally addresses both types of violence within the training, can have an effect on the entire family if members from the family are treated, either together for Situational Violence or separately in Coercive Control Violence. The Love Notes and Within My Reach training does not (to date) separate out participants by violence type, however, it does address dynamics of Coercive Control Violence and Situational Violence within the training. This, along with separating out individuals to take the class on their own as a safety measure, may be related to the reduction of violence that the participants as a whole experienced. Further study, (what this dissertation will address), is how this training impacts child well-being, family cohesion and the parent-child relationship within the two types of violence, to see how the training impacts each type of violence.

\section{Purpose of the Study}

The purpose of this study is to better understand how the Within My Reach training affects child well-being and the parent-child relationship within the two types of relationship violence; Coercive Control Violence and Situational Violence. Exploring these differences will help to discover more about the impact of controlling behaviors on children in a violent relationship and what effect the WMR training has on childwellbeing, family cohesion and the parent-child relationship. Also addressed will be what may have had most impact on the three above items; which may have been 
increasing parental communication, decreasing violence, increasing relationship communication.

\section{Aims \& Objectives}

The aims of this study include determination of 1) the impact of Coercive Control Violence and Situational Violence on child well-being, family cohesion and the parentchild relationship using pre-intervention baseline data, 2) the impact of the Within My Reach training on child well-being, family cohesion and the parent-child relationship by each relationship violence type and 3) determine whether a change in communication skills, reduction in violence, or improvement in the parent's relationship, had an effect on child well-being, family cohesion or the parent-child relationship by violence type. These aims will be met by the separation of WMR participants engaged in physically violent relationships into those containing power and control dynamics (Coercive Control Violence), those without or with low power and control dynamics (Situational Violence) using the Controlling Behaviors Scale and those experiencing no physical violence. The fourth cluster will contain a group that did not receive the WMR intervention and is experiencing CCV, or our (Non-intervention CCV Group) while the fifth cluster is comprised of the Non-Intervention Situational Violence Group, or the group that did not receive the intervention and has indicated violence with little to no control.

The next objective will be to determine the participant's relationship with their children, family cohesion and their child's well-being using the baseline pre-intervention data in the five clusters; Situational Violence, Coercive Control Violence, Non-Violence, Non-Intervention CCV Violence, and Non-Intervention SV Violence. 
A regression analysis of the $\mathrm{SV} \& \mathrm{CCV}$ groups is the third objective to explore what potential mediators (change in relationship quality, communication, violence or controlling behaviors) may impact the impact child well-being, family cohesion and parent-child relationship after the Within My Reach intervention. This multiple regression will be preliminary and exploratory in determining if it is a reduction in violence between the parents, improvement in the quality of the couple relationship, a reduction in controlling behaviors or an in increase in communication or conflict resolution skills that lead to child well-being, family cohesion or a higher quality parentchild relationship.

\section{Criteria for Evaluation}

The Criteria for Evaluation will be evaluated according to the Substance Abuse \& Mental Health Association's (SAMHSA) criteria for research evaluation for rating quality of evidence (SAMHSA, 2014). There are six criteria in this evaluation of research which include:

1. Reliability of Measures

2. Validity of Measures

3. Intervention Fidelity

4. Missing data and Attenuation

5. Potential Confounding Variables

6. Appropriateness of Analysis

(2014, http://www.nrepp.samhsa.gov/ReviewQOR.aspx $)$

Each criterion is evaluated on a $0.0-4.0$ scale with the lowest score, 0 indicating no compelling evidence of the criterion, to a score of 4.0 which shows acceptable 
evidence that the criterion has been met. When the Quality of Research ratings are used in reviews, the reviewers are trained in how to score the criteria. Each outcome of the research is rated separately. For this study, the outcomes that will be evaluated will be child wellbeing and the quality of the parent/child relationship.

The measures chosen were chosen in the many studies of PREP, the training upon which WMR was built, due to their reliability and validity. Their reliability and validity will be discussed in more detail in Chapter 3. This program design was especially unique with regards to intervention fidelity. Dr. Becky Antle and colleagues (2005-2010) collected intervention fidelity on the majority of workshops provided. The information was collected and the intervention fidelity was found to be strong to the evidence-based training. Fidelity is comprised of five components: 1) dosage, 2) adherence to key intervention components; 3) quality of intervention delivery, 4) participants responsiveness and 5) program differentiation (Dane \& Schneider, 1998). The retention rate for participants was $92 \%$. The response rate for immediate post-training was $81 \%$ and for six months post-training was $39 \%$. The adherence to the protocol was $94 \%$, the quality ratings by observers and participants was at $88 \%(\mathrm{M}=66.25 ; \mathrm{SD}=9.24$; Max Range $=75$ ) or an average rating of 4.4 out of 5. Ratings of alliance with facilitators were scored twice as participants assessed both facilitators $(\mathrm{M}=76.72 ; \mathrm{SD}=13.57)(\mathrm{M}=85.15$; 12.76). Participants scored $\mathrm{M}=33.21$; SD 9.92 on group cohesion (Owens \& Antle, 2013). The pattern of missing data appeared "completely random" according to Gelman (2005) criteria and was handled accordingly through case deletion. While the design was not a Randomized Control Trial, the research team did utilize a quasi-experimental design and other measures were given to account for the influence of confounding 
variables. Results of those data showed that there was no significant difference at baseline between those in the treatment, WMR, group and those in the comparison group, IPV rates remained the same from before to after the intervention period for those in the comparison group while some in the WMR group reduced. The analysis plan was chosen based of the multi-layered levels of measurement, sample size and complexities of the variables. A k-means cluster analysis was chosen to delineate physically violent non-control based groups (Situational Violence) from physically violent control-based groups based on similar previous research by Graham-Kevan and Archer (2006) that clustered violence types using the same method. A one-way MANOVA was chosen to evaluate baseline data due to the presence of multiple DVs to test the difference in means between the three outcome variables. Three Repeated Measures ANOVAs were chosen because the same sample was exposed to multiple tests and we wished to determine main effect and interaction effects within and between-subjects present in the data multiple points in time. Unfortunately due to sampling restrictions we were unable to combine the three RM ANOVAs into one RM MANOVA. A Multiple Regression test was chosen to estimate the relationship between the variables and the weight of the four potential change mediators. This test was chosen above Structural Equation Modeling or Principle Component Analysis, due to sampling restrictions as well.

Below are some key terms that are defined and will be used interchangeably throughout this dissertation shown in Table 1. 
Table 1

Definition of Key Terms

\section{TERM}

Intimate Partner Violence
(IPV)

\section{Situational Violence, Common Couple Violence}

Violence occurring between two partners engaged in a relationship of varying commitment (short/long term dating, marriage, co-habitation). Overarching term that developed after the criticism that the previous term "Domestic Violence" did not cover a relationship with similar dynamics between partners that did not live together.

These terms will be used to describe the theory developed and tested by Michael Johnson that the relationship dynamics of IPV are more diverse than the Duluth Model postulates and include a type of physical violence that does not include or includes low-level power and control dynamics. This model is often bidirectional, and often does not have a clear offender and victim but is described often as "arguments that get physical."

These words will be used to describe the type of violence that has been shown to exhibit elements of power and control such as isolating the victim, extreme jealousy and possessiveness, monitoring the victim, and using threats, privilege and emotional abuse in order to control the victim. This type of violence has been found to increase in severity over time. This type of violence is typically male offender/female victim, is seen more often in the shelter population and is highly lethal.

The healthy relationships program that was executed at the University of Louisville from 2006-2011 by a team led by Dr. Becky Antle as part of the Relationship Education Across Louisville (REAL) grant funded by the Office of Financial Assistance. 


\section{Topical Limitations}

The following are topical limitations, which will include the parameters on which the study is defined. These topical limitations include the emphasis of Johnson theory over other typologies, inclusion into relationship violence rather than inclusion into role of victim or perpetrator, exclusion of those who are experiencing controlling behaviors, exclusion of sexual abuse, use of third-party parent report, and exclusion of parental mental health as a component of the research.

Theoretical Model. One topical limitation is the emphasis on Johnson's theoretical approach to relationship typology. There have been many other theoretical typologies for relationship violence and perpetrator typologies given that emphasize pathology, impulse control and conflict management skills. We chose Johnson's theoretical model because it is the most widely used typology in relationship violence education and his inclusion of Coercive Control, as well as his explanation of Situational Violence are both discussed in the Within My Reach training. Acknowledging that many scholars have done research in this area, Johnson's model is not entirely comprehensive, but does present the argument for a multi-layered typological relationship violence approach.

Sampling Limitation. One of the greatest limitations of the study is that while we can accurately assess whether a person is in a physically violent relationship using the validated Conflict Tactics Scale (Straus, Hamby, Boney-McCoy \& Sugarman, 1996), and whether they are in a controlling relationship using the Controlling Behaviors Scale (Graham-Kevan \& Archer, 2003), we are unable to decipher the role of the participants as a victim or perpetrator of violence or if they were in a violent relationship where they 
were both perpetrator and victim. This data could not help us better determine whether the primary parent in the child's life is a victim or perpetrator but could tell us if the violence was bilateral, and both adults are physically abusive to one another. This information did give us more knowledge about the nature of Coercive Control Violence and Situational Violence, however, we were unable to collect this data due to Kentucky State Domestic Violence reporting law which mandated that if IPV were reported amongst a married couple, we would be mandated to report this information.

We informed each participant prior to participation that we were legally obligated to report to Adult Protective Services if they were married and being abused in their relationship. The creators of the survey believed that if the question asked the participants directly if their partner was abusive in the Conflict Tactics Scale or the Controlling Behaviors Scale, they would be less likely to answer truthfully or that if they did, and it was reported, that they could be placed in a more dangerous situation before they were ready to seek help. Therefore, the survey questions were changed to "Do you or your partner" ever do XYZ behaviors rather than "Does you partner do XYZ behavior to you." This information, while limiting, allows us to still discover the level and type of violence that the participant is or was involved in, without having to directly identify whether they were the perpetrator or victim. Both assessments also ask the participant to answer the questions on a current partner or last relationship, thus also blurring the timing.

Inability to identify victim/perpetrator. One of the major limitations of the study was that we were not able to identify whether the participant was a victim or perpetrator (or both) of physical abuse in the study. The original reasons for exclusion of this data 
are written more thoroughly in the topical limitations section. The limitation of this meant that we were unable to test all that we would have liked to within the study. Knowing whether the participant was a victim or perpetrator may have given us more information about whether the intervention was more successful for victims or perpetrators, or a person who fulfilled the roles of both victim and perpetrator. We also could have looked at the impact of the perpetrator parent on the parent-child relationship and compared that with those that identified as the victim parent. We can draw conclusions based on the presence of violence within the relationship, but more specific conclusions could have been drawn should we have been able to identify the violence role of the participant.

Measurement Limitation: Sexual Violence. Sexual violence was also not measured in this study. It could be helpful to measure sexual violence in the relationship in order to gauge the differences in the two types of violence, and to see the relationship of sexual violence to the nature of control and maintaining control. Sexual violence is not measured in the CTS or the CBS and was not measured in the original design of the data as it went beyond the parameters of that particular study and the current study.

Self-Assessment Limitation. Another potential limitation is that parents were asked to assess their child's well-being according to their observations rather than the observations of a neutral party. Self-report can lead to bias due to the possibility of the parent wanting to please the facilitator or researcher, fear that their information could be used to refer them to Child Protective Services or to embellish how well they are doing as a parent. Without an objective party evaluating child wellbeing and potential change after intervention, there is room for bias in the data. Change will still be measured from 
pre to post which should show inter-rater consistency as the participant measured each time. The parent was asked to assess the same child (the oldest) on each survey to help ensure consistency across the survey, as each child expresses well-being differently. Although this helps to maintain consistency, there were some limitations to this practice. In answering questions on the oldest child, the oldest may be an adult, and the parent may not remember accurately how they were raised, disciplined or their adult child's well-being when they were a child. The questions are also generally written to assess younger children rather than adolescent or young adult children. We also did not collect data on parenting style according to the Baumrind (1966) Theory of authoritarian, authoritative and permissive style, which could have been helpful to determining how the two types of violence influenced parenting style. This could have been helpful in establishing if there was any correlation between type of violence experienced and type of parenting style, if the intervention changed the parenting style, if it had an influence on child wellbeing, and if there was any influence on parent/child communication.

Parental Mental Health. We also did not include a measure of parental mental health. We do know that women who are victims of intimate partner violence are more susceptible to poor mental health outcomes such as trauma, depression, anxiety, sleep disturbances, eating disorders, substance abuse and suicidal ideation which could impact the energy available for parenting which could impact child well-being (CDC, 2003). We often infer parental neglect of the child's needs in severe psychological and physical violence cases due to the intensity of interpersonal violence that the victim is managing, so poor parental mental health could be a mediator. We also do not measure abuse of the child which would be a large mediator in child well-being which could influence the data. 
We do know that children that are witnesses to IPV or living in a home where IPV is occurring are at a greater risk of child abuse; however, we did not measure the presence of child abuse in the data.

Assessment on Only One Child. Finally, each child is different in temperament and childhood experience, and assessing one child in the assessment may not account for the difference in parenting of other children in the home. A parent may have parented other children in the home differently based off of family circumstances, child temperament and personality, environmental or relationship stressors at the time, or for a variety of other reasons. When administering the survey, there was often the question from parents regarding which child they should answer questions about. They were instructed to answer on their oldest child, however, there were some parents who had a large age gap between children, whose oldest child was an adult and youngest was a toddler. Some indicated that they were a much different parent in their teens or early twenties than they are now. While these limitations are present, many safeguards to the reliability and validity of the research design were taken and will be further discussed in the third chapter.

\section{Significance of the Study}

This study addresses the impact of high control (CCV) or low/no control behaviors (SV) in violent relationships on the outcomes of family cohesion, the parentchild relationship and child well-being, as well as evaluating the potentially differential impact of an evidence-based training on those three outcomes by relationship type.

Studies to date have examined the impact of IPV on child well-being and the parent-child relationship, but have not evaluated how much experiencing the element of controlling 
behaviors between caretaking adults influences the child versus the impact of experiencing violence alone without controlling behaviors. Much research to date on IPV has also been on a shelter sample, which Johnson (1995) determined is comprised of victims who have experienced predominantly Coercive Control Violence. Some research (Johnson, 1995) has been done on prevalence of relationship violence type in the general community and it was found that Situational Violence, violence without power and control dynamics, was more prevalent in this sample, however much of the research on IPV has not been done in this type of sample. This study is also unique in that it utilizes a sample size that is more heterogeneous; composed of an at-risk community sample, a blend of those in the community at-risk from violence who were not seeking shelter or treatment at that time for IPV. This sample has not been studied in IPV research, especially with an evidence-based intervention.

The impact that this study could have on Social Work aims specifically on broadening our understanding of IPV dynamics and the influence these dynamics have on children and their relationship with parents. This is an underserved, underrepresented population in research, which, if we can show the impact of the Within My Reach course on IPV, the parent-child relationship, and child well-being, we can provide evidence of this course's impact on the family. Already, this has shown to be impactful in affecting future relationship violence and communication patterns in both of the violence types (Antle, Ness Roberts 2012) and the significance of showing the effect on the family unit could help a population that is underserved and under-researched. The study centers around three research questions that evaluate the effect of violence type on parent/child relationship and child wellbeing as well as the effect of WMR on each violence type. 


\section{Research Questions}

Based on the evidence in the literature and the gap in the literature identified, this study will test the following three research questions: Hypotheses for these research questions will be based on the literature from Chapter 1 and in theory presented in the next chapter, and thus will be presented at the end of Chapter 2.

\section{A. Research Question \#1}

What is the effect of relationship type on family cohesion, the parent-child relationship and child well-being?

\section{B. Research Question \#2}

What is the effect of participating in the Within My Reach training on the family cohesion, the parent-child relationship, and child well-being by violence type?

\section{Research Question \#3}

What were the mediating variables in the Within My Reach intervention that contributed to the improvement of family cohesion, the parent/child relationship and child well-being in physically violent relationships over time: Was it a change in communication skills, couple relationship quality or a reduction in physical or psychological violence from pre-intervention to 6 months post?

Overview

Intimate Partner Violence is pervasive in our communities and has a great effect on child well-being, the parent-child relationship and family cohesion. For children, 
often adverse outcomes from witnessing parental violence or being a victim of abuse related to IPV often last into adulthood. To date, intervention success to combat the problem have been mixed, especially when treating perpetrators of violence. This study aims to address a gap in the literature that examines family cohesion, the parent-child relationship and child well-being by violence type and to study the effects of a healthy relationship intervention on the outcomes by violence type. It also seeks to find potential mediating factors that contribute to the change in outcomes in physically violent groups. Throughout the study vigilance will be held to protect against threats to validity and to evaluate outcomes with the limitations of the research in mind. 


\section{CHAPTER II}

\section{THEORETICAL MODELS}

\section{Introduction}

Theories of IPV have evolved over history and have led to greater understanding of the relationship dynamics that comprise partner violence and their impact on children. The primary theoretical model that will be used in this study is the Johnson Model, first developed in 1995 (Johnson, 1995; Johnson, 2008; Johnson \& Gonzalez, 2011) and then advanced over the next 20 years. The Johnson Model incorporates the Duluth Domestic Violence Intervention Project (DAIP) Model (1984), called in the Johnson Model “Coercive Control Violence (CCV)," (previously called Patriarchal Terrorism or Intimate Terrorism) where interpersonal violence between intimates is rooted in power and control motivations and dynamics. Johnson's other major typology called “Situational Violence (SCV)," (previously called Common Couple Violence), occurs when Intimate Partner Violence contains physical violence but no or very few behaviors of power and control. The Johnson Model contains both types of violence and has been validated by Graham-Kevan \& Archer (2003) in looking at relationship violence differences.

A thorough overview of the Duluth model will precede the summary of the Johnson Model later in this section. Additionally, following these models, trauma and attachment theory as well as a synopsis of two social work theories that have been used as a theoretical foundation for this study and their influence on the subject will be 
discussed. The Social Learning Theory (Bandura, 1963) will be included as a foundational theoretical model accepted in the discussion of inter-generationally transmitted violence. A brief discussion of Social Exchange Theory (Homans, 1961) is also necessary as this theory was used in the development of some of the concepts in this study surrounding communication patterns between partners, particularly when partners are involved in relationship decision-making, measuring out costs versus rewards in those decisions. Finally, attachment theory is necessary in understanding parent-child relationship attachment and how IPV affects that attachment. An understanding as well of the impact of the trauma on the parent-child relationship and child well-being is also necessary and thus trauma theory will also be discussed.

All theoretical models are important for a comprehensive understanding of the varying dynamics of IPV. Within these theories, implications of the importance of these theories in the context of intervention, the etiology of violence and the integration of these theories into various components of violence will be discussed.

\section{Historical theories of Intimate Partner Violence}

Early History. Unfortunately, throughout much of recorded history, violence against women was not considered a social issue about which one would define theories, as it was considered an acceptable social practice. In Conflict theory, the domination of the powerful and the rise of patriarchy in many ancient and modern civilizations regarded women as property not subject to the same laws and advantages of citizens. As such, abuse of women was justified when she deviated from social norms, be it in mannerisms, feminine role, maternal or wifely duty, or otherwise. In ancient texts, such as the Hebrew Bible, Old Testament of the Bible and what is also found in Islamic texts, inability to 
prove virginity at time of marriage was considered a capital crime, punishable by death by stoning (Deuteronomy 22: 13-21; in Kelly, 2011). The Code of Hammurabi (1800 BC) decreed that a wife was subservient to her husband and that he could inflict punishment on any member of his household however he saw fit.

Middle Ages. European Feudalism also saw a rise in well-documented and defended incidences of wife-battering for sexual infidelity or suspicions thereof as well as trials for women who deviated from social norms such as child-rearing, domestic life or church attendance that often ended in women being tortured or killed as witches (Kelly, 2011). Following the decline in Feudalism, those who worked outside of the home were given wages from their work (rather than being compensated for work through promise of protection from invading tribes) with women working in the home not receiving wages from their work. This according to Kelly (2011) led to a devaluation of women's contribution to society and to a general devaluation of women. With the descent of power moving from the feudal lord to the husband of the household ruling over a microversion of "his" castle, violence against women was linked to her behaviors and a deviation from the rules set out by the "ruler" of the household. Still alive and well is this example of perpetrator blame of the victim for violence that she created through not following the rules set out in the relationship; "I would not have had to become violent if you hadn't.....", "You made me hit you because.....", etc.

Early Legal History. The first laws that recognized violence against women and spousal violence were ones that restricted violence rather than condemned it. In the $18^{\text {th }}$ Century, English Common Law added that husbands could not beat their wives with an implement wider than their thumb. Courts in the United States upheld laws that legalized 
husband's use of violence against wives until 1871. It was then, only 135 years ago, that in the case Fulgam vs. The State of Alabama found that "The privilege, ancient though it may be, to beat her with a stick, to pull her hair, choke her, spit in her face or kick her about the floor or to inflict upon her other like indignities, is not now acknowledged by our law (WomenSafe, 2011)." However, clarified in 1910 was a law that stated that a woman could not bring charges against her husband for battery because they believed that this may empower women to slander against their husbands (WomenSafe, 2011). It is also around this time, in the 1920 s and 30s that psychoanalysis developed the theory of female machoism that women derived sexual pleasure from being beaten (Dobash $\&$ Dobash, 1992).

This theory was further encouraged by a 1964 article in the Archives of General Psychiatry that stated that abused women were like women of alcoholics and that both fulfilled a masochistic need for themselves through a violent husband (Snell, Rosenwald \& Robey, 1964 in Schecter, 1982). In 1945, California passed the first law against spousal abuse but it is not until 1994 that a federal law was passed that recognized violence against women as a crime (Groban, 2005). A brief timeline of the major laws are contained here to showcase the nascent history of Intimate Partner Violence as a social problem in history; that legally and socially, abuse against one's wife is more recently considered a deviation from societal norms. Although many states did pass laws that restricted partner violence throughout the $20^{\text {th }}$ Century, law and theory that defined what we know of today did not formulate until the late 1960s and 70s.

The Impact of Feminism on the Duluth Model (1970s-Present). To understand the dynamics of Coercive Control Violence, it is important to understand the role of 
Feminism, Conflict Theory and The Duluth Model. These three theories influenced the development of the typology of Coercive Control Violence. The impact of the feminist movement of the late 1960s and 1970s questioned the accepted views of patriarchy and relationship norms and correlated spousal abuse with an imbalance of male power in society. Feminist theory asserts that IPV is directly impacted by cultural patriarchal views that encourage female submission (Pence \& Paymar, 1993). Feminist theory according to Loue, states that men are the dominant "class and have more access to resources (2001)." Although rights for women have progressed substantially in the past one-hundred years, there is still a legacy of being postulated as inferior for many centuries. Feminist Theory advocates for the empowerment of women, who are 7-14 times more likely than male victims to report significant physical attack than males (Tjagen \& Thonnes, 1998).

The first modern work on partner abuse, Violence and pregnancy: A note on the extent of the problem and needed services was published in The Family Co-ordinator (1975) and was quickly followed by two more pivotal works in 1979 with The Battered Woman by Lenore E. Walker and Behind closed doors: Violence in the American Family (1980) by Straus, Gelles, \& Steinmetz. Although the place of patriarchy and feminist theory in IPV theory has been criticized, the foundations led to the Duluth Model, which is still the most commonly used treatment model to date.

\section{The Duluth Model}

The theory that is most commonly used in IPV research, treatment and advocacy is the Duluth Model of Power and Control which began its formation in 1980 after a particularly horrific incident of IPV in Duluth, Minnesota. This model uses the power and control wheel which defines control-based violence on eight factors (Duluth, 2014): 
Using Intimidation: Making the victim afraid through looks, actions, gestures; smashing things, destroying property; abusing pets; displaying weapons

Using Coercion \& Threats: Making or carrying out threats to do something to hurt her; threatening to leave her, to commit suicide or report her to welfare; making her drop charges; making her do illegal things.

Using Emotional Abuse: Putting her down; making her feel bad about herself; calling her names; making her think she is crazy; playing mind games; humiliating her; making her feel guilty.

Using Isolation: Controlling what she does and who she sees and talks to, what she reads and where she goes; limiting her outside involvement; using jealousy to justify actions.

Minimizing, Denying and Blaming: Making light of the abuse and not taking her concerns about it seriously; saying the abuse didn't happen; shifting responsibility for the abusive behavior; saying she caused it. Using Children: Making her feel guilty about the children; using children to relay messages; using visitation to harass her; threatening to take the children away.

Using Male Privilege: Treating her like a servant, making all the big decisions, acting like the "master of the castle," being the one to define male and female roles.

Using Economic Abuse: Preventing her from getting or keeping a job, making her ask for money, giving her an allowance, taking her money, not letting her know about or have access to family income (www.theduluthmodel.org).

The Duluth Model (DAIP) (2004) emphasizes that maintaining power and control over a victim is the driving force of the abuse. Research indicates (Pence \& Paymar, 1993; Johnson 1995) that this type of violence typically is uni-directionally inflicted (generally one person is the victim and one is the perpetrator), and that it is maledominated (male is generally abusive, female is generally victim). The DAIP model also posits that there is a grooming element to the abuse, a period of time where the perpetrator gathers emotional power and control prior to physical abuse. Due to the element of power and control, the theory suggests that violence is generally more lethal and is most dangerous when the victim decides to leave, as violence is contingent on the 
perpetrator maintaining a strict psychological cognition of control that escalates over time.

Duluth Model and Conflict Theory. The Duluth DAIP Model (Pence \& Paymar, 1993) is similar to Conflict Theory, which surmises that social discord and unhealthy social behavior stem from those in power having strict control over the powerless (Marx, 1848). Conflict Theory is also analogous to the DAIP model, in that power is gained and held by some through control and deprivation of another which ultimately results in psychological or physical violence in the domestic realm rather than the community realm. The DAIP model is also like Feminist Conflict Theory, which states that society supports the subjugation of women and the domination of men. Conflict Theory explores the nature of power and control in a macro relationship between those who control resources and social power and those who do not. The Duluth model moves Conflict Theory to a micro level and places the reasons for IPV perpetration on an intimate's need for patriarchal domination.

The Duluth model, much like Conflict Theory also posits that male-dominated perpetrated violence stems from a culturally-supported need to have power and control over a female victim (macro) to the micro level, that men use this socially supported view to bring violence to the family at the micro level (DAIP, 2014). Treatment, according to this model, is the breaking of the power structure on the individual level, and it is done in group therapy by encouraging perpetrators to accept that they hold beliefs of male dominance, to confront their own underlying male privilege and need for power and control, and accept responsibility for their violence (Pence \& Paymar, 1993). A potential issue with this may be that some offenders may feel that their need for power and control 
comes from a feeling of powerlessness which may be exacerbated by confrontation by an authority. This lens of conflict theory addresses the experience of power and powerlessness that those in control-based relationship violence on a micro level however, the micro application of conflict theory of overthrowing a violent perpetrator may be unsafe for a victim. Where Conflict Theory can be helpful in Coercive Control Violence, is that it does give a voice to a dynamic of power and control that may be helpful for victims to realize their experience is not isolated, and that other victims are facing the same phenomenon. Within the realm of Conflict Theory are four other subtheories that help to explain this type of control-based violence. They include Feminist Conflict Theory, Marital Power Theory, Traumatic Bonding Theory and Culture of Violence theory. All of these theories include some aspect of the power and control dynamic that is paradigm to the Duluth-model umbrella. Below is a chart that illustrates the similarities and differences of related violence theory. 
Table 2

\section{Conflict Theory \& Related Theories}

\begin{tabular}{|c|c|c|c|c|c|}
\hline & $\begin{array}{l}\text { CONFLICT } \\
\text { THEORY } \\
\text { (MARX, ) }\end{array}$ & $\begin{array}{l}\text { FEMINIST } \\
\text { CONFLICT } \\
\text { THEORY }\end{array}$ & $\begin{array}{l}\text { MARITAL } \\
\text { POWER } \\
\text { THEORY } \\
\text { (Loue, 2001) }\end{array}$ & $\begin{array}{l}\text { TRAUMATIC } \\
\text { BONDING } \\
\text { THEORY/ } \\
\text { Stockholm } \\
\text { Syndrome (Dutton } \\
\text { \& Galant, 1973) }\end{array}$ & $\begin{array}{l}\text { CULTURE OF } \\
\text { VIOLENCE } \\
\text { THEORY }\end{array}$ \\
\hline IPV Theory & $\mathrm{NO}$ & $\mathrm{NO}$ & YES & $\begin{array}{l}\text { YES/NO; IPV is } \\
\text { one dynamic as } \\
\text { well as kidnapping, } \\
\text { prisoners of war \& } \\
\text { human trafficking. }\end{array}$ & YES; \\
\hline $\begin{array}{l}\text { Based in Power } \\
\text { and Control }\end{array}$ & YES & YES & YES & YES & YES \\
\hline $\begin{array}{l}\text { Power dynamic } \\
\text { that is unequal }\end{array}$ & YES & YES & $\begin{array}{l}\text { YES \& NO; } \\
\text { "Power } \\
\text { Outcomes" } \\
\text { examines who is } \\
\text { the "decision- } \\
\text { maker" in the } \\
\text { relationship, } \\
\text { who drives the } \\
\text { relationship } \\
\text { direction and } \\
\text { makes the } \\
\text { relationship } \\
\text { decisions about } \\
\text { behaviors, } \\
\text { family values, } \\
\text { financial } \\
\text { practices, etc. }\end{array}$ & YES & $\begin{array}{l}\text { YES; if the } \\
\text { culture supports } \\
\text { uneven power } \\
\text { dynamic. }\end{array}$ \\
\hline $\begin{array}{l}\text { Violence \& } \\
\text { Patriarchy are } \\
\text { Cultural }\end{array}$ & & $\begin{array}{l}\text { YES; Patriarchy } \\
\text { and violence } \\
\text { pervades most } \\
\text { cultures. }\end{array}$ & $\mathrm{NO}$ & & $\begin{array}{l}\text { YES; Violence } \\
\text { and Patriarchy } \\
\text { exist within the } \\
\text { family if it is } \\
\text { supported by the } \\
\text { family. }\end{array}$ \\
\hline $\begin{array}{l}\text { One party is } \\
\text { oppressing the } \\
\text { other }\end{array}$ & YES & YES & $\begin{array}{l}\text { YES \& NO; In } \\
\text { unhealthy } \\
\text { relationship }\end{array}$ & & $\begin{array}{l}\text { YES; If the } \\
\text { dominant culture } \\
\text { condones } \\
\text { oppression }\end{array}$ \\
\hline $\begin{array}{l}\text { Dependence on } \\
\text { party in power } \\
\text { for survival. }\end{array}$ & YES & YES & $\begin{array}{l}\text { YES \& NO; In } \\
\text { unhealthy } \\
\text { relationship. }\end{array}$ & YES & \\
\hline $\begin{array}{l}\text { Order is based } \\
\text { on manipulation } \\
\text { and control by } \\
\text { dominant party }\end{array}$ & YES & YES & $\begin{array}{l}\text { YES \& NO; } \\
\text { only in abusive } \\
\text { relationship; } \\
\text { "Power } \\
\text { Processes"- } \\
\text { gaining power } \\
\text { through } \\
\text { negotiation, } \\
\text { assertiveness } \\
\text { and problem- } \\
\text { solving. }\end{array}$ & YES & \\
\hline $\begin{array}{l}\text { Change to } \\
\text { power structure } \\
\text { only comes } \\
\text { through violent } \\
\text { conflict }\end{array}$ & YES & $\begin{array}{l}\text { YES \& NO; } \\
\text { Change to power } \\
\text { structure comes } \\
\text { through } \\
\text { empowerment of } \\
\text { women, change in } \\
\text { roles; not }\end{array}$ & $\begin{array}{l}\text { NO; Change } \\
\text { comes through } \\
\text { renegotiation of } \\
\text { power, resources } \\
\text { and equality of } \\
\text { power }\end{array}$ & $\begin{array}{l}\text { YES; Potentially by } \\
\text { outside resources } \\
\text { who see the power } \\
\text { dynamic. Example: } \\
\text { Rescuing a captive } \\
\text { by police. }\end{array}$ & Does not indicate \\
\hline
\end{tabular}




\begin{tabular}{|c|c|c|c|c|c|}
\hline & & $\begin{array}{l}\text { necessarily } \\
\text { violence }\end{array}$ & & & \\
\hline $\begin{array}{l}\text { Macro vs. } \\
\text { Micro Theory }\end{array}$ & Macro & Macro & Micro & Micro & Macro \\
\hline $\begin{array}{l}\text { Finite amount } \\
\text { of resources; } \\
\text { that have to be } \\
\text { reallocated }\end{array}$ & $\begin{array}{l}\text { YES; AEB jobs, } \\
\text { money, resources }\end{array}$ & $\begin{array}{l}\text { YES; AEB jobs, } \\
\text { money, resources }\end{array}$ & $\begin{array}{l}\text { YES; Concept of } \\
\text { "Power Bases"; } \\
\text { Entitlement to } \\
\text { power; more } \\
\text { resources to } \\
\text { powerful }\end{array}$ & $\begin{array}{l}\text { YES; Oppressor } \\
\text { allocates resources } \\
\text { causing a } \\
\text { relationship of } \\
\text { dependency. }\end{array}$ & \\
\hline $\begin{array}{l}\text { Culture is } \\
\text { influenced by } \\
\text { patriarchal } \\
\text { views }\end{array}$ & $\begin{array}{l}\text { NO; not necessarily } \\
\text { exclusively }\end{array}$ & $\begin{array}{l}\text { YES; Reason for } \\
\text { uneven power } \\
\text { dynamic btwn } \\
\text { sexes }\end{array}$ & & & \\
\hline $\begin{array}{l}\text { Women are } \\
\text { powerless in our } \\
\text { society }\end{array}$ & $\begin{array}{l}\text { YES \& NO; Women } \\
\text { as one of the sub- } \\
\text { populations of lower } \\
\text { socio- } \\
\text { economic/worker } \\
\text { class. }\end{array}$ & YES & $\begin{array}{l}\text { NO; not } \\
\text { necessarily. One } \\
\text { party has power; } \\
\text { one does not } \\
\text { regardless of } \\
\text { gender. }\end{array}$ & $\begin{array}{l}\text { NO; victims could } \\
\text { be either gender. }\end{array}$ & \\
\hline $\begin{array}{l}\text { Patriarchy } \\
\text { oppresses } \\
\text { women }\end{array}$ & $\begin{array}{l}\text { YES \& NO; } \\
\text { bourgeoisie; wealthy } \\
\text { oppress women; Men } \\
\text { have a higher earning } \\
\text { power and thus are } \\
\text { more likely to be in } \\
\text { this category but not } \\
\text { exclusively. }\end{array}$ & YES & & & \\
\hline $\begin{array}{l}\text { Strong } \\
\text { emotional } \\
\text { attachments are } \\
\text { developed } \\
\text { between } \\
\text { oppressed and } \\
\text { oppressor }\end{array}$ & $\begin{array}{l}\mathrm{NO} \text {; Dependence is } \\
\text { due to financial } \\
\text { reasons. }\end{array}$ & $\begin{array}{l}\text { NO; Not } \\
\text { exclusively. Not } \\
\text { addressed fully in } \\
\text { FCT }\end{array}$ & $\begin{array}{l}\text { YES; Emotional } \\
\text { attachments are } \\
\text { within the bonds } \\
\text { of a relationship. }\end{array}$ & $\begin{array}{l}\text { YES; Emotional } \\
\text { attachments are } \\
\text { built between } \\
\text { oppressors and } \\
\text { oppressed in order } \\
\text { to maintain power. }\end{array}$ & \\
\hline $\begin{array}{l}\text { Power is } \\
\text { maintained } \\
\text { through } \\
\text { violence }\end{array}$ & YES & $\begin{array}{l}\text { NO; Not } \\
\text { exclusively }\end{array}$ & $\begin{array}{l}\text { YES \& NO; } \\
\text { Dependent on } \\
\text { whether the } \\
\text { relationship is or } \\
\text { is not violent. }\end{array}$ & YES & \\
\hline
\end{tabular}


Problems with the Duluth Model. The Duluth Model, in taking the power \& control dynamic from conflict theory as a conflict between the powerful and the powerless, fits very well for the relationship typology that Johnson found called "Intimate Terrorism or Coercive Control Violence" and is found mostly in a shelter sample (Johnson, 2005). The Duluth Model has been criticized by some for its inability to be applied to same-sex or female-perpetrated violence, to family cultures that may contain patriarchal views but no violence, in treating violent male perpetrators who don't use control, or treating those who may also be victims of violence (in the case of Common Couple Violence). A study by Hancock \& Siu (2009) found that when they challenged the ideas of male patriarchy to Latino men who were in perpetrator treatment, "The men's cultural ideals of masculinity were interwoven with a self-identity of themselves as family leaders and authority figures (124)." The authors found through their literature review that immigrant families from Mexico who have more traditional roles for males and females actually experienced less violence than those families who had less traditional values. The stress of moving to a new country where their cultural values were not always honored, coupled with discrimination, and financial stress were different factors after moving to the United States that may have factored into risk for abuse. In the Hancock \& Siu (2009) study, the concept of patriarchy was not a predecessor for violence, but traditional male patriarchy was an integral part of their cultural identity and social structure which often prevented violence in the home.

The study also revealed that husbands were more likely to be physically violent when the husband felt he had less power. In Kentucky, a random survey of 1,553 women found that women were more likely to experience life-threatening violence when they 
had jobs that were higher in status than their husbands than women who had jobs at the same status as their husbands (Hornung, McCullough \& Sugimoto, 1981 in Babcock et al, 1993). Although actual marital power is a very difficult concept to measure in research (Scanzoni, 1979 in Babcock et al, 1993), power as it is perceived by the couple has been shown to make a significant difference in the couple's communication. Using only the Duluth Model is problematic in explaining why communities that value traditional gender roles (where a woman may be more likely to stay home and work in the home), why domestic violence rates are not uniformly high. Even in areas where IPV perpetrators blame their culture as the reason why they perpetrate, not everyone in that culture perpetrates. If violence towards women was based solely on maintaining the social structure, as the social structure changed drastically as it did in the $20^{\text {th }}$ century, the abuse of women would have been greatly reduced except with the cases of retaliation. Isolation from family and culture can also have an effect in perpetuating the violence, as a perpetrator may construct their own micro-culture where violence is the norm, and victims are gaslighted or convinced that they are responsible for the violence done to them (Calef \& Wienshel, 1981). Akin to Stolkholm syndrome (Bejerot, 1974), where the perpetrator makes a victim dependent on them, the victim comes to have a relationship where violence is accepted as a better alternative than life without the perpetrator. The Duluth Model, which defined violence rooted in power and control, was the first model that did not blame the victim for the abuse that they sustained and is still the most popular model used today. Michael Johnson incorporated the Duluth Model into his relationship typology theory as Coercive Control Violence and defined more of the particulars of this type of violence. 


\section{Michael Johnson \& Typology-based Theories}

The theoretical foundations of the Situational Violence group in this study originate from work by Michael Johnson and others that have theorized that multiple types of relationship violence occur. The Johnson Model incorporates the presence of control-based (Duluth model) violence but supposes that there are other types of IPV, including types that do not include control-based violence. Through his work he suggests that violence and control are not always mutually exclusive. After a review of the literature, Michael Johnson (1995) found that the violence described in clinical research utilizing shelter samples was very different from the violence described in basic family research utilizing samples from the general population. He found that shelter samples tended to describe high levels of control, escalation of violence over time and extreme fear of perpetrators by victims. On the other hand, that type of description was almost never found in samples included in basic research on family violence. In those more open families, control was not a central or defining motive for violence or aspect of the relationship. Violence was often mutual and did not escalate over time. Most of these couples described becoming out of control due to anger and lack of skills in conflict management during altercations with a partner. Thus, Johnson defined violent relationship types based on the level of control exhibited by the perpetrator. Over his career, Johnson described five different types of violence over two decades: Coercive Control Violence (Johnson, 2007) (also known as Patriarchal Terrorism; Johnson, 1995) and Intimate Terrorism, Johnson \& Ferraro, 2000); Situational Violence (also known as Common Couple Violence, Johnson \& Leone, 1999), Mutual Violent Control (Johnson, 2000a), Violent Resistance (Johnson, 2000a) and Separation-Instigated Violence (Kelly 
\& Johnson, 2008). Throughout the over twenty years of research, Johnson changed names of typologies to better describe the concepts and also emphasized and deemphasized typologies according to occurrence frequency (see table below for changes). 


\section{Table 3}

\section{Johnson's Collected Works}

\begin{tabular}{|c|c|c|}
\hline Articles, Books \& Presentations & TYPOLOGIES & Definitions \& Changes \\
\hline $\begin{array}{l}\text { Johnson, M.P. (1995). Patriarchal terrorism and } \\
\text { common couple violence: Two forms of violence against } \\
\text { women. Journal of Marriage and Family Therapy, } 57 \text {, } \\
2,283-294\end{array}$ & $\begin{array}{l}\text { Patriarchal Terrorism } \\
\text { Common Couple } \\
\text { Violence }\end{array}$ & $\begin{array}{l}\text { Patriarchal Terrorism: High Control } \\
\text { Violence } \\
\text { Common Couple Violence: Low/No } \\
\text { Control Violence }\end{array}$ \\
\hline $\begin{array}{l}\text { Johnson, M.P. (Presentation, 1999). Two types of } \\
\text { violence against women in the American family: } \\
\text { Identifying patriarchal terrorism and common couple } \\
\text { violence. National Council On Family Relations, Irvine } \\
\text { CA, November } 1999 \text {. }\end{array}$ & $\begin{array}{l}\text { Patriarchal Terrorism } \\
\text { Common Couple } \\
\text { Violence }\end{array}$ & \\
\hline $\begin{array}{l}\text { Johnson, M.P. (2000a). Conflict and control: Symmetry } \\
\text { and asymmetry in domestic violence. In Alan Booth, et } \\
\text { al. (Eds.), Couples in Conflict, Hillsdale, NJ: Erlbaum } \\
\text { Associates, pp.94-104. }\end{array}$ & $\begin{array}{l}\text { Patriarchal Terrorism } \\
\text { Common Couple } \\
\text { Violence } \\
\text { Mutual Violent Control } \\
\text { Violent Resistance }\end{array}$ & $\begin{array}{l}\text { Mutual Violent Control: Both partners } \\
\text { are violent and controlling. } \\
\text { Violent Resistant: One partner is violent } \\
\text { but not controlling, the other is violent } \\
\text { and controlling. Responding to violence. }\end{array}$ \\
\hline $\begin{array}{l}\text { Johnson, M.P., \& Ferraro, K.J. (2000). Research on } \\
\text { domestic violence in the 1990s: Making distinctions. } \\
\text { Journal of Marriage and the Family, 62, 948-963. }\end{array}$ & $\begin{array}{l}\text { Intimate Terrorism } \\
\text { Common Couple } \\
\text { Violence } \\
\text { Violent Resistance } \\
\text { Mutual Violent Control }\end{array}$ & $\begin{array}{l}\text { Changed from Patriarchal "to recognize } \\
\text { that not all coercive control was rooted } \\
\text { in patriarchal structures and attitudes } \\
\text { (478, Kelly \& Johnson, 2008). This was } \\
\text { described in a later article. }\end{array}$ \\
\hline $\begin{array}{l}\text { Johnson, M.P. \& Leone, J.M. (2000). The differential } \\
\text { effects of patriarchal terrorism and common couple } \\
\text { violence: Findings from the National Violence against } \\
\text { Women survey. Paper presented at the Tenth } \\
\text { International Conference on Personal Relationships, } \\
\text { Brisbane, Australia. }\end{array}$ & $\begin{array}{l}\text { Patriarchal Terrorism } \\
\text { Common Couple } \\
\text { Violence }\end{array}$ & \\
\hline $\begin{array}{l}\text { Johnson, M.P. (2000b). Conflict and control: Symmetry } \\
\text { and asymmetry in domestic violence. In Alan Booth, et } \\
\text { al. (Eds.), Couples in Conflict, Hillsdale, NJ: Erlbaum } \\
\text { Associates, pp.94-104. }\end{array}$ & $\begin{array}{l}\text { Patriarchal Terrorism } \\
\text { Common Couple } \\
\text { Violence } \\
\text { Mutual Violent Control } \\
\text { Violent Resistant }\end{array}$ & $\begin{array}{l}\text { Mutual Violent Control: Both partners } \\
\text { are violent and controlling. } \\
\text { Violent Resistant: One partner is violent } \\
\text { but not controlling, the other is violent } \\
\text { and controlling. Responding to violence. }\end{array}$ \\
\hline $\begin{array}{l}\text { Johnson, M.P. \& Leone, J.M. (2005). The differential } \\
\text { effects of intimate terrorism and Situational Violence: } \\
\text { Findings from the National Violence Against Women } \\
\text { survey. Journal of Family Issues, 26, 322-349. }\end{array}$ & $\begin{array}{l}\text { Intimate Terrorism } \\
\text { Situational Violence }\end{array}$ & $\begin{array}{l}\text { These two types of violence were the } \\
\text { only types of the four addressed. } \\
\text { Addressed as the "major" types of } \\
\text { violence. } \\
\text { Leone acknowledges the switch to SCV } \\
\text { rather than Common Couple Violence } \\
\text { "which we will refer to as Situational } \\
\text { Violence, as he does in more recent } \\
\text { articles (Johnson \& Leone, 2005, 322)" }\end{array}$ \\
\hline $\begin{array}{l}\text { Johnson, M.P. (2005a). Apples and oranges in child } \\
\text { custody disputes: Intimate terrorism vs. Situational } \\
\text { Violence. Journal of Child Custody, 2, 43-52. }\end{array}$ & $\begin{array}{l}\text { Intimate Terrorism } \\
\text { Situational Violence } \\
\text { Violent Resistance } \\
\end{array}$ & \\
\hline $\begin{array}{l}\text { Johnson, M.P. (2005b.) Domestic violence: It's not } \\
\text { about gender-or is it? Journal of Marriage and } \\
\text { Family Therapy, 67, 1126-1130. }\end{array}$ & $\begin{array}{l}\text { Intimate Terrorism } \\
\text { Situational Violence } \\
\text { Violent Resistance }\end{array}$ & \\
\hline $\begin{array}{l}\text { Johnson, M.P. (2006). Conflict and control: Gender } \\
\text { symmetry and asymmetry in domestic violence, } \\
\text { Violence Against Women, 12, 1003-1018. }\end{array}$ & $\begin{array}{l}\text { Intimate Terrorism } \\
\text { Situational Violence } \\
\text { Mutual Violent Control } \\
\text { Violent Resistance }\end{array}$ & \\
\hline Johnson, M.P. (2007). Wingspread Conference. & $\begin{array}{l}\text { Coercive Control } \\
\text { Violence }\end{array}$ & $\begin{array}{l}\text { Intimate Terrorism was changed to } \\
\text { Coercive Control Violence "after } \\
\text { participants expressed reluctance to } \\
\text { adopt or use the term Intimate Terrorism } \\
\text { in courts (Kelly \& Johnson, 2008, }\end{array}$ \\
\hline
\end{tabular}




\begin{tabular}{|c|c|c|}
\hline & & $\begin{array}{l}\text { 479)." First used in Kelly \& Johnson } \\
\text { article, } 2008 \text { and Jaffe et al., 2008) }\end{array}$ \\
\hline $\begin{array}{l}\text { Johnson, M.P. (2008). A typology of domestic violence: } \\
\text { Intimate terrorism, violent resistance, and Situational } \\
\text { Violence. Boston: Northeastern University Press. }\end{array}$ & $\begin{array}{l}\text { Intimate Terrorism } \\
\text { Violence resistance } \\
\text { Situational Violence }\end{array}$ & \\
\hline $\begin{array}{l}\text { Kelly, J.B. \& Johnson, M.P. (2008). Differentiating } \\
\text { among types of intimate partner violence: Research } \\
\text { update and implications for interventions. Family } \\
\text { Court Review, 46(3), 476-499. }\end{array}$ & $\begin{array}{l}\text { Coercive Control } \\
\text { Violence } \\
\text { Violent Resistance } \\
\text { Situational Violence } \\
\text { Separation-Instigated } \\
\text { Violence } \\
\text { Mutual Violent Control }\end{array}$ & $\begin{array}{l}\text { Coercive Control Violence: Formally } \\
\text { Patriarchal Terrorism and then Intimate } \\
\text { Terrorism. }\end{array}$ \\
\hline $\begin{array}{l}\text { Johnson, M.P. (2009) Where do "Domestic Violence" } \\
\text { statistics come from and why do they vary so much?. } \\
\text { Brief prepared for conference, Toward a Common } \\
\text { Understanding: Domestic Violence Typologies and } \\
\text { Implications Conference, Warrington, VA, May 13-15. }\end{array}$ & $\begin{array}{l}\text { Intimate Terrorism } \\
\text { Violent Resistance } \\
\text { Situational Violence }\end{array}$ & \\
\hline $\begin{array}{l}\text { Johnson, M.P. (2009) Differentiating among types of } \\
\text { violence: Implications for healthy marriages. In } \\
\text { Marriage \& Family: Perspectives and Complexities, } \\
\text { Eds. Peters \& Dush. New York: Columbia University } \\
\text { Press }\end{array}$ & $\begin{array}{l}\text { Intimate Terrorism } \\
\text { Violent Resistant } \\
\text { Situational Violence }\end{array}$ & \\
\hline $\begin{array}{l}\text { Johnson, M.P. (2010). Types of domestic violence: } \\
\text { Implications for policy. Presentation at New Directions } \\
\text { Program February 24, 2010. }\end{array}$ & $\begin{array}{l}\text { Intimate Terrorism } \\
\text { Violent Resistant } \\
\text { Situational Violence }\end{array}$ & \\
\hline \multirow[t]{2}{*}{$\begin{array}{l}\text { Johnson, M.P. (2010). Langhinrichsen-Rolling's } \\
\text { confirmation of the feminist analysis of intimate } \\
\text { partner violence: Comment on "controversies involving } \\
\text { gender and intimate partner violence in the united } \\
\text { states. Sex Roles, 62, 212-219. }\end{array}$} & $\begin{array}{l}\text { Intimate Terrorism } \\
\text { Violent Resistant } \\
\text { Situational Couple } \\
\text { Mutual Violent Control }\end{array}$ & $\begin{array}{l}\text { Johnson emphasizes IT, VR \& SCV } \\
\text { stating that Mutual Violent Control } \\
\text { appears in small numbers and there is } \\
\text { controversy about whether it exists } \\
\text { (213). }\end{array}$ \\
\hline & $\begin{array}{l}\text { Coercive Control } \\
\text { Violence }\end{array}$ & \\
\hline $\begin{array}{l}\text { Derrington, R., Johnson, M.P., Menard, A., Ooms, T., } \\
\text { \& Stanley, S. (2011). Making distinctions among } \\
\text { different types of intimate partner violence: A } \\
\text { preliminary guide. }\end{array}$ & $\begin{array}{l}\text { Intimate Terrorism } \\
\text { Violent Resistance } \\
\text { Situational Violence }\end{array}$ & \\
\hline $\begin{array}{l}\text { Johnson, M.P. (2012). Types of domestic violence: } \\
\text { Research evidence and implications. Women's Refuge } \\
\text { Domestic Violence Conference. Blenheim, New } \\
\text { Zealand. October, 2012. }\end{array}$ & $\begin{array}{l}\text { Intimate Terrorism } \\
\text { Violent Resistance } \\
\text { Situational Violence }\end{array}$ & \\
\hline $\begin{array}{l}\text { Johnson, M.P. Leone, J.M., \& Yili Xu. (2014). Intimate } \\
\text { terrorism and Situational Violence in general surveys: } \\
\text { Ex-spouses required. Violence against Women, 20, 186- } \\
\text { 207. }\end{array}$ & $\begin{array}{l}\text { Intimate Terrorism } \\
\text { Situational Violence }\end{array}$ & \\
\hline $\begin{array}{l}\text { Hardesty, J. L., Crossman, K.A., Haselschwerdt, M.L., } \\
\text { Raffaelli, M., Ogolsky, B.G. \& Johnson, M.P. (in } \\
\text { press). Toward a standard approach to operationalizing } \\
\text { coercive control and classifying violence types. }\end{array}$ & $\begin{array}{l}\text { Coercive Control } \\
\text { Violence } \\
\text { Situational Violence } \\
\text { Separation-Instigated } \\
\text { Violence } \\
\text { Violent Resistance }\end{array}$ & $\begin{array}{l}\text { Separation-Instigated Violence was } \\
\text { presented as a sub-type of Situational } \\
\text { Violence because it is prompted by the } \\
\text { "situation" of leaving. It also occurs for } \\
\text { the first time in that context (Johnston \& } \\
\text { Campbell, 1993a, 1993b) }\end{array}$ \\
\hline
\end{tabular}


Michael Johnson found that while the majority of victims in domestic violence shelter populations experienced violence that was based in power and control, he also found that the majority of victims in the general population have experienced violence that did not contain power and control dynamics.

The two types of violence that this study will address are Coercive Control Violence and Situational Violence. Coercive Control Violence (CCV) looks much like the Duluth (DAIP) Model, defined predominately by controlling behavior that leads to violence (Johnson, 2000). He defined CCV as one ruled by power and control, stalking and calculated violence, most often occurring uni-directionally male to female, rather than verbal violence that escalated into physical violence. Johnson showed through his research that Coercive Control Violence was a less common form of Family Violence in the community (11\%, Johnson, 2006), which he originally named Intimate Terrorism (1995) and later changed to Coercive Control Violence (Johnson, 2008) following claims that using the word "terrorism" in court may not give the accused a fair trial.

Situational Violence (SCV) is verbal violence that escalates into physical violence but is not associated with controlling behaviors (Johnson, 2000). Johnson stated about Situational Violence (2009):

..the most common type of intimate partner violence does not involve any attempt on the part of either partner to gain general control over the relationship. The violence is situationally provoked, as the tensions or emotions of a particular encounter lead someone to react with violence (287). 
He also found that Situational Violence manifests itself very differently, often occurring bilaterally with both parties engaging in physical violence against each other, little to no occurrence of controlling behaviors, equal opportunity for male or female offenders/victims, and a greater presence of communication deficits within the relationship. The violence severity of Situational Violence does not escalate over time, unlike CCV, but can be as violent and lethal as Intimate Terrorism (Johnson, 2008). Serious injury and death does not occur as often as in CCV (Johnson, 2008), however, the violence that escalates in the situation can result in that.

Using a Shelter Sample. Johnson suggested previous research which mainly sampled participants from shelters or the court system, under-represented Situational Violence and over-represented Coercive Control Violence. In looking at data from the National Survey on Domestic Violence, and looking at research studies from shelter samples, he found that Coercive Control Violence was much more common in a shelter or court sample (78-88\%) (Johnson, 2005, 2008, Graham-Kevan \& Archer, 2003 in Antle, 2013). Johnson (2006) found that in the general population, Coercive Control Violence (CCV) was only $11 \%$ while Situational Violence (SCV) accounted for $89 \%$ of IPV. He also found that in a court sample, Coercive Control Violence was also high (68\%) and that $29 \%$ of cases were Situational Violence (Johnson, 2006).

Further adding to the relevance of a multi-typological theoretical approach, in the NACDV data, $52 \%$ of cases determined to be high control, psychologically violent were also never physically violent (Johnson, 2005). Kelly \& Johnson (2008) through additional research distinguished four types of violent relationships: Coercive Control Violence; Violent Resistance, (violent victim resistance to an abusive spouse); Situational Violence; 
and Separation-Instigated Violence or violence that occurs first in a relationship when a partner decides to leave. Over the next decade, Johnson and colleagues discovered other relationship types, and throughout the field, more attention was given to discovering more about relationship typologies and offender typologies (Walsh et al, 2010; Riggs, Calfield \& Street, 2000; Schwinle et al, 2010).

Johnson (2005) also found that in Coercive Control Violence, IPV is much less likely to stop without professional intervention over the course of a year than Situational Violence. This could account for the skew in CCV victims at shelters, where women were more likely to seek shelter multiple times for violence that didn't stop. Without professional interventions, such as therapy, shelter services or social work interventions, those in SCV relationships had a greater likelihood of incidences of physical violence stopping on its own (Johnson, 2005).

Through his research, Johnson addressed a sampling bias. Most IPV research until 1995 had been done on a shelter sample and due to this, our understanding of IPV had been based off of a control-based relationship. This has many ethical implications for how we research and treat IPV. A shelter sample may be readily available to researchers and possibly easier to track longitudinally; however, the evidence of its rarity in the community sample may show a sampling bias and limited generalizability to the body of knowledge for IPV. Furthermore, directing interventions based on a power and control model may be helpful for some, however, if the majority of violent relationships in the community are physically violent without power and control, the interventions may not be appropriate. It may be appropriate, given the high number of control-based relationships in an IPV shelter population that the Duluth model be used in psycho- 
education for victims, and perhaps for perpetrators of control-based relationship violence. In designing research based off of this theoretical approach, these varieties need to be considered in order to understand the complete picture of IPV intervention. If the research suggests different types of violence, ethically we need to disseminate that information and reconsider the design of interventions that are based in a more complex theoretical model.

\section{Theoretical Foundations of Johnson Theory}

Akin to the foundation of Conflict Theory for the Duluth Model, which takes an overarching macro theory to the micro level, Michael Johnson (1995) distilled Systems Theory (and parts of Ecological Systems Theory) to IPV through the concept of Situational Violence (or Common Couple Violence) which states that violence is caused by external stressors, such as discrimination, economic stress, and environmental stress to "arguments that get physical" and internal stressors such as lacking impulse control and conflict management skills rather than the more conflict based "power and control" dynamic that the Duluth model attributed to violence (Johnson, 2005). Michael Johnson has proposed that one type of IPV, Situational Violence, is caused by external stressors, and internal factors such as communication deficits. Kelly \& Johnson (2008) state that SV, "results from situations or arguments between partners that escalate on occasion into physical violence [External]." One or both partners appear to have poor ability to manage their conflicts and/or poor control of anger [Internal] (Ellis \& Stuckless, 1996; Johnson, 1995; 2006; Johnston \& Campbell, 1993).” Many of the components of systems theory are applicable to Johnson's model; that interconnected external stressors effect the individual, and that change within the system that can be used to diffuse stress-level, 
create coping mechanisms and on the macro-level there is a need to advocate for change within the social structure that would end discrimination and social injustice. He also utilized Social Exchange Theory by including communication deficits to this escalation of violence that became physical altercations.

Relationship Typology Research Although Johnson's work is arguably the most well-known division of relationship typology, he was not the first to develop relationship typologies and prior to Johnson's theory, Snyder \& Fruchtman (1981) found five categories of Family Violence relationships: Sporadic violence within a Stable Relationship ( $\mathrm{n}=33)$, Explosive Relationships leading to Severe Injuries $(\mathrm{n}=32)$, Unrelenting Severe Violence $(\mathrm{n}=23)$, Extensive Child Abuse with limited spousal abuse $(\mathrm{n}=13)$, Long history of violent behavior in family of origin to present $(\mathrm{n}=11)$. Snyder \& Fruchtman's typology was much more descriptive and was not ideological in nature. Stith et al (1992) did a cluster analysis on relationship functioning and found four clusters of relationship type: Secure Lovers, violence and psychological abuse is rare; Stable Minimizers, who reported longer relationships and lower reporting of violence; Hostile Pursuers, who used severe psychological violence and moderate physical violence, and high relationship conflict and Hostile Disengaged, who had high physical and low psychological abuse, high conflict, low emotional attachment.

The Stith et al (1992) study might not be completely transferrable because it uses college students in dating violence relationships rather than partners in committed living situations

One of the most interesting studies has been by Holtzworth-Munroe \& Meehan (2004) who have attempted to unify much of the knowledge about perpetrator typologies 
into four subtypes, Family Only, Dysphoric or Borderline, General Violent and Antisocial, and Low Level Antisocial. They validated these typologies in 2000 (Holtzworth-Munroe, Meehan, Herron, Rehman, and Stuart, 2000), using a community sample of 102 who, in the last year had been physically aggressive towards their spouses. Using a cluster analysis they measured marital violence, general violence and personality characteristics. The Lower Level Antisocial was a new group that differed from the 1994 Holtzworth-Munroe \& Stuart study and was marked by "moderate scores on measures of antisociality, marital violence and general violence (Holzworth-Munroe \& Meehan, 2004, 1373)." They have found that the previous IPV perpetrator typologies factor consistently under these four typologies. Other research that this group has done on these typologies to measure perpetrator behavior has been to determine whether aggression continues longitudinally (Holtzworth-Monroe et al, 2003). It was hypothesized that aggressive behaviors would differ significantly between the typologies over time. Using the subjects from the 2000 study, they found that the aggression had stopped in $40 \%$ of the Family Only violent group and in $23 \%$ of the Lower Level Antisocial group. In the Generally Violent/Antisocial group, only $7 \%$ had stopped their violent behaviors and only $14 \%$ of the Dysphoric/Borderline group had stopped in the 3-year period. They also found that the participant's original typology was stable over time. 
Table 4

\section{$\underline{\text { Intimate Partner Violence Typology Literature }}$}

\begin{tabular}{|c|c|c|c|c|}
\hline AUTHOR & TYPOLOGY & BRIEF DESCRIPTION OF STUDY & $\begin{array}{c}\text { THEORETICAL } \\
\text { APPROACH }\end{array}$ & $\begin{array}{c}\text { DESCRIPTIVE } \\
\text { VS. } \\
\text { EXPLANATORY }\end{array}$ \\
\hline $\begin{array}{l}\text { Snyder \& } \\
\text { Fruchtman } \\
\text { (1981) }\end{array}$ & $\begin{array}{l}\text { Relationship typologies; five } \\
\text { subtypes } \\
\text { Sporadic violence within a } \\
\text { Stable Relationship }(\mathrm{n}=33), \\
\text { Explosive Relationships } \\
\text { leading to Severe Injuries } \\
\text { ( } \mathrm{n}=32), \text { Unrelenting Severe } \\
\text { Violence }(\mathrm{n}=23), \text { Extensive } \\
\text { Child Abuse with limited } \\
\text { spousal abuse }(\mathrm{n}=13), \text { Long } \\
\text { history of violent behavior in } \\
\text { family of origin to present } \\
(\mathrm{n}=11) \text {. }\end{array}$ & $\begin{array}{l}\text { Cluster analysis ( } \mathrm{n}=119) \text { from a } \\
\text { structured interview. Sample, } \\
\text { women from domestic violence } \\
\text { shelter. Characterized by an } \\
\text { extensive hx of violence in first } \\
\text { family. Based on husband-wife } \\
\text { configuration. Compared current } \\
\text { violence history to childhood } \\
\text { violence hx. It was also found that } \\
\text { the highest percentage of the } \\
\text { sample of victims stated that when } \\
\text { alcohol was the principal cause of } \\
\text { violence ( } 23-36 \% \text { of women in the } \\
4 \text { groups) they sustained the most } \\
\text { frequent and severe abuse. }\end{array}$ & Behavioral & Descriptive \\
\hline $\begin{array}{l}\text { Hamberger \& } \\
\text { Hastings } \\
\text { (1986) } \\
\text { Hamberger, } \\
\text { Lohr, Bonge \& } \\
\text { Toln (1996) }\end{array}$ & $\begin{array}{l}\text { Perpetrator typologies; } \\
3 \text { subtypes (1986): } \\
\text { Schizoidal/Borderline } \\
\text { Narcissistic/Antisocial } \\
\text { Dependent/Compulsive }\end{array}$ & $\begin{array}{l}\text { Treatment sample of perpetrators; } \\
\text { Used the Millon Clinical Multiaxial } \\
\text { Inventory (Millon, 1983). } \\
\text { Categories were not entirely clear } \\
\text { and most of the sample showed a } \\
\text { mix of the characteristics of all } \\
\text { types. The largest subtype was the } \\
\text { Dependent/compulsive type (16\%). } \\
\text { Participants with the highest } \\
\text { narcissistic \& aggressive } \\
\text { tendencies scored only moderately } \\
\text { at anger "suggesting a philosophy } \\
\text { of "I don't get mad, I get even } \\
\text { (Saunders, 1992)."'" }\end{array}$ & Psychological & Descriptive \\
\hline $\begin{array}{l}\text { White \& } \\
\text { Gondolf (2000) }\end{array}$ & $\begin{array}{l}6 \text { subgroups (White \& } \\
\text { Gondolf, 2000): } \\
\text { Narcissistic-Conforming (32\%) } \\
\text { Avoidant-Depressive }(21 \%) \\
\text { Antisocial Disorder }(11 \%) \\
\text { Narcissistic Disorder }(7 \%) \\
\text { Paranoid Disorder }(9 \%) \\
\text { Borderline Disorder }(4 \%)\end{array}$ & $\begin{array}{l}\text { Cluster analysis (1988) of } 550 \\
\text { shelter residents report of their } \\
\text { history of violence; Found } 3 \\
\text { typologies; Typical Batterers-- } \\
\text { Lowest levels of verbal, physical } \\
\text { and sexual abuse, least likely to } \\
\text { have substance abuse or criminal } \\
\text { record; Sociopathic-Most severe } \\
\text { injuries, mostly likely to be } \\
\text { aggressive outside of home, mostly } \\
\text { likely to abuse children physically, } \\
\text { abuse partners sexually and abuse } \\
\text { alcohol; Anti-Social Batterers- } \\
\text { Extremely abusive, more likely to } \\
\text { use weapons. } \\
\text { Identified } 6 \text { subgroups based off of } \\
\text { the Millon Clinical Multiaxial } \\
\text { Inventory (MCMI). Found that in } \\
\text { all the subgroups were narcisstic } \\
\text { and avoidant tendencies. Able to } \\
\text { classify } 84 \% \text { of sample in one of } \\
\text { six subgroups, the other } 16 \% \text { were } \\
\text { considered to be atypical. } \\
\text { Narcissistic-Conforming: } \\
\text { Defensive, controlling, overly- } \\
\text { confident, believed better than } \\
\text { others }\end{array}$ & Psychological & Descriptive \\
\hline
\end{tabular}




\begin{tabular}{|c|c|c|c|c|}
\hline & & $\begin{array}{l}\text { Avoidant-Depressive: Depressed, } \\
\text { withdrawn, nervous/anxious, } \\
\text { dissatisfied } \\
\text { Antisocial: Vindictive, aggressive, } \\
\text { intimidating, guarded, competitive } \\
\text { Narcissistic: Arrogant, explosive, } \\
\text { anxious, reactive } \\
\text { Paranoid: Bitter, anxious, } \\
\text { suspicious, distrustful } \\
\text { Borderline: Moody, resentful, self- } \\
\text { punishing, impulsive. } \\
\text { Cognitive-Behavioral Therapy is } \\
\text { suggested as most beneficial as it } \\
\text { deals with the self-image } \\
\text { distortions of narcissism and } \\
\text { avoidant pd. }\end{array}$ & & \\
\hline $\begin{array}{l}\text { Bartholomew } \\
\text { \& Horowitz } \\
\text { (1991) }\end{array}$ & $\begin{array}{l}\text { Perpetrator typologies based on } \\
\text { attachment style } \\
\text { Secure Attachment Style }\end{array}$ & $\begin{array}{l}\text { Secure Attachment Style: Positive } \\
\text { internal models of self and of } \\
\text { others; comfortable with intimacy } \\
\text { and autonomy; high view of self } \\
\text { and others } \\
\text { Preoccupied Attachment Style: } \\
\text { Negative internal model of self and } \\
\text { positive internal model of others. } \\
\text { Self-acceptance occurs with } \\
\text { validation from others; continually } \\
\text { striving for acceptance from others } \\
\text { and to be close to others even if it } \\
\text { harms the relationship } \\
\text { Dismissing Attachment Style: } \\
\text { Positive internal model of self and } \\
\text { negative internal model of others; } \\
\text { deny their need for human } \\
\text { relationships and intimacy. } \\
\text { Antisocial men tend to report } \\
\text { dismissing attachment style (Hare, } \\
\text { 1993). } \\
\text { Fearful Attachment Style: Negative } \\
\text { internal model of self and others; } \\
\text { fearful of relationships with others }\end{array}$ & Relational & Descriptive \\
\hline $\begin{array}{l}\text { Saunders, D.G. } \\
\text { (1992) }\end{array}$ & $\begin{array}{l}\text { Perpetrator typologies; three } \\
\text { subtypes: } \\
\text { Aggressors } \\
\text { Generalized Aggressors } \\
\text { Emotionally Volatile } \\
\text { Aggressors }\end{array}$ & $\begin{array}{l}\text { Cluster analysis. Explained } 90 \% \text { of } \\
\text { variance in category assignment. } \\
\text { Aggressors: Generally abused } \\
\text { family only, low levels of anger, } \\
\text { depression, jealousy and high on } \\
\text { social desirability (Marlowe- } \\
\text { Crowne), least likely to have been } \\
\text { abused as children, most } \\
\text { relationship satisfaction, least } \\
\text { psychologically abusive, violence } \\
\text { associated with alcohol } 50 \% \text { of } \\
\text { time, DUIs; } \\
\text { Generalized Aggressors: Most } \\
\text { likely to be aggressive outside of } \\
\text { home; Low - Moderate level anger } \\
\& \text { depression, abuse associated } \\
\text { with alcohol use, most frequent use } \\
\text { of severe violence, more rigid } \\
\text { gender roles, marital satisfaction } \\
\text { moderate, high rates of arrest for } \\
\text { DUI \& violent acts. } \\
\text { Emotionally Volatile Aggressors: } \\
\text { Highest level of anger, depression, } \\
\text { jealousy, violent less frequently } \\
\text { than Generalized Aggressors but }\end{array}$ & Behavioral & Descriptive \\
\hline
\end{tabular}




\begin{tabular}{|c|c|c|c|c|}
\hline & & $\begin{array}{l}\text { highest rate of } \\
\text { psychological/emotional abuse, } \\
\text { least relationship satisfaction, } \\
\text { infrequent alcohol use with } \\
\text { violence, } 50 \% \text { of the men in this } \\
\text { group had already received therapy } \\
\text { which Saunders attributed as an } \\
\text { indication that they would be likely } \\
\text { to continue treatment. }\end{array}$ & & \\
\hline $\begin{array}{l}\text { Stith et al } \\
\text { (1992) }\end{array}$ & $\begin{array}{l}\text { Perpetrator typologies; four } \\
\text { subtypes } \\
\text { Secure Lovers, Stable } \\
\text { Minimizers, Hostile Pursuers, } \\
\text { Hostile Disengaged }\end{array}$ & $\begin{array}{l}\text { Secure Lovers, violence and } \\
\text { psychological abuse is rare; Stable } \\
\text { Minimizers, who reported longer } \\
\text { relationships and lower reporting of } \\
\text { violence; Hostile Pursuers, who } \\
\text { used severe psychological violence } \\
\text { and moderate physical violence, } \\
\text { and high relationship conflict and } \\
\text { Hostile Disengaged, who had high } \\
\text { physical and low psychological } \\
\text { abuse, high conflict, low emotional } \\
\text { attachment. }\end{array}$ & Psychological & Explanatory \\
\hline $\begin{array}{l}\text { Holtzworth- } \\
\text { Monroe \& } \\
\text { Stuart, 1994 } \\
\text { Holtzworth- } \\
\text { Monroe, } \\
\text { Meehan, } \\
\text { Herron, } \\
\text { Rehman and } \\
\text { Stuart, 2000). } \\
\text { Holtzworth- } \\
\text { Monroe et al, } \\
\text { 2003) } \\
\text { Holtzworth- } \\
\text { Munroe \& } \\
\text { Meehan (2004) }\end{array}$ & $\begin{array}{l}\text { Perpetrator typologies; four } \\
\text { subtypes, Family Only, } \\
\text { Dysphoric or Borderline, } \\
\text { General Violent and } \\
\text { Antisocial, and Low Level } \\
\text { Antisocial. }\end{array}$ & $\begin{array}{l}\text { Validated typologies in } 2000 \\
\text { (Holtzworth-Munroe, Meehan, } \\
\text { Herron, Rehman, and Stuart, 2000), } \\
\text { using a community sample of } 102 \\
\text { who, in the last year had been } \\
\text { physically aggressive towards their } \\
\text { spouses. Using a cluster analysis } \\
\text { they measured marital violence, } \\
\text { general violence and personality } \\
\text { characteristics. } \\
\text { The Lower Level Antisocial was a } \\
\text { new group that differed from the } \\
\text { 1994 } \\
\text { Holtzworth-Munroe \& Stuart study } \\
\text { and was marked by "moderate } \\
\text { scores on measures of antisociality, } \\
\text { marital violence and general } \\
\text { violence (Holtzworth-Munroe \& } \\
\text { Meehan, 2004, 1373)." } \\
\text { They have found that the previous } \\
\text { IPV perpetrator typologies factor } \\
\text { consistently under these four } \\
\text { typologies. Other research that this } \\
\text { group has done on these typologies } \\
\text { to measure perpetrator behavior has } \\
\text { been to determine whether } \\
\text { aggression continues longitudinally } \\
\text { (Holtzworth-Monroe et al, 2003). It } \\
\text { was hypothesized that aggressive } \\
\text { behaviors would differ significantly } \\
\text { between the typologies over time. } \\
\text { Using the subjects from the } 2000 \\
\text { study, they found that the } \\
\text { aggression had stopped in } 40 \% \text { of } \\
\text { the Family Only violent group and } \\
\text { in } 23 \% \text { of the Lower Level } \\
\text { Antisocial group. In the Generally } \\
\text { Violent/Antisocial group, only } 7 \% \\
\text { had stopped their violent behaviors } \\
\text { and only } 14 \% \text { of the } \\
\text { Dysphoric/Borderline group had } \\
\text { stopped in the } 3 \text {-year period. They } \\
\text { also found that the participant's } \\
\text { original typology was stable over } \\
\text { time. }\end{array}$ & $\begin{array}{l}\text { Mixed: } \\
\text { Sociological } \\
\text { (Family Only) } \\
\text { Psychological } \\
\text { (Other three } \\
\text { types) }\end{array}$ & Explanatory \\
\hline
\end{tabular}




\begin{tabular}{|c|c|c|c|c|}
\hline $\begin{array}{l}\text { Gottman et al } \\
\text { (1995) }\end{array}$ & $\begin{array}{l}\text { Perpetrator Typology } \\
\text { Type } 1 \text { (Pitbulls) } \\
\text { Type } 2 \text { (Cobras) }\end{array}$ & $\begin{array}{l}\text { Type } 1 \text { showed aggression outside } \\
\text { of the relationship and decreases in } \\
\text { arousal of violence with partner. } \\
\text { Generally antisocial } \\
\text { Type 2: Dependent, needy, very } \\
\text { little aggression shown outside the } \\
\text { home, increases in arousal of } \\
\text { violence with partner, emotionally } \\
\text { volatile }\end{array}$ & Relational & Descriptive \\
\hline $\begin{array}{l}\text { Tweed \& } \\
\text { Dutton, (1998) }\end{array}$ & $\begin{array}{l}\text { Perpetrator Typology: } \\
\text { Type 1: Instrumental Group } \\
\text { Type 2: Impulsive Group }\end{array}$ & $\begin{array}{l}\text { Cluster analysis using the Millon } \\
\text { Clinical Multiaxial Inventory } \\
\text { (version 2) to assess personality } \\
\text { disorder and clustering by } \\
\text { attachment style, anger, trauma } \\
\text { scores and scores on self-report of } \\
\text { Borderline Personality } \\
\text { Organization (BPO). } \\
\text { Type 1: Rated high on Antisocial, } \\
\text { Aggressive/Sadistic scales, more } \\
\text { severe physical violence; } \\
\text { Narcissistic-Aggressive profile on } \\
\text { MCMI-II; suppressed physiological } \\
\text { response in arguments with spouse; } \\
\text { violence outside the home. } \\
\text { Type 2: More dependent on their } \\
\text { wives; in-home violence only; } \\
\text { mixed profile on MCMI-II; some } \\
\text { passive-aggressive, Borderline \& } \\
\text { Avoidant elevations; high score on } \\
\text { BPO; high anger over time, high } \\
\text { fearful attachment }\end{array}$ & Psychological & Descriptive \\
\hline $\begin{array}{l}\text { Swan \& Snow } \\
(2002)\end{array}$ & $\begin{array}{l}\text { Perpetrator Typology } \\
\text { Women as Victims (34\%) } \\
\text { Women as Aggressors (12\%) } \\
\text { Mixed (50\%) }\end{array}$ & $\begin{array}{l}\text { Interview of women; asked to } \\
\text { define their violence and partners } \\
\text { violence. }\end{array}$ & Behavioral & Descriptive \\
\hline $\begin{array}{l}\text { Delsol, } \\
\text { Margolin \& } \\
\text { John (2003) }\end{array}$ & $\begin{array}{l}\text { Perpetrator Typology } \\
\text { Family Only } \\
\text { Medium Violence, } \\
\text { Generally } \\
\text { violent/psychologically } \\
\text { distressed }\end{array}$ & $\begin{array}{l}\text { Latent class analyses for } \\
\text { community sample of men who } \\
\text { used any violence (Capaldi \& Kim, } \\
\text { 2007) } \\
\text { Overlap between } \\
\text { borderline/dysphoric \& generally } \\
\text { violent/anti-social type. }\end{array}$ & Relational & Descriptive \\
\hline Sartin, 2005 & $\begin{array}{l}\text { Perpetrator Typology: } \\
\text { Borderline/Dysphoric } \\
\text { Generally Violent/Antisocial } \\
\text { Type. }\end{array}$ & $\begin{array}{l}\text { Overlap between } \\
\text { borderline/dysphoric \& generally } \\
\text { violent/anti-social type }\end{array}$ & Psychological & Descriptive \\
\hline $\begin{array}{l}\text { Cavanaugh \& } \\
\text { Gelles (2005) }\end{array}$ & $\begin{array}{l}\text { Perpetrator Typology: } \\
\text { Low-Risk Offender } \\
\text { Moderate-Risk Offender } \\
\text { High-Risk Offender }\end{array}$ & $\begin{array}{l}\text { Cavanaugh \& Gelles summarized } \\
\text { the findings of Gondolf (1988), } \\
\text { Gottman et al (1995), Hamberger et } \\
\text { al. (1996), Holtzworth-Monroe and } \\
\text { Stuart (1994) and Johnson (1995). } \\
\text { Low, Moderate or High-risk is } \\
\text { determined by severity and } \\
\text { frequency of violence, } \\
\text { psychopathology and criminal } \\
\text { history. }\end{array}$ & Behavioral & Descriptive \\
\hline
\end{tabular}


Relevance of Typology Research These relationship types are relevant to a historical analysis of IPV behavior because the behaviors within the relationships are very distinct from one another, yet they mirror some of the typological groups that have been studied. CCV is most often male-perpetrated and is distinguished by controlling behaviors, much like the typology that clusters around the use of psychological violence. $\mathrm{SV}$ is multi-directional, non-gender specific and appears close to the clusters of nonpsychological, low level anger, hostility, high relationship satisfaction typologies. Most of the studies are descriptive in nature and do not thoroughly address the relational dynamics that are compelling in the Johnson studies. In the chart above, most of the studies come from a psychological background, whereas Johnson, who is a sociologist comes from more of a socio-environmental perspective. With the inclusion of Coercive Control Violence as a type of violence, Johnson describes an underlying need for power and control that may be due to a variety of personality or psychopathological traits, but does not address those directly in his research. Also present is Johnson's emphasis on studying the entirety of the relationship rather than strictly the perpetrator or victim as was present in many of the above studies. This gives a relationship typology rather than strictly a perpetrator typology to the body of research.

The Creation of the Controlling Behavior Scale \& Use in Research. One of the scales used to determine controlling behaviors is the Controlling Behaviors Scale that was developed by Graham-Kevan \& Archer (2003). They were able to use that scale in conjunction with other violent behavior measures to determine the existence of physical violence that does not include controlling behaviors (Johnson, 2005). This changed the 
current thought on IPV theory and allowed others to do more research into the origins of perpetration and imagine new courses of treatment that move beyond the Duluth Model.

Johnson used a subsample $(n=4,967)$ from the National Violence Against Women survey (Tjaden \& Thoennes, 1999 in Johnson, 2005) and did extensive interviews and surveys with this group. In a replication of Johnson's study by two British researchers, they found that only $27 \%$ of physically violent perpetrators were highcontrol, Duluth model relationship-type while $63 \%$ were low-control, physically violent Johnson Situational Violence relationship type (Graham-Kevan \& Archer, 2000).

Key to Johnson \& Leone's (2005) findings was the distinction and definition of Situational Violence as violence that exhibits low to no controlling behaviors as a measurement marker. Using data from the National Violence Against Women Survey the data was split into two groups, one defined by high control and the other defined by low control using the Control Scale (2005). (Graham-Kevan \& Archer (2008) later referred to this scale as the Controlling Behavior Scale). Those that were designated high control were labeled relationships of Intimate Terrorism and those that were designated low-control were labeled Situational Violent relationships. Johnson \& Leone found that those relationships that were high-control/IT were also defined by more frequent and violent physical assaults, more injuries to the victim as well as more missed days of work, drug use, and psychological effects by and to the victim than Situational Violence.

Although other characteristics of Situational Violence have been suggested by Johnson and colleagues, such as "arguments that get physical", other life stressors that contribute to family violence, less perpetrator-blame of the victim than $\mathrm{CCV}$, communication shortcomings in the relationship and a socio-cultural acceptance of 
violence, Situational Violence in Johnson's article was measured by a lack of controlling behaviors (Johnson \& Leone, 2005). Although this may be a key defining factor between the two types of violence, it is not the only characteristic, and as Graham-Kevan \& Archer (2008) discovered, control can play a mediating role even in relationships defined as Situational Violence.

When Graham-Kevan and Archer (2008) retested Johnson's data using dyadic analysis of subject/partner data, they found that even when they separated relationships by four Johnson subtypes, Coercive Control Violence, Situational Violence, Mutual Violent Control \& Violent Resistance they found that it was controlling behaviors that predicted how physically violent the relationship would become. They found, as was found in Johnson's data, that high-control predicted more violent behavior and lowcontrol predicted less violence in the relationship, less frequency, less injury, less severity (Graham-Kevan \& Archer, 2008). This is an important discovery and speaks to the importance of evaluating the behavior indictors of level of control in the relationship. However, it is unclear whether control defines the typology or defines the level of Intimate Terrorism on a continuum, as low-level Intimate Terrorism (low control) or high-level Intimate terrorism (high-control). Johnson \& Leone (2005) in an OLS regression also found that women in Intimate Terrorism relationships rated higher than those in non-control Situational Violence relationships in experiencing PTSD.

Also interesting is Graham-Kevan \& Archer's discovery of primary mediating control factors in predicting violence that differ based off of subtypes (2008). In relationships defined as Intimate Terrorism, all 5 controlling behaviors (intimidation, threats, undercutting their partner, isolation and economic abuse) were exhibited as 
expected. However, in Situational Violence, only two of the controlling behaviors measured in the CBT were present. The primary association between controlling behaviors and physical violence was intimidation and threats which, as the authors suggest, could be used in a conflict situation that spins out of control.

Intimidation and threats could also be considered the verbal version of physical violence that may be used less to maintain control, and exhibited as a more reactionary verbal expression that leads up to physical violence. While Situational Violence containing two of the five controlling behaviors may seem to contradict with Johnson's assertion that that Situational Violence contains very little to no controlling behaviors, these two particular subscales, intimidation and threats could be either used in an argument with the intention of being able to win the argument, or rather like the purpose of Coercive Control Violence, to use intimidation and threats to gain and keep control over the course of the relationship.

Communication and Johnson Theory. Important to highlight as well is the influence of communication in Johnson's theory, as it is one of the potential mediating factors in this study. As Johnson's principle explanation for Situational Violence is communication deficits within the couple, it is important to understand the impact of conflict escalation and communication in violent relationships. In Michael Johnson's book, A Typology of Domestic Violence: Intimate Terrorism, Violent Resistance and Situational Violence (2008), he speaks to the importance that communication has on the definition of Situational Violence. He states "Situation Violence comes from the interpersonal dynamic of conflict management, " and that while in Coercive Control Violence, the focus is on control, in Situational Violence, the focus is on conflict. He 
writes about "verbal skill deficits" in Situational Violence in which at least one, if not both partners lack the verbal skills to argue constructively. When this occurs, the partner or partners that lacks the argumentative skills resorts to verbal aggression that may turn into physical aggression (Johnson, 2008, p. 65). Feldman and Riley (2000) found that couples that are aggressive resolve less conflict and are more negative than nonaggressive couples.

Other researchers have stated reasons for mutual verbal aggression that suggest similar findings that Feldman \& Riley (2000) catalogued in their article on conflict-based response. Levinson \& Gottman (1983) suggests that the negative physiological arousal becomes mirrored in the receiving partner, which escalates the conflict. These studies on communication patterns and deficits in violent relationships suggest that if the partner violence is based off of a lack of communication (i.e. Situational Violence), given the proper training in communication, those relationships would become less violent. Some of these concepts that address destructive communication and add to beneficial communication, particularly the work of John Gottman, are taught in the Within My Reach training and it is estimated that the training may help increase communication skills and reduce negative feedback patterns. Gottman's concepts in particular further suggests that couples "lock in" to response patterns in theorized models called "crosscomplaining," "invalidation loops," “contempt," “defensiveness," and "stonewalling (Gottman, 1979, 1994).”

Michael Johnson (2005) established through his writings that the etiology of perpetrator communication vary based off of relationship type; Those in Situational Violent relationships (or arguments that get physical) resort to violence due to 
communication deficits (Johnson, 2008) whereas perpetrators from Intimate Terrorist relationships resort to violence as a manifestation of a need to control. While Johnson's theory improves on the history of perpetrator and violent relationship typology, it is by no means a perfect theory and does not concentrate on pathology, impulse control or coping skills outside of communication. Coming from a sociological perspective he concentrates on environmental factors, internal and external factors (see typological limitations).

\section{The Impact of IPV on Couple Communication and Relationship Satisfaction}

Studies on couple communication have examined the differences between control and non-control based violence (Johnson, 1995, Johnson \& Leone, 2005, Johnson, 2006, Holtzworth-Monroe \& Stuart, 1994, Holtzworth-Monroe, Smutzler \& Stuart, 1998, Graham-Kevan \& Archer, 2003, Graham-Kevan \& Archer, 2008) and the effect of relationship education on type of violence (Antle \& Ness Roberts, 2012). Antle \& Ness Roberts, (2012) found that in Coercive Control Violence there was a higher degree of conflict engagement than those in Situational Violence, whereas those in Situational Violent relationships reported a higher degree of positive communication than those in Coercive Control relationships. Pre-to post intervention tests were also run on participants that completed a healthy relationship class, Within My Reach, which focuses on violence education, positive relationship outcomes and communication skills and they found that those engaged in Coercive Control Relationships were able to increase their positive communication skills significantly and reduce violence greater than those in Situational Violence relationships. 
Literature from Johnson (2008) and Burman, Margolin \& John (1993) observed a "pattern of negative reciprocity" between couples that were mutually violent, or like Situational Violent Couples are couples where both are behaving violently. This hypothesis was challenged by the Antle data (2012) which showed that upon original analysis those in the Situational Violence group actually scored higher in communication skills on the Conflict Resolution Styles Inventory than those who were in Intimate Terrorist relationships overall.

Patterns of relationship communication and dissatisfaction with the family are risk factors for victims and abusive partners. Abusive partners of violence are less satisfied with their relationships than are nonviolent men (Aldarondo \& Sugarman, 1996). Abusive partners are more likely to engage in negative communication patterns with their spouses, families and those closest to them (Cordova et al, 1993). Verbal and psychological aggression towards spouses was a significant risk factor for predicting future physical spousal abuse (Riggs, Caulfield \& Street, 2000; Pan, Neidig \& O’Leary, 1994; Sugarman, Aldarondo \& Boney-McCoy, 1996). In those couples that seek marriage counseling, $60 \%$ are experiencing some type of aggression in their marriage, which is 3-4 times higher than the general population (O’Leary, Vivian \& Malone, 1992; Vivian \& Malone, 1997 in Riggs, Caufield \& Street, 2000). Research above suggests that interpersonal communication with the family is a risk factor for IPV and that victims and perpetrators nested in this system can experience stress related to their relationship and are at risk for relationship violence. The prevalence of aggression in the population of counsel-seekers is alarming and when coupled with the predictive factor of future 
physical violence, speaks to the danger in assuming that commonality of violence does not imply safety.

Cox, Paley \& Hunter (2001) also found that those in a high-conflict relationship are more likely to have a negative parent-child relationship. This correlation between parental conflict and the interactions that the parent has with their children effects both parenting and child well-being.

\section{Attachment Theory}

Attachment Theory, developed predominantly by early theorists Bowlby (1969) and Ainsworth, is critical to understand for its implications regarding attachment between parent and child in the midst of and IPV relationship. Attachment theory is defined as the emotional bond and reciprocal relationship quality between caregiver and child that forms the primary model for the infant for forming later relationship bonds. Godbert et al (2009) explained Bowlby’s theory as:

Bowlby hypothesized that the attachment behavioral system regulates the child's attachment behaviors under emotional distress and that attachment figures who offer contact, reassurance, and comfort facilitate the child's development of emotional regulation, well-being, and expectations that close relationships provide a safe haven and a secure base, stimulating the development of positive models of his or her self and others' in relationships (Bowlby, 1973, 1984; Cicchetti \& Lynch, 1993 in Godbert et al. 2009, pp.367). 
In relationship violence between intimates, the child's needs are at risk of being neglected as energy is focused on the perpetrator in a controlling relationship, or on the pervasive drama and turmoil of the relationship distracts the parents from the child's needs. Mental health issues of the caregiver may occur simultaneously, or as a result of the relationship violence, which can cause a parent to be less attentive to the needs of their child. A child will turn to their caretaker when they are frightened, hungry, or sick, they will turn to their primary caretaker, however, if the primary caretaker is concentrating on preventing violence from happening in the home, or may not have the psychological space to provide caretaking to a child amongst their own needs. If a child's needs are not addressed, the child will attempt to revise their model for attachment to their care-giver, which may be maladaptive behaviors. One of these maladaptive behaviors is to no longer depend on a caretaker, where a child may develop an insecure attachment that may be translated to relationship bonding with others.

Bartholomew and Horowitz (1991) developed a quadrant approach to attachment which devised four types of attachment based on positive and negative view of self and others. Those that had a positive view of themselves and other were considered Securely Attached, with a high self-esteem and increased ability to maintain intimate relationships. Those that had a high view of themselves and more negative view of others were defined as having an Avoidant Attachment and are also defined as having low anxiety and high avoidance. Preoccupied Attachment was comprised of individuals with high anxiety/low avoidance (low view of themselves/high view of others) and could appear as seeking constant validation from a partner to renew their self-esteem. Finally, Fearful Attachment was defined as high anxiety/high avoidance (low view of themselves and 
others), whereas individuals in this quadrant could bounce between neediness and avoidance, from wanting an intimate relationship to fearing one (Godbert et al., 1991). Some of the greatest threats to developing a Secure Attachment frequently occur within IPV relationships, specifically exposure to parental violence, child abuse and neglect, absent parenting and maternal depression. Children develop attachment pathways through parental reactions to the child when the child perceives a threat. If the child receives a warm, comforting and protective reaction they learn to rely on their primary caretaker. When witnessing abuse between parents, children often feel threatened, yet they are unable to turn to either parent for comfort. As stated in Chapter 1, living in a home with violence between parents also increases a child's risk for being abused themselves. Child abuse is one of the biggest threats to a secure attachment because the child not only cannot turn to the parent when they are fearful, but they are often fearful of the parent because of the abuse. A child is at a high risk for neglect as well when IPV is present due to the interpersonal stress at play between the parents. Children's needs may be overlooked because of the overwhelming stress and conflict between parents and the child may begin to rely on themselves to meet their own needs or become parentified, attempting the needs of their siblings or parents. Maternal depression that occurs often in IPV relationships can also factor into child attachment, as the depressed individual does not always have the psychic capacities at that time to care for a child with needs. In Coercive Control Violence where the perpetrator often demands the majority of the victim's attention, the child's needs may come secondary to keeping the perpetrator satisfied, (and perhaps less violent). In any type of IPV a child can suffer from a lack of parenting, with one or both parents being either psychologically, 
emotionally or physically absent from their role as parent which can influence a child's attachment to their parent negatively. This can directly influence the child's well-being and the parent-child relationship.

\section{Trauma Theory}

The impact of witnessing violence and its incorporation into the body as trauma has great theoretical implications for children witnessing and experiencing violence within their families. Trauma theory, was originally used to explain the experiences of combat veterans that returned back home with symptoms of PTSD, which included flashbacks, nightmares, unexplained aggression and irritability, depression, suicidality, and psychomotor agitation. The definition of PTSD has been broadened to include the experiencing of an event in which either your own life or another's life was gravely threatened (APA, 2014). Children experiencing violence between their parents often exhibit symptoms of PTSD.

Trauma Theory explains the mechanism through which violence is processed as trauma in the body (Hyde-Nolan \& Juliao, 2012) and how it is integrated into one's personality and relationships with others. Van der Kolk (1989; pp.393) described traumatization as "Traumatization occurs when both internal and external resources are inadequate to deal with the external threat." Sensory stimuli is processed through the limbic system, however, when a high degree of cortisol is released into the system, such as when one is witnessing violence, the limbic system is overridden and the brain switches to a numbing model of reaction (fight, flight or freeze). This theory indicates that witnessed violence changes the way the brain processes information into stored memory, and without integrating memory, future events will be categorized, stored and 
sequenced through the traumatic event pathway (Hyde-Nolan \& Juliao, 2012). These traumatic events can, as Bloom (1999) writes, damage both our bodies and our psyches.

The impact of trauma to a child's well-being can affect multiple systems of the body, and may account for much of the biopsychosocial and behavioral maladaptations that were outlined in Chapter 1. Witnessing partner violence between parents, or having knowledge of a primary caretaker in danger can cause a traumatic response which may include acting out aggressively, disassociation, and learning and cognitive deficits. According to research, memory in the brain is divided into two types; verbal and nonverbal (van derKolk, 1996). Trauma affects the verbal centers of the brain, which is very vulnerable to stress. Damage in this area of the brain often leaves the traumatized individual to process new memories and access older memories through nonverbal memory (Bloom, 1999); thus for children, behaviors are the speech of trauma. Chronic stress can cause prolonged damage to the brain, and some CT scans show that the brain of trauma is significantly smaller, with a recessed prefrontal cortex and enlarged hippocampus, than that of a brain not affected by trauma. Trauma affects behavior and thus could also have an effect on the parent-child relationship, especially should both be affected by trauma and victimization.

\section{Social Learning \& Social Exchange Theory}

The contribution of Social Learning and Social Exchange Theory will also be recognizing as contributing to this research study.

Social Learning. Social Learning Theory (Bandura, 1962) suggests that we learn what we see, and that this has an effect on our beliefs about relationships and future behavior. According to this theory, children that are exposed to IPV early in life may 
learn that an adult relationship is one that contains violence or controlling behaviors because that was modeled for them in childhood.

Social Learning Theory is a very popular model which supposes that what a person learns as a child in their formative years will contribute to perceptions, behaviors, attitudes and cognitions as an adult (Loue, 2001). Aside from the feminist theory-based Duluth model, this theory is used most often in IPV research and treatment. This theory has been tested extensively with perpetrators of IPV to find an intergenerational link between witnessed violence in the home and future perpetration. Although research is still being retested to see to what degree witnessing IPV as a child changes a person's biophysiology, aggression or threshold of acceptance of violence, research has shown that being an IPV child witness does increase one's chance of being a perpetrator or victim as an adult (Berlin, Appleyard \& Dodge, 2011; Collins \& van Dulmen, 2006; Doumas, Margolin \& John, 1994; Ehrensaft et al., 2003; Kwong et al, 2003; Smith et al, 2011).

Social Learning Theory according to Cunningham et al (1998) further postulates that children learn which behaviors will give them a desired result through observing significant others in their lives even if these behaviors are socially inappropriate. If the behaviors are modeled for young children and reinforced in the media, the patterns of behavior can become what they call "entrenched (Cunningham, 1998)." Intervention can be very early on in the family and focuses on making sure children are not exposed to negative influences in the media or at home. If children have been exposed, more intervention is necessary to try and change the cognitive paths of those thought patterns and behaviors. For this reason, Cognitive Behavioral Interventions are common to 
address IPV. Some of the criticisms of this theory are that intergenerational transmission of violence doesn't always occur and is not generalizable to every culture. Also some batterers do not report history of exposure to domestic violence as children (Capaldi \& Gorman-Smith, 2003; Kaufman \& Zigler, 1987; Stith et al., 2000; Widom, 1989). According to Social Learning Theory, lateral peer relationships can also factor into sustaining violence towards victims. Bowker (1983 in Holtzworth-Munroe \& Stuart, 1994) found that abusive husbands that spent more time with male peers were more likely to be physically violent towards their wives and not have the intention to stop the violence. He explained this through a social psychological process called "standards of gratification" which dictates patriarchal domination over their wives (Schwartz \& DeKeseredy, 1997). He also claimed that this concept of domination is learned in childhood from witnessing their fathers dominating their mothers and that they as children are dominated by both parents. Thus, once they discover this is a social pattern of hierarchy, and this pattern is threatened, it can cause the male patriarch much psychological stress which manifests as rage in order to regain the hierarchy (Schwartz \& DeKeseredy, 1997).

Also, in the context of IPV, repeating violence because one has witnessed them as a child is more complicated than just seeing violent acts. This study looks at the presence of witnessing controlling behaviors in a violent relationship, and how they contribute to the internal processing of violence and its effect on the behavior of the parent and the well-being of the child (Figure 1). 
Figure 0: Social Learning Theory (Bandura, 1962)

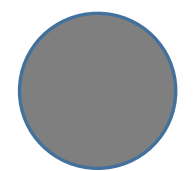

Condition

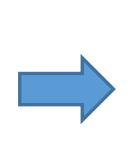

\section{Internal Process}

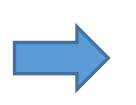

Behavior

Social Learning Theory also takes into account that which is learned from one's culture regarding gender roles and violence. The acceptance of discrimination, oppression and abuse of women has been a part of the social order and can be seen through differential pay grades of males and females, hypersexualization and being pejorative towards women in the media and commercials, unequal and unrealistic roles for men and women and the acceptance of violence in our culture. Critics of this argument state that although we do not have adequate records of spousal abuse rates prior to the middle of the $20^{\text {th }}$ Century we should see the decrease in violence when we have seen the domestic violence rates rise or stay the same since the 1970s. Also, some argue that even in communities that value the equality of the sexes, domestic violence still remains.

Social Exchange Theory. The final theoretical model that will also be utilized, especially in relation to examining parental behavior and relationship communication as a potential mediating factor contributing to child wellbeing and the parent-child relationship is Social Exchange Theory, which posits that in relationship decision-making one balances costs and benefits. In parenting in an IPV relationship, this may manifest as protecting one's child by paying more attention to one's partner instead of the child in order to mitigate the chance for violence towards that child or towards the spouse (thus exposing the child to witnessing violence). Often in control-based IPV relationships, the 
perpetrator of the violence demands to be the center of attention and is jealous of any entity that detracts from the victim's attention. In that type of dynamic, it is a greater risk physically to the child to pay them more attention than the perpetrator, even if that is rewarding to the victim and child emotionally. As such, making those decisions can be very much based in social exchange theory. Homans (1958) discusses this concept in more detail:

Suppose we are dealing with two men. Each is emitting behavior reinforced to some degree by the behavior of the other. How it was in the past that each learned the behavior he emits and how he learned to find the other's behavior reinforcing we are not concerned with. It is enough that each does find the other's behavior reinforcing, and I shall call the re-enforcers the equivalent of the pigeon's corn values, for this, I think, is what we mean by this term. As he emits behavior, each man may incur costs, and each man has more than one course of behavior open to him (pp.598-599).

\section{Theoretical Integration to Intervention: Implications for this Study}

Each theory presented has important implications for the Within My Reach intervention and the impact on child well-being and on the parent-child relationship. The below figure shows the relationship between each of the theories (Theory of Violence Typology is split into CCV \& SCV) and Within My Reach interventions that are hypothesized to have an effect on family cohesion, the parent-child relationship and child well-being. While the purpose of this dissertation is not a curriculum evaluation, the diagram explores potential curriculum pieces that may have impacted the potential mediators hypothesized in Research Question 3. This figure is also important in reflecting on the proposed etiological origins of abuse in the literature that have been presented in 
Chapter 2. Considering these curriculum items also helped to predict which types of violence would be affected most prevalently by the Within My Reach evaluation. 


\section{Figure 1}

\section{Typologies in Theory and Potential Curriculum Pieces that Support Change}

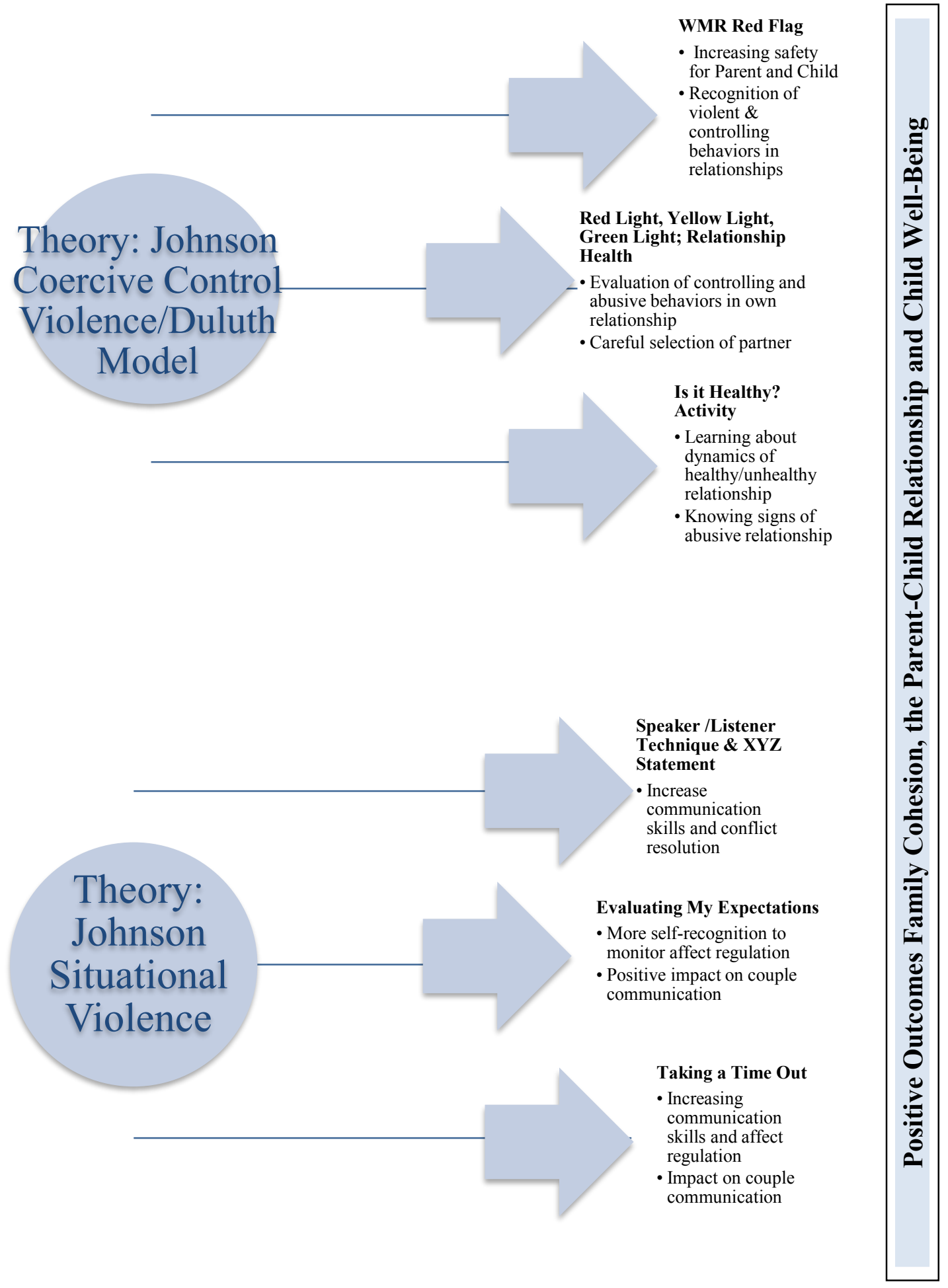


Sliding vs. Deciding

- Challenging Social view of whirlwind

romance

- Consciencious

decision-making

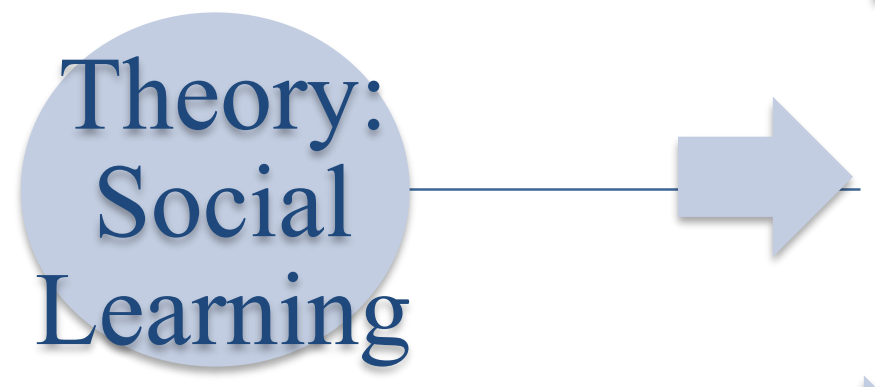

Evaluating My Expectations

- Looking at what I have come to generally accept because

my family/culture/peers states

that this is how things are vs. what I want.

- Looking at abusive bxs

"Baggage" Activity

- Evaluating what from childhood one wants to keep or

change

- Evaluating

childhood hurts and reflecting on how not to repeat them.

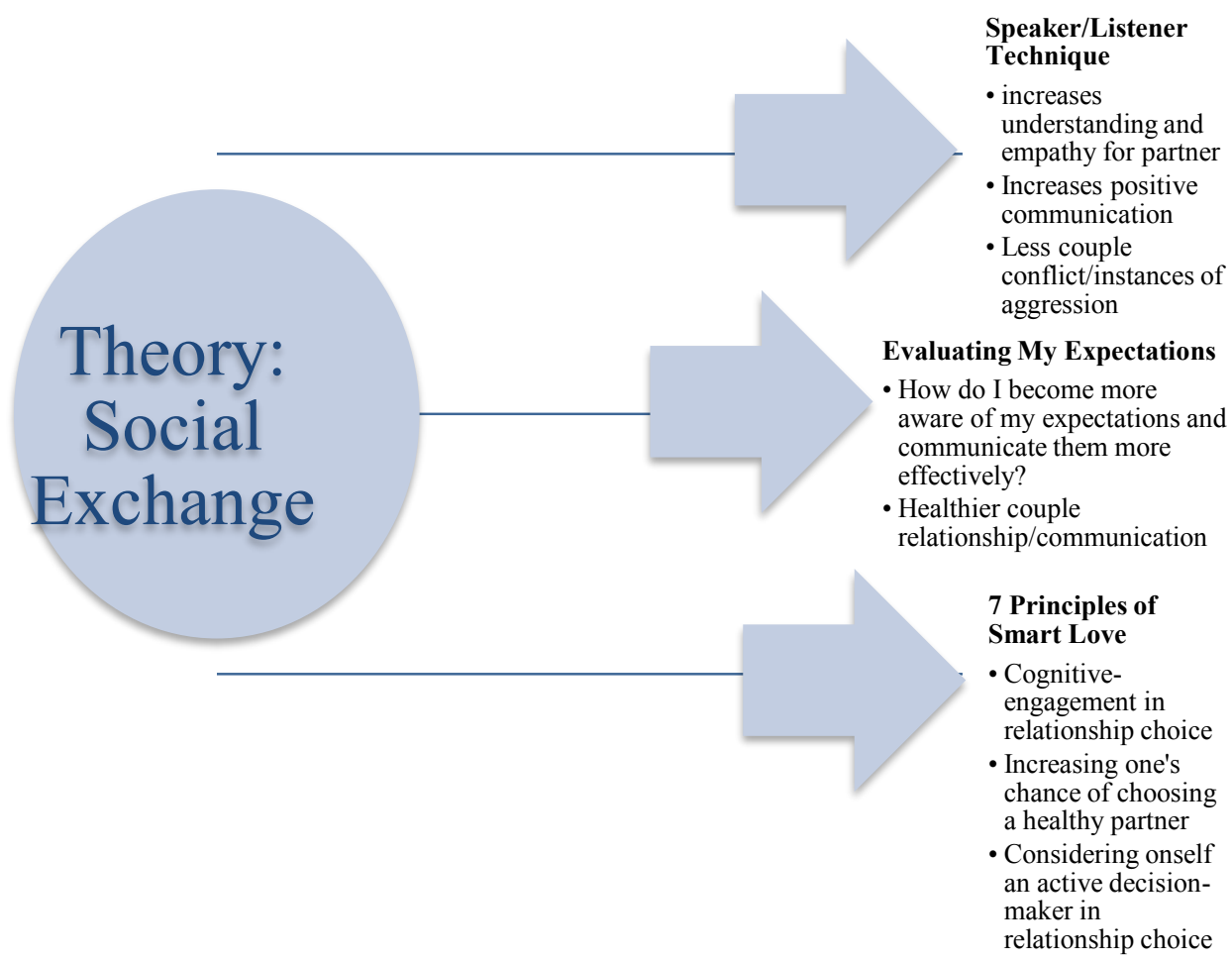


The figures illustrate how each theory is visible throughout the Within My Reach training, which, has been shown in previous research (Antle et al. 2013; Antle \& Ness, 2012) to reduce couple violence and increase couple communication and relationship satisfaction in both Situational Violence and Coercive Control Violence. Within My Reach is effective because it focuses on change mechanisms for the couple. Chapter 1 discussed the negative impact of couple relationship violence on child well-being and the parent/child relationship. Due to the knowledge that Within My Reach is effective at impacting the couple relationship positively by decreasing relationship violence, increasing positive couple communication and relationship satisfaction, research questions were developed that reflect the link between the impact of Within My Reach on positively impacting the couple relationship and how that relationship can impact the parent-child relationship and child well-being.

\section{Hypotheses}

Hypothesis Research Question \#1. It is believed that due to evidence in the literature review and proposed theories that high control/psychological violence and physical violence will have more of an effect on family cohesion, the parent-child relationship and child well-being than Situational Violence or No Violence at all. It is proposed as well that Situational Violence will have significantly worse outcomes than No Violence due to the presence of physical violence and the theorized etiology of SV that it is due to an unhealthy inability to communicate during conflict. It is believed that the No Violence Group will score the highest in family cohesion, the parent-child relationship and child well-being. 
Hypothesis Research Question \#2. It is hypothesized that the Within My Reach training improves overall family cohesion, the parent-child relationship and child wellbeing in all violence and non-violent groups (CCV, SV, NV). Due to the heavy emphasis in the Within My Reach training on communication and conflict management it is believed that the Situational Violence group will improve the most. This hypothesis is generated mostly from Johnson's (2008) writing that "Situational Violence comes from the interpersonal dynamic of conflict management (65)" and "verbal skill deficit (65)." It is believed that the Coercive Control Violent group will improve the next most, as they have the most room for improvement, should hypothesis for Question 1 be confirmed. Finally, it is believed that although each violence type will improve that Situational Violence and Coercive Control Violence will improve significantly more than the No Violence group, as it is hypothesized that they will have the highest family cohesion, parent-child relationships and child well-being at baseline.

Hypothesis Research Question \#3. It is believed that improvements in family cohesion, the parent-child relationship and child well-being will be most influenced by the reduction in violence and controlling behaviors for the CCV group and by communication and couple relationship quality in the SV group. Due to a low sample size, we will not be able to run each violence group separately. For this reason, it is believed that reduction in violence will have the most impact because that is a shared component of both types of violence followed by equal weight of reduction of controlling behaviors and communication improvement, as these are the theoretical etiological foundations of each type of violence. It is believed there will be an overall main effect for all outcomes. 


\section{CHAPTER III}

\section{METHODOLOGY}

The Methods for the study are below, which include the background of the study, research design, sample, recruitment and data collection procedures, how human subjects were protected, measures and the data analysis plan.

\section{Background of the Study}

This research study utilizes the data from the Relationship Education Across Louisville (REAL) Grant was an intervention study of at-risk adults and adolescents attending the Neighborhood Place social services centers, that was funded by the U.S. Department of Health and Family Services, Office of Family Assistance (\#90FE000201; Antle, PI). Aims of the REAL grant included reduction of violence in couples and families, increasing relationship satisfaction and communication, and examining the effect of violence on parenting.

\section{Research Design}

This is a quasi-experimental, pre-multiple post-test comparison group research design. The participants attended the class voluntarily and were recruited from the Neighborhood Places, social service collectives in Louisville, Kentucky that provide food stamps, TANF, WIC, work-force education, case management, CPS services and therapy to low-income families. The 882 participants attended the Within My Reach training between 2006-2011. Those that did not participate in the training within the first two 
years were invited to participate as a control group sample. Those in the comparison groups were also encouraged to attend a class following data collection. Data were collected at pre-intervention, immediate post, 6-month post and 12-month post for the experimental (Within My Reach) group and at baseline and six months post for the comparison.

The instruments used to collect data were self-administered surveys containing scales that measured presence of physical abuse, presence of controlling behaviors, the parent-child relationship, child well-being, the relationship quality of the couple, couple communication and conflict resolution and demographic information. More detail on the instrumentation and its validation will occur later in Chapter 3.

\section{Sample}

There were 882 individuals who attended the initial Within My Reach class at Neighborhood Place sites within a five-year period. Recruitment of participants was accomplished through printed advertisements, word of mouth by former participants, and direct invitation by Neighborhood Place staff. The program was offered in four, fourhour sessions either in mixed gender or men's only groups. Individuals were not allowed to attend class with their partners. The retention rate of participants for all subsequent classes (e.g. classes two through four) across all sites and formats was 92\%. All 882 adults who participated in an initial Within My Reach session were invited to participate in the study. The number of participants who attended at least $75 \%$ of the training (which is equivalent to three out of the four classes) was 829 . For this study, the sample size was 806 subjects for the pre-training surveys, 779 subjects for the immediate post-training surveys, and 409 subjects for the six months post-training surveys and 91 participants for 
the 12 -months post-training surveys. The 806 subjects represented a $100 \%$ response rate to the surveys at the pre-training data collection point. The response rate for immediate post-training was $95 \%$ and for six months post-training was $51 \%$ and $11 \%$ for the 12 months post-training surveys. In the control group (those that did not take the WMR Intervention) 220 subjects started the pre-test, 219 completed the pre-test (one subject did not finish), and at 6 months post pre-test, 105 participants (48\%) completed the survey. This significant decline in the response rate over time is reflective of the transient nature of the target population. Although standard procedures were used to maintain contact with and track participants over time (e.g. postcards, periodic giveaways, reminder phone calls, incentives), due to the housing and economic instability of participants, researchers often had difficulty finding participants at the six-month follow-up data collection point. There were no significant differences in demographic variables between the pretest, posttest and 6 mos post group indicating that the results for the follow-up periods are representative of the entire study population (see below). 
Table 5

Participant Demographics

\begin{tabular}{|c|c|c|c|c|c|c|}
\hline DEMOGRAPHIC & $\begin{array}{c}\text { N } \\
\text { Pre }\end{array}$ & $\begin{array}{c}\% \\
\text { Pre }\end{array}$ & $\begin{array}{c}\text { N } \\
\text { Post }\end{array}$ & $\begin{array}{c}\% \\
\text { Post }\end{array}$ & $\begin{array}{c}\mathrm{N} \\
\text { 6mos }\end{array}$ & $\begin{array}{c}\% \\
6 \mathrm{mos}\end{array}$ \\
\hline \multicolumn{7}{|l|}{ GENDER } \\
\hline Gender: Male & 166 & $20.5 \%$ & 154 & $19.7 \%$ & 85 & $16.3 \%$ \\
\hline Gender: Female & 637 & $79 \%$ & 609 & $78.0 \%$ & 427 & $81.6 \%$ \\
\hline Gender: Unknown & 3 & $.004 \%$ & 18 & $2.3 \%$ & 11 & $2.1 \%$ \\
\hline \multicolumn{7}{|l|}{ AGE } \\
\hline $17-21$ years of age & 82 & $10.5 \%$ & 59 & $7.2 \%$ & 36 & $7.2 \%$ \\
\hline $22-30$ years of ae & 232 & $29.6 \%$ & 254 & $31.1 \%$ & 138 & $27.6 \%$ \\
\hline $31-40$ years of age & 204 & $26 \%$ & 195 & $23.9 \%$ & 121 & $24.4 \%$ \\
\hline 41-50 years of age & 161 & $20.5 \%$ & 156 & $19.1 \%$ & 130 & $26 \%$ \\
\hline $51-60$ years of age & 83 & $10.6 \%$ & 131 & $6.25 \%$ & 62 & $12.4 \%$ \\
\hline 61 years or older & 22 & $2.8 \%$ & 21 & $2.6 \%$ & 13 & $2.6 \%$ \\
\hline \multicolumn{7}{|l|}{ RACE / ETHNICITY } \\
\hline African American/Black & 544 & $68.1 \%$ & 517 & 66.2 & 325 & $62.1 \%$ \\
\hline Caucasian/White & 206 & $25.8 \%$ & 195 & 25 & 163 & $31.2 \%$ \\
\hline Other & 20 & $2.4 \%$ & 19 & 2.4 & 6 & $1.1 \%$ \\
\hline Native American & 12 & $1.5 \%$ & 11 & 1.4 & 7 & $1.3 \%$ \\
\hline Multiracial & 10 & $1.2 \%$ & 10 & 1.3 & 2 & $.4 \%$ \\
\hline Hispanic/Latino & 5 & $.6 \%$ & 4 & .5 & 2 & $.4 \%$ \\
\hline Asian American/Pacific Isl. & 2 & $.2 \%$ & 2 & $.3 \%$ & 1 & $.2 \%$ \\
\hline Race/Ethnicity: Not Indicated & 7 & $1 \%$ & 23 & $2.9 \%$ & 13 & $2.5 \%$ \\
\hline \multicolumn{7}{|l|}{ RELIGION } \\
\hline Other & 420 & $51.1 \%$ & 401 & $51.3 \%$ & 261 & $49.9 \%$ \\
\hline No religious affiliation & 142 & $17.3 \%$ & 131 & $16.8 \%$ & 82 & $15.7 \%$ \\
\hline Catholic & 86 & $10.5 \%$ & 83 & $10.6 \%$ & 55 & $10.5 \%$ \\
\hline Protestant & 77 & $9.4 \%$ & 73 & $9.3 \%$ & 58 & $11.1 \%$ \\
\hline Jewish & 7 & $1 \%$ & 7 & $.9 \%$ & 7 & $1.3 \%$ \\
\hline \multicolumn{7}{|l|}{ MARITAL STATUS } \\
\hline Single, Never Married & 349 & $42.5 \%$ & 333 & $42.6 \%$ & 207 & $39.6 \%$ \\
\hline Divorced & 129 & $15.7 \%$ & 124 & $15.9 \%$ & 93 & $17.8 \%$ \\
\hline Living Together, Cohabitation & 121 & $14.7 \%$ & 115 & $14.7 \%$ & 75 & $14.3 \%$ \\
\hline Married & 99 & $12 \%$ & 91 & $11.7 \%$ & 73 & $14 \%$ \\
\hline Other & 64 & $7.8 \%$ & 61 & $7.8 \%$ & 33 & $6.3 \%$ \\
\hline Widowed & 19 & $2.3 \%$ & 18 & $2.3 \%$ & 15 & $2.9 \%$ \\
\hline Remarried & 3 & $.4 \%$ & 3 & $.4 \%$ & 4 & $.8 \%$ \\
\hline Not Indicated & 36 & $4.6 \%$ & 36 & $4.6 \%$ & 23 & $4.4 \%$ \\
\hline \multicolumn{7}{|l|}{ EDUCATION LEVEL } \\
\hline Completed $2^{\text {nd }}$ grade $-8^{\text {th }}$ grade & 22 & $2.7 \%$ & 39 & $4.9 \%$ & 34 & $5.5 \%$ \\
\hline Completed 9-11 ${ }^{\text {th }}$ grade & 120 & $14.8 \%$ & 108 & $13.6 \%$ & 81 & $13.1 \%$ \\
\hline Graduated high school/ GED & 141 & $17.5 \%$ & 266 & $33.6 \%$ & 260 & $42 \%$ \\
\hline Completed post high-school or tech school & 32 & $4.6 \%$ & 32 & $4.0 \%$ & 26 & $4.2 \%$ \\
\hline Completed 1 year of college & 149 & $18.5 \%$ & 147 & $18.6 \%$ & 81 & $13.1 \%$ \\
\hline Completed yrs 2-3 of college & 132 & $16.4 \%$ & 129 & $16.3 \%$ & 86 & $13.9 \%$ \\
\hline Graduated w/a Bachelors Deg & 14 & $1.7 \%$ & 6 & $.76 \%$ & 3 & $.49 \%$ \\
\hline Graduated w/a Masters Deg & 26 & $3.2 \%$ & 25 & $3.1 \%$ & 20 & $3.2 \%$ \\
\hline Ph.D. & 4 & $.5 \%$ & 3 & $.38 \%$ & 3 & $.49 \%$ \\
\hline Other & 4 & $.5 \%$ & 4 & $.50 \%$ & 3 & $.49 \%$ \\
\hline Not Indicated & 20 & $2.5 \%$ & 33 & $4.2 \%$ & 20 & $3.2 \%$ \\
\hline \multicolumn{7}{|l|}{ EMPLOYMENT STATUS } \\
\hline Employment Status: Unemployed & 429 & $52.2 \%$ & 411 & $52.6 \%$ & 274 & $52.4 \%$ \\
\hline Employment Status: Employed Full Time & 147 & $17.9 \%$ & 140 & $17.9 \%$ & 82 & $15.7 \%$ \\
\hline Employment Status: Employed Part-Time & 92 & $11.2 \%$ & 87 & $11.1 \%$ & 60 & $11.5 \%$ \\
\hline Employment Status: Retired & 22 & $2.7 \%$ & 20 & $2.6 \%$ & 19 & $3.6 \%$ \\
\hline Employment Status: Other & 76 & $9.2 \%$ & 71 & $9.1 \%$ & 50 & $9.6 \%$ \\
\hline Employment Status: Not Indicated & 40 & $6.8 \%$ & 52 & $6.7 \%$ & 38 & $7.3 \%$ \\
\hline \multicolumn{7}{|l|}{ GROSS FAMILY INCOME } \\
\hline Less than $\$ 20,000$ annually & 548 & $68 \%$ & 526 & $67.3 \%$ & 368 & $67.3 \%$ \\
\hline$\$ 20,000-30,000$ annually & 85 & $10.5 \%$ & 82 & $10.5 \%$ & 50 & $9.16 \%$ \\
\hline More than $\$ 30,000$ annually & 58 & $7.2 \%$ & 55 & $7.4 \%$ & 58 & $10.6 \%$ \\
\hline Not indicated & 115 & $14.3 \%$ & 118 & $8.9 \%$ & 70 & $12.8 \%$ \\
\hline
\end{tabular}


The majority of the participants were unemployed 52.2\% (429) which is expected due to the nature of recruitment at a Neighborhood Place where individuals often seek financial help during hardship. The economic downturn of 2007 also fell during the years of the grant 2006-2011 which may account for the high unemployment rate. Although $52 \%$ of participants were unemployed, $68 \%$ (548) had a gross annual family income of less than $\$ 20,000$.

\section{Variables \& Instruments}

Presence of Physical Abuse:_The presence of physical violence in relationships will be determined by the Conflict Tactics Scale (Straus, Hamby, Boney-McCoy, \& Sugarman, 1996), which is a 5 -point Likert Scale ( $0=$ Never to $4=A l w a y s)$, that measure violence with 8 -items that increase in the severity of violence from " 1 . threw something at the other one" to "8. Used a weapon (e.g. a knife)." The scale will be used to filter out only the cases where physical violence is present and create that group as the No Violence group. Although it is acknowledged that psychological/emotional violence is a very damaging form of abuse, and can also lead to physical violence, for the purposes of this study, we are only using cases where physical violence is present or has been present to form the $\mathrm{CCV}$ and $\mathrm{SV}$ groups. This is the most widely used scale in domestic violence research to indicate presence of physical violence.

Presence of Controlling Behaviors: The presence of controlling behaviors will divide the Situational Violent relationships (no/low presence of controlling behaviors) and the Coercive Control relationships (high presence of controlling behaviors) from the larger group of presence of physical violence through a k-means cluster analysis. The scale that will be used to indicate controlling behaviors is the Controlling Behaviors 
Scale (Graham-Kevan \& Archer, 2003). It is a 5-point Likert Scale $(0=$ Never to 4=Always) and measures 24 items on 5 sub-scales. Items 1-4 measure economic control, items 5-8 are threatening control, items 9-13 are intimidating control; items $14-18$ are emotional control; and items 19-24 are isolating control (Corcoran \& Fischer, 2013) that indicate control such as "Do you/your partner make or carry out threats to do something to harm the other", "Do you/your partner use looks, actions, and/or gestures to change the others behavior," and "Did you/your partner restrict the amount of time the other spent with friends and/or family." The Cronbach's alpha scores ranging from .85 to .95 with good discriminant validity for students, women in domestic violence shelters, male prisoners, and couples attending domestic violence treatment programs (Archer \& Graham-Kevan, 2003; Graham-Kevan \& Archer, 2003; Graham-Kevan \& Archer, 2005). Family Adaptability and Cohesion Evaluation (FACES IV). Family Cohesion will be measured by the FACES Scale (Olson et al, 1982) which is a 10-item scale that is divided into six scales measuring Enmeshed, Disengaged, Chaotic, Rigid, Cohesion and Flexibility. Items include: "Family members feel very close to each other," "When our family gets together for activities, everybody is present", "We can easily think of things to do together as a family." Reliability ranges from .77-.89 (Olson, 2011) and it has been found to be reliable and valid with diverse groups, including Italian school children (Baiocco, Cacioppo, Laghi \& Tafa, 2009).

Parent-Child Relationship. The parent-child relationship will be measured by The Parent-Child Relationship Scale (Gerard, 1994) which is a 4-point Likert scale of 15 items which measure the parent-child relationship. Six of these items measure how well the parent and child get along, how well the child gets along with the parent's 
spouse/partner, the parent/child communication, trust, respect and feeling of closeness, while items 7-15 measure various feelings of the parent when they think about their experience as the parent of their child. These items are feelings such as "Bothered/upset," "Emotionally worn out" "Worried" "Satisfied", "successful” and "Contented" and parents indicate whether these feelings apply to them from 4=Very to $1=$ Not at all.

Child Well-being. Child well-being will be measured by the Child-Wellbeing Inventory which participants self-report on a 3 point Likert scale (Never, Sometimes or Often), on 17 items which evaluate child well-being. Some of these items ask if the child, "Feels sad, unhappy," "Has trouble concentrating," or "Does not listen to rules" and screens for possible indicators of depression, ADHD, conduct disorder, anxiety or disassociation. In this study, if the parent had more than one child, the parent was asked to choose the most challenging child and report answers based on that child.

Couple Communication: Change in Couple Communication from pre to 6months post is being considered as a potential variable to explain change in Family Cohesion, the Parent-Child Relationship, and Child Well-being at 6-months post. Couple relationship quality will be measured by the change in the Relationship Dynamics Scale (RDS) (Renick et al, 1992; Stanley \& Markman, 1996) from pre to 6-months post. The RDS is a 3-point Likert Scale (1=Almost Never or Never to 3=Frequently) measuring relationship quality and likelihood of relationship failure across 11 items. Examples of the 11 items are "I feel lonely in this relationship," "My partner criticizes or belittles my opinions, feelings or desires" and "I hold back from telling my partner what I really think and feel." It also measures who in the relationship withdraws from an argument 
most frequently. Strong discriminant validity and Chronbach's alpha levels ranging from .73 to .88 [99] (Stanley et al., 2001). The Stanley-Markman Relationship Dynamics Scale predicts the likelihood of future relationship failure, with reported Chronbach's alpha levels of .73 [101] and .81 [107] (Antle, 2011; Ripley \& Worthington, 2002).

Couple Relationship Quality. Couple relationship quality will be measured by Dyadic Adjustment Scale (DAS-7) (Spanier, 1976). The DAS-7 Seven-Item Short Form of the Dyadic Adjustment Scale (Spanier, 1976) is a shortened version of the 32-item scale, measuring relationship quality over 4 areas: satisfaction, cohesion, consensus, and affection/expression. The DAS-7 is adapted for non-married couples and contains 7-items such as agreement on philosophy of life, goals, time spent together, exchange of ideas, calm discussion and working on projects together on a 6-point Likert scale. The final item is on a 7 point Likert scale asking the participant to rate their degree of happiness in the relationship from $0=$ Extremely Unhappy to $6=$ Perfect. Chronbach's alpha ranges from .76 to .96 . Construct validity has been reported as .88 and .86 (Spanier, 1976).

\section{Procedure}

Recruitment Participants were recruited from the Neighborhood Places, a group of ten "one-stop" social services agencies that offer services related to health, employment, and education for at-risk populations. Each Neighborhood Place is strategically located in areas that have the most socioeconomic need, and along with services and classes also distribute food stamps, WIC, housing assistance, \& mental health counseling specific to the needs of that particular community. The Neighborhood Places have received multiple community and national awards for innovation. Dr. Becky Antle and colleagues that began the REAL grant initiated the grant here in the 
Neighborhood Places, as there was already trust within the communities that the Neighborhood Places served. The grantees also hired facilitators that were employees of each specific Neighborhood Place and trained them in the curriculum. This was also a method for endearing trust in the community and offering a curriculum that could be used in the neighborhood place in the future, after the grant was finished.

Participants were offered the class by three methods 1) Personal invitation by a staff member at the Neighborhood Place 2) Passively through flyers which were posted at the Neighborhood Places through the grant 3)Word-of-Mouth of other participants in WMR or from friends and family who receive services through the Neighborhood Places. All participants were invited to participate, and though this grant was targeted to test the efficacy of this curriculum in at-risk, low socioeconomic populations, we did have some participants who were not within federal poverty guidelines (see chart). Exclusion criteria for the Within My Reach curriculum included those 17 years of age or younger, repeat participants, participants had to understand and read English, and participants could not take the curriculum with a family member or significant other. The final exclusion criterion was malleable however, and participants could take the course, as long as the family member or friend was not in the class. This was for participant physical as well as emotional safety. Participants then called the research manager and were signed up for a class, most often at the neighborhood place that they regularly attended. If the dates were not convenient for participants at their neighborhood place, they were invited to participate at another neighborhood place and offered free bus tickets on the first night of class. Transportation was a barrier that the grant writers anticipated, and to minimize this barrier, wrote in a transportation budget into the grant. Many of the 
Neighborhood Places are centrally located within the communities and were within walking distance for many participants, which served as a natural preventative for transportation barriers.

Once the participant called the research manager they were brought through a brief survey to determine eligibility and signed up for their chosen class day. The list went up to 20 participants and continued onto a wait list. Those on the wait-list were called on the first night of training if all participants did not come to the training, and a facilitator would go over the missed material. There was an active reminder system prior to the first class. Participants were called the week before, then three days before, then the day before to remind them of the class. If at that time, they opted out of the class, someone on the wait list would fill their place. This became a very popular class, especially after previous participants began recruiting by word-of-mouth, and often classes were full to over-capacity throughout the grant.

\section{Retention Strategies}

The retention on this grant was $97 \%$ for a 4 -week, 16 -hour grant. Retention strategies included financial compensation, travel compensation, strategic facilitator choice, childcare, and a hot dinner. Participants were given $\$ 150$ in gift cards to the local grocery store, Kroger, over the course of 4-weeks as an incentive to return as well as bus tickets. The facilitators were interviewed and chosen from the local Neighborhood Places and often prior to the class, participants were familiar with the facilitators, often meeting one-on-one with facilitators. Childcare was provided through the first year of the program, however, some problems began to arise with having on-site child-care and this incentive was dropped. The participants were notified that there would not be on-site 
childcare ahead of time, and often the classes would fill weeks ahead of time, allowing for ample time for childcare to be found. We found that this did not significantly affect turn-out. A full, nutritious, hot dinner was also provided to participants, which included a protein and vegetable was often given. When we started the program, many of the sites were located in "grocery store deserts" and the participants voiced appreciation of a wellbalanced, warm meal.

Retention was also maintained by utilization of multiple follow-up calls and the opportunity to take a supplemental class on the material weeks later. Reminder calls were made 48 hours before the next class as well as a few hours prior the class. Often when the phone calls were made, participants voiced appreciation for the phone calls as they had forgotten what day it was. More study is needed to know why this was, but the disorientation of time may have been the high unemployment rate amongst participants, that without having to keep a work schedule that days may have run together. The supplemental class was offered to participants at 6 -weeks post intervention to continue engagement in the curriculum. The participants were given $\$ 25$ to participate in the class.

\section{Randomization and Intervention}

Data from a control group was gathered and the control group was offered the opportunity to take WMR after the year of data collection. Participants that elected to take the class were offered placement in a class that was convenient for them. In this present study, participants were clustered into group by violence type, which will be discussed further in the methods section. This clustering was random and blind, as we 
did not know which participatory WMR group the participants in each group were assigned.

The intervention was a 4-week, 16 hour program that utilized the Within My Reach curriculum by Stanley \& Markman. This curriculum is empirically-based and has been tested for reduction in violence and efficacy. The curriculum covers the topics of communication strategies \& skills, self-knowledge, partner evaluation, signs and course of intimate partner violence relationships, how to facilitate a healthy relationship, relationship decision-making \& safety, effects of abuse on intimate partners and children, family-of-origin transference and a relationship's effect on children. The curriculum was interactive, encouraged discussion and included multiple group activities and individual workbook activities. Survey data was collected at pre-intervention (in class), immediate post-intervention (in class), six-month post intervention (via mail) and twelvemonth post intervention (via mail) and was by self-report. There was also behavioral data that was collected via video of communication skills demonstration that was not used for this dissertation. A follow-up supplemental class was offered six-weeks after the end of the WMR program. Data was not collected for this class, but an incentive of $\$ 25$ was given for attendance. A qualitative diary study was also done in the final year of the grant due to the large number of participants (approx. 15\%) that chose to end their relationships at the end of the 4-wk program. Those participants were invited to participate in a 12 week study on their relationship decision making. This data has not yet been analyzed.

The intervention classes were held at the Neighborhood Places in 4-hour increments either in the evening or the morning hours. 1.5-2 hours of curriculum would 
be administered, followed by a lunch or dinner break, and then 1.5-2 hrs. of curriculum would follow. Participants were seated with desks a U-shape or around a large conference table in order to facilitate discussion. A curriculum-supplied power-point of the curriculum was used by facilitators who were all required to attend a Within My Reach Training of Trainers by a Certified PREP trainer. Any facilitator that teaches this curriculum is required by the PREP corporation to be taught by a PREP approved trainer. This training occurred in March of 2005. Data was collected prior to the course beginning and at the end of the final class. Trained observers were also in every class to document facilitator fidelity to the curriculum. This data was collected and analyzed by study faculty.

\section{Informed Consent Procedures}

Approval for the study was obtained from the Institutional Review Board by the principal investigator of the study, Dr. Becky Antle. A full consent was given to participants prior to the pre-test to inform them of benefits and risks involved prior to participation in the study, their right to refuse participation in the training or discontinue participation at any time or discontinue surveys at any time without penalty and right to not answer specific questions that might make them feel uncomfortable. The participants were also informed that they could become distressed at any time during the data collection or program and were given referrals for community resources as well as encouraged to speak to the facilitator or research team member.

\section{Participant Reimbursement}

Participants were given $\$ 150$ in Kroger gift cards for completing the intervention. They were given $\$ 15$ Kroger gift cards for return of the 3, $6 \& 12$ month surveys as well 
as pre-stamped envelopes for return. Participants were also reimbursed for their travel through a bus ticket.

\section{Pre-Treatment}

The pre-test was implemented prior to the first lecture on the first day of the training and included measurements on demographics, relationship satisfaction, parenting, communication with significant person identified, violence measures, attraction measures as well as a knowledge test. The measures from the pre-test that were utilized for the purposes of this study are found below.

\section{Post-Treatment}

The immediate post-test was given the last day of the training after the last unit and included measures of relationship satisfaction, communication, controlling behaviors, relationship status (did they stay or leave), participant satisfaction, knowledge and perceived skills. Surveys were mailed with an included postage-paid envelope at 6 and 12 month follow-up and gift-card were mailed upon survey receipt.

\section{Data Analysis Plan}

Overview of Data Analysis Plan. SPSS statistics 22 was used to analyze data. The data was cleaned and missing data points removed. Following cleaning of the data, the control group will be removed from the study as well as participants without children by selecting cases and removing cases of number of children in the home $n=<1$. A new variable "Presence of Physical Violence" will be created using the Conflict Tactics Scale (CTS) and those with a violence score of $n<1$ will be categorized as the No Violence group. The filter feature will be used to de-select the No Violence groups while the clusters are formed using a k-means cluster analysis. Once the groups are created, 
demographic information will be collected on the sample and a test for normality will be done prior to testing Question 1 using histograms. A one-way MANOVA will be used to determine impact of violence group on family cohesion, the parent-child relationship and child well-being. Three Repeated Measures ANOVAs will be used to test the impact of the Within My Reach training on each of the three outcomes by violence type. Post hoc analyses will be used to examine differences between groups if significance is found. Finally, a Multiple Regression Analysis will be run to determine if the change in couple communication, relationship quality, reduction in physical or psychological violence impacted the change in family cohesion, the parent-child relationship and child wellbeing from pre to 6 months post. Included below is a figure that illustrates the data analysis plan. It outlines the connection between variables and the overall direction for data analysis. 


\begin{tabular}{|l|}
\hline Figure 2 \\
Data Analysis Plan \\
\hline
\end{tabular}

Impact of Violence Type on DVs

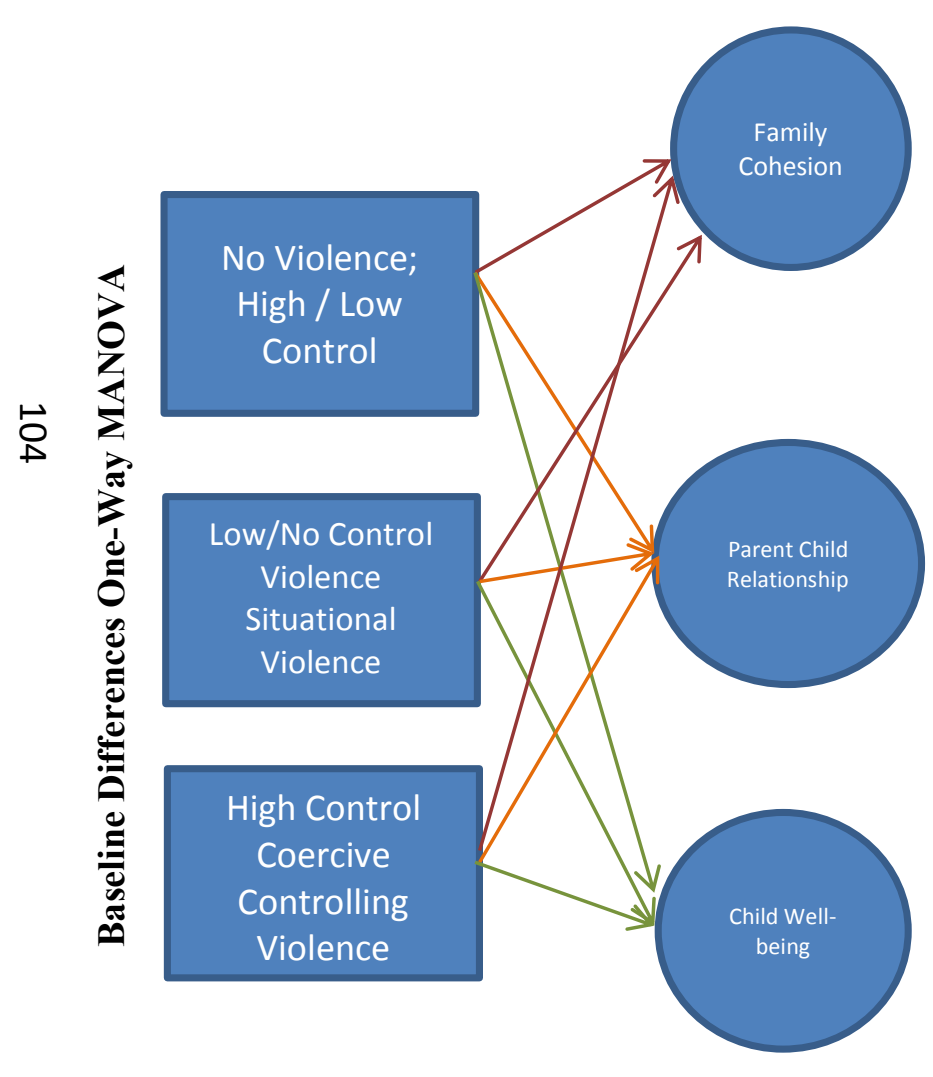

\section{Impact of Within My Reach}
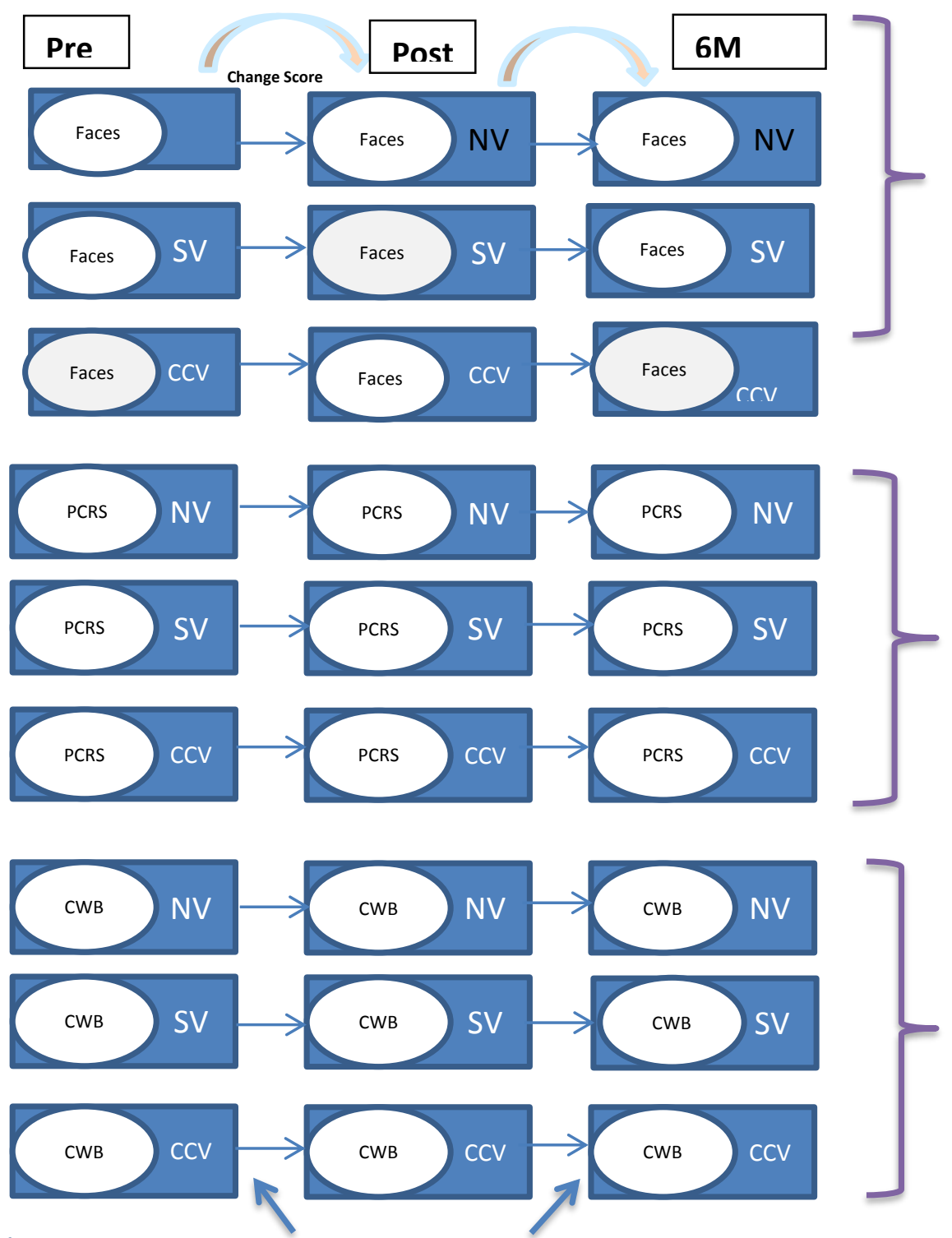


\section{Statistical Tests Used}

K-Means Cluster Analysis. A k-means group cluster analysis is a vector analysis that partitions a set number of clusters around the means of those clusters. The values for those means are reported in the output. A k-means cluster analysis will also determine Euclidian distance from each mean. The greater the distance that each cluster has from each other, the more dissimilar the clusters will be. This cluster analysis will create a high-control violent group (Coercive Control Violence) and low-control violent group (Situational Violence) using the same method that Graham-Kevan and Archer (2003) used to create groups by the same name.

Repeated Measures ANOVA.: A repeated measures ANOVA was used to answer research question 2: What is the effect of the Within My Reach training on participant's parent/child relationship, family cohesion and child well-being and does it differ by violence type? A repeated measures ANOVA is used when the sample is exposed to multiple tests, particularly time tests. A repeated measures ANOVA is necessary to measure changes over time. A repeated measures ANOVA was used in this study to determine main effect and interaction effect within and between-subjects.

The Assumptions of a Repeated Measures ANOVA are:

Dependent variable is always an interval or ratio level variable (continuous level)

Independent variable consists of at least two categorical "related groups" or " matched pairs"-Same subjects in each measured subjects No significant outliers 
Approximate normal distribution of the dependent variables; Can test for approximate normality using Shapiro-Wilk test of normality.

Sphericity: Sphericity is tested using Mauchley's Test for Sphericity as part of the GLM Repeated Measures procedure.

MANOVA. A one-way MANOVA was used to answer research question one, is there a difference in family cohesion, parent/child relationship and child well-being by relationship violence type? to determine the baseline differences between three groups; Coercive Control Violence, Situational Violence and No Violence. A MANOVA is used whenever there is more than one dependent variable and a test for the difference in means between two or more groups is necessary. A MANOVA would not be appropriate if the DVs were too highly correlated or if they are not correlated at all.

Assumptions of a MANOVA:

“Observations are randomly and independently sampled from population Each dependent variable has an interval measurement Dependent variables are multivariate normally distributed within each group of the independent variables (which are categorical)

The population covariance matrices of each group are equal (extension of homogeneity of variances required for univariate ANOVA) (Zaiontz, 2015)"

Regression Analysis: A Regression Analysis estimates the relationships among variables. It includes techniques for analyzing several variables when the focus is on the relationship between a dependent variable and one or more independent variables (or 'predictors'). A regression analysis shows how the typical value of the dependent variable changes when any one of the independent variables is varied, while the other 
independent variables are held fixed. A regression analysis is used for prediction and forecasting.

The Statistical Assumptions for a Regression Analysis are:

Dependent Variable is measured on a continuous scale: Interval or Ratio;

Two or more independent variables which are either continuous or categorical (ordinal or nominal)

Independence of observations/residuals (Run a Durbin-Watson statistic)

"Linear relationship between the dependent variable and each of the independent variables used AND the dependent variable and the independent variables collectively (Laird, 2013)"; Create scatterplots and partial regression plots to check for linearity.

Homoscedasticity has been obtained; variances following the line of best fit continue along the line

No Multicollinearity; 2 or more independent variables cannot be highly correlated with one another. The independent variables (predictors) are linearly independent

No significant outliers, high leverage points or highly influential points

The errors are uncorrelated; Normally distributed residuals (errors); use a histogram and a Normal P-P plot or Normal Q-Q plot.

The sample is representative of the population for the inference prediction;

The error is a random variable with a mean of zero on the explanatory variables;

The independent variables are measured with no error;

Group Formation: Illustrated below are the three groups that will be formed post cluster analysis. 


\section{Figure 3:}

Formation of Coercive Control, Situational Violent and No Violence Groups

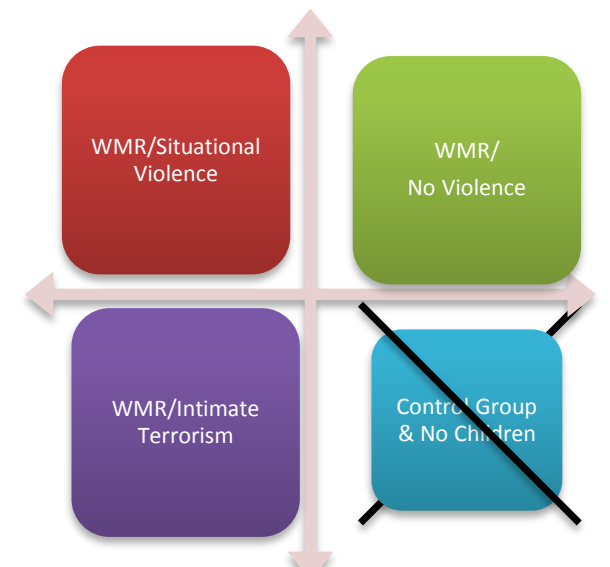

Figure 4.

$\underline{\text { Results of the Cluster Analysis }}$

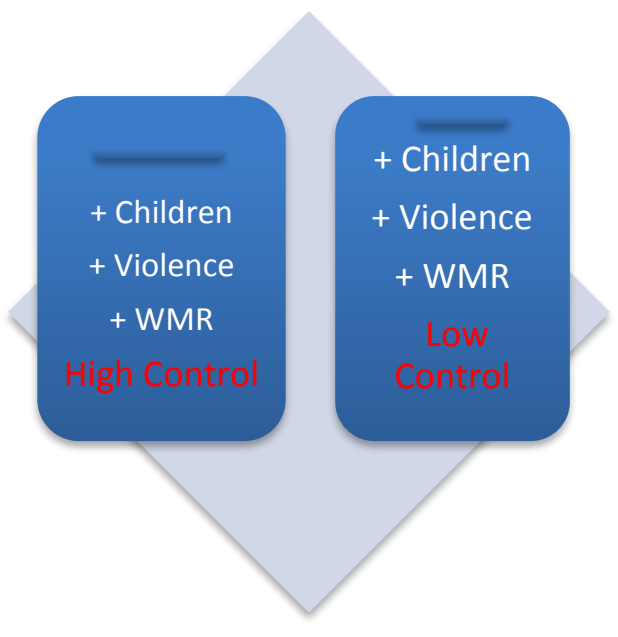




\section{Assumptions}

Participants volunteered to participate in research, were assured of their rights, anonymity and confidentiality in completing their surveys, and were given ample time and privacy to complete their surveys, in order for every effort to be made to answer their surveys truthfully. They also were told that they could withdraw at any time without ramification. Participants were also sent postage-paid envelopes with their 6 and 12 month post surveys in order to ensure a large enough sample for at those time intervals.

Drawing from a population seeking services for low-income and family distress, we can probably assume that the sample contains participants who have experienced or are experiencing both Coercive Control Violence (control-based) and Situational Violence (non control-based violence) due to heavy stress-levels in those populations which is known to exacerbate violence in families. Each survey was administered by two trained student workers who read the same script regarding instructions on the survey and its administration in order for there to be administrative fidelity in the surveys. The facilitators of the training each attended a Within My Reach training and every WMR class was also assessed for fidelity to the training by trained student workers using the same fidelity form. All efforts were made to ensure that each participant received the same information over the course of the training. Basic needs, according to Maslow's hierarchy of needs, were also taken care of, in order that each participant was able to concentrate on the training, and participants were given a travel voucher for the bus, provided childcare, given a meal and drink and were compensated financially for attending the class. Safety was also accounted for by holding the training in a locked neighborhood place, and participants were not allowed to attend with their partner, 
regardless of violence status, to safeguard against violent incidents happening in the classroom or due to the training. Participants were also advised on how to create or get to safety should they be in a violent relationship, and what to do with their books so the information within did not spark violence in the home. This was in an effort to create a feeling of physical and emotional safety so that participants could concentrate more fully on the class. 


\section{CHAPTER IV}

\section{RESULTS}

\section{Introduction}

This chapter presents study results, beginning with the process that produced the violence clusters. The results of the one-way MANOVA for baseline measures will follow, as well as the repeated measures ANOVA for differences between groups and finally the multiple regression analysis.

\section{Process}

The original sample size consisting of the Intervention and Control group was 1,100 ; once the control group was filtered out the experimental group the sample size was 882.

Those who did not have children were filtered out of the data set. Afterwards, the sample went from 882 to 588. The range of number of children was 1 child to 14 children living in the home. $37.4 \%$ of parents had 1 child (largest percent) followed by $29.3 \%$ had 2 children in the home.

Table 6 below gives the number of participants that have children that participated in Within My Reach that will be included in the study. Other descriptive such as mean number of children $(\mathrm{M}=2.26 ; \mathrm{SD}=1.43)$ are included. 


\section{Table 6}

\section{Participants with Children}

\begin{tabular}{|c|c|c|}
\hline \multirow[t]{2}{*}{$N$} & Valid & 588 \\
\hline & Missing & 0 \\
\hline \multicolumn{2}{|c|}{ Mean } & 2.2568 \\
\hline \multicolumn{2}{|c|}{ Median } & 2.0000 \\
\hline \multicolumn{2}{|c|}{ Std. Deviation } & 1.43349 \\
\hline \multicolumn{2}{|c|}{ Skewness } & 1.959 \\
\hline \multicolumn{2}{|c|}{ Std. Error of Skewness } & .101 \\
\hline \multicolumn{2}{|c|}{ Kurtosis } & 8.404 \\
\hline \multicolumn{2}{|c|}{ Std. Error of Kurtosis } & .201 \\
\hline
\end{tabular}

Table 3 shows the sample of participants post statistical procedure that removed participants that did not have children from the sample. Participants with children $n=588 ; M=2.2568 ; S D=1.433$. The data was positively skewed (1.959) and kurtotic (8.404) indicating that the majority of participants with children had 1-3 children.

\section{Figure 5}

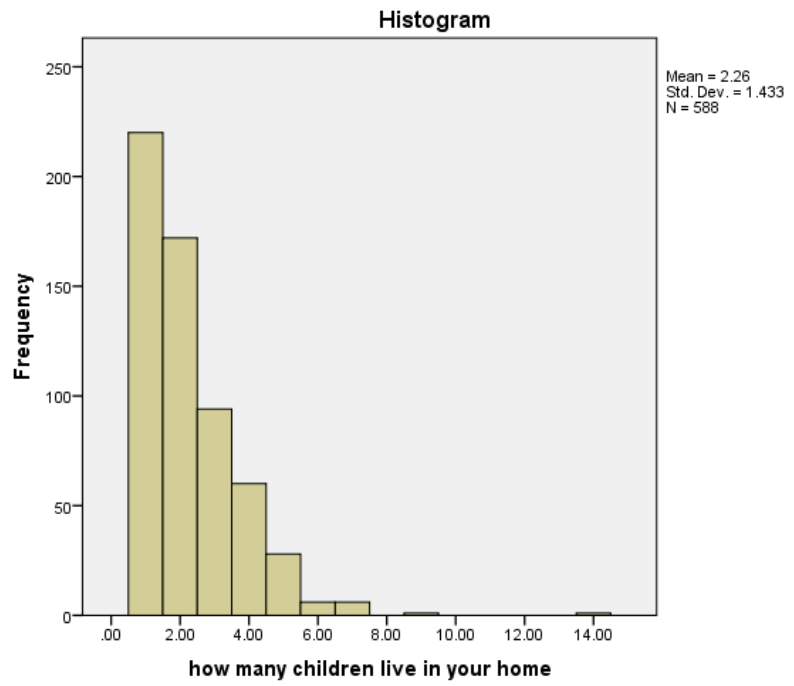

Figure R.P.1 is a visual demonstration of Table R.P.1. $n=588 ;$ Mean $=2.26 ; S D=1.433$. Positive skewness and Kurtosis indicated. 


\section{Table 7}

Number of Children Living in Participant's Homes

How many children live in your home

\begin{tabular}{|rr|r|r|r|r|}
\hline & Frequency & Percent & Valid Percent & Cumulative Percent \\
\hline Valid & 1.00 & 220 & 37.4 & 37.4 & 37.4 \\
& 2.00 & 172 & 29.3 & 29.3 & 66.7 \\
& 94 & 16.0 & 16.0 & 82.7 \\
4.00 & 60 & 10.2 & 10.2 & 92.9 \\
5.00 & 28 & 4.8 & 4.8 & 97.6 \\
6.00 & 6 & 1.0 & 1.0 & 98.6 \\
7.00 & 6 & 1.0 & 1.0 & 99.7 \\
9.00 & 1 & .2 & .2 & 99.8 \\
14.00 & 1 & .2 & .2 & 100.0 \\
& 588 & 100.0 & 100.0 & \\
\hline
\end{tabular}

Table R.P.2 shows the distribution of number of children per participant. Range 1-14. Participants indicating $1-3$ children $=82.7 \%$ of sample; indicating $1-4$ children $=92.9 \%$.

Sample Characteristics. The sample consisted of 500 women (85\%) 75 men $(12.6 \%)$ and 13 gender not identifed (2.4\%). Participants were mainly between the ages of 21-34 $(\mathrm{n}=302)$ with a range in age from $17-76$. The majority of participants identified as African American 67.5\% $(\mathrm{n}=397)$ followed by Caucasian $25.5 \%(\mathrm{n}=150)$.

Creation of No Violence and Physical Violence Groups. Presence of Physical Violence variable was created using the CTS pre intervention scores by recoded No Physical Violence Reported (indication of zero on CTS pretest) and Physical Violence Reported. (indication of $>=1$ ). Table R.P.3 shows the sample of participants prestatistical procedure that recoded participants into those with presence of physical violence and those without. $\mathrm{n}=584 ;(\mathrm{M}=4.9743 ; \mathrm{SD}=6.75656)$. The data was positively skewed (1.642), kurtotic (2.12) and negatively sloped, indicating that the majority of participants indicated no physical violence. The slope was less severe following 
indication of no violence (see Figure R.P.3) The range of possible scores was 0-40; Mean=4.97; SD-6.757; N=584. Range of Actual Scores $=0-32 ; 8$ items measuring physical violence in a conflict which included 0 "Never" to 4 "Always." Conflict items included: "(1) threw something at the other one," "(2) pushed, grabbed, or shoved the other one" "(3) slapped the other one," "(4) kicked, bit, or hit with a fist," "(5) hit or tried to hit with something," "(6) beat up the other one," "(7) threatened with a weapon (e.g. a knife)," "(8) used a weapon (e.g. a knife)."

\section{Table 8}

Sample of Participants prior to Violence \& Non-Violence Groupings

\begin{tabular}{|c|c|c|}
\hline \multicolumn{3}{|c|}{ Conflict Tactics Scale Total Pre } \\
\hline$N$ & Valid & 588 \\
\hline & Missing & 0 \\
\hline \multicolumn{2}{|c|}{ Mean } & 2.18 \\
\hline \multicolumn{2}{|c|}{ Median } & 2.00 \\
\hline \multicolumn{2}{|c|}{ Std. Deviation } & .734 \\
\hline \multicolumn{2}{|c|}{ Skewness } & -.293 \\
\hline \multicolumn{2}{|c|}{ Std. Error of Skewness } & .101 \\
\hline \multicolumn{2}{|c|}{ Kurtosis } & -1.104 \\
\hline \multicolumn{2}{|c|}{ Std. Error of Kurtosis } & .201 \\
\hline
\end{tabular}

\section{Figure 6}

Histogram showing variance in CTS scores

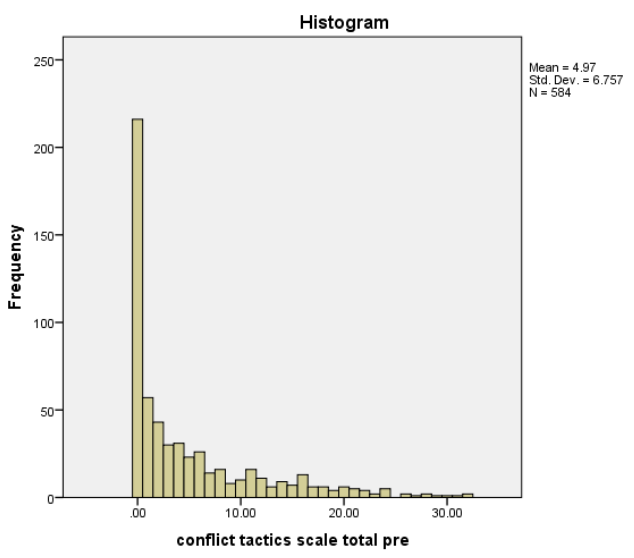




\section{Table 9}

\section{$\underline{\text { Presence of Physical Violence Groups }}$}

\begin{tabular}{|c|c|c|c|c|c|}
\hline \multicolumn{6}{|c|}{ Presence of Physical Violence } \\
\hline & & Frequency & Percent & Valid Percent & Cumulative Percent \\
\hline \multirow[t]{4}{*}{ Valid } & No Physical Violence & & & & \\
\hline & Reported & 216 & 36.7 & 37.0 & 37.0 \\
\hline & Physical Violence Reported & 368 & 62.6 & 63.0 & 100.0 \\
\hline & Total & 584 & 99.3 & 100.0 & \\
\hline Missing & System & 4 & .7 & & \\
\hline Total & & 588 & 100.0 & & \\
\hline
\end{tabular}

Table R.P.4 shows the distribution of presence of physical violence. Group totals: No physical violence reported $n=216$ (36.7\%); Physical Violence Reported $n=368$ (62.6\%).

Creation of groups based on presence of controlling behaviors. A k-means

group cluster analysis is a vector analysis that clusters around the mean and partitions a set number of clusters around the means of those clusters. The values for those means are reported in the output. A k-means cluster analysis will also determine Euclidian distance from each mean.

The CTS was recorded into new variables $0=$ No violence and $1=$ Violence and those in the No Violence group were selected out prior to running the K-means cluster analysis. A k-means cluster analysis was run on group 1 (Presence of Violence) using the Controlling Behaviors Scale (CBS). Those that clustered in Group 1 following the kmeans cluster, showing moderate to high levels of controlling behaviors were labeled Coercive Control Violence (1) and those that had few to no controlling behaviors were labeled Situational Violence (2). Finally, those that showed no violence were labeled as the No Violence group (3). Three clusters were created, namely those with Coercive Control Violence (CCV) ( $\mathrm{n}=115)$, Situational Violence (SV) $(\mathrm{n}=253)$ and No Violence (NV) $(n=220)$. 
$1=$ Coercive Control Violence

$2=$ Situational Violence

$3=$ Non Violence

The ANOVA differences between cluster results are $\mathrm{F}(1,365)=736.403, \mathrm{p}<.0005$;

$(\mathrm{M}=2.18 ; \mathrm{SD}=.734)$. Iterations stopped because the maximum number of iterations was performed. Iterations failed to converge which may indicate strongly that highlights the fact that the groups are divergent and dissimilar. The maximum absolute coordinate change for any center is 4.872 . The current iteration is 2 . The minimum distance between initial centers is 81.000 . To illustrate the difference, the mean on the controlling behaviors scale for group 1, Coercive Control Violence is 43.22 and Group 2, Situational Violence is 15.81.

\section{Table 10}

\section{$\underline{\text { Final Clusters post K-means cluster analysis }}$}

Clusters based on Controlling Behaviors Scale

\begin{tabular}{|c|c|c|c|c|c|}
\hline & & Frequency & Percent & Valid Percent & $\begin{array}{c}\text { Cumulative } \\
\text { Percent }\end{array}$ \\
\hline \multirow[t]{4}{*}{ Valid } & Coercive Control Violence & 115 & 19.6 & 19.6 & 19.6 \\
\hline & Situational Violence & 253 & 43.0 & 43.0 & 62.6 \\
\hline & No Violence & 220 & 37.4 & 37.4 & 100.0 \\
\hline & Total & 588 & 100.0 & 100.0 & \\
\hline
\end{tabular}

Table R.P.5 shows the final violence type groupings; CCV $n=115(19.6 \%), S V n=252$ (43\%), $N V=220(37.4 \%)$. As anticipated, due to evidence in the literature, CCV violence is less prevalent in the community than $S V$. 


\section{Table 11}

$\underline{\text { Iteration History for Cluster Analysis }}$

\begin{tabular}{|l|r|r|}
\hline \multicolumn{2}{c|}{ Iteration History } \\
\hline \multirow{2}{*}{ Iteration } & \multicolumn{1}{|c|}{ Change in Cluster Centers } \\
\cline { 2 - 3 } & \multicolumn{1}{|c|}{1} & \multicolumn{1}{c|}{2} \\
\hline 1 & 30.250 & 19.644 \\
2 & 4.872 & 2.227 \\
\hline
\end{tabular}

Table R.P.6 shows the iteration history. Iterations stopped at two.

\section{Table 12}

\section{$\underline{\text { Final Cluster Centers for Cluster Analysis }}$}

\section{Final Cluster Centers}

\begin{tabular}{|l|c|c|}
\hline \multirow{2}{*}{} & \multicolumn{2}{|c|}{ Cluster } \\
\cline { 2 - 3 } & 1 & 2 \\
\hline control beh scale total pre & 43.22 & 15.81 \\
\hline
\end{tabular}

Table 12 shows final cluster centers. CCV means centered around 43.22; and SV violence means centered around 15.81. Potential range for the CBS is 0-96.

Table 12 above illustrates the large distance between the two cluster means which show the difference between the two clusters.

\section{Table 13}

\section{Cluster Number of Cases}

\begin{tabular}{|l|r|}
\hline N & \multicolumn{1}{c|}{$\begin{array}{r}\text { Valid } \\
\text { Missing }\end{array}$} \\
Mean & 0 \\
Median & 2.18 \\
Std. Deviation & 2.00 \\
Skewness & .734 \\
Std. Error of Skewness & -.293 \\
Kurtosis & .101 \\
Std. Error of Kurtosis & -1.104 \\
\hline
\end{tabular}




\section{Table 14}

Differences in Mean in Cluster Analysis: ANOVA test

\begin{tabular}{|c|c|c|c|c|c|c|}
\hline \multicolumn{7}{|c|}{ ANOVA } \\
\hline & \multicolumn{2}{|c|}{ Cluster } & \multicolumn{2}{|c|}{ Error } & \multirow[b]{2}{*}{$\mathrm{F}$} & \multirow[b]{2}{*}{ Sig. } \\
\hline & Mean Square & df & Mean Square & df & & \\
\hline control beh scale total pre & 59370.663 & 1 & 80.622 & 366 & 736.403 & .000 \\
\hline
\end{tabular}

Table 14 shows the differences in mean in cluster analysis. The F tests should be used only for descriptive purposes because the clusters have been chosen to maximize the differences among cases in different clusters. The observed significance levels are not corrected for this and thus cannot be interpreted as tests of the hypothesis that the cluster means are equal.

\section{Overview of Data Analysis}

Research questions posed in the introduction. The research was guided by three main questions: (a) Is there a difference in family cohesion, parent/child relationship and child well-being by relationship violence type? (b) What is the effect of the Within My Reach training on participant's parent/child relationship, family cohesion and child wellbeing and does it differ by violence type? (c) Which variables are mediators of the improvement in the parent/child relationship, family cohesion and child well-being for each relationship violence type: communication skills, reduction in family violence or couple relationship quality?

\section{Research Question 1}

Baseline Differences in Violence Type. The first research question surrounded baseline differences between violence type groups in family cohesion, parent/child relationship and child well-being. A MANOVA with relationship violence type as the IV and family cohesion, parent/child relationship and child well-being as the DVs using the baseline measure was run. A MANOVA was used to answer research question one, is there a difference in family cohesion, parent/child relationship and child well-being by relationship violence type? to determine the baseline differences between three groups; 
Coercive Control Violence, Situational Violence and No Violence. A MANOVA is used whenever there is more than one dependent variable and a test for the difference in means between two or more groups is necessary. A MANOVA would not be appropriate if the DVs were too highly correlated or if they are not correlated at all. The following table documents the Descriptive Statistics for the three DVs for each of the groups.

\section{Table 15}

Descriptive Statistics for Baseline MANOVA

\section{Descriptive Statistics for MANOVA}

\begin{tabular}{|l|l|r|r|r|}
\hline & Cluster Number of Case & Mean & Std. Deviation & $\mathrm{N}$ \\
\hline Family Adaptability & Coercive Control Violence & 29.2778 & 9.74082 & 54 \\
and Cohesion at & Situational Violence & 34.8864 & 7.88626 & 132 \\
pre-test & No Violence & 37.0000 & 7.45478 & 123 \\
& Total & 34.7476 & 8.48955 & 309 \\
\hline Parent Child & Coercive Control Violence & 41.9444 & 6.90479 & 54 \\
Relationship at & Situational Violence & 45.4697 & 6.03987 & 132 \\
pre-test & No Violence & 47.6504 & 5.32237 & 123 \\
& Total & 45.7217 & 6.24137 & 309 \\
\hline Child Well-being at & Coercive Control Violence & 31.6852 & 8.03254 & 54 \\
pre-test & Situational Violence & 28.0076 & 6.41027 & 132 \\
& No Violence & 26.9187 & 7.12602 & 123 \\
& Total & 28.2168 & 7.17600 & 309 \\
\hline
\end{tabular}




\section{Figure 7}

Illustration of Difference in Outcomes by Violence Type.

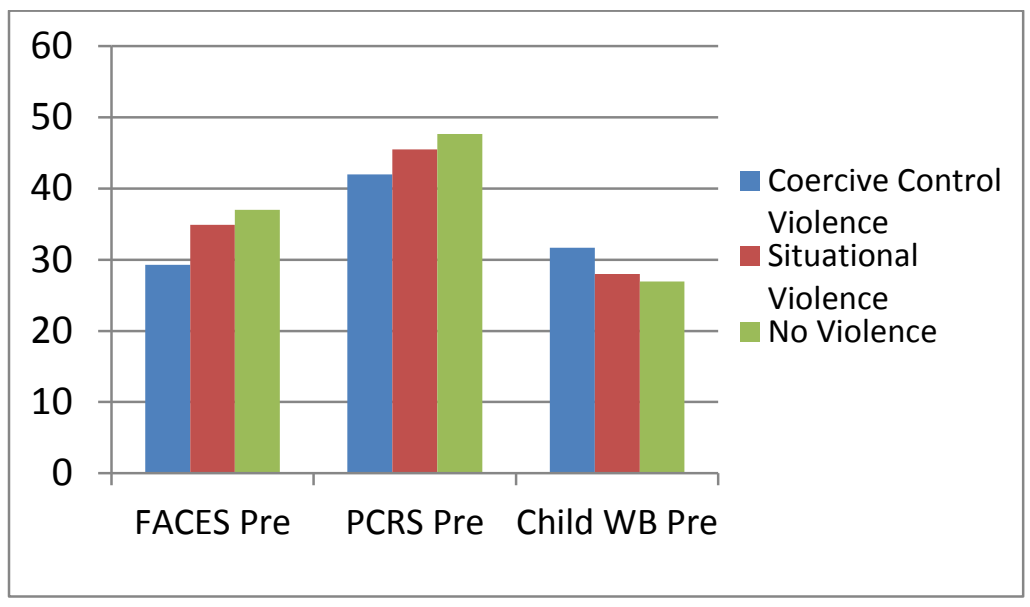

The MANOVA showed a statistically significant difference in the DVs based on type of violence, $F(6,608)=9.25, \mathrm{p}<.0005$; Wilk's $\chi=.840$, partial $\eta^{2}=.08$. See

Multivariate Tests Table below for results. Subjects in the CCV group score significantly lower on outcomes than SV or NV. See Descriptive Statistics Table above (as well as post hoc analyses to follow).

\section{Table 16}

\section{$\underline{\text { Results of Baseline MANOVA }}$}

\begin{tabular}{|c|c|c|c|c|c|c|c|}
\hline \multicolumn{8}{|c|}{ Multivariate Tests ${ }^{a}$} \\
\hline \multicolumn{2}{|l|}{ Effect } & Value & $\mathrm{F}$ & Hypothesis df & Error df & Sig. & $\begin{array}{l}\text { Partial Eta } \\
\text { Squared }\end{array}$ \\
\hline \multirow[t]{4}{*}{ Intercept } & Pillai's Trace & .991 & $11761.544^{b}$ & 3.000 & 304.000 & .000 & .991 \\
\hline & Wilks' Lambda & .009 & $11761.544^{\mathrm{b}}$ & 3.000 & 304.000 & .000 & .991 \\
\hline & Hotelling's Trace & 116.068 & $11761.544^{b}$ & 3.000 & 304.000 & .000 & .991 \\
\hline & $\begin{array}{l}\text { Roy's Largest } \\
\text { Root }\end{array}$ & 116.068 & $11761.544^{\mathrm{b}}$ & 3.000 & 304.000 & .000 & .991 \\
\hline \multirow{4}{*}{$\begin{array}{l}\text { ViolenceTyp } \\
\text { e }\end{array}$} & Pillai's Trace & .161 & 8.894 & 6.000 & 610.000 & .000 & .080 \\
\hline & Wilks' Lambda & .840 & $9.247^{b}$ & 6.000 & 608.000 & .000 & .084 \\
\hline & Hotelling's Trace & .190 & 9.599 & 6.000 & 606.000 & .000 & .087 \\
\hline & $\begin{array}{l}\text { Roy's Largest } \\
\text { Root }\end{array}$ & .186 & $18.910^{c}$ & 3.000 & 305.000 & .000 & .157 \\
\hline
\end{tabular}


a. Design: Intercept + ViolenceType

b. Exact statistic

c. The statistic is an upper bound on $\mathrm{F}$ that yields a lower bound on the significance level.

To determine how the dependent variables differ for the independent variable, the tests of between subjects effects were examined. See Tests of Between Subjects Effects below. Violence type had a statistically significant effect on all three dependent variables: family cohesion $\left(F(2,306)=17.19 ; \mathrm{p}<.0005 ;\right.$ partial $\left.\eta^{2}=.10\right) ;$ parent-child relationship $\left(F(2,306)=17.58 ; \mathrm{p}<.0005 ;\right.$ partial $\left.\eta^{2}=.10\right) ;$ and child well-being $(F(2,306)=8.80$; $\mathrm{p}<.0005$; partial $\eta^{2}=.05$ ). These results suggest the effect of violence type were strongest for family cohesion and parent-child relationship, although still significant for child wellbeing. 


\section{Table 17}

Test of Between-Subjects Effects for MANOVA

Tests of Between-Subjects Effects

\begin{tabular}{|c|c|c|c|c|c|c|c|}
\hline Source & $\begin{array}{l}\text { Dependent } \\
\text { Variable }\end{array}$ & $\begin{array}{l}\text { Type III Sum } \\
\text { of Squares }\end{array}$ & df & $\begin{array}{l}\text { Mean } \\
\text { Square }\end{array}$ & $\mathrm{F}$ & Sig. & $\begin{array}{l}\text { Partial Eta } \\
\text { Squared }\end{array}$ \\
\hline Corrected & faces pre-test & $2242.182^{a}$ & 2 & 1121.091 & 17.190 & .000 & .101 \\
\hline \multirow[t]{2}{*}{ Model } & PCR pre-test & $1236.385^{b}$ & 2 & 618.193 & 17.578 & .000 & .103 \\
\hline & CWB pre-test & $862.645^{c}$ & 2 & 431.322 & 8.800 & .000 & .054 \\
\hline \multirow[t]{3}{*}{ Intercept } & faces pre-test & 299032.160 & 1 & 299032.160 & 4585.250 & .000 & .937 \\
\hline & PCR pre-test & 533024.825 & 1 & 533024.825 & 15156.147 & .000 & .980 \\
\hline & CWB pre-test & 219187.316 & 1 & 219187.316 & 4472.069 & .000 & .936 \\
\hline \multirow[t]{3}{*}{ ViolenceType } & faces pre-test & 2242.182 & 2 & 1121.091 & 17.190 & .000 & .101 \\
\hline & PCR pre-test & 1236.385 & 2 & 618.193 & 17.578 & .000 & .103 \\
\hline & CWB pre-test & 862.645 & 2 & 431.322 & 8.800 & .000 & .054 \\
\hline \multirow[t]{3}{*}{ Error } & faces pre-test & 19956.129 & 306 & 65.216 & & & \\
\hline & PCR pre-test & 10761.680 & 306 & 35.169 & & & \\
\hline & CWB pre-test & 14997.828 & 306 & 49.013 & & & \\
\hline \multirow[t]{3}{*}{ Total } & faces pre-test & 395283.000 & 309 & & & & \\
\hline & PCR pre-test & 657954.000 & 309 & & & & \\
\hline & CWB pre-test & 261883.000 & 309 & & & & \\
\hline \multirow{3}{*}{$\begin{array}{l}\text { Corrected } \\
\text { Total }\end{array}$} & faces pre-test & 22198.311 & 308 & & & & \\
\hline & PCR pre-test & 11998.065 & 308 & & & & \\
\hline & CWB pre-test & 15860.472 & 308 & & & & \\
\hline
\end{tabular}

a. $R$ Squared $=.101$ (Adjusted $R$ Squared $=.095)$

$b . R$ Squared $=.103$ (Adjusted $R$ Squared $=.097)$

c. $R$ Squared $=.054$ (Adjusted $R$ Squared $=.048)$

Given these significant ANOVAs, Tukey's HSD post-hoc tests were conducted.

See below for Multiple Comparisons table. The table below shows that mean scores for family cohesion were statistically significantly different between CCV and NV

$(\mathrm{p}<.0005), \mathrm{CCV}$ and SV $(\mathrm{p}<.0005)$, but not between SV and NV $(\mathrm{p}=.094)$. Mean scores for parent-child relationship were statistically significantly different between CCV and $\mathrm{NV}(\mathrm{p} .<.0005)$, and between CCV and SV $(\mathrm{p}<.001)$, and between CV and NV $(\mathrm{p}=.01)$. 
Mean scores for child well being were statistically significantly different between CCV

and NV $(\mathrm{p} .<.0005)$, and CCV and SV $(\mathrm{p}<.01)$, but not between $\mathrm{CV}$ and $\mathrm{NV}(\mathrm{p}=.43)$

\section{Table 18}

\section{Multiple Comparison of MANOVA Using Tukey HSD}

\begin{tabular}{|c|c|c|c|c|c|c|c|}
\hline \multicolumn{8}{|c|}{ Multiple Comparisons } \\
\hline \multicolumn{8}{|l|}{ Tukey HSD } \\
\hline \multirow{2}{*}{$\begin{array}{l}\text { Dependent } \\
\text { Variable }\end{array}$} & \multirow[t]{2}{*}{ (I) Cluster Number of Case } & \multirow[t]{2}{*}{ (J) Cluster Number of Case } & \multirow{2}{*}{$\begin{array}{c}\text { Mean } \\
\text { Difference (I- } \\
\mathrm{J}) \\
\end{array}$} & \multirow[t]{2}{*}{ Std. Error } & \multirow[t]{2}{*}{ Sig. } & \multicolumn{2}{|c|}{ 95\% Confidence Interval } \\
\hline & & & & & & Lower Bound & Upper Bound \\
\hline \multirow{6}{*}{$\begin{array}{l}\text { faces } \\
\text { pre-test }\end{array}$} & \multirow[b]{2}{*}{ Coercive Control Violence } & Situational Violence & $-5.6086^{*}$ & 1.30452 & .000 & -8.6810 & -2.5362 \\
\hline & & No Violence & $-7.7222^{*}$ & 1.31830 & .000 & -10.8271 & -4.6174 \\
\hline & \multirow[b]{2}{*}{ Situational Violence } & $\underline{\text { Coercive Control Violence }}$ & $5.6086^{*}$ & 1.30452 & .000 & 2.5362 & 8.6810 \\
\hline & & No Violence & -2.1136 & 1.01206 & .094 & -4.4972 & .2700 \\
\hline & \multirow[b]{2}{*}{ No Violence } & $\underline{\text { Coercive Control Violence }}$ & $7.7222^{*}$ & 1.31830 & .000 & 4.6174 & 10.8271 \\
\hline & & Situational Violence & 2.1136 & 1.01206 & .094 & -.2700 & 4.4972 \\
\hline \multirow{6}{*}{$\begin{array}{l}\text { PCRS } \\
\text { pre-test }\end{array}$} & \multirow[b]{2}{*}{ Coercive Control Violence } & Situational Violence & $-3.5253^{*}$ & .95797 & .001 & -5.7814 & -1.2691 \\
\hline & & No Violence & $-5.7060^{*}$ & .96809 & .000 & -7.9860 & -3.4259 \\
\hline & \multirow[b]{2}{*}{ Situational Violence } & $\underline{\text { Coercive Control Violence }}$ & $3.5253^{*}$ & .95797 & .001 & 1.2691 & 5.7814 \\
\hline & & No Violence & $-2.1807^{*}$ & .74321 & .010 & -3.9311 & -.4303 \\
\hline & \multirow[b]{2}{*}{ No Violence } & Coercive Control Violence & $5.7060^{*}$ & .96809 & .000 & 3.4259 & 7.9860 \\
\hline & & Situational Violence & $2.1807^{*}$ & .74321 & .010 & .4303 & 3.9311 \\
\hline \multirow{6}{*}{$\begin{array}{l}\text { CWB } \\
\text { pre-test }\end{array}$} & \multirow[b]{2}{*}{ Coercive Control Violence } & Situational Violence & $3.6776^{*}$ & 1.13090 & .004 & 1.0141 & 6.3411 \\
\hline & & No Violence & $4.7665^{*}$ & 1.14285 & .000 & 2.0749 & 7.4581 \\
\hline & \multirow[b]{2}{*}{ Situational Violence } & $\underline{\text { Coercive Control Violence }}$ & $-3.6776^{*}$ & 1.13090 & .004 & -6.3411 & -1.0141 \\
\hline & & No Violence & 1.0889 & .87737 & .430 & -.9775 & 3.1552 \\
\hline & \multirow[b]{2}{*}{ No Violence } & Coercive Control Violence & $-4.7665^{*}$ & 1.14285 & .000 & -7.4581 & -2.0749 \\
\hline & & Situational Violence & -1.0889 & .87737 & .430 & -3.1552 & .9775 \\
\hline
\end{tabular}

Based on observed means.

The error term is Mean Square(Error) $=49.013$

*. The mean difference is significant at the .05 level. 
These differences can be visualized by the plots generated by this procedure, as shown below:

\section{Figure 8}

Estimated Marginal Means of Family Cohesion by Type of Violence

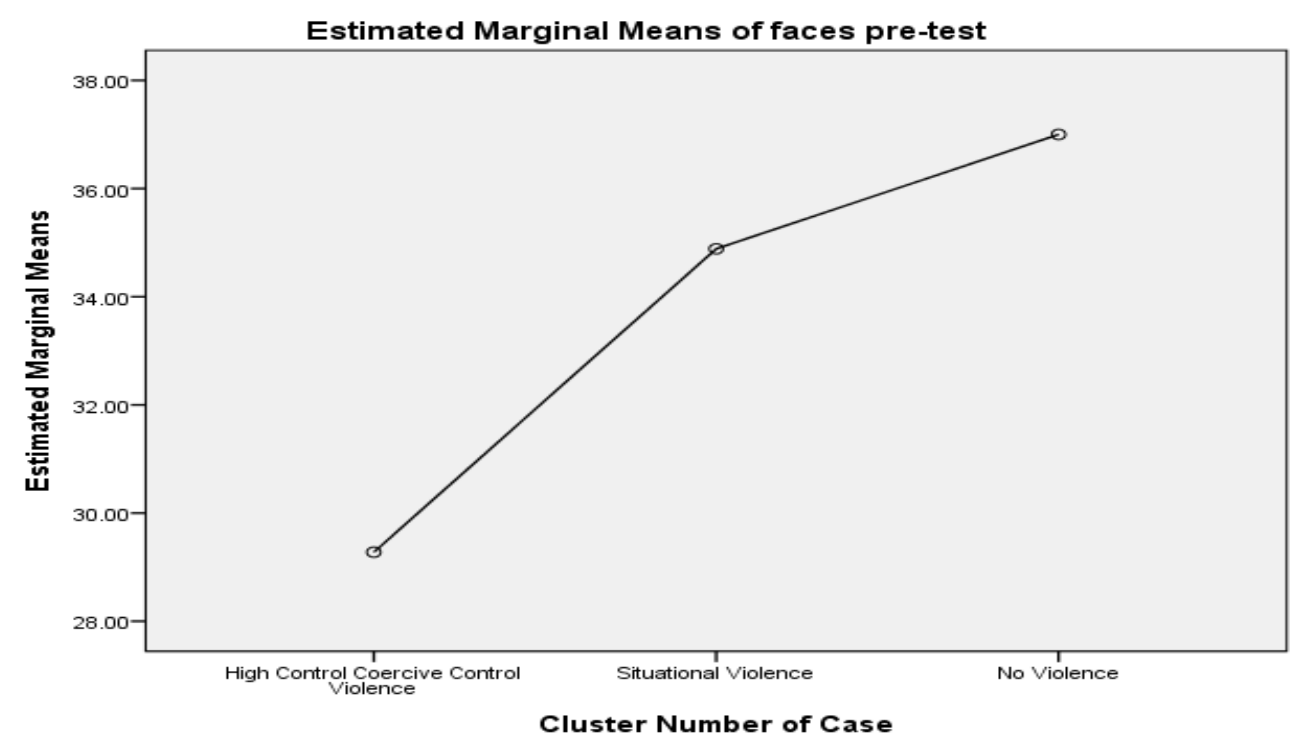

\section{Figure 9}

Estimate Marginal Means for Parent-Child Relationship

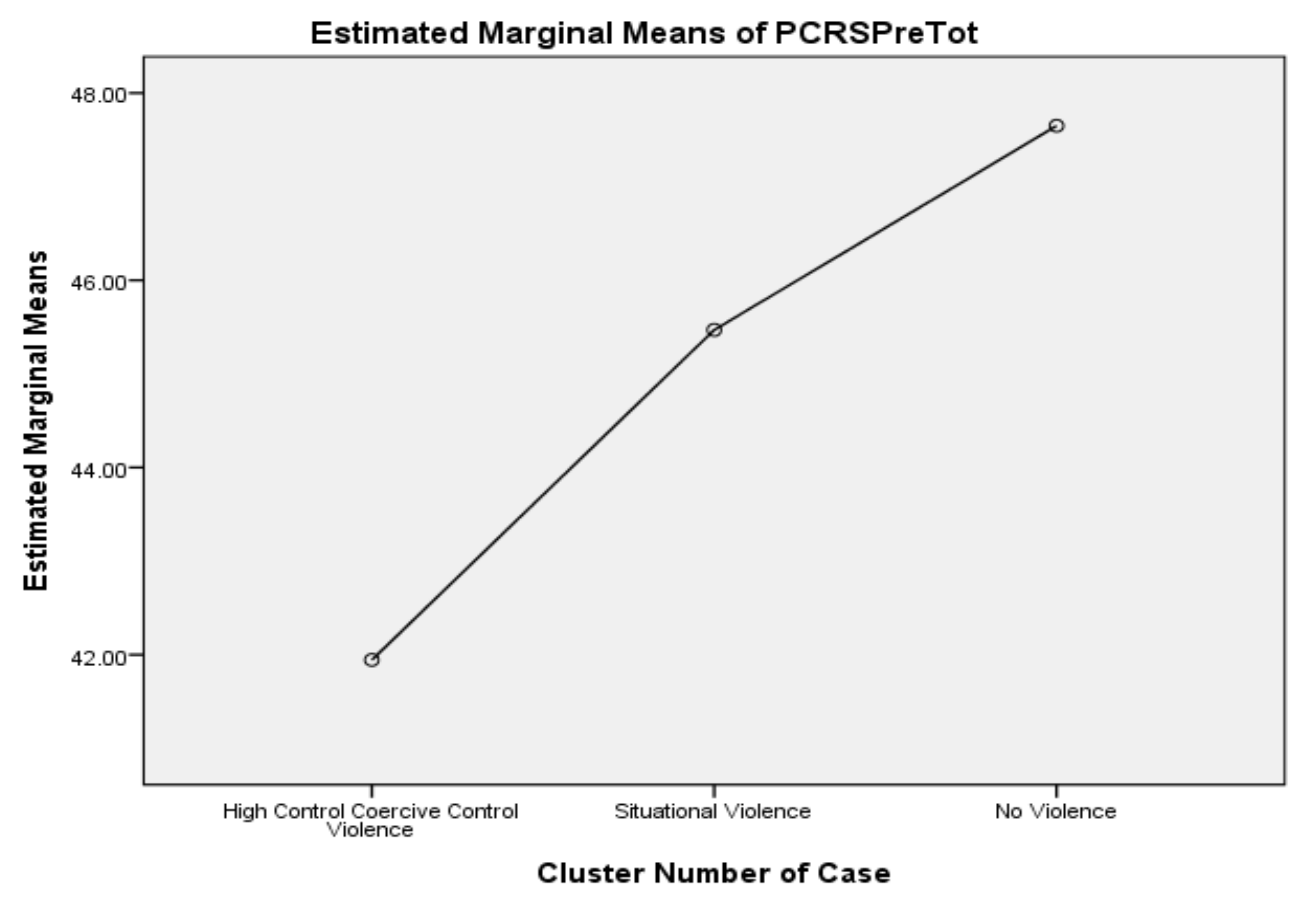




\section{Research Question 2}

Impact of Within My Reach program over time between groups. The second research question concerned the effect of the Within My Reach program on family cohesion, the parent-child relationship and child well-being by violence type through three points in time (pre, post, 6 mos. post). A two-way (two-factor) repeated measures ANOVA was conducted on the dependent variables, Family Cohesion, Parent-Child Relationship and Child Problems, to investigate impact of relationship education on the variables over time, and the differences between groups in this change over time. A repeated measures MANOVA was originally considered to test question two, what is the effect of the Within My Reach training on participant's parent/child relationship, family cohesion and child well-being and does it differ by violence type? A Repeated Measures MANOVA is a MANOVA that is measured over multiple points in time and was considered due to the three dependent variables in this study: Family Cohesion, the Parent-Child Relationship and Child Well-being that are being measured over three time points; Pre, Post, \& 6-months post. Once participants without children were excluded, and cluster groups were formed, the sample size was not great enough to run a Repeated Measures MANOVA and individual Repeated Measures ANOVAs were run on each dependent variable. A repeated measures ANOVA was used to answer research question 2: What is the effect of the Within My Reach training on participant's parent/child relationship, family cohesion and child well-being and does it differ by violence type? A repeated measures ANOVA is used when the sample is exposed to multiple tests, particularly time tests. A repeated measures ANOVA is necessary to measure changes 
over time. A repeated measures ANOVA was used in this study to determine main effect and interaction effect within and between-subjects.

Although a MANOVA was advised to analyze the multiple DVs at baseline to understand differences in the DVs by violence type, the sample size was too small at the follow up data collection point of 6 months to allow for a Repeated Measures MANOVA to be utilized for this question. Therefore, three separate two-way (two-factor) repeated measures ANOVAs were run to answer the question (one for each DV).

Testing for Normal Distribution of Parent Child Relationship. To ensure normal distribution, descriptive statistics with histograms were run in SPSS on the three dependent variables in the three points in time. The results of the histogram show that family cohesion is normally distributed in the baseline sample $(\mathrm{M}=34.86, \mathrm{SD}=8.42)$, Skewness $=-.545 ;$ Kurtosis $=-.223$, as well as the post $(\mathrm{M}=34.11 ; \mathrm{SD}=9.00)$, Skewness $=-$ .684 ; Kurtosis $=.009$ and the 6-mos post sample $(\mathrm{M}=35.31 ; \mathrm{SD}=8.05)$, Skewness=-.562; Kurtosis $=.069$. Kurtosis measures the "peakness" of the distribution and should be near 0 for normal distribution. Skewness is the measure of symmetry/asymmetry of the sample and should also be near 0 for normal distribution. 
Table 19

FACES Distribution: Descriptive statistics

\begin{tabular}{|l|r|r|r|}
\hline & \multicolumn{3}{|c|}{ Statistics } \\
& faces pre-test & $\begin{array}{r}\text { faces immediate } \\
\text { post test }\end{array}$ & $\begin{array}{c}\text { faces six months } \\
\text { post test }\end{array}$ \\
\hline $\mathrm{N}$ & 401 & 366 & 210 \\
\multicolumn{1}{|c|}{ Valid } & 187 & 222 & 378 \\
Mean & 34.8628 & 34.1120 & 35.3095 \\
Median & 36.0000 & 36.0000 & 36.0000 \\
Std. Deviation & 8.41984 & 9.00082 & 8.05213 \\
Skewness & -.545 & -.684 & -.562 \\
Std. Error of Skewness & .122 & .128 & .168 \\
Kurtosis & -.223 & .009 & .069 \\
Std. Error of Kurtosis & .243 & .254 & .334 \\
\hline
\end{tabular}

Table RQ2.1 shows the sample size for the three points in time for family cohesion. From pre to 6 mos. post the sample decreases by approx. 50\%. However, regardless of the severe drop in population, the mean score stays relatively similar. 


\section{Figure 10}

Histograms for family cohesion, pre, post and 6-mos post
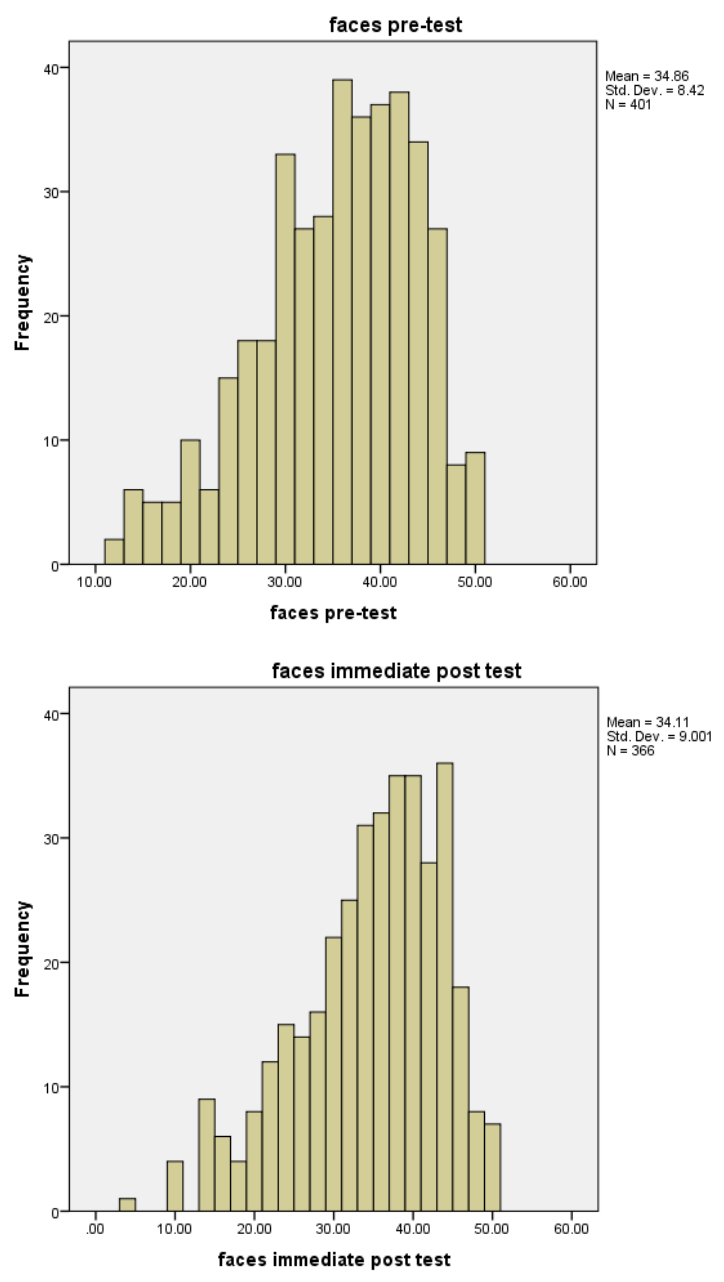
All three points in time demonstrate normal distribution.

FACES Pre $\mathrm{n}=401(\mathrm{M}=34.86$; $\mathrm{SD}=8.42)$;

FACES Post $\mathrm{n}=366(\mathrm{M}=34.11$; $S D=9.001)$;

FACES 6-months post ( $M=35.31 ;$ SD 8.052).

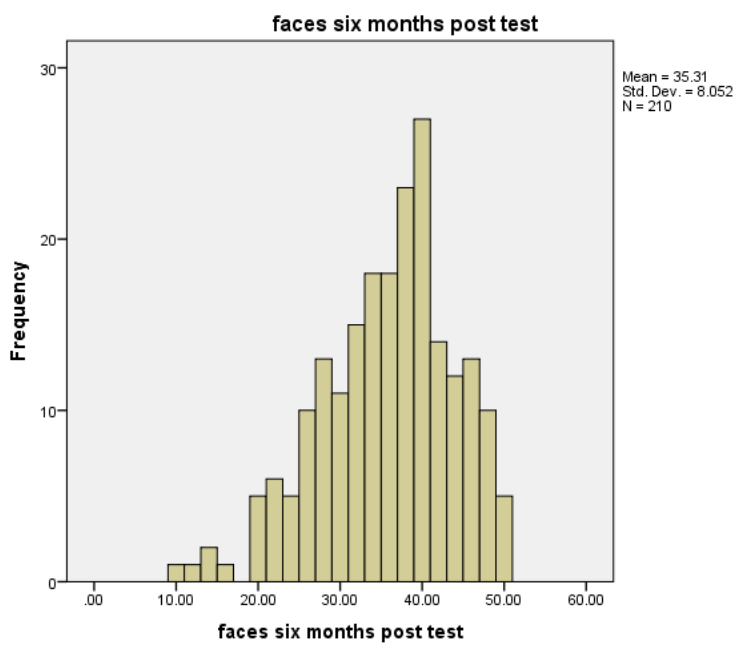


Testing for Normal Distribution of Parent Child Relationship. The results of the test for Normal Distribution over the three points in time show that the parent-child relationship is normally distributed in the baseline sample $(\mathrm{M}=41.03, \mathrm{SD}=4.56)$, Skewness $=-.401 ;$ Kurtosis $=1.966$, as well as the post $(\mathrm{M}=46.64 ; \mathrm{SD}=7.24)$, Skewness= $.632 ;$ Kurtosis $=.160$ and the $6-$ mos post sample $(M=45.79 ; \mathrm{SD}=6.23)$, Skewness=-.678; Kurtosis $=.010$

Table 20

$\underline{\text { Parent-Child Relationship Distribution: Descriptive Statistics }}$

\begin{tabular}{|c|c|c|c|c|}
\hline \multicolumn{5}{|c|}{ Statistics } \\
\hline & & PCRS6mosPostTot & PCRSPostTot & PCRSPreTot \\
\hline \multirow[t]{2}{*}{ N } & Valid & 183 & 326 & 352 \\
\hline & Missing & 405 & 262 & 236 \\
\hline \multicolumn{2}{|c|}{ Mean } & 41.0328 & 46.6350 & 45.7869 \\
\hline \multicolumn{2}{|c|}{ Median } & 41.0000 & 47.0000 & 47.0000 \\
\hline \multicolumn{2}{|c|}{ Std. Deviation } & 4.55600 & 7.24252 & 6.23313 \\
\hline \multicolumn{2}{|c|}{ Skewness } & -.401 & -.632 & -.678 \\
\hline \multicolumn{2}{|c|}{ Std. Error of Skewness } & .180 & .135 & .130 \\
\hline \multicolumn{2}{|c|}{ Kurtosis } & 1.966 & .160 & .010 \\
\hline \multicolumn{2}{|c|}{ Std. Error of Kurtosis } & .357 & .269 & .259 \\
\hline
\end{tabular}




\section{Figure 11}

Histograms depicting Parent-Child Relationship distributions of means by time
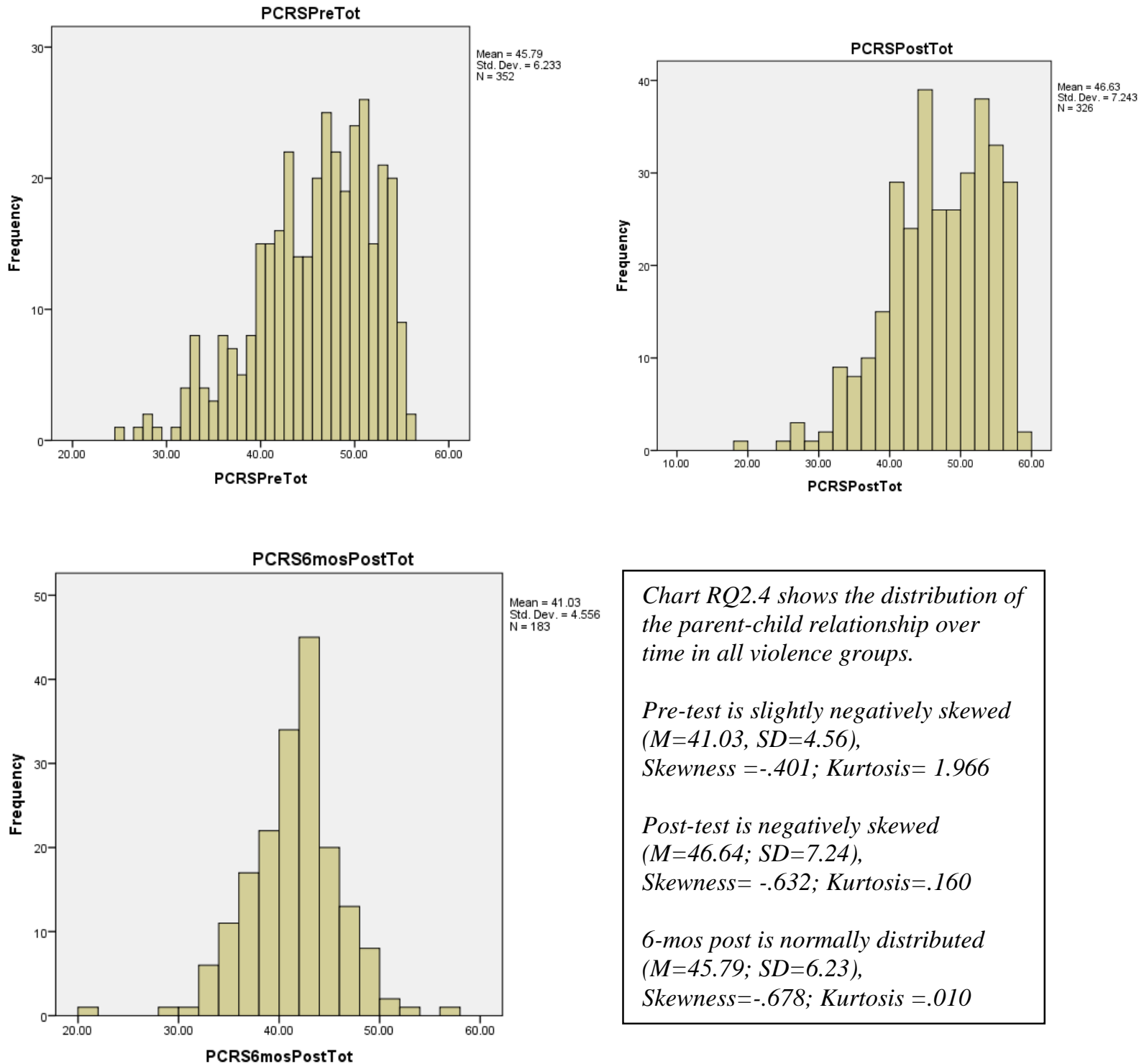

Chart RQ2.4 shows the distribution of the parent-child relationship over time in all violence groups.

Pre-test is slightly negatively skewed $(M=41.03, S D=4.56)$,

Skewness $=-.401 ;$ Kurtosis $=1.966$

Post-test is negatively skewed $(M=46.64 ; S D=7.24)$,

Skewness $=-.632 ;$ Kurtosis $=.160$

6-mos post is normally distributed $(M=45.79 ; S D=6.23)$,

Skewness=-.678; Kurtosis $=.010$

Figure 11 depicts the distributions of means of family cohesion by pre, post and 6months intervals of time. PCRS pre and 6 months post show normal distribution whereas immediate post shows a slight negative skew. 
Testing for Normal Distribution of Child Well-being. The results of the test for Normal Distribution over the three points in time show that the parent-child relationship is normally distributed in the baseline sample $(\mathrm{M}=28.0649, \mathrm{SD}=7.13)$, Skewness $=.462$; Kurtosis $=-.427$, as well as the post $(\mathrm{M}=25.00 ; \mathrm{SD}=6.89)$, Skewness $=.490$; Kurtosis $=-$ .589 and the 6 -mos post sample $(\mathrm{M}=26.79 ; \mathrm{SD}=6.75)$, Skewness=.410; Kurtosis $=-.748$.

\section{Table 21}

Distribution Statistics of Child Well-being

\begin{tabular}{|c|c|c|c|c|}
\hline & & CWB Pre-test & $\begin{array}{c}\text { CWB } \\
\text { Immediate Post }\end{array}$ & CWB 6 mos Post \\
\hline \multirow[t]{2}{*}{$\mathrm{N}$} & Valid & 339 & 336 & 187 \\
\hline & Missing & 249 & 252 & 401 \\
\hline \multicolumn{2}{|c|}{ Mean } & 28.0649 & 25.4345 & 26.7861 \\
\hline \multicolumn{2}{|c|}{ Median } & 27.0000 & 25.0000 & 25.0000 \\
\hline \multicolumn{2}{|c|}{ Std. Deviation } & 7.13326 & 6.88814 & 6.74953 \\
\hline \multicolumn{2}{|c|}{ Skewness } & .462 & .490 & .410 \\
\hline \multicolumn{2}{|c|}{ Std. Error of Skewness } & .132 & .133 & 178 \\
\hline \multicolumn{2}{|c|}{ Kurtosis } & -.427 & -.589 & -.748 \\
\hline \multicolumn{2}{|c|}{ Std. Error of Kurtosis } & .262 & 265 & .354 \\
\hline
\end{tabular}

Table 22 shows distribution statistics of Child-Wellbeing over time. 


\section{Figure 12}

Distribution of Parent-Child Relationships over three points of time
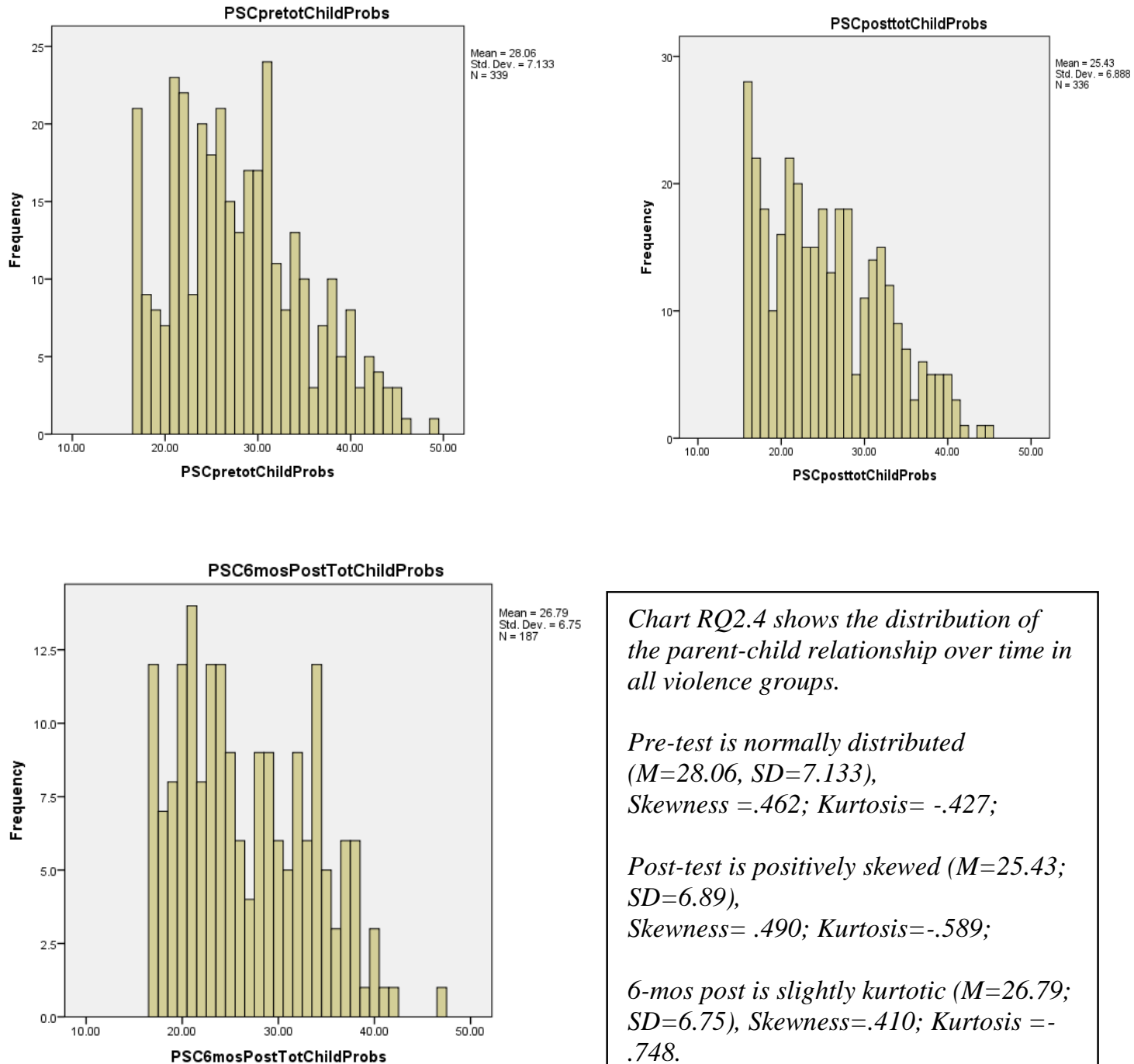

Mean $=26.79$
Stdd Dever. $=6.75$
N. $=187$

Chart RQ2.4 shows the distribution of the parent-child relationship over time in all violence groups.

Pre-test is normally distributed $(M=28.06, S D=7.133)$,

Skewness $=.462$; Kurtosis $=-.427$;

Post-test is positively skewed $(M=25.43$; $S D=6.89$ ),

Skewness $=.490 ;$ Kurtosis $=-.589$;

6-mos post is slightly kurtotic $(M=26.79$; $S D=6.75)$, Skewness $=.410 ;$ Kurtosis $=-$ .748 . 
Repeated Measures ANOVA for Family Cohesion. The two-way (two-factor)

repeated measures ANOVA for changes over time in family cohesion between violence groups showed no significant main effect of time $F(2,176)=31.33$, Wilks $\lambda=.988$, $\mathrm{p}=.307$; Partial $\eta^{2}=.007$. There were no significant changes in family cohesion over the three points in time across all groups. See tables below for results of Multivariate Tests.

\section{Table 22}

$\underline{\text { Results of Multivariate Test for Family Cohesion: RM ANOVA }}$

\begin{tabular}{|c|c|c|c|c|c|c|c|}
\hline \multicolumn{8}{|c|}{ Multivariate Tests ${ }^{a}$} \\
\hline \multicolumn{2}{|l|}{ Effect } & Value & $\mathrm{F}$ & $\begin{array}{c}\text { Hypothesis } \\
\text { df }\end{array}$ & Error df & Sig. & $\begin{array}{c}\text { Partial Eta } \\
\text { Squared }\end{array}$ \\
\hline \multirow[t]{4}{*}{ FACES } & Pillai's Trace & .012 & $1.108^{b}$ & 2.000 & 176.000 & .332 & .012 \\
\hline & Wilks' Lambda & .988 & $1.108^{\mathrm{b}}$ & 2.000 & 176.000 & .332 & .012 \\
\hline & Hotelling's Trace & .013 & $1.108^{b}$ & 2.000 & 176.000 & .332 & .012 \\
\hline & $\begin{array}{l}\text { Roy's Largest } \\
\text { Root }\end{array}$ & .013 & $1.108^{b}$ & 2.000 & 176.000 & .332 & .012 \\
\hline \multirow{4}{*}{$\begin{array}{l}\text { FACES * } \\
\text { ViolenceType }\end{array}$} & Pillai's Trace & .053 & 2.409 & 4.000 & 354.000 & .049 & .026 \\
\hline & Wilks' Lambda & .947 & $2.413^{b}$ & 4.000 & 352.000 & .049 & .027 \\
\hline & Hotelling's Trace & .055 & 2.417 & 4.000 & 350.000 & .048 & .027 \\
\hline & $\begin{array}{l}\text { Roy's Largest } \\
\text { Root }\end{array}$ & .048 & $4.248^{c}$ & 2.000 & 177.000 & .016 & .046 \\
\hline
\end{tabular}

a. Design: Intercept + ViolenceType

Within Subjects Design: FACES

b. Exact statistic

c. The statistic is an upper bound on F that yields a lower bound on the significance level.

The following table shows mean scores at three points in time across groups (pre, immediate post, and 6 months post). As these descriptive statistics indicate, scores on the FACES were very similar at the three points in time: Pre-Test $(\mathrm{M}=34.60)$, Immediate Post Test ( $M=33.86)$, and 6 Month Post Test $(M=34.68)$. 


\section{Table 23}

\section{Main Effect of Time for FACES: RM ANOVA}

\section{Descriptive Statistics for Main Effect of Time}

Measure: TIME

\begin{tabular}{|l|r|r|r|r|}
\hline \multirow{2}{*}{ FACES } & \multirow{2}{*}{ Mean } & Std. Error & \multicolumn{2}{|c|}{$95 \%$ Confidence Interval } \\
\cline { 4 - 5 } & & Lower Bound & Upper Bound \\
\hline 1 & 34.596 & .588 & 33.436 & 35.755 \\
2 & 33.861 & .716 & 32.448 & 35.274 \\
3 & 34.675 & .635 & 33.421 & 35.929 \\
\hline
\end{tabular}

There was a significant main effect of group, $F(2,177)=5.86, \mathrm{p}<.01$, Partial $\eta^{2}=$ .06. See table below for results of Tests of Between Subjects Effects. The table summarizing Descriptive Statistics for Main Effect of Group below reveals that subjects in the NV group had higher scores on FACES $(\mathrm{M}=36.44, \mathrm{SD}=.76)$ than those in the $\mathrm{SV}$ group $(\mathrm{M}=35.12, \mathrm{SD}=.85)$ and the $\mathrm{CCV}$ group $(\mathrm{M}=31.57, \mathrm{SD}=1.20)$.

\section{Table 24}

Main Effect of Group for FACES: RM ANOVA

Tests of Between-Subjects Effects: Main Effect of Group

Measure: TIME

Transformed Variable: Average

\begin{tabular}{|l|r|r|r|r|r|r|}
\hline Source & $\begin{array}{c}\text { Type III Sum of } \\
\text { Squares }\end{array}$ & df & Mean Square & F & Sig. & $\begin{array}{c}\text { Partial Eta } \\
\text { Squared }\end{array}$ \\
\hline Intercept & 551261.109 & 1 & 551261.109 & 3847.716 & .000 & .956 \\
ViolenceType & 1680.111 & 2 & 840.055 & 5.863 & .003 & .062 \\
Error & 25358.739 & 177 & 143.270 & & & \\
\hline
\end{tabular}




\section{Table 25}

Main Effect of Violence Group for FACES: RM ANOVA

\begin{tabular}{|c|c|c|c|c|}
\hline \multirow[b]{2}{*}{ Cluster Number of Case } & \multirow[b]{2}{*}{ Mean } & \multirow[b]{2}{*}{ Std. Error } & \multicolumn{2}{|c|}{ 95\% Confidence Interval } \\
\hline & & & Lower Bound & Upper Bound \\
\hline $\begin{array}{l}\text { High Control Coercive } \\
\text { Control Violence }\end{array}$ & 31.566 & 1.203 & 29.192 & 33.940 \\
\hline Situational Violence & 35.123 & .857 & 33.432 & 36.815 \\
\hline No Violence & 36.443 & .763 & 34.937 & 37.949 \\
\hline
\end{tabular}

Lastly, there was a significant interaction of group by time $\mathrm{F}(4,352)=2.41$, $\mathrm{p}<.05$, Wilks $\chi=.947$; Partial $\eta^{2}=.027$. See table above for Multivariate Tests with these results. See table below for Descriptive Statistics for family cohesion (FACES) scores over the three points in time by group. As this chart indicates, those in the CCV group experienced an increase in FACES from Pre $(M=30.52)$ to Immediate Post $(M=31.30)$ to 6 Months Post $(M=32.88)$. Those in the SV group experienced a decrease in FACES from Pre $(M=35.72)$ to Immediate Post $(M=34.94)$ to 6 Months Post $(M=34.71)$. Those in the NV group experienced a decrease in FACES from Pre $(\mathrm{M}=37.55)$ to Immediate Post $(M=35.34)$, with a slight increase at 6 Months Post $(M=36.44)$. 


\section{Table 26}

Descriptive Statistics for Changes in FACES over Time by Group

Measure: TIME

\begin{tabular}{|ll|r|r|r|r|}
\hline & & & & \multicolumn{2}{|c|}{$95 \%$ Confidence Interval } \\
\cline { 5 - 6 } Cluster Number of Case & FACES & Mean & Std. Error & Lower Bound & Upper Bound \\
\hline Coercive Control Violence & 1 & 30.515 & 1.275 & 27.998 & 33.032 \\
& 2 & 31.303 & 1.554 & 28.237 & 34.370 \\
& 3 & 32.879 & 1.379 & 30.157 & 35.600 \\
\hline Situational Violence & 1 & 35.723 & .909 & 33.930 & 37.516 \\
& 2 & 34.938 & 1.107 & 32.754 & 37.123 \\
& 3 & 34.708 & .983 & 32.768 & 36.647 \\
\hline No Violence & 1 & 37.549 & .809 & 35.952 & 39.145 \\
& 2 & 35.341 & .986 & 33.396 & 37.287 \\
& 3 & 36.439 & .875 & 34.712 & 38.166 \\
\hline
\end{tabular}

These differences can be easily visualized by the chart generated by this procedure, as shown below:

\section{Figure 13}

Cluster number of Cases: Family Cohesion of Time by Group

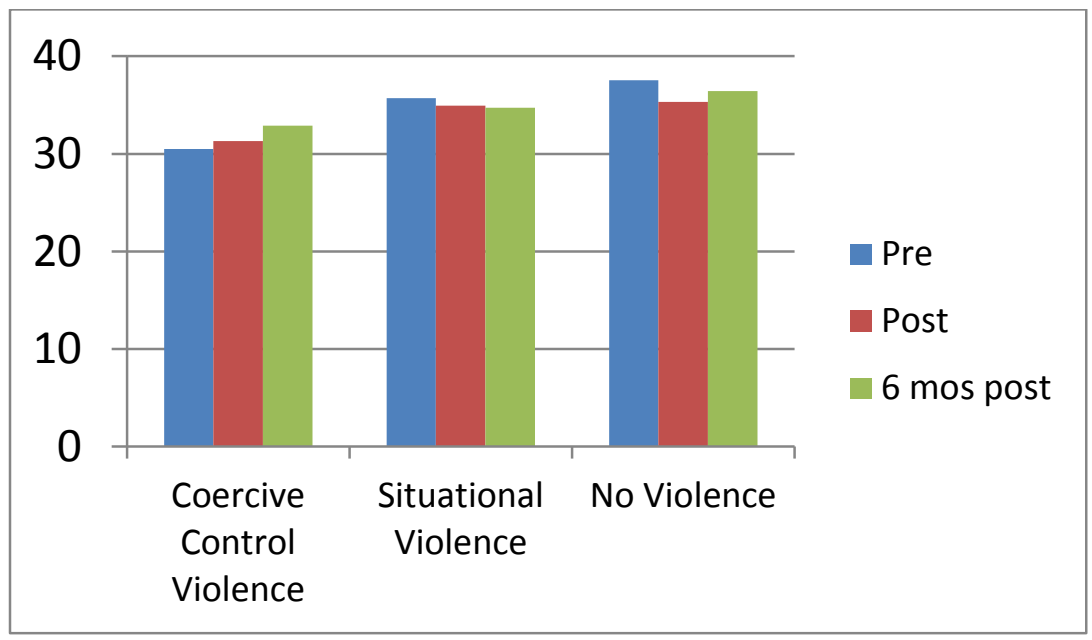




\section{Figure 14}

\section{Family Cohesion Over Time by Group}

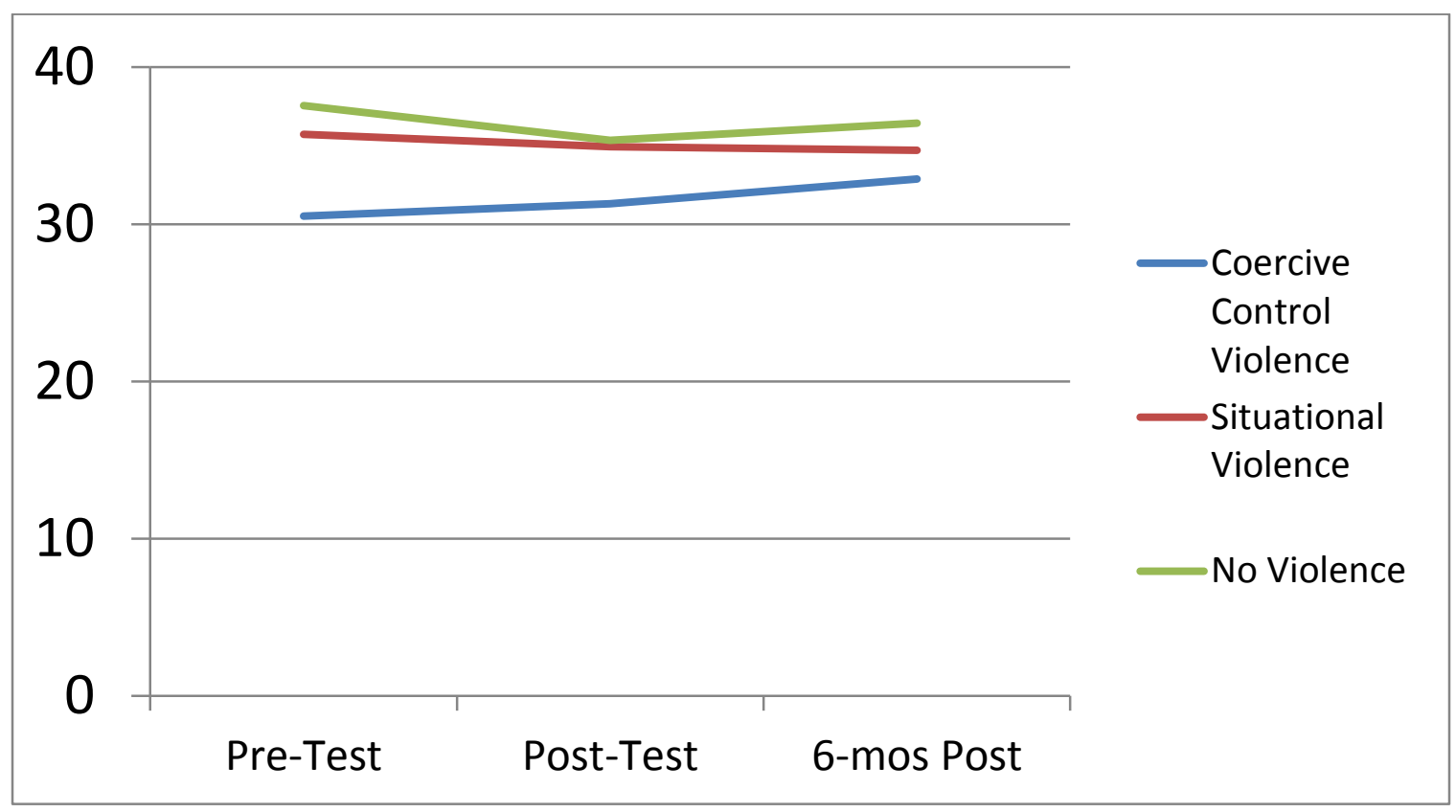

Based upon these significant results, Bonferroni post hoc analyses were conducted to examine differences between each group. These post hoc analyses showed there were significant differences between CCV and NV groups in family cohesion change over time $(\mathrm{p}<.01)$, and a significant trend in the difference between CCV and SV $(p=.0510$, but there were no significant differences between SV and NV $(p=.755)$. 
Table 27

\section{$\underline{\text { Post Hoc Analysis for PCRS RM ANOVA }}$}

Bonferroni Post Hoc Analysis for FACES

Measure: TIME

Bonferroni

\begin{tabular}{|c|c|c|c|c|c|c|}
\hline \multirow[t]{2}{*}{ (I) Cluster Number of Case } & \multirow[t]{2}{*}{ (J) Cluster Number of Case } & \multirow{2}{*}{$\begin{array}{c}\text { Mean Difference } \\
\text { (I-J) }\end{array}$} & \multirow[t]{2}{*}{ Std. Error } & \multirow[t]{2}{*}{ Sig. } & \multicolumn{2}{|c|}{ 95\% Confidence Interval } \\
\hline & & & & & Lower Bound & Upper Bound \\
\hline & Situational Violence & -3.5574 & 1.47712 & .051 & -7.1275 & .0127 \\
\hline & No Violence & $-4.8774^{*}$ & 1.42463 & .002 & -8.3207 & -1.4342 \\
\hline \multirow{3}{*}{ Situational Violence } & Coercive Control Violence & 3.5574 & 1.47712 & .051 & -.0127 & 7.1275 \\
\hline & No Violence & -1.3200 & 1.14766 & .755 & -4.0938 & 1.4538 \\
\hline & Coercive Control Violence & $4.8774^{*}$ & 1.42463 & .002 & 1.4342 & 8.3207 \\
\hline No Violence & Situational Violence & 1.3200 & 1.14766 & .755 & -1.4538 & 4.0938 \\
\hline
\end{tabular}

Based on observed means.

The error term is Mean Square(Error) $=47.757$.

*. The mean difference is significant at the .05 level. 
Repeated Measures ANOVA for Parent Child Relationship. A two-way (twofactor) repeated measures ANOVA for changes over time in family cohesion between violence groups showed a significant main effect of time $F(2,126)=13.278$, Wilks $\lambda=$ $.826, p=.0005$; Partial $\eta^{2}=.174$. See tables below for results of Multivariate Tests.

\section{Table 28}

$\underline{\text { Results of Multivariate Test for Parent-Child Relationship: RM ANOVA }}$

\begin{tabular}{|c|c|c|c|c|c|c|c|}
\hline \multicolumn{8}{|c|}{ Multivariate Tests ${ }^{a}$} \\
\hline \multicolumn{2}{|l|}{ Effect } & Value & $\mathrm{F}$ & $\begin{array}{c}\text { Hypothesis } \\
\text { df }\end{array}$ & Error df & Sig. & $\begin{array}{l}\text { Partial Eta } \\
\text { Squared }\end{array}$ \\
\hline \multirow[t]{4}{*}{ PCRS } & Pillai's Trace & .174 & $13.278^{b}$ & 2.000 & 126.000 & .000 & .174 \\
\hline & Wilks' Lambda & .826 & $13.278^{b}$ & 2.000 & 126.000 & .000 & .174 \\
\hline & Hotelling's Trace & .211 & $13.278^{b}$ & 2.000 & 126.000 & .000 & .174 \\
\hline & $\begin{array}{l}\text { Roy's Largest } \\
\text { Root }\end{array}$ & .211 & $13.278^{b}$ & 2.000 & 126.000 & .000 & .174 \\
\hline \multirow{4}{*}{$\begin{array}{l}\text { PCRS * } \\
\text { ViolenceType }\end{array}$} & Pillai's Trace & .140 & 4.765 & 4.000 & 254.000 & .001 & .070 \\
\hline & Wilks' Lambda & .861 & $4.904^{b}$ & 4.000 & 252.000 & .001 & .072 \\
\hline & Hotelling's Trace & .161 & 5.040 & 4.000 & 250.000 & .001 & .075 \\
\hline & $\begin{array}{l}\text { Roy's Largest } \\
\text { Root }\end{array}$ & .158 & $10.063^{c}$ & 2.000 & 127.000 & .000 & .137 \\
\hline
\end{tabular}

The following table shows mean scores at three points in time across groups (pre, immediate post, and 6 months post). As these descriptive statistics indicate, scores on the PCRS were very similar at two points in time: Pre-test $(M=44.091)$, Immediate Post Test $(\mathrm{M}=45.232)$ and much lower at point three, 6-Month Post Test ( $\mathrm{M}=41.070)$. 


\section{Table 29}

Main Effect of Time for Parent-Child Relationship: Descriptive Statistics

Measure: TIME
\begin{tabular}{|l|r|r|r|r|}
\hline \multirow{2}{*}{ PCRS } & \multirow{2}{*}{ Mean } & Std. Error & \multicolumn{2}{|c|}{$95 \%$ Confidence Interval } \\
\cline { 4 - 5 } & & Lower Bound & \multicolumn{1}{c|}{ Upper Bound } \\
\hline 1 & 44.091 & .632 & 42.840 & 45.342 \\
\hline 2 & 45.232 & .741 & 43.766 & 46.697 \\
\hline 3 & 41.070 & .484 & 40.112 & 42.028 \\
\hline
\end{tabular}

There was a significant main effect of group, $F(2,127)=9.785, \mathrm{p}<.003$, Partial $\eta^{2}=.062$. See table below for results of the Tests of Between-Subjects Effects. The table summarizing Descriptive Statistics for Main Effect of Group below reveals that subjects in the NV group had higher scores on the PCRS $(\mathrm{M}=46.00 ; \mathrm{SE}=.599)$ than those in the $\mathrm{SV}$ group $(\mathrm{M}=43.837 ; \mathrm{SE}=.679)$ and the $\mathrm{CCV}$ group $(\mathrm{M}=40.556 ; \mathrm{SE}=1.21)$.

\section{Table 30}

Main Effect of Group for Parent-Child Relationships: RM ANOVA

\section{Tests of Between-Subjects Effects: Main Effect of Group}

Measure: TIME

Transformed Variable: Average

\begin{tabular}{|l|r|r|r|r|r|r|}
\hline Source & $\begin{array}{c}\text { Type III Sum of } \\
\text { Squares }\end{array}$ & df & Mean Square & F & Sig. & $\begin{array}{c}\text { Partial Eta } \\
\text { Squared }\end{array}$ \\
\hline Intercept & 555403.546 & 1 & 555403.546 & 8183.415 & .000 & .985 \\
\hline ViolenceType & 1328.216 & 2 & 664.108 & 9.785 & .000 & .134 \\
\hline Error & 8619.415 & 127 & 67.869 & & & \\
\hline
\end{tabular}




\section{Table 31}

Main Effect of Violence Group for Parent-Child Relationship: RM ANOVA

Measure: TIME
\begin{tabular}{|l|r|r|r|r|}
\hline & & & \multicolumn{2}{|c|}{$95 \%$ Confidence Interval } \\
\cline { 4 - 5 } Cluster Number of Case & Mean & Std. Error & Lower Bound & Upper Bound \\
\hline High Control Coercive & 40.556 & 1.121 & 38.337 & 42.774 \\
Control Violence & & & & \\
Situational Violence & 43.837 & .679 & 42.492 & 45.181 \\
No Violence & 46.000 & .599 & 44.814 & 47.186 \\
\hline
\end{tabular}

Lastly, there was a significant interaction effect of time by group $F(4,252)=$ 4.904, Wilk's $\lambda=.861, \mathrm{p}=.001 ;$ Partial $\eta^{2}=.070$. See table above for Multivariate Tests with these results. See table below for Descriptive Statistics for parent-child relationship (PCRS) scores over the three points in time by group. As this chart indicates, those in the CCV group experienced an increase in PCRS in from Pre $(M=39.611)$ to Immediate Post $(M=41.056)$ with little change to 6-months post (41.00). Those in the SV group experienced a decrease in PCRS from Pre $(M=44.551)$ to Immediate Post $(M=40.939)$ and stayed the same at 6-mos Post $(M=40.939)$. Those in the NV group stayed the same PCRS from Pre $(M=48.11)$ to Post $(M=48.619)$ and sharp decrease in 6-mos Post $(\mathrm{M}=41.270)$. 


\section{Table 32}

Descriptive Statistics for the Changes in PCRS Over Time by Group: RM ANOVA

\begin{tabular}{|c|c|c|c|c|c|}
\hline \multirow[b]{2}{*}{ Cluster Number of Case } & \multirow[b]{2}{*}{ PCRS } & \multirow[b]{2}{*}{ Mean } & \multirow[b]{2}{*}{ Std. Error } & \multicolumn{2}{|c|}{$95 \%$ Confidence Interval } \\
\hline & & & & Lower Bound & Upper Bound \\
\hline \multirow{3}{*}{ Coercive Control Violence } & 1 & 39.611 & 1.475 & 36.692 & 42.530 \\
\hline & $\underline{2}$ & 41.056 & 1.728 & 37.636 & 44.475 \\
\hline & 3 & 41.000 & 1.130 & 38.765 & 43.235 \\
\hline \multirow[t]{3}{*}{ Situational Violence } & 1 & 44.551 & .894 & 42.782 & 46.320 \\
\hline & $\underline{2}$ & 46.020 & 1.047 & 43.948 & 48.093 \\
\hline & 3 & 40.939 & .685 & 39.584 & 42.294 \\
\hline \multirow[t]{3}{*}{ No Violence } & 1 & 48.111 & .789 & 46.551 & 49.671 \\
\hline & 2 & 48.619 & .924 & 46.791 & 50.447 \\
\hline & 3 & 41.270 & .604 & 40.075 & 42.465 \\
\hline
\end{tabular}


These differences can be visualized by the figures generated by this procedure, as shown below:

\section{Figure 15}

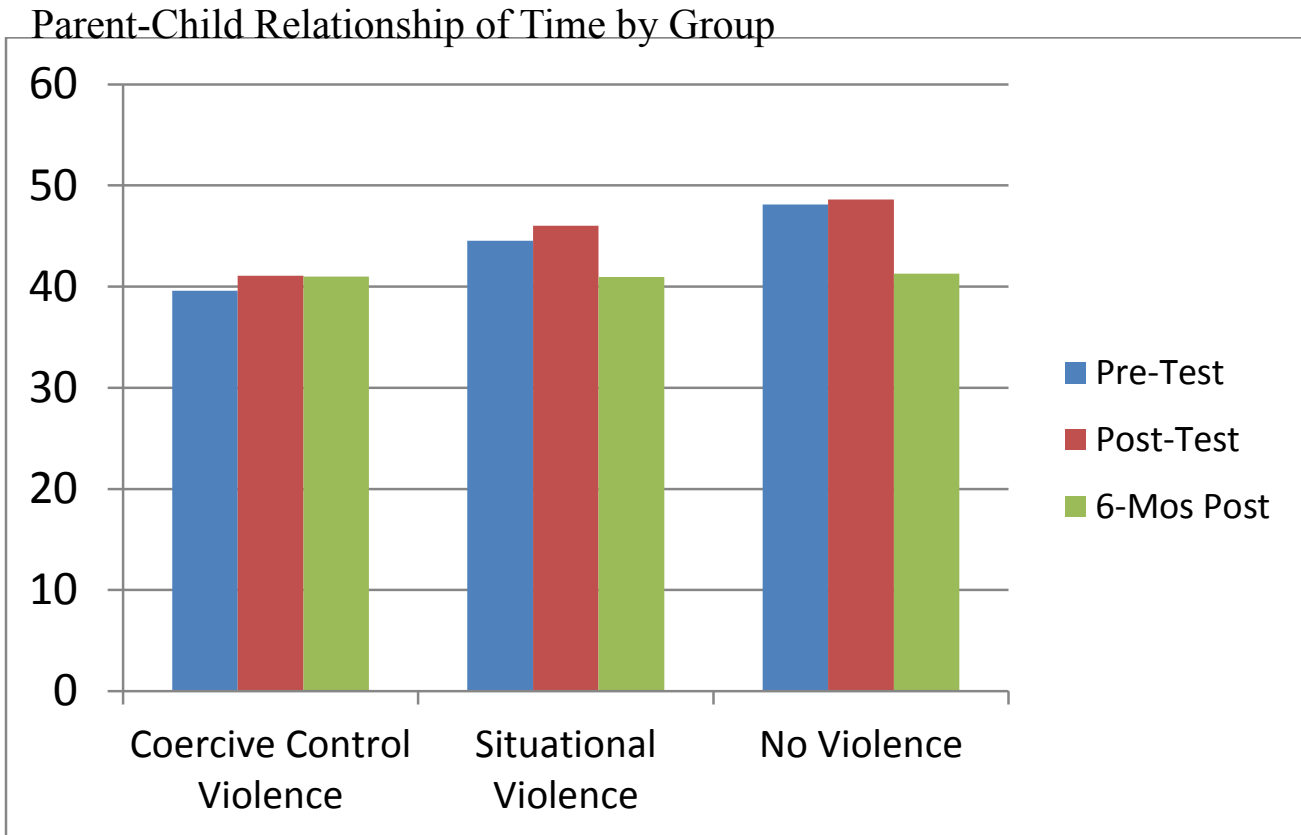

\section{Figure 16}

Parent-Child Change Over Time by Group: Potential Regression to Mean

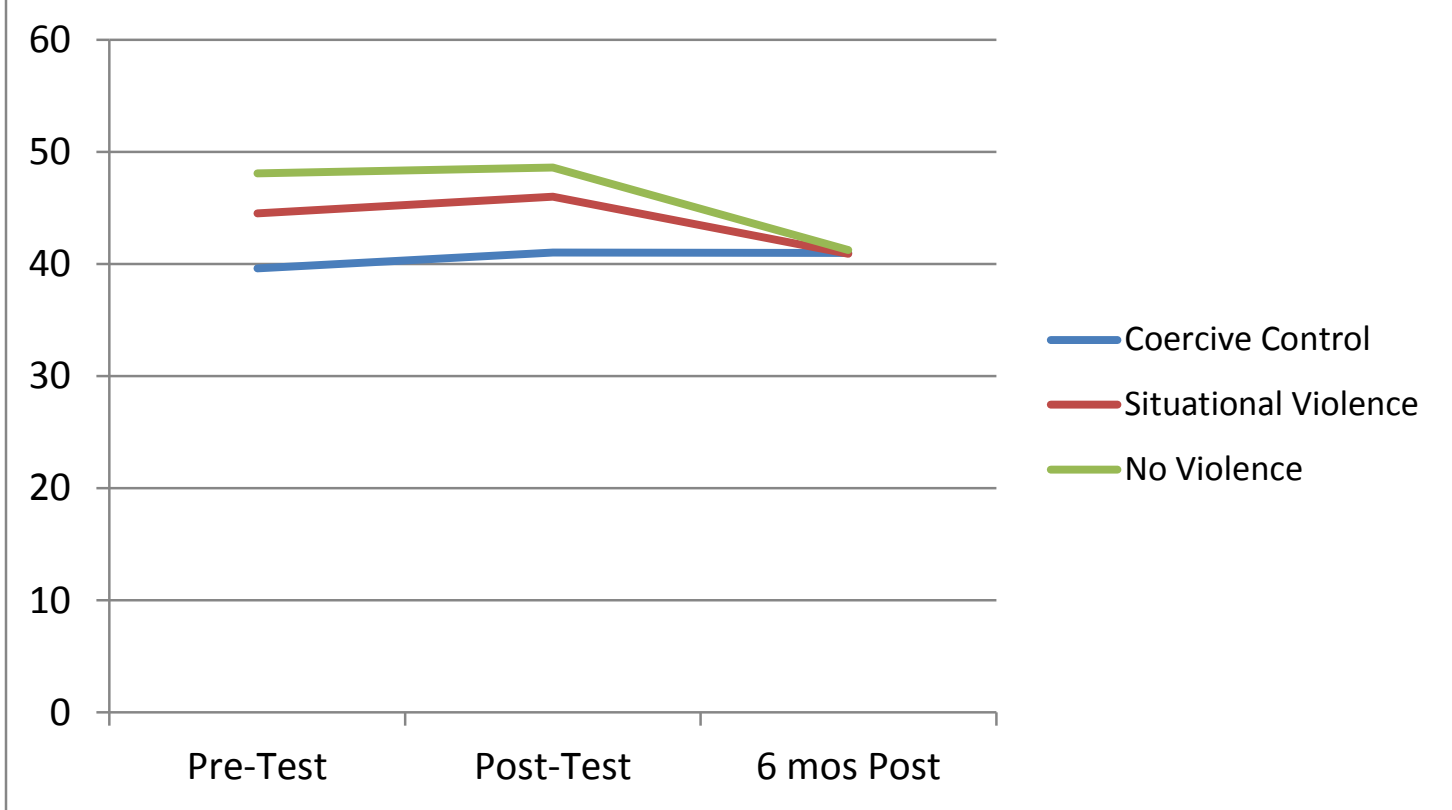


Based upon these significant results, Bonferroni post hoc analyses were conducted to examine differences between each group. These post hoc analyses showed there were significant differences between CCV and NV groups in parent-child relationship change over time $(\mathrm{p}<.0005)$, significant differences between CCV and SV groups $(\mathrm{p}<.041)$ and a significant trend in the difference between SV and NV $(p=.055)$.

\section{Table 33}

$\underline{\text { Post Hoc Analysis for Parent-Child Relationship: RM ANOVA }}$

\section{Bonferroni post hoc Analysis}

Measure: TIME

Bonferroni

\begin{tabular}{|c|c|c|c|c|c|c|}
\hline \multirow[b]{2}{*}{$\begin{array}{l}\text { (I) Cluster Number of } \\
\text { Case }\end{array}$} & \multirow[b]{2}{*}{$\begin{array}{l}\text { (J) Cluster Number of } \\
\text { Case }\end{array}$} & \multirow{2}{*}{$\begin{array}{c}\text { Mean } \\
\text { Difference (I- } \\
\mathrm{J})\end{array}$} & \multirow[b]{2}{*}{$\begin{array}{l}\text { Std. } \\
\text { Error }\end{array}$} & \multirow[b]{2}{*}{ Sig. } & \multicolumn{2}{|c|}{ 95\% Confidence Interval } \\
\hline & & & & & $\begin{array}{l}\text { Lower } \\
\text { Bound }\end{array}$ & $\begin{array}{l}\text { Upper } \\
\text { Bound }\end{array}$ \\
\hline Coercive Control & Situational Violence & $-3.2812^{*}$ & 1.31093 & .041 & -6.4616 & -.1007 \\
\hline Violence & No Violence & $-5.4444^{*}$ & 1.27120 & .000 & -8.5285 & -2.3604 \\
\hline \multirow[t]{2}{*}{ Situational Violence } & $\begin{array}{l}\text { High Control Coercive } \\
\text { Control Violence }\end{array}$ & $3.2812^{*}$ & 1.31093 & .041 & .1007 & 6.4616 \\
\hline & No Violence & -2.1633 & .90598 & .055 & -4.3613 & .0347 \\
\hline \multirow[t]{2}{*}{ No Violence } & $\begin{array}{l}\text { High Control Coercive } \\
\text { Control Violence }\end{array}$ & $5.4444^{*}$ & 1.27120 & .000 & 2.3604 & 8.5285 \\
\hline & Situational Violence & 2.1633 & .90598 & .055 & -.0347 & 4.3613 \\
\hline
\end{tabular}

Based on observed means.

The error term is Mean Square(Error) $=22.623$.

*. The mean difference is significant at the .05 level. 
Repeated Measures ANOVA for Child Well-Being. A two-way (two-factor)

repeated measures ANOVA for changes over time in child well-being between violence groups showed a significant main effect of time $F(2,135)=29.011$, Wilks $\lambda=.699$, $\mathrm{p}=.0005$; Partial $\eta^{2}=.301$. See tables below for results of Multivariate Tests.

\section{Table 34}

Results of Multivariate Test for Child Well-Being: RM ANOVA

Multivariate Tests ${ }^{a}$

\begin{tabular}{|c|c|c|c|c|c|c|c|}
\hline Effect & & Value & $\mathrm{F}$ & $\begin{array}{c}\text { Hypothesis } \\
\text { df }\end{array}$ & Error df & Sig. & $\begin{array}{l}\text { Partial Eta } \\
\text { Squared }\end{array}$ \\
\hline \multirow[t]{4}{*}{ PCS } & Pillai's Trace & .301 & $29.011^{b}$ & 2.000 & 135.000 & .000 & .301 \\
\hline & Wilks' Lambda & 699 & $29.011^{b}$ & 2.000 & 135.000 & .000 & .301 \\
\hline & Hotelling's Trace & .430 & $29.011^{b}$ & 2.000 & 135.000 & .000 & .301 \\
\hline & $\begin{array}{l}\text { Roy's Largest } \\
\text { Root }\end{array}$ & .430 & $29.011^{b}$ & 2.000 & 135.000 & .000 & .301 \\
\hline \multirow{4}{*}{$\begin{array}{l}\text { PCS * } \\
\text { ViolenceType }\end{array}$} & Pillai's Trace & .030 & 1.040 & 4.000 & 272.000 & .387 & .015 \\
\hline & Wilks' Lambda & .970 & $1.036^{b}$ & 4.000 & 270.000 & .389 & .015 \\
\hline & Hotelling's Trace & .031 & 1.031 & 4.000 & 268.000 & .392 & .015 \\
\hline & $\begin{array}{l}\text { Roy's Largest } \\
\text { Root }\end{array}$ & .025 & $1.690^{c}$ & 2.000 & 136.000 & .188 & .024 \\
\hline
\end{tabular}

a. Design: Intercept + ViolenceType

Within Subjects Design: PCS

b. Exact statistic

c. The statistic is an upper bound on F that yields a lower bound on the significance level. 
The following table shows mean scores at three points in time across groups (pre, immediate post, and 6 months post). As these descriptive statistics indicate, scores on the PSC decreased then increased within the three points in time: Pre-test $(\mathrm{M}=28.681)$, decreased at Immediate Post Test ( $\mathrm{M}=25.841)$ and increased, 6-Month Post Test $(\mathrm{M}=27.524)$.

\section{Table 35}

Main Effect of Time for Child Well-Being: RM ANOVA

\begin{tabular}{|c|c|c|c|c|}
\hline leasure & ГIME & & & \\
\hline \multirow[b]{2}{*}{ PCS } & \multirow[b]{2}{*}{ Mean } & \multirow[b]{2}{*}{ Std. Error } & \multicolumn{2}{|c|}{ 95\% Confidence Interval } \\
\hline & & & Lower Bound & Upper Bound \\
\hline 1 & 28.681 & .619 & 27.458 & 29.905 \\
\hline 2 & 25.841 & .589 & 24.676 & 27.006 \\
\hline 3 & 27.524 & .597 & 26.343 & 28.706 \\
\hline
\end{tabular}

There was a significant main effect of group, $F(2,136)=3.296, \mathrm{p}<.040$, Partial $\eta^{2}=.046$. See table below for results of the Tests of Between-Subjects Effects. The table summarizing Descriptive Statistics for Main Effect of Group below reveals that subjects in the NV group had higher scores re: Child Well-Being $(\mathrm{M}=46.00$; $\mathrm{SE}=.599)$ than those in the $\mathrm{SV}$ group $(\mathrm{M}=43.837 ; \mathrm{SE}=.679)$ and the $\mathrm{CCV}$ group $(\mathrm{M}=40.556 ; \mathrm{SE}=1.21)$. 


\section{Table 36}

Main Effect of Group for Child Well-Being: RM ANOVA

Tests of Between-Subjects Effects

Measure: TIME

Transformed Variable: Average

\begin{tabular}{|l|r|r|r|r|r|r|}
\hline Source & $\begin{array}{c}\text { Type III Sum of } \\
\text { Squares }\end{array}$ & df & Mean Square & F & Sig. & $\begin{array}{c}\text { Partial Eta } \\
\text { Squared }\end{array}$ \\
\hline Intercept & 279507.269 & 1 & 279507.269 & 2557.468 & .000 & .950 \\
\hline ViolenceType & 720.367 & 2 & 360.183 & 3.296 & .040 & .046 \\
\hline Error & 14863.523 & 136 & 109.291 & & & \\
\hline
\end{tabular}

Table 37

Main Effect of Violence Group for Child Well-Being: RM ANOVA

Descriptive Statistics for Main Effect of Violence Group

Measure: TIME

\begin{tabular}{|c|c|c|c|c|}
\hline \multirow[b]{2}{*}{ Cluster Number of Case } & \multirow[b]{2}{*}{ Mean } & \multirow[b]{2}{*}{ Std. Error } & \multicolumn{2}{|c|}{ 95\% Confidence Interval } \\
\hline & & & Lower Bound & Upper Bound \\
\hline Coercive Control Violence & 28.845 & 1.141 & 26.590 & 31.101 \\
\hline Situational Violence & 27.626 & .862 & 25.921 & 29.331 \\
\hline No Violence & 25.575 & .767 & 24.059 & 27.091 \\
\hline
\end{tabular}

Lastly, there was a not significant interaction of group by time $F(4,270)=1.036$,

Wilks $\lambda=.970, p=.387$; Partial $\eta^{2}=.015$. See table above for Multivariate Tests with these results. See table below for Descriptive Statistics for child well-being (PSC) scores over the three points in time by group. As this chart indicates, those in the CCV group experienced an improvement in child well-being from Pre $(M=30.786)$ to Immediate Post $(M=27.143)$ with a slight increase in problems at 6-mos Post $(M=28.607)$. The SV group also experienced an improvement from Pre $(\mathrm{M}=28.388)$ to Post (26.041) then slight rise in problems 6-mos Post $(\mathrm{M}=28.449)$. The NV group experienced the same trend with an improvement from Pre $(M=26.871)$ to Post $(M=24.339)$ and slight increase in problems at 6-mos Post $(\mathrm{M}=25.516)$ 


\section{Table 38}

Descriptive Statistics for Changes in Child Well-Being: RM ANOVA

Descriptive Statistics for Changes in Child Well-being Over Time by Group

Measure: Time

\begin{tabular}{|ll|r|r|r|r|}
\hline & & & & \multicolumn{2}{|c|}{$95 \%$ Confidence Interval } \\
\cline { 5 - 6 } Cluster Number of Case & Violence TypePSC & Mean & Std. Error & Lower Bound & Upper Bound \\
\hline Coercive Control Violence & 1 & 30.786 & 1.305 & 28.205 & 33.366 \\
& 2 & 27.143 & 1.243 & 24.686 & 29.600 \\
& 3 & 28.607 & 1.260 & 26.115 & 31.099 \\
\hline Situational Violence & 1 & 28.388 & .987 & 26.437 & 30.339 \\
& 2 & 26.041 & .939 & 24.183 & 27.898 \\
& 3 & 28.449 & .953 & 26.565 & 30.333 \\
\hline No Violence & 1 & 26.871 & .877 & 25.137 & 28.605 \\
& 2 & 24.339 & .835 & 22.687 & 25.990 \\
& 3 & 25.516 & .847 & 23.842 & 27.191 \\
\hline
\end{tabular}

These differences can be visualized by the figure generated by this procedure, as shown below:

\section{Figure 17}

\section{Child Well-Being of Time by Group (Lower \# is Better)}

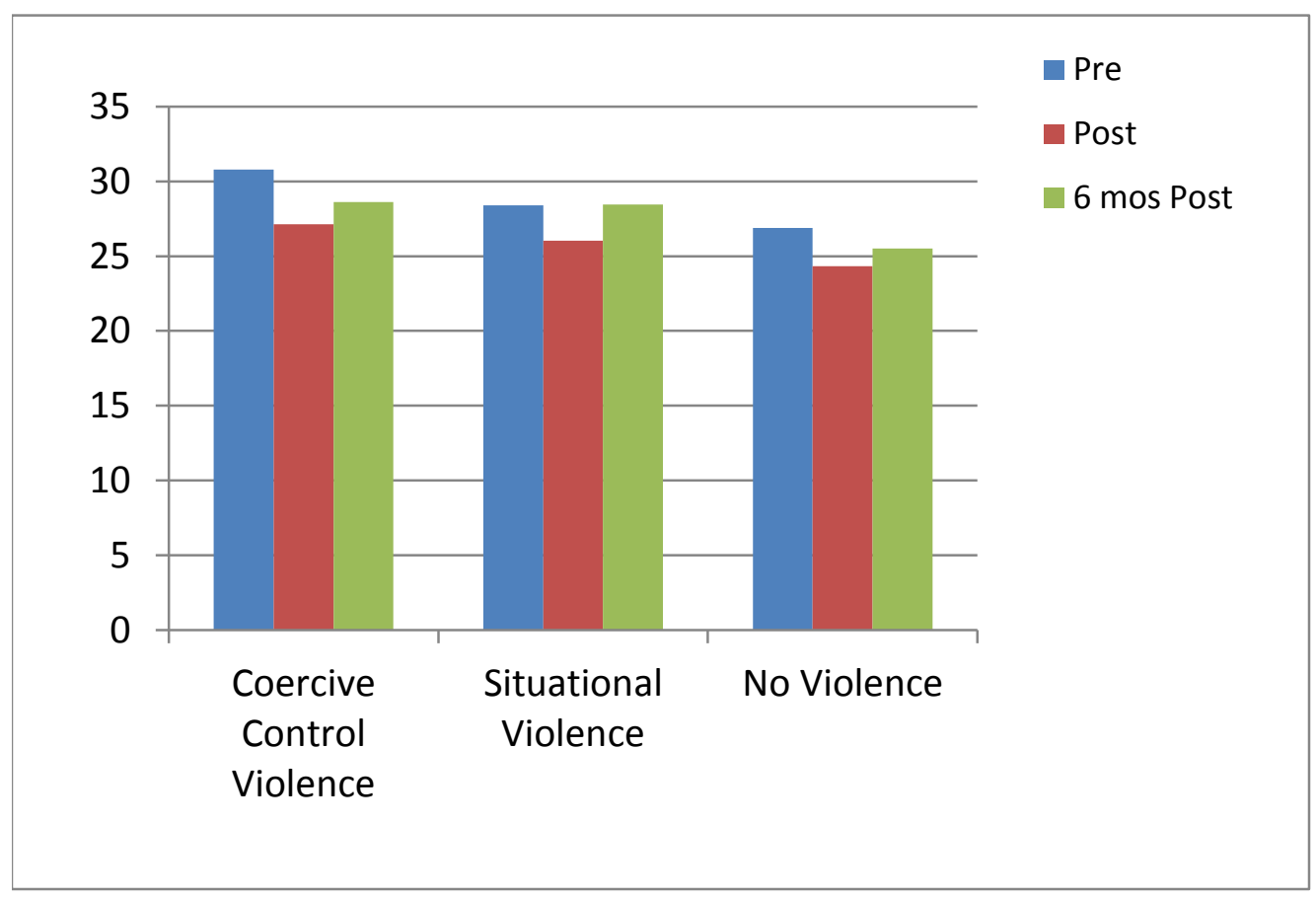




\section{Figure 18}

\section{Child Well-being Change Over Time By Group}

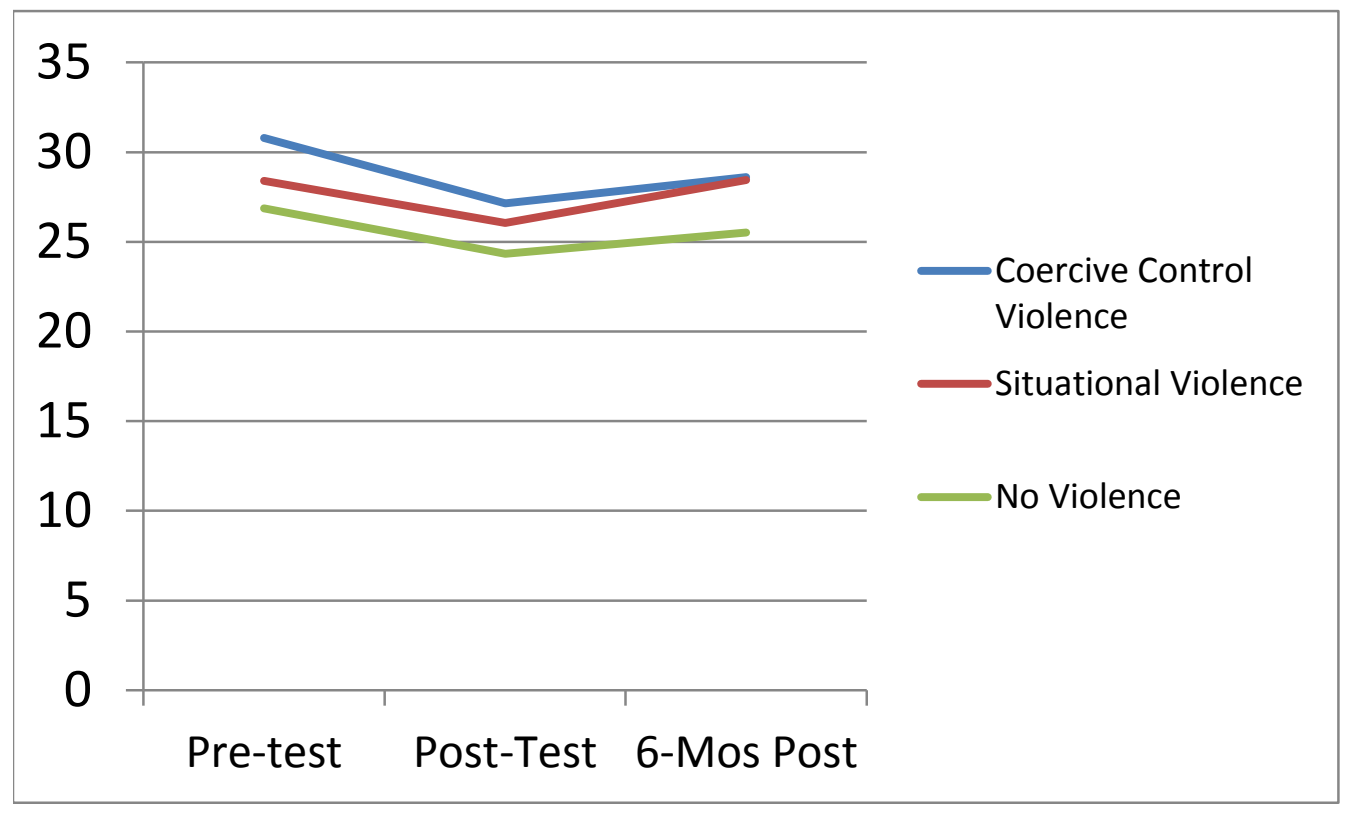


Based upon significant main effect by group, Bonferroni post hoc analyses were conducted to examine differences between each group. These post hoc analyses showed there were no significant differences between violence groups. There was a significant trend towards difference between CCV and NV groups $(\mathrm{p}=.056)$.

\section{Table 39}

Post Hoc Analysis for Child Well-Being: RM ANOVA

Bonferroni post hoc Analysis for Child Well-being

Measure: TIME

Bonferroni

\begin{tabular}{|c|c|c|c|c|c|c|}
\hline \multirow[b]{2}{*}{$\begin{array}{l}\text { (I) Cluster Number of } \\
\text { Case }\end{array}$} & \multirow[b]{2}{*}{$\begin{array}{l}\text { (J) Cluster Number of } \\
\text { Case }\end{array}$} & \multirow{2}{*}{$\begin{array}{c}\text { Mean } \\
\text { Difference (I- } \\
\mathrm{J})\end{array}$} & \multirow[b]{2}{*}{$\begin{array}{l}\text { Std. } \\
\text { Error }\end{array}$} & \multirow[b]{2}{*}{ Sig. } & \multicolumn{2}{|c|}{ 95\% Confidence Interval } \\
\hline & & & & & $\begin{array}{l}\text { Lower } \\
\text { Bound }\end{array}$ & $\begin{array}{l}\text { Upper } \\
\text { Bound }\end{array}$ \\
\hline Coercive Control & Situational Violence & 1.2194 & 1.42988 & 1.000 & -2.2466 & 4.6853 \\
\hline Violence & No Violence & 3.2700 & 1.37429 & .056 & -.0612 & 6.6012 \\
\hline \multirow[t]{2}{*}{ Situational Violence } & $\begin{array}{l}\text { Coercive Control } \\
\text { Violence }\end{array}$ & -1.2194 & 1.42988 & 1.000 & -4.6853 & 2.2466 \\
\hline & No Violence & 2.0506 & 1.15371 & .233 & -.7460 & 4.8471 \\
\hline \multirow[t]{2}{*}{ No Violence } & $\begin{array}{l}\text { Coercive Control } \\
\text { Violence }\end{array}$ & -3.2700 & 1.37429 & .056 & -6.6012 & .0612 \\
\hline & Situational Violence & -2.0506 & 1.15371 & .233 & -4.8471 & .7460 \\
\hline
\end{tabular}

Based on observed means.

The error term is Mean Square(Error) $=36.430$. 


\section{Research Question 3}

Multiple Linear Regression Analysis Overview. A Regression Analysis estimates the relationships among variables. It includes techniques for analyzing several variables when the focus is on the relationship between a dependent variable and one or more independent variables (or 'predictors'). A regression analysis shows how the typical value of the dependent variable changes when any one of the independent variables is varied, while the other independent variables are held fixed. A regression analysis is used for prediction and forecasting.

A multiple regression analysis was run to test question 3: Which variables are mediators of the improvement in the parent/child relationship, family cohesion and child well-being for those with relationship violence: communication skills, couple relationship quality, reduction in physical violence and/or controlling behaviors? Three separate linear regression analyses were run for the three DVs FACES, PCRS \& PSW (CWB) using the change scores from pre to 6 months post. The IVs or predictor variables entered into the analysis were communication quality (RDS; Relationship Dynamics Scale), relationship quality (DAS; Dyadic Adjustment Scale), physical violence (CTS; Conflict Tactics Scale) and emotional abuse/control (CBS; Controlling Behaviors Scale). The change scores from pre to 6 months post were also used for each of these IVs. This allows us to examine how changes in predictors based on WMR impact changes in outcomes. The groups with violence were combined for these two analyses in order to have an adequate sample size to run the regression. Although this eliminates the potential to generate unique models for each type of violence, we maintain the ability to 
generate models of prediction for the three key outcomes when any type of IPV is present.

Family Cohesion. A Multiple Regression analysis was run to estimate the relationship between family cohesion (DV) and the potential predictors of change (IVs) in communication skills (RDS change), couple relationship quality (DAS change), reduction in physical family violence (CTS change), reduction in violent control (CBS change). Using the enter method it was found that communication, relationship dynamics, decrease in physical and psychological abuse explain a significant amount of the variance in the change of family cohesion from pre to 6 months post produced $F(4,96)=3.270$, p $<.015, \mathrm{R}_{2}=.120, \mathrm{R}^{2}$ Adjusted $\left.=.083\right)$.

Table 40 showed a multiple correlation coefficient value (R) of 0.346 and a coefficient of determination $\left(\mathrm{R}_{2}\right)$ of .120 (or $12 \%$ ) which indicates the proportion of variation in the DV that can be explained by the IVs. The data met the assumption of independent errors (Durbin-Watson value $=1.644)$.

See tables below for results of the Model Summary.

\section{Table 40}

Model Summary ${ }^{b}$ for Family Cohesion

\begin{tabular}{|l|r|r|r|r|r|}
\hline & & & & \multicolumn{2}{c|}{$\begin{array}{c}\text { Std. Error of the } \\
\text { Model }\end{array}$} \\
\hline 1 & $\mathrm{R}$ & R Square & Adjusted R Square & \multicolumn{1}{c|}{ Estimate } & Durbin-Watson \\
\hline
\end{tabular}

a. Predictors: (Constant), change in cbs from pre to six mos post, change in das from pre to six mos post, change in cts from pre to six mos post, change in rds from pre to six mos post

b. Dependent Variable: change in faces from pre to six mos post

The table below indicates that the overall regression model is a good fit for the data and statistically significantly predicts the dependent variable. 


\section{Table 41}

\section{$\underline{\text { ANOVA table for Family Cohesion }}$}

\begin{tabular}{|c|c|c|c|c|c|c|}
\hline \multicolumn{7}{|c|}{ ANOVA $^{a}$} \\
\hline \multicolumn{2}{|c|}{ Model } & Sum of Squares & df & Mean Square & $\mathrm{F}$ & Sig. \\
\hline \multirow[t]{3}{*}{1} & Regression & 738.678 & 4 & 184.670 & 3.270 & $.015^{\mathrm{b}}$ \\
\hline & Residual & 5421.995 & 96 & 56.479 & & \\
\hline & Total & 6160.673 & 100 & & & \\
\hline
\end{tabular}

a. Dependent Variable: change in faces from pre to six mos post

b. Predictors: (Constant), change in cbs from pre to six mos post, change in das from pre to six mos post, change in cts from pre to six mos post, change in rds from pre to six mos post

The Coefficients table show unstandardized coefficients, which indicate how much the DV varies with the IV when all of the other IVs are held constant. With all other variables held constant, the change in the relationship dynamic scale (RDS) contributed to .019 units of change in family cohesion, the DAS contributed to -.115 units of change, the CTS contributed to .135 units of change and the CBS contributed .069 units of change. 
The analysis shows that change in couple communication did not significantly predict family cohesion $($ Beta $=.12, \mathrm{t}(96)=.084, \mathrm{~ns})$, couple relationship quality (Beta $=$ $-.112, \mathrm{t}(96)=-.971, \mathrm{~ns})$, change in physical violence $($ Beta $=.129, \mathrm{t}(96)=1.021, \mathrm{~ns})$ or change in psychological violence $($ Beta $=.170, \mathrm{t}(96)=1.31, \mathrm{~ns})$. Although there is an overall significance $(\mathrm{p}<.05)$, none of the individual IVs are significant.

\section{Table 42}

FACES Coefficients Table

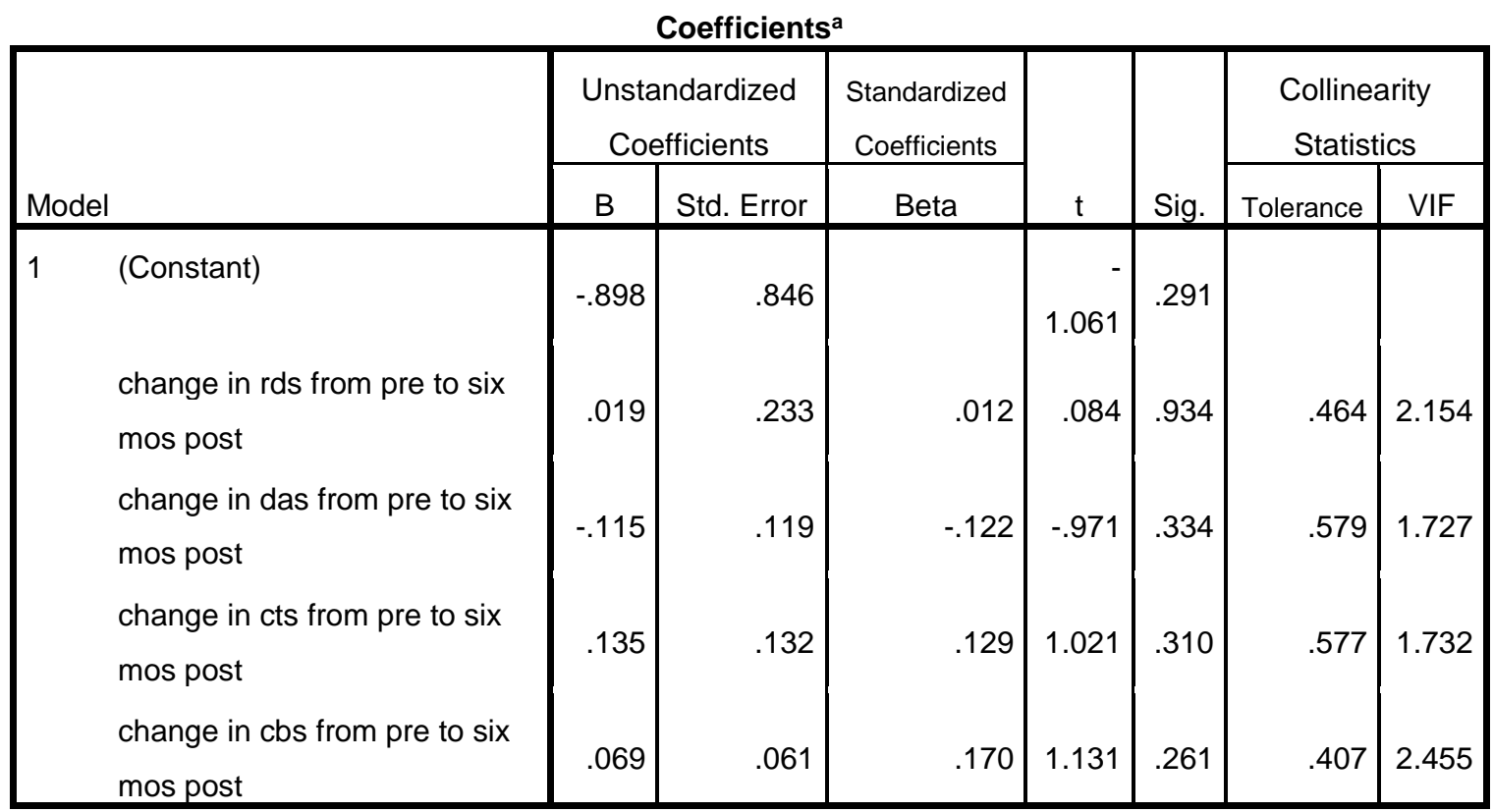

a. Dependent Variable: change in faces from pre to six mos post

The Collinearity Diagnostics show how dissimilar the Independent Variables are from each other. $($ RDS Scores, Tolerance $=.464, V I F=2.154 ;$ DAS Scores, Tolerance $=$ $.579, V I F=1.727 ;$ CTS Scores, Tolerance $=.577$, VIF $=1.732 ;$ CBS Scores, Tolerance $=$ $.407, V I F=2.455)$. The data indicates that the IVs were dissimilar enough for there not to be a problem with collinearity. 


\section{Table 43}

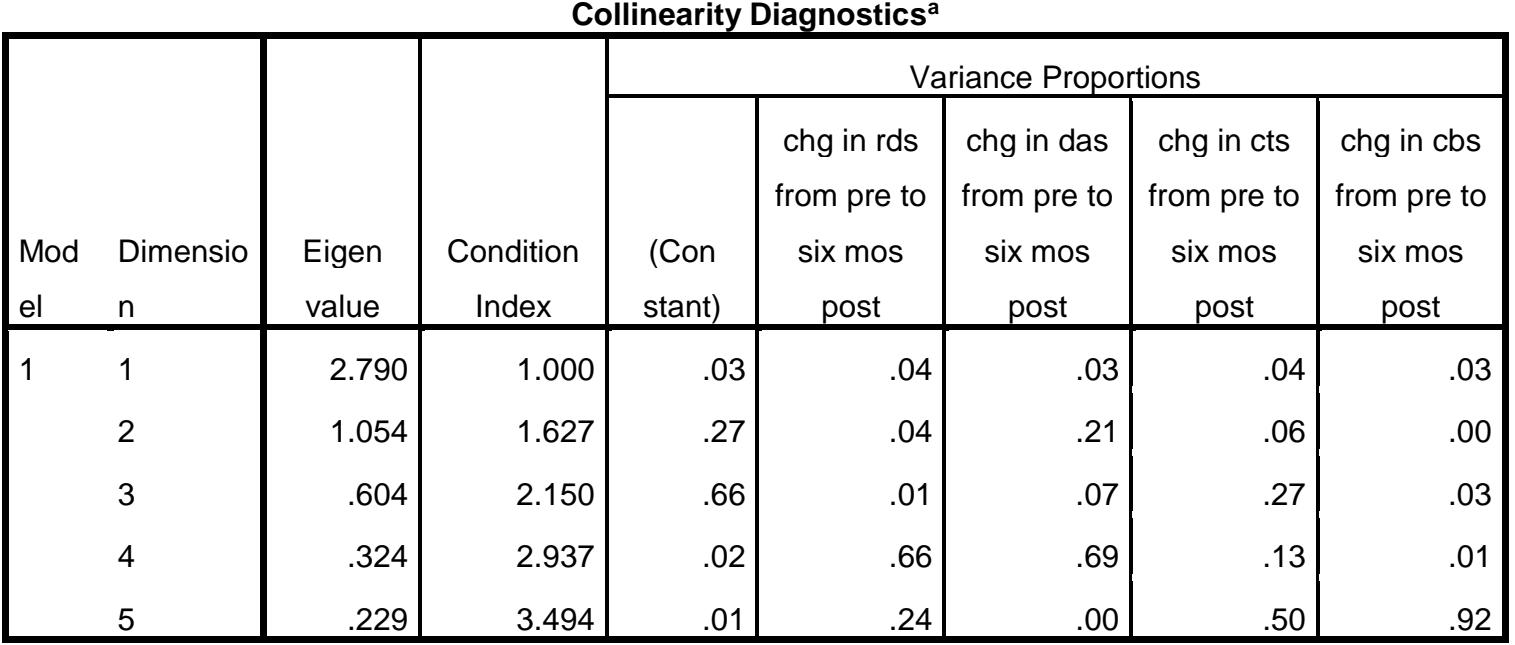

a. Dependent Variable: change in faces from pre to six mos post

Parent Child Relationship. A Multiple Regression analysis was run to estimate the relationship between the Parent Child Relationship (DV) and the potential predictors of change (IVs) in communication skills (RDS change), couple relationship quality (DAS change), reduction in physical family violence (CTS change), reduction in violent control (CBS change). Using the enter method it was found that communication, relationship dynamics, decrease in physical and psychological abuse explain a significant amount of the variance in the change in the parent-child relationship from pre to 6 months post produced $\mathrm{F}(4,66)=3.784, \mathrm{p}<.008, \mathrm{R}_{2}=.187, \mathrm{R}^{2}$ Adjusted $\left.=.137\right)$.

Table RQ3 showed a multiple correlation coefficient value (R) of 0.432 and a coefficient of determination $\left(\mathrm{R}_{2}\right)$ of .187 (or $18.7 \%$ ) which indicates the proportion of variation in the DV that can be explained by the IVs. The data met the assumption of independent errors (Durbin-Watson value $=2.344$ ). See tables below for results of the Model Summary. 


\section{Table 44}

Model Summary for Parent-Child Relationship

\begin{tabular}{|l|r|r|r|r|r|}
\hline & & & & Model Summary \\
Model & $\mathrm{R}$ & R Square & Adjusted R Square & \multicolumn{1}{c|}{$\begin{array}{c}\text { Std. Error of the } \\
\text { Estimate }\end{array}$} & Durbin-Watson \\
\hline 1 & $.432^{\mathrm{a}}$ & .187 & .137 & 7.56681 & 2.344 \\
\hline
\end{tabular}

a. Predictors: (Constant), change in cbs from pre to six mos post, change in das from pre to six mos post, change in cts from pre to six mos post, change in rds from pre to six mos post

b. Dependent Variable: change in pcrs from pre to six mos post

The table below indicates that the overall regression model is a good fit for the data and statistically significantly predicts the dependent variable.

\section{Table 45}

ANOVA Table for Parent-Child Relationship Regression

ANOVA $^{\mathrm{a}}$

\begin{tabular}{|ll|r|r|r|r|r|}
\hline \multicolumn{1}{|l|}{} & Sudel & Sum of Squares & df & Mean Square & F & Sig. \\
\hline 1 & Regression & 866.640 & 4 & 216.660 & 3.784 & $.008^{\mathrm{b}}$ \\
& Residual & 3778.938 & 66 & 57.257 & & \\
& Total & 4645.577 & 70 & & & \\
\end{tabular}

a. Dependent Variable: change in pcrs from pre to six mos post

b. Predictors: (Constant), change in cbs from pre to six mos post, change in das from pre to six mos post, change in cts from pre to six mos post, change in rds from pre to six mos post

The Coefficients table show unstandardized coefficients, which indicate how much the DV varies with the IV when all of the other IVs are held constant. With all other variables held constant, the change in the rds contributed to -.378 units of change, the DAS contributed to -.195 units of change, the CTS contributed to -.397 units of change and the CBS contributed .218 units of change. The CTS score was a significant predictor in the model, $\mathrm{t}-2.48, \mathrm{p}<.05$, and the CBS score was also a significant predictor $\mathrm{t}=2.97, \mathrm{p}<.01$. 
The analysis shows that change in couple communication did not significantly predict change in the parent-child relationship $($ Beta $=.221, \mathrm{t}(66)=1.342, \mathrm{~ns})$ or couple relationship quality $($ Beta $=-.209, \mathrm{t}(66)=-1.403, \mathrm{~ns})$, however change in physical violence did significantly predict value of the parent-child relationship (Beta $=.363, \mathrm{t}(66)$ $=2.475, \mathrm{p}<.05)$ as did change in psychological violence $($ Beta $=.522, \mathrm{t}(66)=2.968$, $\mathrm{p}<.01)$.

\section{Table 46}

Parent-Child Relationship Coefficients Table

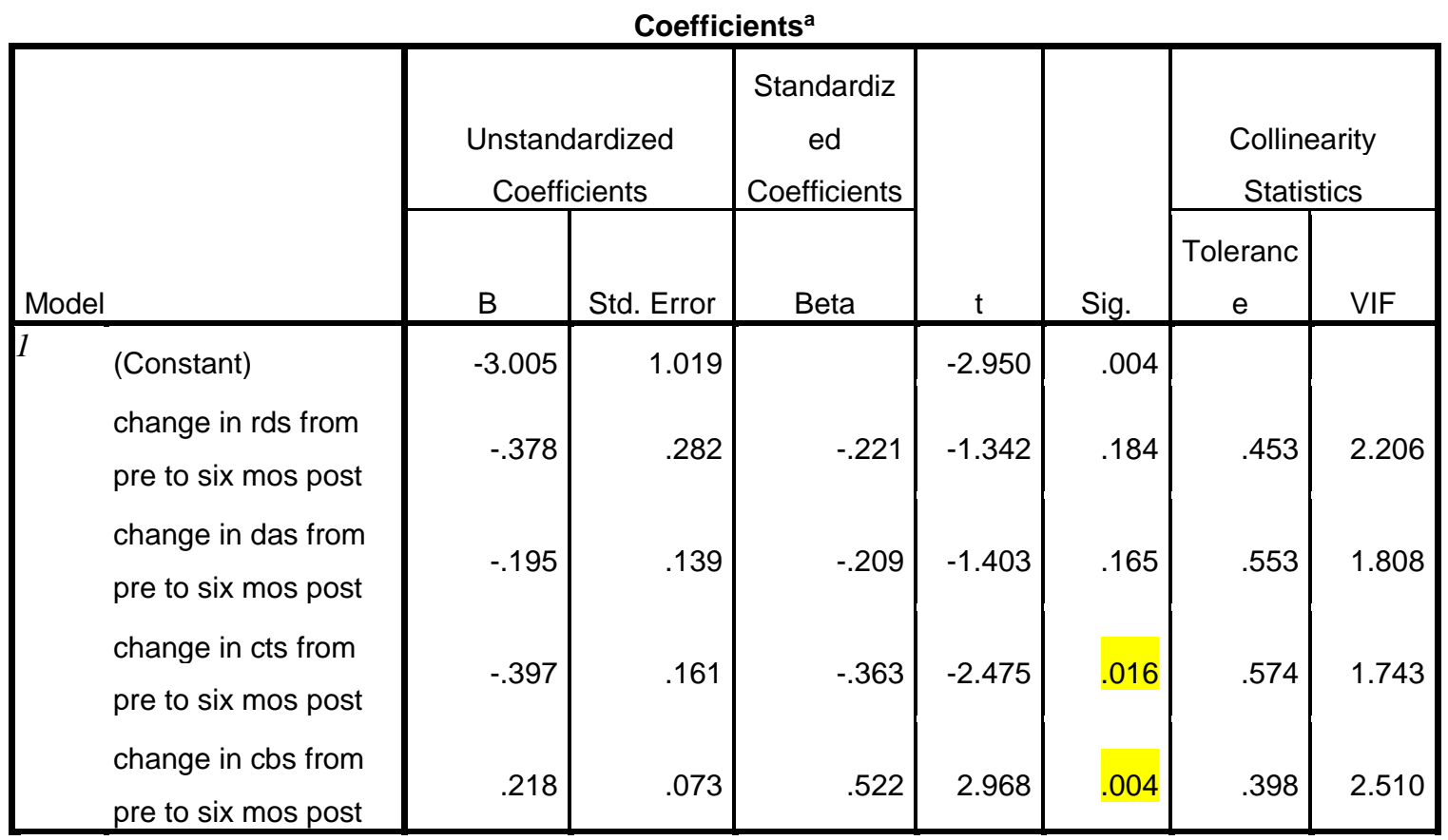

a. Dependent Variable: change in pcrs from pre to six mos post

The Collinearity Diagnostics show how dissimilar the Independent Variables are from each other. Tests to see if the data met the assumption of collinearity indicated that multicollinearity was not a concern (RDS Scores, Tolerance $=.453, V I F=2.206$; DAS Scores, Tolerance $=.553, V I F=1.808 ;$ CTS Scores, Tolerance $=.574, \mathrm{VIF}=1.743 ; \mathrm{CBS}$ 
Scores, Tolerance $=.398, \mathrm{VIF}=2.510$ ). The data indicates that the DVs were dissimilar enough for there not to be a problem with collinearity.

\section{Table 47}

Collinearity Diagnostics for the Parent-Child Relationship

\begin{tabular}{|c|c|c|c|c|c|c|c|c|}
\hline \multicolumn{9}{|c|}{ Collinearity Diagnostics ${ }^{a}$} \\
\hline \multirow[b]{2}{*}{ Mode } & \multirow[b]{2}{*}{ Dimension } & \multirow[b]{2}{*}{$\begin{array}{l}\text { Eigen } \\
\text { value }\end{array}$} & \multirow[b]{2}{*}{$\begin{array}{c}\text { Condition } \\
\text { Index }\end{array}$} & \multicolumn{5}{|c|}{ Variance Proportions } \\
\hline & & & & (Constant) & $\begin{array}{l}\text { chg in rds } \\
\text { from pre to } \\
\text { six mos post }\end{array}$ & $\begin{array}{l}\text { chg in das } \\
\text { from pre to } \\
\text { six mos post }\end{array}$ & $\begin{array}{c}\text { chg in cts } \\
\text { from pre to } \\
\text { six mos post }\end{array}$ & $\begin{array}{l}\text { chg in cbs } \\
\text { from pre to } \\
\text { six mos post }\end{array}$ \\
\hline \multirow[t]{5}{*}{1} & 1 & 2.931 & 1.000 & .03 & .03 & .03 & .03 & .03 \\
\hline & 2 & .922 & 1.783 & .37 & .03 & .23 & .05 & .00 \\
\hline & 3 & .625 & 2.165 & .53 & .01 & .07 & .33 & .03 \\
\hline & 4 & .294 & 3.156 & .06 & .74 & .65 & .11 & .00 \\
\hline & 5 & .228 & 3.587 & .02 & .18 & .02 & .47 & .94 \\
\hline
\end{tabular}

a. Dependent Variable: change in pcrs from pre to six mos post 
Child Well-Being. A Multiple Regression analysis was run to estimate the relationship between Child Well-being (DV) and the potential predictors of change (IVs) in communication skills (RDS change), couple relationship quality (DAS change), reduction in physical family violence (CTS change), reduction in violent control (CBS change). Using the enter method it was found that communication, relationship dynamics, decrease in physical and psychological abuse did not explain any significant amount of the variance in the change in child well-being from pre to 6 months post, $F(4,76)=1.371$, n.s., $\mathrm{R}_{2}=.067, \mathrm{R}^{2}$ Adjusted $\left.=.018\right)$.

Table RQ3.CWB1 showed a multiple correlation coefficient value (R) of 0.259 and a coefficient of determination $\left(\mathrm{R}_{2}\right)$ of .067 (or 6.7\%) which indicates the proportion of variation in the DV that can be explained by the IVs. The data met the assumption of independent errors (Durbin-Watson value $=1.909$ ). See table below for results of the Model Summary.

\section{Table 48}

Model Summary for Child Well-Being

\begin{tabular}{|l|r|r|r|r|r|}
\hline & \multicolumn{5}{|c|}{ Model Summary $^{\mathbf{b}}$} \\
\hline 1 & $\mathrm{R}$ & R Square & Adjusted R Square & $\begin{array}{c}\text { Std. Error of the } \\
\text { Estimate }\end{array}$ & Durbin-Watson \\
\hline 1 & $.259^{\mathrm{a}}$ & .067 & .018 & 5.70959 & 1.909 \\
\hline
\end{tabular}

a. Predictors: (Constant), change in cbs from pre to six mos post, change in das from pre to six mos post, change in cts from pre to six mos post, change in rds from pre to six mos post

b. Dependent Variable: change in psc from pre to six mos post

The table below indicates that the overall regression model is a not a good fit for the data and does not predict the dependent variable of child well-being, $F(4,76) 1.371$, n.s.. 


\section{Table 49}

\section{ANOVA Table for Child Well-Being Regression}

\begin{tabular}{|ll|r|r|r|r|r|}
\hline \multicolumn{1}{|c|}{ ANOVA $^{\mathrm{a}}$} & \multicolumn{1}{l|}{ Sig. } \\
\hline 1 & Sum of Squares & $\mathrm{df}$ & Mean Square & F & $.252^{\mathrm{b}}$ \\
& Regression & 178.769 & 4 & 44.692 & 1.371 & \\
& Residual & 2477.552 & 76 & 32.599 & & \\
& Total & 2656.321 & 80 & & & \\
\hline
\end{tabular}

a. Dependent Variable: change in psc from pre to six mos post

b. Predictors: (Constant), change in cbs from pre to six mos post, change in das from pre to six mos post, change in cts from pre to six mos post, change in rds from pre to six mos post

The Coefficients table show unstandardized coefficients, which indicate how much the DV varies with the IV when all of the other IVs are held constant. With all other variables held constant, the change in the RDS contributed to -.026 units of change, the DAS contributed to .082 units of change, the CTS contributed to .160 units of change and the CBS contributed -.061 units of change. As expected the model was not significant and none of these IVs was a significant predictor of child well-being.

The analysis shows that change in couple communication did not significantly predict child well-being $($ Beta $=-.021, \mathrm{t}(76)=.651, \mathrm{~ns})$, couple relationship quality (Beta $=.748, \mathrm{t}(76)=.748, \mathrm{~ns})$, change in physical violence $($ Beta $=.216, \mathrm{t}(76)=1.405, \mathrm{~ns})$ or change in psychological violence $($ Beta $=-.211, \mathrm{t}(76)=1.103, \mathrm{~ns})$. 


\begin{tabular}{|c|c|c|c|c|c|c|c|c|}
\hline \multicolumn{9}{|c|}{ Coefficients $^{a}$} \\
\hline \multirow{2}{*}{\multicolumn{2}{|c|}{ Model }} & \multicolumn{2}{|c|}{$\begin{array}{c}\text { Unstandardized } \\
\text { Coefficients }\end{array}$} & \multirow{2}{*}{$\begin{array}{c}\text { Standardiz } \\
\text { ed } \\
\text { Coefficients } \\
\\
\text { Beta }\end{array}$} & \multirow{3}{*}{$\frac{\mathrm{t}}{-.651}$} & \multirow{3}{*}{$\frac{\text { Sig. }}{.517}$} & \multicolumn{2}{|c|}{$\begin{array}{c}\text { Collinearity } \\
\text { Statistics }\end{array}$} \\
\hline & & $\mathrm{B}$ & Std. Error & & & & $\mathrm{e}$ & VIF \\
\hline \multirow{5}{*}{\multicolumn{2}{|c|}{$\begin{array}{l}\text { (Constant) } \\
\text { change in rds from } \\
\text { pre to six mos post } \\
\text { change in das from } \\
\text { pre to six mos post } \\
\text { change in cts from } \\
\text { pre to six mos post } \\
\text { change in cbs from } \\
\text { pre to six mos post }\end{array}$}} & -.463 & .712 & & & & & \\
\hline & & -.026 & .198 & -.021 & -.129 & .898 & .453 & 2.207 \\
\hline & & .082 & .110 & .119 & .748 & .457 & .486 & 2.058 \\
\hline & & .160 & .114 & .216 & 1.405 & .164 & .518 & 1.931 \\
\hline & & -.061 & .055 & -.211 & -1.103 & .274 & .337 & 2.970 \\
\hline
\end{tabular}

a. Dependent Variable: change in psc from pre to six mos post

The results of the Multiple Regression Analysis are exploratory in nature and are by no means indicative of specific prediction models. Due to sampling limitations, the violence types had to be run together, thus limiting the knowledge we could gain from the analysis. There does show significant change values in family cohesion and the parentchild relationship when influenced by all mediators. Figure 19 shows the final results model for the study with information from the regression analysis. While it was unclear what specific IVs caused overall significance, both change in physical violence and controlling behaviors both influenced the parent-child relationship and were individually significant. Change scores for child well-being were not significant overall or by individual IVs. 
Figure 19

Final Conceptual Figure for Study

\section{Physical Violence}

Control

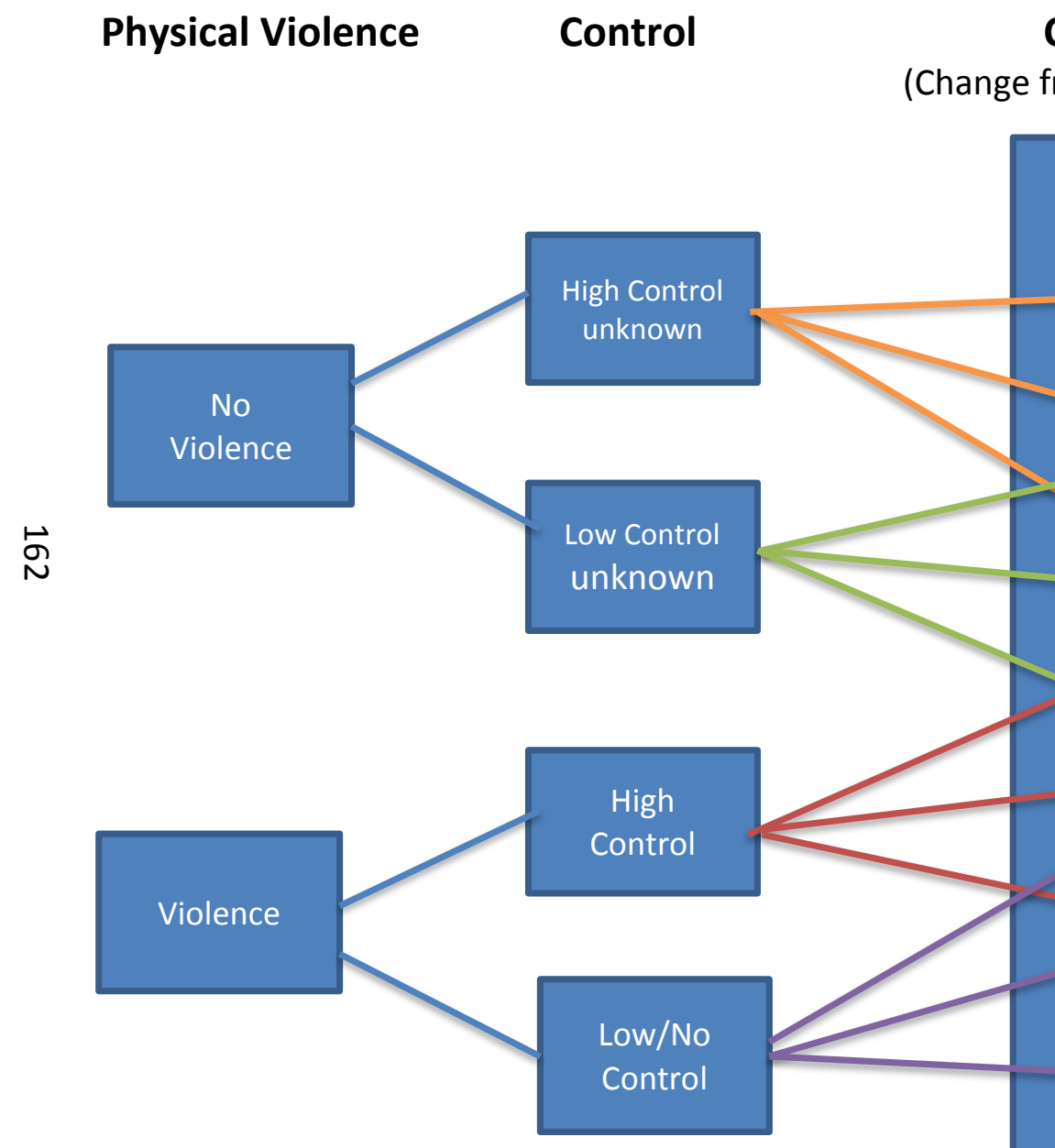

Change Mediators

Outcomes

from Pre to 6 Months Post)

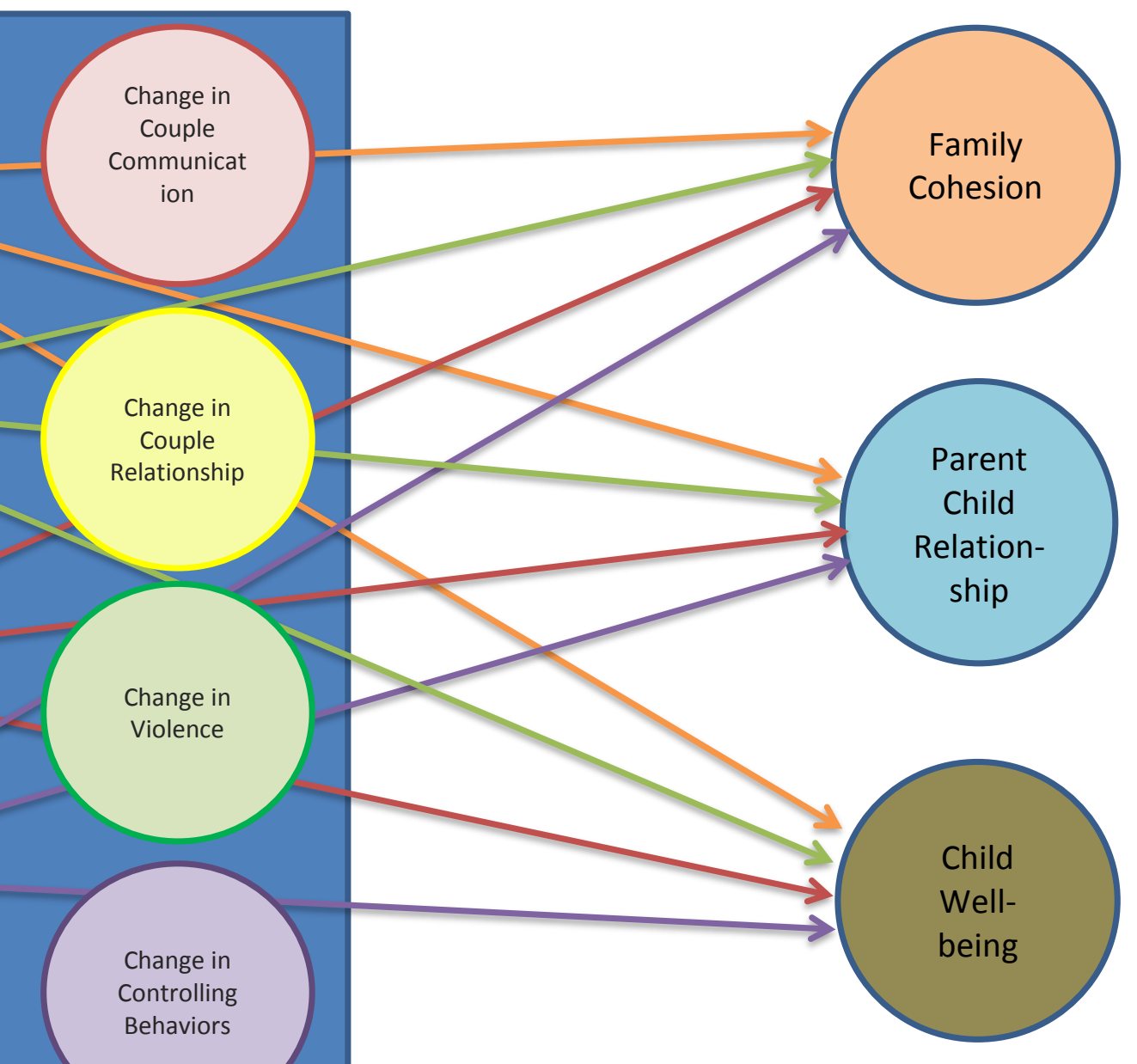




\section{CHAPTER V \\ DISCUSSION}

\section{Overview}

This chapter presents discussion on the study findings in each of the three research questions, limitations of the study, future research directions, policy and practice implications, a summary of the discussion and the dissertation conclusion.

\section{Study Findings}

The study found that violence type does make a difference at baseline in family cohesion, the parent-child relationship and child well-being, and there are significant differences the intervention by violence type. Those in the CCV group had that lowest scores on these outcomes at baseline, but his group experienced the greatest benefit (improvement in scores) as a result of the intervention. Those in the SV group fell between the CCV and NV groups on both outcomes at baseline and improvement from the WMR intervention, although the differences between SV and NV were not statistically significant for family cohesion and child well-being. The types of violence also have been shown to be significantly different from each other in communication (Antle \& Ness, 2012), severity of violence, impact of intervention on learning (Antle \& Ness, 2012), gender differences and perpetrator differences (Johnson, Graham-Kevan \& Archer). This strengthens the evidence that there is a significant difference between these types of violence in multiple areas of manifestation including the parent-child relationship, child well-being and family cohesion. There is also a difference in how the 
study impacts each type of violence, which will be discussed more below, that raises the question of how to create programs that can be effective for each group. This study also found that reduction in physical violence and controlling behaviors were predictors of improvement in the parent-child relationship for those in violent relationships. The findings will be discussed more at length below.

\section{Baseline Differences}

No Violence at Baseline. The study found that there were significant differences in family cohesion, the parent/child relationship and child wellbeing between the violence groups. At baseline, those who did not experience any physical violence in their relationship had the best outcomes for all three measures, which corroborates the previous research showing that child well-being, family cohesion and the parent child relationship are adversely affected by physical violence in the caretakers' relationship (Rizo et all, 2011; Ireland \& Smith, 2009; Brown \& Bzostek, 2003; Silvern et al., 1995; Roustit et al., 2009; Russell, Springer \& Greenfield 2010; Graham, Bermann \& Seng, 2005; Anda, Block, Felitti, 2003; Kernsmith, 2006; Levendosky \& Graham-Bermann, 2000, 2001; Margolin, Gordis, Medina \& Oliver, 2003). This finding was significant $(\mathrm{p}<.001)$, showing that those with no physical violence in a relationship had significantly better family cohesion, parent-child relationship, and child well-being than those with

\section{CCV or SV.}

Coercive Control Violence at Baseline. Another contribution of the research was the finding that those experiencing Coercive Control Violence, relationships with physical violence and high control, had the worst outcomes for child well-being, family cohesion and the parent-child relationship. Those in CCV relationships had significantly 
lower scores on these three outcomes than those with No Violence and Situational Violence. The literature has explored other characteristics of CCV vs. SV such as direction of violence (uni-directional/bilateral), perpetrator gender (male-directed/nongender directed), population differences (shelter/community), nature of power $\&$ control (high/low control), etiology (need for control/anger management) communication differences (high command/low command) and potential for lethality (high/low) (Johnson, 1995; 2000; 2005; 2006; 2008; Kelly \& Johnson, 2008; Graham-Kevan \& Archer, 2003; Antle \& Ness Roberts, 2012; Ellis \& Stuckless, 1996; Johnson \& Campbell, 1993), but this is the first study to evaluate factors related to parenting had yet to be explored.

The data support the original hypothesis that control dynamics (as measured by the CBS and present in CCV relationships) have a significant impact on parent-child relationships and child well-being. The finding that those in CCV relationships had worse outcomes then SV relationship highlights he critical role of control dynamics, since those in SV experience violence without control and have better outcomes than the CCV group. The contribution of unhealthy control dynamics in the couple relationship could contribute to low family cohesion by creating parent-child dyads for an increased sense of security, unhealthy loyalties in the family to one parent or the other out of fear or self-preservation, or increased secrecy in the family. A child may also align with the victim parent to protect that parent or they may be used as a "control tactic" by the perpetrator which creates distance from the victim parent (Bancroft, 2003). These schisms in family cohesion could lead to a low baseline score for those involved in the 
high-control CCV-type relationships that would not have the same effect on the lowcontrol SV-type relationship.

Those in CCV relationships also scored significantly worse than SV and NV groups in the parent-child relationship, potentially for many of the same reasons listed above. The parent-child relationship is adversely affected by control in the couple relationship (Levondosky \& Graham-Berman 2000; 2001; Levondosky et al 2009), potentially due to stress that power and control behaviors put on the couple relationship. High jealousy and doubt in the relationship, as well as maternal depression and substance abuse are all frequently present in CCV and could all have an effect on the parent-child relationship (Levondosky et al, 2009, Margolin, Gordis-Medina \& Oliver, 2003; Warshaw, Sullivan, \& Rivera, 2013; Lovejoy et al, 2000). There is also a high degree of instability and uncertainty with Coercive Control Violence due to the cycle of violence that is a feature of CCV. A victim may leave and return to their partner seven to eight times (Duluth, 2014) as well as have ambiguous feelings about their perpetrator that cycle rapidly with the cycle of violence. This could confuse children and contribute to feelings of being unsafe and unsure in their primary needs of shelter, protection and safety contributing to either mental health or cognitive disturbances in the child or self-reliance that can erode parent-child attachment and child well-being.

Those in CCV relationships scored lowest in child well-being, and it is believed that this may be due to the high impact that witnessing or experiencing psychological abuse on the psyche. This is consistent with the literature which already states that children in violent relationships have adverse outcomes such as cognitive delays and disturbances, psychological pathology, and physiological delays and disorders that can 
also lead into adulthood (Noland et al, 2004; Kernsmith, 2006; Srofe, Egeland \& Carlson, 1999; Sover, 2005; Mitchel \& Finkelhor, 2001; Augustyn et al, 1995; Grych et al, 2002; Holden \& Richie, 199; Bowker 1988; McKibben, Devos \& Newberger, 1989; Straus \& Gelles, 1990; Black, Susman, \& Unger, 2010; Capaldi \& Clark, 1998; Fite et al, 2008; Foo \& Margolin, 1995; Foshee, Bauman \& Linder; 1999; Foshee et al., 2011; Jouriles et al., 2012; O’Heare \& Margolin, 2000; Ritzel-Jaffe \& Wolfe, 2001; Riggs \& O'Leary; 1996; Williams et al., 2008; Wolfe et al., 1998; Anda, Block \& Felitti, 2003; Silvern et al, 1995).

The significantly lower child well-being scores for CCV make a new contribution to the literature by highlighting the impact of control dynamics on child well-being. The scores for the SV group were not significantly different from the NV group for child well-being despite the presence of physical violence in the relationship. Within relationships of high control and psychological abuse of a victim, which include contributing factors of social isolation, high jealousy \& possessiveness, reversing blame of abuse to victim, steep hierarchies that includes decreasing the victim's self-esteem, or using children to inflict control; the impact of witnessing these unhealthy relationship dynamics on the formation of children's malleable psyches can have an impact on a child's well-being. Mixed messages of "I love you and I am going to make you feel bad about yourself" or "I am doing this (bad behavior) for your own good/because you made me do this" give an adverse example of human connection and attachment to children that can be stressful, especially when exposed to other families that have a very different and healthier intra-familiar dynamic. 
Situational Violence at Baseline. Those in the SV group reported significantly lower scores on the parent-child relationship than the No Violence group. Possible contributing factors may be the high level of explosive conflict in the family (Johnson, 1995; 2006; Ellis \& Stuckless, 1996), and lower levels of communication (Antle \& Ness Roberts, 2012). The presence of physical violence in these relationships may produce an unsafe feeling for a child as Maslow's secondary need on the pyramid, safety, is threatened. A child that sees a parent/parents become out-of-control due to emotional dysregulation or communication deficits may question their own physical safety. As was stated in the literature review, physical child abuse is higher in violent couple relationships (Edleson, 1999, Hamby, Finkelhor, Turner \& Omrod, 2010, Moylan et al, 2010, Rizo, Macy Ermentrout \& Johns, 2011; Bowker, 1983; McKibbon, Devo \& Newberger, 1989; Straus \& Gelles, 1990). Johnson (2006) also found that SV has a higher rate of mutual violence in the couple relationship, which could lead a child to wonder, "who is in control here?" With both parents/adults losing control, a child may also turn to self-reliance or externalizing behavior problems that may impact the parentchild relationship adversely. Although those in the SV group reported lower parent-child relationship scores than the $\mathrm{NV}$ group, the post hoc analysis showed no significant differences between SV \& NV in family cohesion or child well-being. This suggests that the elements of control associated with CCV make more of a difference in family cohesion and child well-being than physical violence alone.

In summary the $\mathrm{CCV}$ group reported the lowest scores for all three outcomes and was significantly worse than both the SV \& NV groups in post hoc analysis. The SV group reported significantly lower scores on the parent-child relationship than the NV 
group but was not significantly different from the NV group in family cohesion or child well-being.

\section{Impact of Relationship Education on Key Outcomes of Family Cohesion, Parent- \\ Child Relationship and Child Well-being by each Violence Type}

Family Cohesion. Unlike the baseline results for each group, each violence group benefitted differently from the Within My Reach treatment in family cohesion, the parent-child relationship and child well-being. Overall, in family cohesion there was not a significant main effect of time, showing that when the three groups were combined, the scores stayed relatively the same from pre to post to 6-months post. There was a significant main effect of group for family cohesion, meaning that each group reacted to the intervention significantly differently. The CCV group steadily increased throughout the three time periods showing that the intervention did raise family cohesion from baseline to 6-mos post. Family cohesion for Situational Violence surprisingly decreased, although not significantly from pre to post to 6-mos post. Those in the No Violence group scored higher in family cohesion initially and then, like the SV group had a sharp decline from pre to post intervention test. The data then went slightly up at 6-months post, which is still lower than the baseline measure. The decrease from pre-to-post may be due to inflation of scores for family cohesion prior to the program due to potential parental concerns about reporting to child protective agencies. The Neighborhood Places where the trainings took place over the period of 4 weeks did not house Child Protective Services (CPS), but were places that CPS referred families to for case management, WIC benefits and other services either during or post-investigation. As a student assisting these classes, some anecdotal collaborating information for this theory came from my 
experience with participants who would ask what access CPS had to the information provided in surveys, along with questions that implicated potential distrust of the research and course. Throughout the course, (even after the initial day) participants began to trust the program much more, and in fact, requested to take the program again after the program ended, sometimes calling years later. Unfortunately, this dissertation cannot determine how much initial distrust may have influenced these scores. Another possible explanation for the decline in scores is regression to the mean or greater awareness of parent-child dynamics.

The Bonferroni post hoc analysis showed a trend toward significance between Coercive Control Violence and Situational Violence, no significant difference between Situational Violence and No Violence and a significant difference between CCV and NV groups. These results implicate the impact of high-control on family cohesion over time or the impact that this particular intervention had on control within the family in regulating family cohesion. The reason why the intervention appears to have affected family cohesion in Coercive Control Violence Relationships more than Situational Violence is unknown, however, that it did affect CCV groups is significant for the research. Within the introduction it was discussed that perpetrator treatment that is mainly derived of concepts of power and control was only $5 \%$ more effective in reperpetration than no treatment (Babcock et al, 2004) potentially implicating the difficulty that interventionists have in treating control-based violence. Although a clear explanation of this cannot be derived, (this study did not collect who was the perpetrator or victim, and the literature is mixed in overall impact of interventions for victims, AND family cohesion in specifically high control-based violence has not been studied), this study does 
point to a positive change that this intervention had on family cohesion, which may give credence to the strength of this intervention for a difficult violence type to treat.

Parent-Child Relationship. Unlike the main effect of time for FACES, the results of the RM ANOVA for parent-child relationship showed a significant main effect of time indicating that when the three violence groups were combined, the scores were significantly different at the three points in time. There was an increase in parent-child relationship scores from pre to post and a decrease at 6 months post. This may indicate a regression to the mean or more realistic or accurate assessment at follow-up.

There was also a significant main effect of group, for parent-child relationship, with the highest scores reported by the NV group followed by SV and then CCV this is consistent with the results of question \#1. There is a significant interaction of group by time, with a different pattern of change for each group. The CCV group experienced an increase in the parent-child relationship from pre to immediate post and then scores stayed the same at six month follow-up. The SV group also reported an increase in the parent-child relationship from pre to immediate post and then a sharp decrease at 6month follow up. The NV group reported no change from pre to immediate post and a sharp decline at 6-months post. This pattern suggests that those in violent relationships benefit from Within My Reach in their parent-child relationship and for the CCV group these benefits are sustained over time. The sharp decline reported by the SV and NV groups may again reflect regression to the mean or a more accurate assessment at followup. Although the SV group may have experienced a true decline in the quality of the parent-child relationship, the fact that the NV group reported a similar decline suggests this may be an artifact of the research process. 
The Within My Reach intervention does place a great deal of emphasis on how a romantic relationship can affect children, not only in child well-being but with the parentchild relationship. Particularly, the two chapters called "Through a Child's Eyes" emphasize how relationship decision-making can affect children. It is interesting how it appears that SV and NV parent-child relationships seem to get worse over time which could be an influence of a re-definition of a healthy parent-child relationship. It could also be that Johnson reports is a source of Situational Violence that when communication techniques are introduced that they change the dynamic of the parent-child relationship, which at 6-months may be worse before they get better. If we had a large enough $\mathrm{n}$ for the one-year post intervention mark, it may be interesting to see if the parent-child relationship gets better over the course of one year. When we look at the multiple regression, we do see that reduction in violence does impact the parent-child relationship.

Bonferroni post hoc analysis show there was a significant difference between Coercive Control Violence and Situational Violence, significant differences between $\mathrm{CCV}$ and $\mathrm{NV}$ groups in parent-child relationship change over time and a significant trend in the difference between SV and NV. This is a similar trend to the family cohesion data which show the distance of greatest significance between the NV and CCV groups, and data pivoting right around .05 between CCV \& SV data, as well as SV \& NV data. This data, like the FACES data, seem to show that control has a significant impact on parenting

Child Well-being. Much like the Parent-Child Relationship, the results of the RM ANOVA for child well-being showed a significant main effect of time, indicating that scores on child well-being were significantly different at the three points in time. There 
was a decrease in the scores from pre to immediate post indicating an improvement in child well-being as higher scores reflect more emotional and behavioral problems. The six months follow up scores increased, approaching baseline levels while there may have been a brief improvement in child well-being, and this effect was gone by six month follow-up. Also, like the results for the parent-child relationship, there was also a significant main effect of group for parent-child relationship. The scores for the CCV and SV groups were very similar, with those in the CCV group reporting slightly more problems in child well-being. The scores for the NV group were lower than the two violence groups, indicating better child well-being. There was no significant interaction of group by time.

The similar findings for the CCV and SV groups in child well-being may mean that it is the dynamic of the physical violence that makes this difference in child wellbeing. The findings regarding changes over time suggest the WMR intervention was not powerful enough to produce lasting changes in child well-being. This explanation is also supported by results of the regression analysis below.

\section{The Potential Mediation of Change in Parental Communication, Relationship Satisfaction, Physical or Psychological Violence}

The results of the Multiple Regression Analysis found that there was overall significance in family cohesion and the parent-child relationship but no overall significance in child well-being. Individual mediators were examined for significance, and the change scores for parent-child relationship were significantly influenced by the reduction in violence and in reduction of controlling behaviors. No individual mediators were significant for the family cohesion regression model. 
Although overall significance was found in combining the two types of violence, it is important to consider the impact that a relatively small sample size could have had on the data. We were unable to separate the two types of violence which could have shown specifically what change components were most effective in increasing family cohesion, parent-child relationships and child well-being. It is important that we were able to find that the change in physical and psychological violence did have a significant impact on the parent-child relationship. This could be due to the child feeling more secure in either type of relationship, regardless of level of control, once physical and psychological violence was decreased. Elements of the curriculum that could have contributed to the reduction of physical and psychological violence include education on each type of violence, becoming familiar with red flags early in a relationship, increasing relationship decision-making and educating on consequences of violent relationships on children. This finding makes a significant contribution to the literature as we identified important change targets to improve parent-child outcomes in DV situations.

\section{Limitations}

Sampling Limitations. This study had a number of sampling limitations which included a disproportionate sample of women. After the removal of the control group and participants without children living in their home, the sample included 500 women and 85 men. This sampling limitation may have impacted the data potentially in the number of perpetrators vs victims that were included in the sample. As mentioned previously, one of the study limitations were that data was not collected that identified the participant as a victim or perpetrator of family violence, so we do not know if this gender distribution had the expected impact. Based on previous research (Johnson, 
2005; Graham-Kevan \& Archer, 2003) we know that in CCV there is typically a victim and a perpetrator, with the perpetrator being generally male and the victim female. Similar to what Johnson proposed occurred in the community, there was a as 2:1 ratio of SV to CCV in the sample therefore, it is quite possible based on this gender and violence type distribution that we had a mix of victims, perpetrators, and those in mutually violence relationships.

The sample size also played into the regression analysis even with the two violence types combined. That the other components in the regression were not significant is not surprising with the sample size, however, it would be interesting to run further studies with a larger sample size. Change in child well-being may have been more influenced by parental mental health, which was not measured (see limitations), by poverty, or by lack of family social support.

Another limitation is how generalizable this information may be for future interventions with men. Future research would need to evaluate if similar results were obtained for men only. It is also important to consider that men typically underreport physical violence, but may report more psychological violence from their partner. We also may have a disproportionate picture in our heads of how this intervention impacted family cohesion, parent-child relationship and child well-being if by self-report there is a gender bias within the scales. It may be important in the future to decipher whether there is a difference in how fathers rate family cohesion, the parent-child relationship and child well-being as opposed to mothers.

Response rate at follow-up. Another key sampling limitation was the response rate at follow-up which decreased substantially at 6 months. As a result, we were not 
able run certain tests with the limited six-month follow-up data included. This did not allow us to run statistical tests that may have given us further information, which will be discussed more.

Potential Participants with Children Excluded. A sampling limitation of this study may have inadvertently excluded participants with children due to their children not living in their home. The method for structuring the sample included asking participants how many of their children lived at home. Those who answered "0" were excluded from this particular study, as we were looking at the impact of children in the home on family cohesion, the parent-child relationship and child well-being. We may have not been able to capture parents that could have had children removed by CPS due to family violence, or parents that for financial or other reasons have their children live with family members. This could have impacted the data by limiting the scope of the study to parents with full-time custody of children. It could have also not been able to capture some of the more severe cases of household violence where a child was removed.

Shortcomings of Methods. The major limitations of the study methods include being unable to identify victim or perpetrator, potential self-report biases, exclusion of psychologically-abusive, controlling, non-physically violent relationships, and data analysis decisions.

Potential self-report bias. Another methodological limitation was potential selfreport bias, not only in the parenting scales but also in reporting extent of violence and controlling behaviors. Participants were given a thorough informed consent where they were told that their surveys would be kept confidential. However, due to the at-risk sample population, it is probable that many participants had previous CPS involvement 
either as an adult with their own children or as a child. As a result, there may have been distrust in revealing sensitive information to data collectors, even with the assurances of confidentiality. Participants may have rated their child's well-being, their relationship with their child or family cohesion as higher than how they actually felt. There could have been some bias in violence and controlling behavior reporting as well. One of the dynamics of Intimate Partner Violence (it has not been studied which type it may be true for) is family secrecy and keeping the secret about the violence and abuse at home (MacMillan et al., 2013). Participants with high controlling behaviors, especially, may have experienced feelings of anxiety, fear or disloyalty in committing to paper an assessment of the violence in their home.

Psychologically Violent Relationships without Physical Violence. The other limitation of this study is that inclusion in the violence clusters were first determined by the Conflict Tactics Scale measuring physical violence and then by the Controlling Behaviors Scale that measures various forms of control (psychological violence) so that psychological or sexual violence without the presence of physical violence was not analyzed (or in the case of sexual violence not reported). The study isolates first the participants that experienced physical violence and then divides those that experienced physical violence only from those that experienced physical violence and some attributes of psychological/emotional violence. This study does not account for those who did not experience physical violence as determined by the CTS but rated high on the Controlling Behaviors Scale, which would show a high degree of psychological/emotional violence. This was due to measurement decisions made at the start of the study (sexual violence not 
measured) and analytic procedures that were externally determined by those who have previously done research on the Johnson model (Graham-Kevan \& Archer, 2003). In some cases, a partner can enact many controlling behaviors that follow the pattern of intimate terrorism such as isolation, put downs, threatening violence, gas lighting, etc. however physical violence is never used. Although we did measure controlling behaviors through the Controlling Behaviors Scale, the groups were first clustered for physical violence and thus, those that had not had physical violence as a part of their experienced violence did not make it into the study. This is a definite limitation of the study as this type of psychological violence can lead to a greater likelihood of depression, anxiety, PTSD, and substance abuse in victims, much like victims of intimate terrorism with the physical violence component, with psychological violence being the strongest predictor of PTSD in women (Pico-Alfonso, 2004).

Data Analysis Decisions. Another limitation of the study was the statistical choices that we had to make due to sample size. Although we started with a sample size of 1,100 , once non-intervention participants without children were removed from the sample, we were left with a sample of 575 prior to cluster grouping. To answer question 2, which tested the impact of the intervention on family cohesion, the parent-child relationship and child well-being, the original plan was to use a Repeated Measures MANOVA so we could more carefully study the interactional patterns and effects of all of the dependent variables within violence type. Unfortunately, we did not have the sample size for a large MANOVA and we needed to run each of the DVs in separate Repeated Measures ANOVAs. 
Another testing choice that had to be made due to sample size was determining the potential mediators in the Multiple Regression. Structural Equation Modeling was originally considered but due to the sample size of the clusters, we were unable to do SEM. Next, separate regression analysis was planned for each violence type, but unfortunately, with the inclusion of the four change scores, change in communication, parental relationship, physical violence and controlling behaviors, each cluster $n$ was between 20-30 participants. The decision was made to combine Coercive Control Violence and Situational Violence to have a larger number of participants for the regression. Although we could not answer questions about unique predictors of outcomes for each group, we could answer questions about predictors of outcomes for all those who experienced IPV (CV \& SV). Unfortunately, the sample size was still small, and while we found overall significance in models for family cohesion and the parentchild relationship, as well as individual predictors parent-child relationship (change in physical violence and controlling behaviors), more study with a larger sample size is needed to identify other potential mediators. Significance was not obtained the overall model or individual predictors with child well-being, and it is unclear whether this is because of a low sample-size or due to other untested variables. Given the other findings on child well-being, it is likely there are other variables that should be included in future research.

Threats to Validity. Campbell and Stanley (1963) identified five threats to internal validity, history, maturation, testing, regression and mortality that will be evaluated within the context of the study. The first threat, history, could have been impacted as it lasted approximately a year between 2005-2010. The economic recession of 2008 could 
have had some implications for some participants which may have caused housing and financial instability that may have had an effect on child well-being, the parent-child relationship, and family cohesion. There may have also been an effect on physical or psychological violence in the family as well. Due to the study being longitudinal, maturation may have had an effect on child well-being, as the children may have done better on their own. The threat of testing may have been a factor, as the results of the immediate post test showed a decline in outcomes, which may reflect greater awareness of relationship problems as a result of both the intervention and completing the survey multiple times. This could have been why participants rated the parent-child relationship as more detrimental at immediate post. Regression to the mean may be reflected at 6month data collection point. This may explain why the scores of the NV group regress to the mean at 6 month follow up. The threat of mortality did occur, as we did lose a lot of participants at six months, which limited our ability to run some of the statistical tests mentioned earlier in this section.

\section{Future Research}

Based on the study findings, future research could be in the following areas: further definition and exploratory research into the behavioral nature of these two types of violence, the impact of findings on other theoretical approaches, and the impact of this knowledge on future treatment and practice.

Further Definition and Exploratory Research. Further research is needed in defining the different behavioral patterns of the two types of violence, especially in the realm of children and families. From the study, we know that Coercive Control has more of an impact on family cohesion, the parent-child relationship and child well-being than 
on Situational Violent relationships, but it is unknown exactly why. While this study looked at potential mediators of the change scores across both groups post-intervention, future research could look at how the contributing factors parental communication, couple relationship quality, physical violence and controlling behaviors differentially impact child-related outcomes for each group separately. As was discussed in the limitations, with the sample size becoming so small, future research with larger samples is needed to explore and confirm mediators for each type of violence post-intervention. Knowing how these mediators affect each type of violence could help drive future intervention research, and create specific relationship education curriculum targeted at reducing specific harmful effects of Coercive Control Violence and Situational Violence.

The types of violence were also impacted by the healthy relationship curriculum differently, and further exploratory research is needed to determine the potential reasons behind the differing interactions. Research on effective curriculum components of Within My Reach may be helpful to determining the most important elements for each type of violence. Future research could "dismantle" the curriculum to identify which components of Within My Reach have the greatest impact on each group. Similar "dismantling" research has shown the importance of communication skills in the training (Owen, Manthos, \& Quirk, 2013) but this procedure could be applied to the violence groups to determine which components are most important.

Another area of exploratory research is how controlling behaviors and psychological violence without the presence of physical violence may affect victims, children and families. A further study looking at this data and extrapolating a fourth group from the No Violence group of those that scored high on the Controlling 
Behaviors Scale may show differences in family cohesion, parent-child relationship and child well-being. To date, research has not been done in this area, and it is not a Johnson sub-type. Studies on how purely psychological violence influences the victim and then in turn the parent-child relationship would add to the knowledge of these violence groups converge or differentiate (Coker et.al., 2002).

Theoretical Approaches. Future research is also needed on how other theoretical approaches factor into violence-based control, in particular attachment theory and psychodynamic theory. From this study, we know that the parent-child relationship is significantly more adversely affected by Coercive Control Violence, however, we do not know the longitudinal effects of the violence on the child's attachment to their parent/s. Future research is needed on whether the two types of violence influence attachment differently and what the differing effects may be.

The role of attachment in the intergenerational transmission of violence in relation to the effect on attachment may also be an area of research. We know from the literature that the likelihood of becoming a victim or perpetrator of relational violence is higher in child witnesses of parental violence and it would be advantageous to study attachment is a common factor. Understanding if Coercive Control Violence increases the likelihood for future violent relationships in child witnesses more than Situational Violence may also be important.

It is also unknown what influenced the improvement of the child well-being the Within My Reach intervention. In the Multiple Regression, none of the four mediators individually, or as a whole, indicated significance. It could have been the low sample 
size, or it could be that more research is necessary in understanding other mediators within the intervention that may have contributed to the improvement in child well-being. Understanding the influence of parental mental health and substance abuse on the two types of violence is also an area of future research. In this study, we collected information regarding whether the participant had accessed mental health services or not, however, we did not utilize any instrumentation to assess for participant mental health. Gathering this data along with whether the participant identified as a victim or perpetrator (or both) would give us an indication of how prevalent mental health issues are in each type of violence. Also including in future research a measure of childhood mental health with a measure of adult mental health may give indication to influence to weight that violence or parental mental health issues may have on the child's mental health.

Future treatment and practice. Additional research on how type of violence impacts future treatment and practice could influence programming, curriculum formation, clinical practice, and policy decisions. While possible curriculum components that may be related to outcomes were hypothesized, more research is needed to explore and confirm which parts of the curriculum influenced each type of violence more effectively. This information could influence the creation of curriculum that specifically targets violence type or the creation of curriculum that encompasses effective factors for both types of violence.

Another area of future research is targeting treatment for violence type at the perpetrator, victim and family level. Determining type of violence prior to treatment could be influential in grouping perpetrators appropriately to specified curriculum for their violence type. Studying the impact of a specified treatment on a group of all 
Coercive Control perpetrators or Situational Violence perpetrator is an area that is necessary to see if that curriculum is more or less effective. Future research could also be done to evaluate the court's ability to differentiate by type and write appropriate orders to intervention program.

Future research is necessary as well on the impact of training therapists and counselors on the differences of Coercive Control Violence and Situational Violence, and how those two may be treated differently in practice. The effectiveness of clinical treatment with victims using violence-type is an area that could be studied including specific treatment models and the role of specifying violence type and customizing treatment in promoting the therapeutic alliance.

\section{Implications of Study: Policy and Practice}

This study may have implications for policy and practice moving forward. In conjunction with the study findings that there are significant baseline differences between the two types of violence in three other outcomes (family cohesion, parent-child relationship and child-well-being) adds to the prior knowledge that these types of violence behave in significantly separate ways. Implications for policy-making and practice in lieu of this knowledge will be explored in this section. The study findings that the two types of violence react differently to a healthy relationship intervention, also has policy and practice implications that will be explored as well.

Policy Implications. In this section, policy implications that will be discussed include court-ordered perpetrator treatment, consideration of different types of violence in CPS cases, as well as funding for programs that treat different types of violence and implications for first responders to IPV. 
Court-Ordered Treatment of Perpetrators. One of the main areas of future research of interest is identifying violence type at the legal level, in court-mandated perpetrator treatment programs through pre-screening. Research on appropriate grouping by violence type and the impact that this may have on the effectiveness of treatment is an area of future research. Future research is needed in the court whether this may make a difference in improving outcomes for batterer treatment.

Policy throughout many states includes court-ordered treatment for perpetrators of physical abuse against an intimate partner. As stated in the introduction, there have been disappointing outcomes related to recidivism of violence with perpetrators that have been through batterers' intervention programs (Babcock et al., 2006). The research indicates that while other outcomes such as adhering to the group or acknowledgement of abuse may occur with perpetrators mandated to treatment, the recidivism rate is very high. The evidence may imply that one of the contributing factors for the unsuccessful outcomes may be that the wrong violence type is being addressed in treatment with the individual. The data analyzed in this and previous studies (Antle et al., 2011) suggest that there was a reduction of violence by violence type and that the violence type data interacted differently with the healthy relationship intervention. Acknowledging the impact that both types of violence, but especially Coercive Control Violence, has on child well-being and family dynamics implicates the necessity of creating programs that treat the violence types using typology-appropriate methods, for the reduction of violence, but also for the impact on the entire family unit. The policy implication to be considered in courtmandated treatment for perpetrators is the potential for perpetrators to be assigned to a group that treats their specific type of violence. 
Mandated Reporting Implications. Further, policy on mandated reporting and treatment should be considered in light of the research. Nationally, each state has their own policy of mandated reporting which may differentiate mandated reporting for married couples only, couples with children, heterosexual couples only, or couples that are sharing a residence only. In Kentucky, the mandated reporting is necessary in any married couple experiencing physical Intimate Partner Violence. Some states also have mandated treatment for victims, that they receive therapy and psychoeducation on Intimate Partner Violence. Kentucky does not have this statute but does offer IPV services to victims if they choose. Considering type of violence may be advantageous for policy-makers in directing clients to services that specifically target their type of violence. Previous evidence (Antle et al, 2011) shows that approximately $15 \%$ of participants who took the Within My Reach class left their relationships, with the majority of those relationships rating as highly physically and psychologically violent. However, even when participants stayed in the violent relationships, significantly Coercive Control Violence Relationships, the relationships improved and violence lessened. For those states with Mandatory Treatment programs for victims, using a curriculum that framed learning positively such as moving towards having a healthy relationship rather than exiting an unhealthy relationship may have more positive outcomes for victims. The policy implication for these findings may be that in knowing that this program is effective in reducing family violence, and that it does have an effect on family cohesion, the parent-child relationship and child well-being, that it may be an effective program to use with victims as they are offered services. 
Child Protective Services Implications. Further policy implications for victims include potential reform for Child Protective Services (CPS) policies and governmental laws regarding protection of children inside homes of Intimate Partner Violence. The literature review spoke to the history of victim-blame, in the form of identifying mothers as perpetrators of neglect and placing the responsibility on them to end the relationship, removing the abuser from the home and maintaining safety of children in the process.

Due to the known detriments that witnessing violence has on a child, the victim is given a choice between moving out of the home with her child/ren or being charged with neglect and having her children placed in foster care. We need to be mindful of our systematic response as a society due to the consequences of IPV, because some violence is more dangerous than others, although both types have been shown to be dangerous and should be taken seriously. Ethically we have an obligation to protect the vulnerable which includes the children, but we also need to consider what, in the context of violence, may be the best protection for children within the specific relationship dynamics of each type of violence.

More knowledge about the effects of specifically SV on children's well-being may have policy implications for this CPS policy. If the relationship has low to no control and there is no clear victim or perpetrator this may have differing implications on policy than if a relationship is high-control, and the victim fears for her safety and the safety of her children if the direction of the perpetrator is not heeded. There also may be implications in the types of interventions that CPS implements to help family stability based on violence type. Implications for treatment which is discussed below may include more family and systemic treatment for families. 
Funding Implications. The final policy implication is how funding for programs that treat different types of violence may be impacted. Currently, funding mainly addresses physical violence in the family, regardless of violence type, with a heavy emphasis on the Duluth Model of violence. Gottman et al (2013) and Antle et al (2011) have conducted federally funded research using programs that acknowledge the types of violence, most programs that are federally funded do not make these distinctions. There is strong evidence from the literature that these two types of violence behave very differently, and while much funding from federal, state and private foundations go into addressing the social issue of IPV as a whole, evidence from the research suggests that in educating treatment providers and providing treatment that addresses each type of violence as very different types of family violence, we could have a greater impact on preventing and treating IPV. Funding could potentially go further if addressing each type according to their relationship dynamics.

Implications for First Responders. Knowledge of the relationship dynamics as each type of violence also may impact the way that first responders address crises situations that may influence outcomes of safety. As discussed in the literature review, $\mathrm{CCV}$ has a greater lethality, and due to issues of perpetrator control, a victim leaving an IPV relationship is the time of the greatest danger. Knowledge of how the types of violence influence relationship and interpersonal dynamics could help the responder assess the situation more appropriately to violence type. Assessing for power and control dynamics may influence the decision to interview the person who made the crisis call separately or in front of a potential perpetrator. It may also, in the case of Situational 
Violence where there may not be a clear perpetrator, influence who the officer arrests for perpetration of IPV.

A paramedic trained in violence types may also have a different approach to interviewing patients who have been in a domestic altercation. Assessing for high control within the relationship may change the policies and procedures on who is allowed in the ambulance, who is giving corroborating information to paramedics and what information the paramedics pass on for future patient care. Evidence-based practice suggests that a positive domestic violence screen predicts future violence, and when the screen is done in a primary care setting, more patients disclose IPV and are able to be directed to helpful services (Houry et al, 2004). Training primary-care physicians on screening and recognizing the signs of IPV by violence type could influence the type of care that patients receive. Implementing policies on partner access to medical records, even with patient permission, on specific IPV related questions (such as a positive screen for IPV) may be more important in relationships with CCV than SV. A perpetrator, out of need for power and control, may have mandated that the victim give them access to medical records. HIPPA guidelines cannot protect against the release of information that the patient has given permission for, and information that could be dangerous for the victim may be contained within that record.

Overall, there are policy implications on many levels of governing bodies, both private and public that could be explored further with the addition of further research on the impact of each violence type. There are also practice implications that will be discussed below. 
Practice Implications. Following this study, we now know more about the differences of Coercive Control Violence and Situational Violence and how they impact family cohesion, parent-child relationship and child well-being. We also know that the Within My Reach intervention impacted each group differently, with the impact being greatest with the Coercive Control Violent groups. Practice implications in the context of the research results may include relationship education for children and families, a broader definition of family violence, teaching violence types to students and practitioners, screening for type of violence, effective treatment for each type of violence, and relationship education for adults to benefit dependents.

Relationship Education for Children and Families. The data in this study indicated the overall positive impact that Relationship Education had on children and family dynamics, especially in Coercive Control Violence, even with typically only one member of the family in attendance. Practice implications may involve inclusion of healthy relationship trainings with families experiencing violence at the community level as an alternative to batterer treatment or victim education. Overall the Within My Reach program shows effectiveness in increasing family cohesion the parent-child relationship and child well-being, but we do know that WMR affects those in CCV relationships significantly more. This may be due to the theoretical approach of the Within My Reach program which is strengths-based and may empower families to make their relationships healthier rather than stop unhealthy behaviors without having indication of how to change them.

A healthy relationship program for children of families that have been impacted by IPV may also help mitigate the harmful effects of future relationship violence for 
children. Distinguishing between types of violence in an age-appropriate way for children may include topics such as healthy communication, recognizing harmful power and control dynamics (jealousy and possessiveness is a red flag rather than a natural part of a relationship) and the basics of what a healthy relationship is and is not.

Knowing that WMR improved child well-being could have implications for using Relationship Education with adults. Relationship education for adults to target child outcomes is an innovative approach to improving child well-being, as it intervenes at the couple relationship level, with trickle-down effects to the child and the parent-child relationship. Teaching healthy resolution skills to parents can also impact the relationship dynamics in the family. Those skills can be applied to the parent-child relationship and can be modeled for the child which may have positive future outcomes for childhood communication development.

Broader Definition of Family Violence. Although the definition of family violence has been through several iterations over the years, this evidence has practice implications for a broader definition of family violence. The evidence suggests that high control has a different effect than low control on entire family, in particular with children. Tailoring definition of Family Violence by violence subtypes may increase the availability of helpful treatment modalities to victims and families. It may also increase the availability of programs specified to violence type.

Teaching to Students and Practitioners. Another practice implication is the impact of educating future social work students and practitioners in the field on the types of violence. In giving students and practitioner's knowledge of these two types, they can implement this knowledge into their practice to be able to better recognize types of 
family violence in clients, and apply treatment strategies that may be more applicable to the type of violence experienced by their clients. Students entering macro practice may be able to advocate for policies and practices that address the two forms of violence more thoroughly. The knowledge that Within My Reach does help family cohesion, the parent-child relationship and child well-being may also have teaching implications, in that future teachers and practitioners can design relationship education programs specifically designed to address each type of program.

Screening for Type of Violence. Screening for type of violence has implications at the clinical and social level. As mentioned in the policy implications, doctors who screen for violence are better able to help their patients receive care that targets IPV. The additional element for screening for type of violence may help triage patients to appropriate services and assess for risk level. Therapists and counselors may also screen for type of violence upon inauguration of services which can help them given more tailored treatment for type of violence and initiate other care coordination that may increase the client's safety. There is also implications for child well-being, in that in screening for violence type, the service provider is able to help the child through deciphering type of violence that the parent's may be experiencing, thus, in treating the system are able to treat the child.

At the judicial level, as was discussed in the policy implications, screening the perpetrator for type of violence may increase likelihood for the perpetrator to receive appropriate treatment for the type of violence perpetrated. Screening for direction of perpetration may also have implications. The ambiguity of perpetrator and victim in Situational Violence may mean that both parties are mandated to treatment that is more 
specific to Situational Violence approaches. The practice implication in treatment may mean that fewer perpetrators of Situational Violence are included in classes that teach about Coercive Control and fewer CCV perpetrators are included in anger management classes; both of which may not be beneficial in reducing the recidivism of either type. Effective Treatment for Each Type of Violence. The biggest practice implication is that in recognizing violence type, there may be a greater chance that those experiencing relationship violence, including child witnesses, will receive effective treatment. It was found that those experiencing Coercive Couple Violence improved communication skills, lowered violence, improved the couple relationship and in the present study, had positive outcomes for family cohesion, the parent-child relationship and child well-being. The program was not as effective for those in Situational Violence relationships in improving communication skills and the couple relationship, family cohesion, parent-child relationship and child well-being. Acknowledging that control does make a difference in how these programs are received implies that a different treatment modality may need to be used for each violence type in order to increase efficacy. Knowing the influence that type of violence has on children, the impact of creating a children's program as a companion's program to Within My Reach that can teach children about healthy relationships with others specific to violence type, may be a key new area of research. 


\section{CHAPTER VI \\ SUMMARY AND CONCLUSIONS}

In summary, although much research has been done on Intimate Partner Violence, IPV is more complex than we have historically been taught. Family Cohesion, the parent-child relationship and child well-being are all affected by the presence of violence in the relationship, however, the type of violence and presence of high and low controlling behaviors within the couple relationship does make a difference. The sample post cluster-analysis centered around drastically different means without any presence of collinearity. Prior to the intervention, each type of violence was significantly different than the other in each of the three measured outcomes, with the exception of Situational Violence and No Violence on the measures of family cohesion and child well-being. Repeated Measures ANOVAs showed that each violence type interacted differently to the intervention at the three points in time in each of the three measures. And finally, the only individual significant variables found in the regression were change in physical violence and psychological violence in the parent-child relationship for both SV and CCV, which may be a further indicator of the importance of these variables. That the types of violence behave so differently in the data with these three outcomes and to the intervention speak to the complexity of the dynamics of Intimate Partner Violence. 
Although we know that the dynamics are complex, our ideas and models regarding treatment, etiology and dynamics of IPV are not based on this more complex view, and further understanding is needed to further address IPV as a social problem. The historically adverse treatment outcomes could be revised with these dynamics in mind, which could give innovative and successful outcomes to all members of an affected family. Policies that address these more complicated dynamics may simplify the progression towards recovery and create more preventative models. Finally, grassroots education of the community on creating healthy relationships and recognizing signs of multiple types of violence could have beneficial health and social outcomes.

The study accomplished two goals. The first goal accomplished was the understanding of the difference in types of violence for family cohesion, parent-child relationship and child well-being, as they had not been studied before by type. Coercive Control Violence significantly affects family cohesion, the parent-child relationship and child well-being more adversely than Situational Couple Violent or No Violence Relationships. At baseline for the parent-child relationship, Situational Violence and No Violence were significantly different with NV having better relationships, however in the other two outcomes, the two behaved the same at baseline. The difference between SV and $\mathrm{NV}$ is the presence of physical violence and some controlling behaviors. More research is necessary to know why these two groups were similar in the baseline measures. Knowing that those three outcomes are affected differently by types of violence enhances our understanding of the complexities of IPV in relation to children, families and family dynamics. 
The second goal accomplished was the understanding of the effect that treatment has by type of violence and what makes it effective. Prior studies have examined treatment for IPV, especially for perpetrators of IPV and found disappointing results. The Within My Reach treatment has been empirically tested and known to reduce violence for both types of violence, however, this finding shows the differential effects on childhood outcomes such as child well-being, family cohesion and the parent-child relationship, with $\mathrm{CCV}$ groups improving more. This is an exciting find, and speaks to the innovation of the curriculum, that it affects a violence type that has traditionally been difficult to treat. We hypothesize that this may be due to the emphasis on healthy relationships and strengths-based approach rather than perhaps more of a punitive approach that is found in some batterer's intervention programs. Also, that the treatment is effective and differentially effective by type of violence is exciting. The treatment was overall, more effective for $\mathrm{CCV}$ groups than SV groups, although there was a complex pattern of change for each type of violence that warrants future study. There was also a sustained benefit on each outcome for CCV groups. The models show that the biggest contributor to outcomes for violence families is reduction in physical and psychological violence, which has historically been an outcome that is difficult to change with an IPV intervention.

This study points to many areas of future research and significant policy and practice implications, but within the complex results it offers hope for families dealing with the daily intricacies of IPV, in giving them treatment models that are innovative and offer a better understanding of positive outcomes. 


\section{REFERENCES}

Adler-Baeder, F., Shirer, K., \& Bradford, A. (2007) What's love got to do with it? The role of healthy couple relationships and marriages in promoting child, family and community well-being. Forum for Family and Consumer Issues (12/1).

Aldarondo \& Sugarman (1996). Risk maker analysis of the cessation and persistence of wife assault. Journal of Consulting and Clinical Psychology, 26, 313-337.

Anda, R., Block, R., Felitti, V. (2003). Adverse childhood experiences study [Report]. Centers for Disease Control and Prevention, Kaiser Permanente's Health Appraisal Clinic in San Diego. Retrieved from http://www.cdc.gov/NCCDPHP/ACE/index.htm

Anderson, K.L. (2008). Is partner violence worse in the context of control? Journal of Marriage and Family, 70, 1157-1168.

Antle, B.F., Karam, E., Christensen, D.N., Barbee, A.P., Sar, B.K. (2011). An evaluation of healthy relationship education to reduce intimate partner violence. Journal of Family Social Work, 14:5, 387-406; DOI: 10.1080/10522158.2011.616482

Antle, B.F. \& Ness Roberts, E.E. (2012). Can You Hear Me?!?!: Differentiating Communication Patterns and Communication Changes in Intimate Terrorism and Situational Violence after a Relationship Education Class, International Violence, Abuse and Trauma Conference, Poster Presentation, San Diego, California, September 10-13.

Antle, B.F., Sar, B.K. \& Christensen, D.N., Karam, E., Ellers, F., Barbee, A., vanZyl, M. 
(2013). The impact of the within my reach relationship training on relationship skills and outcomes for low-income individuals. Journal of Marital and Family Therapy, 39(3), 346-357.

Augustyn, M., Parker, S., Groves, B., \& Zuckerman, B. (1995). Silent victims: Children who witness violence. Contemporary Pediatrics, 12(6), 35-87.

Babcock, J.C., Green, C.E. \& Robie, C. (2004). Does batterer's treatment work? A metaanalytic review of domestic violence treatment. Clinical Psychology Review, 23, 1023-1053.

Babcock, J.C., Waltz, J., Jacobsen, N.S., \& Gottman, J.M. (1993). Power and Violence: The relationship between communication patterns, power discrepancies, and domestic violence. Journal of Consulting and Clinical Psychology, 61(1), 40-50.

Bancroft, R.L., \& Silverman, J.G. (2011). The Batterer as Parent: Addressing the impact of domestic violence on family dynamics. Sage Series on Violence Against Women; Los Angeles: Sage Publications

Bancroft, Silverman, \& Ritchie (2012). The batterer as parent: Addressing the effect of domestic violence on family dynamics. Sage Publishing: Los Angeles. Retrieved from:

http://books.google.com/books?hl=en\&lr=\&id=SQSRO5HPyw0C\&oi=fnd\&pg=P $\underline{\text { R9\&dq }=\text { Intimate }+ \text { Violence }+ \text { Perpetrators }+ \text { as }+ \text { parents\&ots }=H N h x y E g W s \& s i g=Q}$ $\underline{\text { SFww2MUpMB0MIWQTlqZlYs3vFk\#v=onepage\&q=Intimate } \% 20 \text { Violence } \% 20}$ Perpetrators\%20as\%20parents\&f=false

Bandura, Albert (1963). Social learning and personality development. New York: Holt, Rinehart, and Winston. 
Bennett, L. \& Williams, O. (2001). Controversies and recent studies of batterer intervention program effectiveness. Harrisburg, PA: VAWnet: The National Online Resource Center on Violence Against Women; www.vawnet.org.

Bartholomew, K. \& Horowitz, L.M. (1991). Attachment styles among young adults: A test of a four-category model" Journal of Personality and Social Psychology, 52, $511-524$

Baumrind, D. (1966). The effect of authoritative parental control on child behavior. Child Development, 37(4), 887-907.

Bejerot (1974). The six day war in Stockholm, New Scientist, 61, no. 886, 496-486.

Bellow. S.M., Boris, N.W., Larrieu, J.A., Lewis, M.L., \& Eliot, A. (2005). Conceptual and clinical dilemmas in defining and assessing role reversal in young childcaregiver relationships. Journal of Emotional Abuse, 5(2-3), 43-66.

Bennett, L., \& O’Brien, P. (2007). Effects of coordinated services for drug-abusing women who are victims of Intimate Partner Violence. Violence Against Women, 13(4), 395-411.

Berlin, L.J., Appleyard, K., Dodge, K.A. (2011). Intergenerational continuity in child maltreatment: Mediating mechanisms and implications for prevention. Child Development, 82 (1); 162-176.

Black, V.D., Covington, C., Ondersman, S.J., Klee, B.K., Templin, T., Ager, J., Sokol, R. (2002) Violence exposure, trauma and IQ and/or reading deficits among urban children. Archives Pediatric Adolescent Medicine, 156(3); 280-285. Doi: 10.1001/archpedi.156.3.280.

Black D. S., Susman, S., \& Unger, J. B. (2010). A further look at the intergenerational 
transmission violence: Witnessing interparental violence in emerging adulthood. Journal of Interpersonal Violence, 25, 1022-1042.

doi: $10.1177 / 0886260509340539$

Bloom, S.L. (1999). Trauma theory abbreviated. Community Works, October 1999. Retrieved from: http://iheartenglish.pbworks.com/f/Trauma+Theory+Explained+14+pages.pdf Bogat, G.A., Levendosky, A.A., Theran, S., von Eye, A., \& Davidson, W.S. (2003). Predicting the psychosocial effects of interpersonal partner violence (IPV): How much does woman's history of IPV matter? Journal of Interpersonal Violence, $18,121-142$.

Bowker, L.H., Arbitell, M., McFerron, J.R. (1988). On the relationship between wife beating and child abuse. In: Feminist Perspectives on Wife Abuse, Yllo, K., \&

Bograd, M (eds). Newbury Park, CA: Sage Publications.

Bowker, L.H. (1983) Beating Wife-Beating. Lexington Books: New York

Bowlby (1969). Attachment and loss, Vol 1. New York: Basic Books.

Bowlby (1973). Attachment and loss, Vol 2. New York: Basic Books

Bowlby (1988). A secure base: Parent-child attachment and healthy human development. New York: Basic Books.

Bradley \& Gottman (2012). Reducing situational violence in low-income couples by fostering healthy relationships. Journal of Marital Family Therapy, 38(1), 187198.

Bradley, R.P., Fried, D.J. \& Gottman, J.M. (2011). Supporting healthy relationships in 
low-income, violent couples: Reducing conflict and strengthening relationship skills and satisfaction. Couple and Relationship Therapy, 10(2), 97-116.

Breiding, M.J., Smith, S.G, Basile, K.C., Walters, M.L., Chen, J., Merrick, M.T. (2011). Prevalence and characteristics of sexual violence, stalking, and intimate partner violence victimization. National Intimate Partner and Sexual Violence Survey, September 5, 2014 DOI: / 63(SS08);1-1

Brown, B.V. \& Bzostek, S. (2003, August). Violence in the lives of children. Child Trends DataBank: Cross Currents, 1, 1-13.

Buchbinder, E. \& Eisikovits, Z. (2004). Reporting bad results: The ethical responsibility of presenting abused women's parenting practices in a negative light. Child and Family Social Work, 9, 359-367.

Burke, J.G., Lee, L.C., O'Campo, P. (2008). An exploration of maternal intimate partner violence experiences and infant temperament. Maternal and Child Health Journal, 12, 172-179. DOI: 10.1007/s10995-007-0218-z.

Burman, B., Margolin, G. \& John, R.S. (1993). America's angriest home videos: Behavioral contingencies observed in home reenactments of marital conflict. Journal of Consulting and Clinical Psychology, 61(1), 28-39.

Buttell \& Pike, (2003). Investigating the differential effectiveness of a batterer treatment program on outcomes for African American and Caucasian batterers. Research on Social Work Practice, 13(6), 675-692.

Calef, V. \& Weinshel, E.M. (1981). Some clinical consequences of introjection; gaslighting. The Psychoanalytic Quarterly, 50(1), 44-66.

Capaldi, D. M., \& Clark, S. (1998). Prospective family predictors of aggression toward 
female partners for at-risk young men. Developmental Psychology, 34, 11751188. doi:10.1037/0012-1649.34.6.1175

Capaldi, D.M., Gorman-Smith, D., Florsheim, P. (Eds.) (2003). The development of aggression in young male/female couples. Adolescent Romantic Relations and Sexual Behavior: Theory, Research, and Practical Implications, pp.243-278. Xvii, 414pp. Mahwah, NJ: Lawrence Erlbaum Associates Publishers.

Cascardi, M. \& O'Leary, K.D. (1992). Co-occurrence and correlates of posttraumatic stress disorder and major depression in physically abused women. Journal of Family Violence, 7(4), 249-259.

Centers for Disease Control (CDC). (2010). National Intimate Partner and Sexual Violence Survey: 2010 Summary Report. National Center for Injury Prevention and Control, Division of Violence Prevention. Retrieved from: http://www.cdc.gov/violenceprevention/pdf/nisvs_report2010-a.pdf

Chase, N., Demming, M., \& Wells, M. (1998). Parentification, parental alcoholism, and academic status among young adults. The American Journal of Family Therapy, $25,105-114$

Cicchetti, D. \& Lynch, M. (1993). Toward an ecological/transactional model of community violence and child maltreatment: Consequences for children's development. Psychiatry: Interpersonal and Biological Processes; 56(1), 96-118.

Collins, A. \& van Dulman, M., Arnett, J.J (Ed.) \& Tanner, J.L. (2006). Friendships and romance in emerging adulthood: Assessing distinctiveness in close relationships. Emerging Adults in America: Coming of Age in the $21^{\text {st }}$ Century, (pp.219-234). Washington D.C.: American Psychological Association, xxii, 340pp. 
Conron, K.J. \& Beardslee, W. (2009). A longitudinal study of maternal depression and child maltreatment in a national sample of families investigated by child protective services. Archives Pediatric and Adolescent Medicine, 163(10), 922930.

Corcoran, K. \& Fischer, J. (2013). Controlling behaviors scale. Measures for Clinical Practice and Research, Volume 1: Couples, Families and Children. Oxford University Press; p. 85.

Cox, M.J., Paley, B. \& Harter, K. (2001). Intimate partner conflict and parent-child relationships. In: Grych, J., Fincham, F., editors. Child development and intimate partner conflict. New York: Cambridge University Press; 2001. Pp.249-272.

Cummings, E.M. \& Davis, P.T. (1994). Children and marital conflict: The impact of family dispute and resolution. New York: Guilford.

Cunningham, A., Jaffe, P.G., Baker, L., Dick, T., Malla, S., Mazaheri, N., Poisson, S. (1998). Theory-derived explanations of male violence against female partners: Literature update and related implications for treatment and evaluation. London Family Court Clinic (Pub), September 1998, 1-81.

Daisy, N.V., Hien, D.A. (2014). The role of dissociation in the cycle of violence. Journal of Family Violence, 29, 99-107. DOI.1007/s10896-013-9568-z.

Dayton, C.J., Levendosky, A.A., Davidson, W.S., Bogat, G.A. (2010). The child as held in the mind of the mother: The influence of prenatal maternal representations on parenting behaviors. Infant Mental Health Journal, 31(2), 220-241.

DeJonghe, E.S., von Eye, A., Bogat, A., Levendosky, A.A. (2011). Does witnessing intimate partner violence contribute to toddlers' internalizing and externalizing 
behaviors? Applied Developmental Science, 15(3), 129-139.

Derrington, R., Johnson, M.P., Menard, A., Ooms, T., \& Stanley, S. (2011). Making distinctions among different types of intimate partner violence: A preliminary guide.

Dobash, R. and Dobash, R. (1992). Women, violence and social change. New York: Routledge.

Dobash, R., and Dobash, R. (2001). Violence against women: A review of recent angloamerican research. Journal of Conflict and Violence Research, 3(2), 5-22.

Domenech Rodriguez, M.M., Donovick, M.R. Crowley, S.L. (2009). Parenting styles in a cultural context: Observations of "Protective parenting" in first-generation Latinos. Family Process, 48(2), 195-210.

Downey \& Coyne (1990). Children of depressed parents: An integrative review. Psychological Bulletin, 108(1), 50-76.

Doumas, Margolin \& John (1994). Intergenerational transmission of aggression across three generations. Journal of Family Violence, 9(2), 157-175.

Ducharme, J.M., Atkinson, L. \& Poulton, L. (2000). Success-based, noncoercive treatment of oppositional behavior in children from violent homes. Journal of American Academy of Adolescent Psychiatry, 39(8), 95-1004.

Duluth DAIP (1984).

Duluth website (2014) Retrieved from: http://www.theduluthmodel.org/training/wheels.html Eckhardt, C.I., Murphy, C., Black, D., Suhr, L. (2006). Intervention programs for 
perpetrators of Intimate Partner Violence: Conclusions from a clinical research perspective. Public Health Report, 121(4), 369-381.

Edleson, J.L. (1999). The overlap between child maltreatment and women battering. Violence Against Women, 5(2), 134-154.

Edleson, J.L. \& Tolman, R.M. (1992). Intervention for men who batter: An ecological approach. Newbury Park: Sage Publications.

Ehrensaft, M.K., Cohen, P., Brown, J., Smailes, E., Chen, H., \& Johnson, J.G. (2003). Intergenerational transmission of partner violence: A 20-year prospective study. Journal of Consulting \& Clinical Psychology. 71(4), 741-753.

Einhorn, L., Williams, T., Stanley, S., Wunderlin, N., Markman, H., Eason, J. (2008). PREP inside and out: Marriage education for inmates. Family Process, 47(3), $373-356$

Ellis, D. \& Stuckless, N. (1996). Mediating and negotiating marital conflicts. Thousand Oaks, CA: Sage Publications, Inc.

Ernst, A., Weiss, S.J., Enright-Smith, S., Byrd, E.C. (2008). Perpetrators of intimate partner violence uses significantly more methamphetamine, cocaine, and alcohol than victims: A report by victims. American Journal of Emergency Medicine, 26(5), 592-596.

Fainsilber Katz, L., Hessler, D.M., Annest, A. (2007). Domestic violence, emotional competence and child adjustment. Social Development, 16(3), 513-538.

Fals-Stuart, W., Kashdan, T.B., O’Farrell, T.J., \& Birchler, G.R. (2001). Behavioral 
couples therapy for male substance-abusing patients: Effects on relationship adjustment and drug-using behavior. Journal of Consulting and Clinical Psychology, 1996(64), 959-972.

Feder, L. \& Wilson, D.B. (2005). A meta-analytic review of court-mandated batterer intervention programs: Can courts affect abusers' behavior? Journal of Experimental Criminology, 1, 239-232.

Feldman, C.M., \& Ridley, C.A. (2000). The role of conflict-based communication responses and outcomes in male domestic violence towards female partners. Journal of Social and Personal Relationships, 17, 552-573.

Fite, J. E., Bates, J. E., Holtzworth Munroe, A., Dodge, K. A., Nay, S. Y., \& Pettit, G. S. (2008). Social information processing mediates the intergenerational transmission of aggressiveness in romantic relationships. Journal of Family Psychology 22, 367-376. doi:10.1037/0893-3200.22.3.367

Foo, L., \& Margolin G. (1995). A multivariate investigation of dating aggression. Journal of Family Violence, 10, 351-377. doi:10.1007/BF02110711

Foshee, V. A., Bauman, K. E., \& Linder, G. F. (1999). Family violence and the perpetration of adolescent dating violence: Examining social learning and social control processes. Journal of Marriage and the Family, 61, 331-342. doi: $10.2307 / 353752$

Foshee, V. A., McNaughton Reyes, H. L., Ennett, S. T., Suchindran, C., Mathias, J. P., Karriker-Jaffe, K.J., Bauman, K.E., \& Benefield, T.S. (2011). Risk and protective factors distinguishing profiles of adolescent peer and dating violence perpetration. Journal of Adolescent Health, 48(4), 344-350. 
Gelfand \& Teti (1990). The effects of maternal depression on children. Clinical Psychology Review, 10, 329-353.

Gelles, R. (1975). "Violence and Pregnancy: A Note on the Extent of the Problem and Needed Services," The Family Co-ordinator, 24 (1975) 81-86.

Gerard, A. (1994). The Parent-child relationship inventory (PCRI) manual. Los Angeles: WMI

Gondolf, E.W. (1997). Batterer programs: What we know and need to know. Journal of Interpersonal Violence, 12, 83-98.

Gondolf, E.W. (2002). Theoretical and research support for the Duluth model: A reply to Dutton and Corvo. Aggression and Violent Behavior, 12(6), 644-657.

Gottman, J.M. (1993). The roles of conflict engagement, escalation and avoidance in marital interaction: A longitudinal view of five types of couples. Journal of Consulting and Clinical Psychology, 61(1), 6-15.

Gottman, J.M. (1979). Marital interaction. Experimental Investigations. New York: Academic Press.

Graham-Kevan, N. \& Archer, J. (2003). Intimate terrorism and common couple violence: A test of Johnson's prediction samples. Journal of Interpersonal Violence, 18, $1247-1270$.

Graham-Kevan \& Archer, J. (2008). Does controlling behavior predict physical aggression and violence to partners. Journal of Family Violence, 23, 539-548.

Graham-Bermann, S.A. \& Seng, J. (2005). Violence Exposure and Traumatic Stress Symptoms as Additional Predictors of Health Problems in High-Risk Children. Journal of Pediatrics, 146(3), 309-10 
Groban, M.S. (2005). The federal domestic violence laws and the enforcement of these laws. Minnesota Center Against Violence and Abuse. Retrieved from: http://www.mincava.umn.edu/documents/ffc/chapter5/chapter5.pdf

Grych, J.H., Wachsmuth-Schlaefer, T., Klockow, L.L. (2002). Interparental aggression and young children's representation of family relationships. Journal of Family Psychology, 16(5), 259-279.

Gustafasson, H.C., Cox, M.J. (2012). Relations among intimate partner violence, maternal depressive symptoms, and maternal parental behaviors. Journal of Marriage and Family, 74, 1005-1020.

Hahlweg, K. \& Markman, H.J., Thurmaier, F., Engl, J. \& Eckert,V. (1998). Prevention of marital distress: Results of a German prospective longitudinal study. Journal of Family Psychology, 12(4), 543-556.

Halford, Sanders \& Behrens (2001). Can skills training prevent relationship problems in at-risk couples? Four-year effects of a behavioral relationship education program. Journal of Family Psychology, 15(4), 750-768.

Hamby, S., Finkelhor, D., Turner, H., \& Omrod, R., (2010). The overlap of witnessing partner violence with child maltreatment and other victimizations in a nationally representative survey of youth. Child Abuse \& Neglect, 34, 734-741.

Hancock, T.U. \& Siu, K. (2009). A culturally sensitive intervention with domestically violent Latino immigrant men. Journal of Family Violence, 24(2), 123-132.

Hardesty, J. L., Crossman, K.A., Haselschwerdt, M.L., Raffaelli, M., Ogolsky, B.G. \& Johnson, M.P. (in press). Toward a standard approach to operationalizing coercive control and classifying violence types. 
Holden, G.W. (1998). Introduction: The development of research into another consequence of family violence. In G.W. Holden, R. Geffner \& E.N. Jouriles (Orgs.) Children exposed to marital violence: Theory, research and applied issues (pp.1-18). Washington: American Psychological Association.

Holden \& Richie (1991). Linking extreme marital discord, child rearing and child behavior problems: Evidence from battered women. Child Development, 62(2), 311-327.

Holtzworth-Monroe, A. \& Stuart, G.L. (1994). Typologies of male batterers: Three subtypes and the differences among them. Psychological Bulletin, 116(3), 476496.

Holtzworth-Monroe, A., Smutzler, N. \& Stuart, G.L. (1998). Demand and withdraw communication among couples experiencing husband violence. Journal of Consulting and Clinical Psychology, 66(5), 731-743.

Holtzworth-Monroe, A., Meehan JC, Herron K, Rehman U, Stuart GL (2000). Testing the Holtzworth-Munroe and Stuart (1994) batterer typology. Journal of Consulting and Clinical Psychology. 2000;68:1000-1019.

Holzworth-Monroe, A. et al. (2000). General and spouse specific anger and hostility in subtypes of martially violent and nonviolent men. Behavior Therapy, 31(4), 603630.

Holzworth-Monroe, A. \& Meehan, J.C. (2004). Typologies of men who are martially violence: Scientific and clinical applications. Journal of Interpersonal Violence, 19, 1369-1389.

Homans, G.C. (1958). Social behavior as exchange. American Journal of Sociology, 
63(6), 597-606.

Homans, George (1961). Social Behavior: Its Elementary Forms. New York: Harcourt Brace Jovanovich. p. 13.

Hooper, L.M. (2007). Expanding the discussion regarding parentification and its varied outcomes; Implications for mental health research and practice. Journal of Mental Health Counseling, 29(4), 322-337.

Hornung, C.A., McCullough, C., \& Sugimoto, T. (1981). Status relationships in marriage: Risk factors in spouse abuse. Journal of Marriage and Family, 43(3), 675-692.

Houskamp \& Foy (1991). The assessment of posttraumatic stress disorder in battered women. Journal of Interpersonal Violence, 6(3), 367-375.

Hyde-Nolan, M.E. \& Juliao, T. (2012). Theoretical basis for family violence. Family Violence: What Health Care Providers Need to Know. R. S. Fife \& S. Schrager (Eds.). Sudbury, MA: Jones \& Bartlett Learning, LLC.

Ireland, T.O. \& Smith, C.A. (2009). Living in partner-violent families: Developmental links to antisocial behavior and relationship violence. Journal of Youth and Adolescence, 38(3), 323-339.

Jacobson, N. \& Gottman, J. (1998). When men batter women: New insights into ending abusive relationships. New York, NY: Simon \& Schuster.

Jaffe, P.G., Lemon, N.K.D., Poisson, S.E. (2003). Child custody and domestic violence: A call for safety and accountability. Thousand Oaks, CA: Sage Publications, Inc. Jaffe, P.G., Johnston, J.R., Crooks, C.V., Bala, N. (2008). Custody disputes involving 
allegations of domestic violence: Toward a differentiated approach to parenting plans. Family Court Review, 46(3), 500-522.

Jaffe, K. J., ... Benefield, T. S. (2011). Risk and protective factors distinguishing profiles of adolescent peer and dating violence perpetration. Journal of Adolescent Health, 48, 344-350. doi:10.1016/j.jadohealth.2010.07.03

Jakubowsky, S.F., Milne, E.P., Brunner, H., Miller, R.B. (2004). A review of empirically supported marital enrichment programs. Family Relations, 53(5), 528-536.

Johnson, M.P. (1995). Patriarchal terrorism and common couple violence: Two forms of violence against women. Journal of Marriage and Family Therapy, 57(2), 283294.

Johnson, Michael P. (1996). Violence against women in the family: The United States and Vietnam. Pp. 287-296 in Kathleen Barry (ed.), Vietnam's Women in Transition. New York: St. Martin's Press.

Johnson, M.P. (Presentation, 1999). Two types of violence against women in the American family: Identifying patriarchal terrorism and common couple violence. National Council On Family Relations, Irvine CA, November 1999.

Johnson, M.P. \& Ferraro, K.J. (2000). Research on domestic violence in the 1990s: Making distinctions. Journal of Marriage and Family Therapy, 948-963.

Johnson, M.P. (2000a). Conflict and control: Symmetry and asymmetry in domestic violence. In Alan Booth, et al. (Eds.), Couples in Conflict, Hillsdale, NJ: Erlbaum Associates, pp.94-104.

Johnson, M.P. (2000b). Conflict and control: Symmetry and asymmetry in domestic 
violence. In Alan Booth, et al. (Eds.), Couples in Conflict, Hillsdale, NJ: Erlbaum Associates, pp.94-104.

Johnson, M.P. \& Leone, J.M. (2000). The differential effects of patriarchal terrorism and common couple violence: Findings from the National Violence against Women survey. Paper presented at the Tenth International Conference on Personal Relationships, Brisbane, Australia.

Johnson, M. P. (2003). Intimate violence and relationship health. In S. M. Jekielek, K. A. Moore, J. Carrano \& G. Matthews (Eds.), Conceptualizing and measuring "healthy marriages" for empirical research and evaluation studies:

Recommendation memos from experts in the field (pp. 185-193). Washington, DC: Child Trends.

Johnson, M.P. \& Leone, J.M. (2005). The differential effects of intimate terrorism and Situational Violence: Findings from the national violence against women survey. Journal of Family Issues, 26, 322-349.

Johnson, M.P. (2005a). Apples and oranges in child custody disputes: Intimate terrorism vs. Situational Violence. Journal of Child Custody, 2, 43-52.

Johnson, M.P. (2005b.) Domestic violence: It's not about gender—or is it? Journal of Marriage and Family Therapy, 67, 1126-1130.

Johnson, M.P. (2006). Conflict \& control: Gender symmetry and asymmetry in domestic violence. Violence Against Women, 12(11), 1003-1018

Johnson, M.P. (2007). Wingspread Conference.

Johnson, M.P. (2008). A typology of domestic violence: Intimate terrorism, violent resistance, and Situational Violence. Boston: Northeastern University Press. 
Johnson, M.P. (2009) Where do "Domestic Violence" statistics come from and why do they vary so much?. Brief prepared for conference, Toward a Common Understanding: Domestic Violence Typologies and Implications Conference, Warrington, VA, May 13-15.

Johnson, M.P. (2009) Differentiating among types of violence: Implications for healthy marriages. In Marriage \& Family: Perspectives and Complexities, Eds. Peters \& Dush. New York: Columbia University Press

Johnson, M.P. (2010). Types of domestic violence: Implications for policy. Presentation at New Directions Program February 24, 2010.

Johnson, M.P. (2010). Langhinrichsen-Rolling's confirmation of the feminist analysis of intimate partner violence: Comment on "controversies involving gender and intimate partner violence in the united states. Sex Roles, 62, 212-219.

Johnson, M.P. (2012). Types of domestic violence: Research evidence and implications. Women's Refuge Domestic Violence Conference. Blenheim, New Zealand. October, 2012.

Johnson, M.P. Leone, J.M., \& Yili Xu. (2014). Intimate terrorism and situational couple violence in general survey: Ex-spouses required. Violence against Women, 20, $186-207$.

Johnston \& Campbell (1993). Parent-child relationships in domestic violence families disputing custody. Family Court Review, 31(3), 282-298.

Jones, R. \& Wells, M. (1996). An empirical study of parentification and personality. The American Journal of Family Therapy, 24, 145-152.

Juodis, M., Sartzomski, A., Porter, S., Woodworth, M. (2014). A comparison of domestic 
and non-domestic homicides: Further evidence for distinct dynamics and heterogeneity of domestic homicide perpetrators. Journal of Family Violence, DOI 10:1007//s10896-014-9583-8

Jouriles, E. N., McDonald, R., Mueller, V., \& Grych, J. H. (2012). Youth experiences of family violence and teen dating violence perpetration: Cognitive and emotional mediators. Clinical Child \&Family Psychology Review, 15, 58-68. doi:10.1007/s10567-011-0102-7

Kaufman, J. \& Zigler, E. (1987). Do abused children become abusive parents? American Journal of Orthopsychiatry, 57(2), 186-192.

Kelly, J.B., Johnson, M.P. (2008). Differentiation among types of intimate partner violence: Research update and implications for interventions. Family Court Review, 46(3), 476-499.

Kelly, UA., Skelton, K., Patel, M., Bradley, B. (2011). More than military sexual trauma: Interpersonal violence, PTSD, and mental health in women veterans. Research in Nursing and Health, 34(6), 457-467.

Kemp, A., Green, B. L., Hovanitz, C., and Rawlings, E. I. (1995). Incidence and correlates of post-traumatic stress disorder in battered women: Shelter and community samples. Journal of Interpersonal Violence. 10: 43-55.

Kemp, A., Rawlings, E. I., and Green, B. L. (1991). Post-traumatic stress disorder (PTSD) in battered women: A shelter sample. Journal of. Trauma \& Stress 4: $137-148$.

Kernsmith, P. (2006). Gender differences in the impact of family of origin violence on perpetrators of domestic violence. Journal of Family Violence, 21(2), 163- 
171.

Kessler, R.C., Molnar, B.E., Feurer, I.D. \& Applebaum, M. (2001). Patterns and mental health predictors of domestic violence in the United States: Results from the national comorbidity survey. International Journal of Law and Psychiatry, 24(45), 487-508.

Kurdek, L.A., (1994). Areas of conflict for Gay, Lesbian, and Heterosexual Couples: What couples argue influences relationship satisfaction. Journal of Marriage and the Family, 56, 923-934.

Kwong, M.J., Bartholomew, K., (2003). The intergenerational transmission of relationship violence. Journal of Family Psychology, 17(3), 288-301.

Laird Statistics (2015). Two-way repeated measures ANOVA using SPSS Statistics. Retrieved from: https://statistics.laerd.com/spss-tutorials/two-way-repeatedmeasures-anova-using-spss-statistics.php

Lapierre, S. (2008). Mothering in the context of domestic violence: the pervasiveness of a deficit model of mothering. Child and Family Social Work, 13, 454-463.

Leonardo Buck, N.M., Leenaars, P.E.M., Gerardus Emmelkamp, P.M., Carel van Marie, H.J. (2014). Personality traits are related to intimate partner violence among securely attached individuals. Journal of Family Violence, DOI 10.1007/s10896014-9584-7.

Leschied, A.W., Chiodo, D., Whitehead, P.C., Hurley, D. (2005). The relationship between maternal depression and child outcomes in a child welfare sample: Implications for treatment and policy. Child and Family Social Work, 10(4), 281291. 
Levendosky, A.A., Bogat, G.A., Huth-Bocks, A.C., Rosenblum, K., von Eye, A. (2014). The effects of domestic violence on the stability of attachment from infancy to preschool. Journal of Clinical Child \& Adolescent Psychology, 40(3), 398-410.

Levendosky, A.A., Graham-Berman, S.A. (2000). Behavioral observations of parenting in battered women. Journal of Family Psychology, 14(1), 80-94.

Levendosky, A.A., Graham-Bermann, S.A. (1998). The moderating effects of parenting stress on children's adjustment of woman-abusing families, Journal of Interpersonal Violence, 13, 383-397.

Levenson, R. W. \& Gottman, J. M. (1985). Physiological and affective predictors of change in relationship satisfaction. Journal of Personality of Social Psychology, 49, 85-94.

Levondosky, A.A., Graham-Bermann, S.A. (2001). Parenting in battered women: The effects of domestic violence on women and their children. Journal of Family Violence, 16(2), 171-192.

Lovejoy, M.C., Gracyzk, P.A., O’Hare, E., \& Neumen, G. (2000). Maternal depression and parenting behavior: A meta-analytic review. Clinical Psychological Review, 20(5), 561-592.

Loue, S. (2001). The definition and epidemiology of Intimate Partner Violence. Intimate Partner Violence: Societal, Medical, Legal and Individual Responses.

Lyons-Ruth, K., Lyubchik, A., Wolfe, R., \& Bronfman, E. (2002). Parental depression and child attachment: Hostile and helpless profiles of parent and child behavior among families at risk. In S. H. Goodman \& I. H. Gotlib (Eds.), Children of 
depressed parents: Mechanisms of risk and implications for treatment. (pp. 89120). Washington, DC: American Psychological Association.

MacMillan, H.L., Wathen, C.N., Varcoe, C.M. (2013). Intimate partner violence in the family: Considerations for children's safety. Child Abuse \& Neglect, 37(12), $1186-1191$.

Magdol, L., Moffitt, T. E., Caspi, A., \& Silva, P. (1998). Developmental antecedents of partner abuse: A prospective-longitudinal study. Journal of Abnormal Psychology, 107 (3), 375-389.

Margolin, G., Gordis, E. B., Medina, A. M., \& Oliver, P. (2003). The co-occurrence of husband-to-wife aggression, family-of origin aggression, and child abuse potential in a community sample: Implications for parenting. Journal of Interpersonal Violence, 18, 413-440.

Markman, H.J., Floyd, F.J. Stanley, S.M., Storaasil, R.D. (1988). Prevention of marital distress: A longitudinal investigation. Journal of Consulting and Clinical Psychology, 56(2), 210-217.

Markman, H.J. \& Hahlweg, K. (1993). The prediction and prevention of marital distress: An international perspective. Clinical Psychology Review, 13(1), 29-43.

Markman, H. J., \& Rhoades, G. K. (2012). Relationship education research: Current s tatus and future directions. Journal of Marital and Family Therapy, 38, 169-200.

McCloskey, L.A., Figueredo, A.J., \& Koss, M.P. (1995). The effects of systemic family violence on children's mental health. Child Development, 66, 1239-1261.

McDonad, R., Jouriles, Ramisetty-Mikler (2006). Estimating the number of American 
children living in partner-violent families. Journal of Family Psychology 20(1): 137-142.

McFarlane J.M., Groff J.Y., O’Brien J.A., Watson K. (2006) Secondary prevention of intimate partner violence: a randomized controlled trial. Nursing Research, 55(1):52-61.

McKibben, L., DeVos, E., \& Newberger. E. (1989). Victimization of mothers of abused children. A controlled study. Pediatrics, 84, 531-535.

Miller, K.M., Orellana, E.R., Briggs, H.E., Quinn, A. (2014). Influence of caregiver substance dependence and serious mental illness on children's mental health: Moderating effects of social support. Child and Adolescent Social Work Journal, 31, 435-454. DOI: $10.1007 / \mathrm{s} 10560-014-0326-8$

Mitchell, K.J., Finkelhor, D., \& Wolak, J. (2001). Highlights of the youth internet safety survey. Juvenile Justice Fact Sheet FS200104 (pgs. 1-2). Washington, DC: US Government Printing Office.

Moylan, C. A., Herrenkohl, T. I., Sousa, C., Tajima, E. A., Herrenkohl, R. C., \& Russo, M. J. (2010). The effects of child abuse and exposure to domestic violence on adolescent internalizing and externalizing behavior problems. Journal of Family Violence, 25, 53-63. doi:10.1007/s10896-009-9269-9

Nabi, R.L., Horner, J.R. (2001). Victims with voices: How abused women conceptualize the problem of spousal abuse and implications for intervention and prevention. Journal of Family Violence, 16(3), 237-253.

National Center for Domestic Violence, Trauma and Mental Health (NCDVTMH). 
(2012). Retrieved from: http://www.nationalcenterdvtraumamh.org/wpcontent/uploads/2012/04/Substance-Use-Disorders.pdf

Noland, V.D., Liller, K.D., McDermott, R.J., Coulter, M.L. \& Seraphine, A.E. (2004). Is adolescent sibling violence a precursor to college dating violence? American Journal of Health Behaviors, 28, Supplement: 1:S, 13-23.

Noller, P. \& White, A. (1990). The validity of the Communication Patterns Questionnaire. Psychological Assessment: A Journal of Consulting and Clinical Psychology, Vol 2(4), Dec 1990, 478-482. doi: $\underline{10.1037 / 1040-3590.2 .4 .478}$

O'Hearn, H. G., \& Margolin, G. (2000). Men's attitudes condoning marital aggression: A moderator between family of origin abuse and aggression against female partners. Cognitive Therapy and Research, 24, 159-174. doi:10.1023/A:1005493908363

O’Leary, K.D., Heyman, R.E., \& Neidig, P.H. (2012). Treatment of wife abuse: A comparison of gender-specific and conjoint approaches. Behavior Therapy, 30, 475-505.

O’Leary, D., Vivian, D., \& Malone, J. (1992). Assessment of physical aggression against women in marriage: The need for multimodal assessment. Behavioral Assessment, 14, 5-14.

Olson, D.H., Protner, J. \& Bell, R.Q. (1982). FACES II: Family Adaptability and cohesion evaluation scales. Minnesota: Family Social Science, University of Minnesota.

Olson, D.H. (2011). FACES IV and the circumplex model: validation study. Journal of Marital and Family Therapy, 37(1): 64-80.

Owen, J., Antle, B., \& Barbee, A. P. (in press). Alliance and group cohesion in 
relationship education. Family Process.

Pan, H.S., Neidig, P.H., \& O’Leary, K.D. (1994). Predicting mild and severe husband-towife physical aggression. Journal of Consulting and Clinical Psychology, 62(5), 975-981.

Peled, E., Davidson-Arad, B. \& Perel, G. (2010). The mothering of women abused by their partner: An outcome evaluation of a group intervention. Research on Social Work Practice, 20(4), 2010.

Pence, E. \& Paymar, M. (1986). Power and Control: Tactics of men who batter. Duluth Minnesota Program Development, Inc.

Pence \& Paymar (1993). Education groups for men who batter: The Duluth model. New York: Springer.

Pianta, R.C. \& Egeland, B. (1990). Life stress and parenting outcomes in a disadvantaged sample: Results of the mother-child interaction project. Journal of Child Clinical Psychology, 1990; 19: 329-336.

Reitzel-Jaffe, D., \& Wolfe, D. A. (2001). Predictors of relationship abuse among young men. Journal of Interpersonal Violence, 16, 99-115. doi:10.1177/088626001016002001

Riggs, D.S., Caulfield, M.B. \& Street, A.E. (2000). Risk for domestic violence: Factors associated with perpetration and victimization. Journal of Clinical Psychology, 56(10), 1289-1316.

Riggs, D. S., \& O’Leary, K. D. (1996). Aggression between heterosexual dating partner: An examination of a causal model of courtship aggression. Journal of Interpersonal Violence, 11, 519-540. doi:10.1177/088626096011004005 
Rizo, C.F., Macy, R.J., Ermentrout, D.M., Johns, N.B. (2011). A review of family interventions for intimate partner violence with a child focus or child component. Aggression and Violent Behavior, 16, 144-166.

Roberts, Y.H., Campbell, C.A., Ferguson, M., Crusto, C.A. (2013). The Role of parenting stress in young children's mental health functioning after exposure to family violence. Journal of Traumatic Stress, 26, 605-612.

Rodriguez, M.M., Donovick, M.R., Crowley, S.L. (2009). Parenting styles in a cultural context: Observations of "protective parenting" in first-generation Latinos," Family Process, 48(2), 195-210.

Rosenbaum \& Leisring (2003). Beyond power and control: Towards an understanding of abusive men. Journal of Comparative Family Studies, 34(1), 7-22/

Rosenthal, J.A., Groze, V., Curiel, H. (1990). Race, social class \& special needs adoption. Social Work, 35(6), 532-539.

Russell, D., Springer, K.W., \& Greenfield, E.A. (2010). Witnessing domestic abuse in childhood as an independent risk factor for depressive symptoms in young adulthood. Child Abuse and Neglect, 34, 448-453 [Online]. DOI: 10.1016/j.chiabu.2009.10.004.

Roustit, C., Renahy, E., Guernec, G., Lesieur, S., Parizot, I. \& Chauvin, P. (2009) Exposure to Interparental Violence and Psychosocial Maladjustment in the Adult Life Course: Advocacy for early prevention. Journal of Epidemiology and Community Health, 63, 563-568. DOI:10.1136/jech.2008.077750

Scanzoni, J. (1979). Social processes and power in families. In W.R. Burr, R. Hill, F.J 
Nye, \& I.L. Reiss (Eds.), Contemporary theories about the family (Vol.1. pp.295316). New York: Free Press.

Schechter, Susan (1982). Women and male violence. Boston, MA: South End Press.

Schwartz, J.P., Hage, S.M., Bush, I., Key Burns, L. (2006). Unhealthy parenting and potential mediators as contributing factors to future intimate violence: A review of the literature. Trauma, Violence, \& Abuse, 7(3), 206-221.

Schwartz, M.D. \& DeKeseredy, W.S. (1997). Sexual assault on the college campus: The Role of male peer support.

Schweinle, W., Ickes, W., Rollings, K., Jacquot, C. (2010). Maritally aggressive men: Angry, egocentric, impulsive, and/or biased. Journal of Language and Social Psychology.

Shamai, M. \& Buchbinder, E. (2009). Control of the self: Partner-violent men's experienced of therapy. Journal of Interpersonal Violence, 25(7), 1338-1362.

Shephard, J.P. \& Rivara, F.P. (1993). Vulnerability, victims and violence. Journal of Accident and Emergency Medicine, 15(1): 39-45.

Silvern, L., Karyl, J., Waede, L. Hodges, W.F., Starek, J., Heidt, E., \& Min, K. (1995). Retrospective reports of parental partner abuse: Relationships to depression, trauma symptoms, and self-esteem among college students. Journal of Family Violence, 10(2), 177-202.

Snell, J.E., Rosenwald, R.J. \& Robey, A. (1964). The wifebeaters wife: A study of family interaction. Archives of General Psychiatry, 11(2): 107-112.

Snyder, D.K. \& Fruchtman, L.A. (1981). Differential patterns of wife abuse: A databased typology. Journal of Consulting and Clinical Psychology, 49(6): 878-85. 
Sousa, C., Herrenkohl, T.I., Moylan, C.A., Tajima, E.A., Klika, J.B., Herrenkohl, R.C., Russo, M.J. (2010). Journal of Interpersonal Violence, 26(1), 111-136.

Spanier, G. B. (1976). Measuring dyadic adjustment: New scales for assessing the quality of marriage and similar dyads. Journal of Marriage and the Family, 38, 15-28.

Srofe, A., Carlson, E., Levy, A., \& Egeland, B. (1999). Minnesota Longitudinal Study.

Stanley, S., \& Markman, H. J. (1996). National survey of couples relationships in the United States. Denver, CO: University of Denver.

Stanley, S. M., \& Markman, H. J. (1992). Assessing commitment in personal relationships. Journal of Marriage and Family, 54, 595-608.

Straus, M. A., Gelles, R. J., \& Smith, C. (1990). Physical violence in American families: Risk factors and adaptations to violence in 8,145 families. New Brunswick: Transaction Publishers.

Straus, M. A., Hamby, S. L., Buncy-McCoy, S.. \& Sugarman, D. B. (1996). The revised Conflict tactics scales (CTS2): Development and preliminary psychometric data. Journal of Family Issues, 17(3), 283-316.

Straus, M.A. (1992). Children as witnesses to marital violence: A risk factor for lifelong problems among a nationally representative sample of American men and women. Report of the Twenty-Third Ross Roundtable. Columbus, OH: Ross Laboratories. Stith et al (1993). A predictive model of male spousal violence. Journal of Family Violence, 8(2), 183-201.

Stith, S.M., Rosen, K.H., Middleton, K.A., Busch, A.L., Lundeberg, K., Carlson, R.P. (2000). The intergenerational transmission of spousal abuse: A meta-analysis. Journal of Marriage and Family Therapy, 62(3), 640-654. 
Stith, SM., Rosen, K.H. \& McCullum, E.E. (2007). Effectiveness of couples treatment for spouse abuse. Journal of Marital and Family Therapy, 29(3), 407-426.

Stith, S.M., Smith, D.B., Penn, C.E., Ward, D.B., Tritt, D. (2004). Intimate partner physical abuse perpetration and victimization risk factors: A meta-analytic review. Aggression and Violent Behavior, 10(1), 65-98.

doi:10.1016/j.avb.2003.09.001

Stith, S.M., Rosen., K.H., McCollum, E.E.,\& Thomsen, C. J. (2004). Treating intimate partner violence within intact couple relationships: Outcomes of multi-couple versus individual couple therapy. Journal of Marital and Family Therapy, 30, $305-318$.

Stith, S. M., McCollum, E. E., \& Rosen, K. H. (2011). Couples therapy for domestic violence: Finding safe solutions. Washington, DC: American Psychological Association.

Stith, S. M. \& McCollum, E. E. (2009). Couples treatment for physical and psychological aggression. In D.K. O’Leary \& E. M. Woodin. Understanding Psychological and Physical Aggression in Couples: Existing Evidence and Clinical Implications (pp.233-250).Washington, DC: American Psychological Association.

Stover, C.S. (2005). Domestic violence research: What we have learned and where do we go from here? Journal of Interpersonal Violence, 20(4), 448-454. doi: $10.1177 / 0886260504267755$

Sullivan, M., Egan, M., Gooch, M. (2004). Conjoint interventions for adult victims and children of domestic violence: A program evaluation. Research on Social Work Practice, 14, 163-170. 
Tjaden, P. \& Thonnes, N. (1998). Prevalence, incidence and consequences of violence against women: Findings from the national violence against women survey. National Institute of Justice Centers for Disease Control and Prevention Research Brief, November 1998, 1-16.

Tjaden, P. \& Thonnes, N. (1999). Full report of the prevalence, incidence, and consequences of violence against women: Findings from the national violence against women survey. U.S. Department of Justice, 1-71.

Van der Kolk, B.A. (1989). The compulsion to repeat the trauma: Re-enactment, revictimization and masochism. Psychiatric Clinics of North America, 12(2), 389411.

Van der Kolk, Bessel A; Pelcovitz, David; Roth, Susan H; Mandel, Francine S; McFarlane, Alexander Cowell; Herman, Judith Lewis. (1996). Dissociation, somatization, and affect dysregulation: the complexity of adaptation to trauma. American Journal of Psychiatry (ISSN: 0002-953X), v. 153, no. 7 Festschrift Supplement, pp. 83-93 (July 1996).

van der Kolk, B. A. (1994). The body keeps score: Memory and the evolving psychobiology of post-traumatic stress. Harvard Review Psychiatry,1 (5), 253-26

Van Widenfelt, B., Markman, H., Guerney, B., Behrens, B. \& Hosman, C. (1997). Primary prevention of relationship problems. W. K. Halford \& H. J. Markman (Eds.), Clinical Handbook of Marriage and Couple Interventions. Chichester: Wiley

Van Wormer \& Bednar (2002). Working with male batterers: A restorative strengths 
perspective. Families in Society: The Journal of Contemporary Social Services, 83(5), 557-565.

Vitanza, S., Vogel, L. C., M., \& Marshall, L. L. (1995). Distress and symptoms of posttraumatic stress disorder in abused women. Violence and Victims, 10(1), 2334.

Vivian, D. \& Malone, J. (1997). Relationship factors and depressive symptomology associated with mild and severe husband-to-wife physical aggression. Violence and victims, 12(1), 3-18.

Walsh, Z., Swogger, M.T., O’Conner, B.P., Chatev Schonbrun, Y., Shea, M.T., Stuart, G. (2010) Subtype of partner violence perpetrators among male and female psychiatric patients. Journal of Abnormal Psychology, 119(3), 563-574.

Warshaw, C., Sullivan, C.M., Rivera, E.A. (2013). A systematic review of traumafocused interventions for domestic violence survivors. National Center on Domestic Violence, Trauma \& Mental Health. Retrieved from: http://www.nationalcenterdvtraumamh.org/wpcontent/uploads/2013/03/NCDVTMH_EBPLitReview2013.pdf

Webster-Stratton, C. \& Hammond, M. (1988). Maternal depression and its relationship to life stress, perceptions of child behavior problems, parenting behavior and child conduct problems. Journal of Abnormal Child Psychology, 16(3), 299-315.

Whiting, J.B., Parker, T.G., Houghtaling, A.W. (2014). Explanations of a violent relationship: The male perpetrator's perspective. Journal of Family Violence, DOI $10.1007 / \mathrm{s} 10896-014-9582-9$

Williams, T. S., Connolly, J., Pepler, D., Craig, W., \& Laporte, L. (2008). Risk models of 
dating aggression across different adolescent relationships: A developmental psychopathology approach, Journal of Consulting and Clinical Psychology, 76, 622-632. doi:10.1037/0022-006X.76.4.622

Wolfe, D. A., Wekerle, C., Reitzel-Jaffe, D., \& Lefebvre L. (1998). Factors associated with abusive relationships among maltreated and nonmaltreated youth.

Development and Psychopathology, 10,61-85. doi:10.1017/S0954579498001345

WomenSafe (2011). Overview of historic laws that supported domestic violence.

WomenSafe.net. Retrieved from:

http://www.womensafe.net/home/index.php/domesticviolence/29-overview-ofhistorical-laws-that-supported-domestic-violence

Zaiontz, C. (2015). MANOVA assumptions. Real Statistics Using Excel. Retrieved from: www.real-statistics.com/multivariate 


\section{APPENDX 1}

Neighborhood Place Sites in Louisville

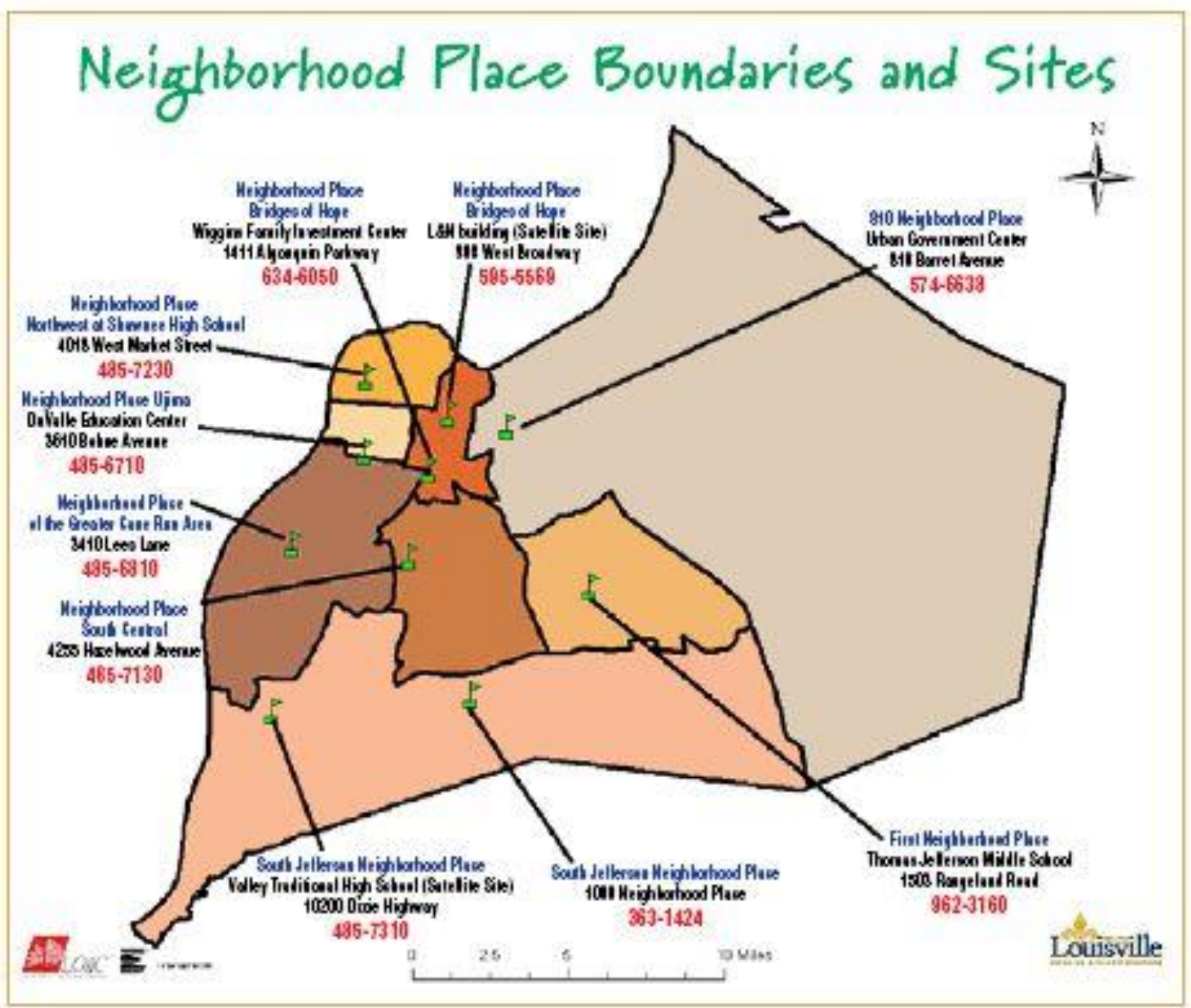


APPENDIX 2

\section{Survey Directions}

We are interested in how you and your romantic partner typically deal with problems in your relationship. If you do not currently have a romantic partner, please choose the most significant relationship you currently have (friend, family, etc.) You will consider that person and that relationship for all of the questions in the survey and she/he will be referred to as "partner".

Please check the type of relationship you have with the person you are rating:
girl/boyfriend
wife/husband
parent
friend
co-worker

$\square$ other (for example, an ex-girl/boyfriend or ex-spouse)

If other, please indicate the type of relationship

Is this the same person you referred to on the surveys you completed on the first day of the Within My Reach training?
$\square$ Yes
$\square$ No
$\square$ Don't remember
Didn't do surveys during training 


\section{APPENDIX 3}

Conflict Tactics Scale (CTS): To measure presence of physical violence

Directions: Here is a list of things you and your current or most recent romantic partner might have done when you had a conflict. Taking all disagreements into account, not just the most serious ones, indicate how often each of you did the following during the conflict: from Never (0) to Always (4).

1. threw something at the other one

2. pushed, grabbed, or shoved the other one

3. slapped the other one

4. kicked, bit, or hit with a fist

5. hit or tried to hit with something

6. beat up the other one

7. threatened with a weapon (e.g., a knife)

8. used a weapon (e.g. a knife)

\section{NEVER}

0

$\begin{array}{lllll}0 & 1 & 2 & 3 & 4\end{array}$

$\begin{array}{lllll}0 & 1 & 2 & 3 & 4\end{array}$

$\begin{array}{lllll}0 & 1 & 2 & 3 & 4\end{array}$

$\begin{array}{lllll}0 & 1 & 2 & 3 & 4\end{array}$

$\begin{array}{lllll}0 & 1 & 2 & 3 & 4\end{array}$




\section{APPENDIX 4}

\section{Directions: Answer these questions using the following scale: $0=$ Never to $4=$ Always}

\section{NEVER}

ALWAYS

1. Do you/your partner disapprove of the other $\quad \begin{array}{lllll}0 & 1 & 2 & 3\end{array}$ working or studying?

2. If yes, do you/your partner try and prevent or make difficult the other working or studying?

?

$0 \quad 1 \quad 2$

34

3. Do you/your partner feel it is necessary to have control of the other's money (e.g., wage, benefits)?
4. If yes, do you/your partner give the other an allowance $\quad \begin{array}{lllllll}0 & 1 & 2 & & 3 & 4\end{array}$ or require other to ask for money?

5. Do you/your partner have knowledge of the family income?

0

1

$0 \quad 1 \quad 2$

34
to do something to harm the other?

7. Do you/your partner ever threaten to leave the other and/or commit suicide?

8. Do you/your partner threaten to report the other to welfare?

$0 \quad 1-2$

3

$\begin{array}{llll}1 & 2 & 3 & 4\end{array}$

9. Do you/your partner encourage the other to do illegal things 0 he/she would not otherwise do?

10. Do you/your partner use looks, actions, and/or gestures to change the other's behavior?

11. If yes, do you/your partner make the other afraid when this is done?

12. Do you/your partner smash property when annoyed/angry?

0

NEVER

ALWAYS

(continued from previous page)

$\begin{array}{lllll}0 & 1 & 2 & 3 & 4\end{array}$

0

12

3

4

4

(1)

13. If yes, is it the other's property?

0

0

1

2

34
14. When angry, do you/your partner vent anger on household pets?

$\begin{array}{lllll}0 & 1 & 2 & 3 & 4\end{array}$


15. Do you/your partner put the other down when they

$0 \quad 1$

feel the other is getting "too big for their boots"?

16. If yes, did you/your partner put the other down in front of others (friends, family, children)?

$\begin{array}{lllll}0 & 1 & 2 & 3 & 4\end{array}$

17. Did you/your partner try to humiliate the other in front of others?

$\begin{array}{lllll}0 & 1 & 2 & 3 & 4\end{array}$

18. Did you/your partner tell the other that he/she was going crazy?

$\begin{array}{lllll}0 & 1 & 2 & 3 & 4\end{array}$

19. Did you/your partner call the other unpleasant names?

20. Did you/your partner restrict the amount of time the other spent with friends and/or family?

$\begin{array}{lllll}0 & 1 & 2 & 3 & 4 \\ 0 & 1 & 2 & 3 & 4 \\ 0 & & & & \end{array}$

21. If you/your partner went out, did the other want 0 to know where the other went and who the other spoke to?

22. Did you/your partner limit the other's activities outside the relationship?

$\begin{array}{lllll}0 & 1 & 2 & 3 & 4\end{array}$

23. Did you/your partner feel suspicious and 4 jealous of the other?

24. If yes, was this used as a reason to monitor and control the other's activities?

$\begin{array}{lllll}0 & 1 & 2 & 3 & 4\end{array}$


Directions: Please rate how often you use each of the following communication styles when arguing or disagreeing with your partner.

1. Launching personal attacks.

Never Rarely

$3^{\text {Sometimes }}$

Often

Always

5

2. Focusing on the problem at hand.

2

3

4

5

3. Remaining silent for long periods of time.

12

3

4

5

4. Not being willing to stick up for myself.

12

3

4

5

5. Exploding and getting out of 12

3

4

5 control

6. Sitting down and discussing differences constructively.

$1 \quad 2$

3

4

5

7. Reaching a limit, "shutting down," and refusing to talk any further.

8. Being too compliant.

12

3

4

5

9. Getting carried away and saying things that aren't really meant.

12

3

4

5

10. Finding alternatives that are acceptable to each of us.

12

23

4

5

11. Tuning the other person out.

1

2

3

4

5

12. Not defending my position.

12

3

4

5

13. Throwing insults and digs.

12

3

4

5

14. Negotiating and compromising.

12

3

4

5

15. Withdrawing, acting distant and not interested.

,, 12

3

4

5

16. Giving in with little attempt to present my side of the issue. 


\section{APPENDIX 5}

\section{Family Adaptability and Cohesion Scale (FACES)}

\section{Please use the following scale to answer the questions below:}

$1=$ Almost never

$2=$ Once in a while

3 = Sometimes

$4=$ Frequently

$5=$ Almost always

\section{Describe your family now:}

1. Family members ask each other for help.

2. We approve of each other's friends.

3. We like to do things with just our immediate family.

4. Family members feel closer to other family members than to people outside the family.

5. Family members like to spend free time with each other.

6. Family members feel very close to each other.

7. When our family gets together for activities, everybody is present.

8. We can easily think of things to do together as a family.

9. Family members consult other family members on their decisions.

10. Family togetherness is very important. 


\section{APPENDIX 6}

Parent-Child Relationship Inventory

DIRECTIONS: Please circle your response to each question below.

1. How well do you and your child get along?

Very well Fairly well Not so well Very poorly

2. How well does your child get along with your spouse/partner or significant other?
Very well Fairly well
Not so well
Very poorly

3. How would you rate the communication between you and your child?
Excellent Good
Fair
Poor

4. Do you feel close to your child?

Yes, very much $\quad$ Yes, for the most part $\quad$ Not sure $\quad$ No

5. Do you trust your child?

Yes, very much $\quad$ Yes, for the most part Not sure No

6. Do you feel respected by your child?

Yes, very much $\quad$ Yes, for the most part Not sure $\quad$ No 


\section{APPENDIX 6}

(PAGE 2)

7. When you think of your current experiences as the parent of this child, do you feel:

Use the scale below to CIRCLE the response for each item that best applies to you.

$\begin{array}{lcccc} & \text { Very } & \text { Somewhat } & \text { Only A Little } & \text { Not At All } \\ \text { Bothered or Upset? } & 4 & 3 & 2 & 1 \\ \begin{array}{l}\text { Frustrated? } \\ \text { Emotionally Worn } \\ \text { Out? }\end{array} & 4 & 3 & 2 & 1 \\ \text { Worried? } & 4 & 3 & 2 & 1 \\ \text { Tense? } & 4 & 3 & 2 & 1 \\ \text { Satisfied? } & 4 & 3 & 2 & 1 \\ \text { Successful? } & 4 & 3 & 2 & 1 \\ \text { Contented? } & 4 & 3 & 2 & 1 \\ \text { Unsure Of Yourself? } & 4 & 3 & 2 & 1\end{array}$




\section{APPENDIX 7}

Child Well-being Scale: Measures Child Problems

Directions: If you have more than one child, please choose the child you consider to be the most challenging to complete this scale.

\begin{tabular}{|l|l|l|l|}
\hline \multicolumn{2}{|l|}{} & \multicolumn{2}{l|}{$\begin{array}{l}\text { Please mark a or an } \\
\text { under the heading that best fits your } \\
\text { child. }\end{array}$} \\
\hline & NEVER & SOMETIMES & OFTEN \\
\hline 1. Fidgety, unable to sit still & & & \\
\hline 2. Feels sad, unhappy & & & \\
\hline 3. Daydreams too much & & & \\
\hline 4. Refuses to share & & & \\
\hline 5. Does not understand other people's feelings & & & \\
\hline 6. Feels hopeless & & & \\
\hline 7. Has trouble concentrating & & & \\
\hline 8. Fights with other children & & & \\
\hline 9. Is down on him or herself & & & \\
\hline 10. Blames others for his or her troubles & & & \\
\hline 11. Seems to be having less fun & & & \\
\hline 12. Does not listen to rules & & & \\
\hline 13. Acts as if driven by a motor & & & \\
\hline 14. Teases others & & & \\
\hline 15. Worries a lot & & & \\
\hline
\end{tabular}




\section{APPENDIX 8}

\section{Relationship Dynamics Scale (RDS)}

DIRECTIONS: Use the following 3 point scale to rate how often you and partner experience the following:

$$
1=\text { Almost never or Never } \quad 2=\text { Once in a while } \quad 3=\text { Frequently }
$$

1. 1233 Little arguments escalate into ugly fights with accusations, criticisms, name calling, or bringing up past hurts.

2. $123 \quad 3 \quad$ My partner criticizes or belittles my opinions, feelings, or desires.

3. $123 \quad 3 \quad$ My partner seems to view my words or actions more negatively than I mean them to be.

4. $12 \quad 3 \quad$ When we have a problem to solve, it is like we are on opposite teams.

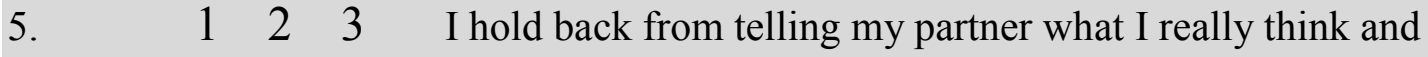
feel.

6. $123 \quad$ I feel lonely in this relationship.

7. 1253 When we argue, one of us withdraws..that is, doesn't want to talk about it anymore; or leaves the scene.

Circle your response using the same 3 point scale:

\section{1 (Almost never or Never), (Frequently)

8. Who tends to withdraw more when there is an argument?

$\begin{array}{llll}\text { YOU } & 1 & 2 & 3 \\ \text { YOUR PARTNER } & 1 & 2 & 3 \\ \text { BOTH } & 1 & 2 & 3 \\ \text { NEITHER } & 1 & 2 & 3\end{array}$




\section{Dyadic Adjustment Scale (DAS)}

\section{APPENDIX 9}

Please indicate below how much you agree or disagree with your partner on each of the following:

1. Philosophy of life

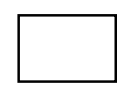

2. Aims, goals, and things believed important

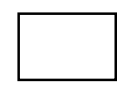

3. Amount of time spent together

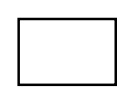

5

Always Agree
4

$\begin{array}{ll}\text { Almost } & \text { Occasionally } \\ \text { Always } & \text { Disagree } \\ \text { Agree } & \end{array}$

2

Frequently

Disagree
1

Almost

Always

Disagree
0

Always

Disagree

How often would you say the following events occur between you and your partner?

4. Have a stimulating exchange of ideas

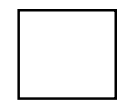

5. Calmly discuss something together

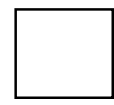

6. Work together on a project

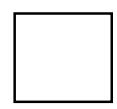

0

$$
1
$$

Less than

once a

month

2

3

4

5

Once or

twice a

month

Once or

Once a More often

twice a week

day

7. The dots below represent different degrees of happiness in your relationship. The middle point, "happy" represents the degree of happiness of most relationships. Please circle the dot which best describes the degree of happiness, all things considered, in your relationship.

\begin{tabular}{|c|c|c|c|c|c|c|}
\hline $\mathbf{0}$ & 1 & 2 & 3 & 4 & 5 & 6 \\
\hline$\bullet$ & $\bullet$ & $\bullet$ & $\bullet$ & $\bullet$ & $\bullet$ & $\bullet$ \\
\hline $\begin{array}{c}\text { Extremely } \\
\text { Unhappy }\end{array}$ & $\begin{array}{l}\text { Fairly } \\
\text { Unhappy }\end{array}$ & $\begin{array}{c}\text { A little } \\
\text { Unhappy }\end{array}$ & Нарру & $\begin{array}{l}\text { Very } \\
\text { Happy }\end{array}$ & $\begin{array}{c}\text { Extremely } \\
\text { Happy }\end{array}$ & Perfect \\
\hline
\end{tabular}


APPENDIX 10

DIRECTIONS: Please rate each item on this scale with1 meaning VERY UNLIKELY to happen to 9 meaning VERY LIKELY to happen.

\section{When an issue or problem comes up:}

$1=$ Very Unlikely to $9=$ Very Likely

\begin{tabular}{|l|l|l|l|l|l|l|l|l|l|}
\hline $\begin{array}{l}\text { 1. both of us avoid discussing the } \\
\text { problem }\end{array}$ & 1 & 2 & 3 & 4 & 5 & 6 & 7 & 8 & 9 \\
\hline 2. both of us try to discuss the problem. & 1 & 2 & 3 & 4 & 5 & 6 & 7 & 8 & 9 \\
\hline $\begin{array}{l}\text { 3. I try to start a discussion while he/she } \\
\text { tries to avoid a discussion. }\end{array}$ & 1 & 2 & 3 & 4 & 5 & 6 & 7 & 8 & 9 \\
\hline $\begin{array}{l}\text { 4. he/she tries to start a discussion } \\
\text { while I try to avoid a discussion. }\end{array}$ & 1 & 2 & 3 & 4 & 5 & 6 & 7 & 8 & 9 \\
\hline
\end{tabular}

During a discussion of the issue or problem: $1=$ Very Unlikely to $9=$ Very Likely

5. both of us express our feelings to each other.

6. both of us blame, accuse and criticize each other.

7. both of us suggest possible solutions and compromises.

8. I pressure, nag or demand while he/she withdraws, becomes silent, or refuses to discuss the matter further.

9. he/she pressures, nags, or demands while I withdraw, become silent or refuse to discuss the matter further. 10. I criticize while he/she defends him/herself.

11. he/she criticizes while I defend myself.

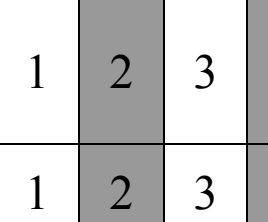

\begin{tabular}{|l|l|l|l|l|l|}
4 & 5 & 6 & 7 & 8 & 9 \\
\hline 4 & 5 & 6 & 7 & 8 & 9 \\
\hline
\end{tabular}

\begin{tabular}{ll|l|l|}
1 & 2 & 3 & 4
\end{tabular}

\begin{tabular}{lll|l|}
1 & 2 & 3
\end{tabular}

4

5

\begin{tabular}{l|l|l}
7 & 8 & 9
\end{tabular}

\begin{tabular}{|l|l|l|l|l|l|l|l|l|}
1 & 2 & 3 & 4 & 5 & 6 & 7 & 8 & 9 \\
\hline 1 & 2 & 3 & 4 & 5 & 6 & 7 & 8 & 9 \\
\hline 1 & 2 & 3 & 4 & 5 & 6 & 7 & 8 & 9 \\
\hline
\end{tabular}




\section{CURRICULUM VITAE}

\section{Erin Elizabeth Ness Roberts}

HOME

2212 Richland Ave

Louisville, KY 40218

(425) 213-4361

erinnessroberts@gmail.com

\author{
WORK \\ Willow Oak Counseling \\ 125 Fairfax Ave, Louisville, KY \\ (502) 509-5773 \\ erinroberts@willowoakcounseling.com
}

\section{EDUCATION}

Ph.D. Candidate, 2011-Present, Kent School of Social Work, University of Louisville Anticipated Graduation: December $18^{\text {th }}, 2015$

Research Emphasis: Dynamics of Intimate Partner Violence

Dissertation: Differences in the impact of a healthy relationships intervention on family cohesion, the parent-child relationship and child well-being by Intimate Partner Violence relationship type

MSSW-MFT, 2010, Kent School of Social Work, University of Louisville

Culminating Research Project: Optimistic bias in relationships of Intimate Terrorism

BA, 2004, English, Dickinson College

PROFESSIONAL APPOINTMENTS

Adjunct Instructor, 2012-2014, Kent School of Social Work, University of Louisville

Spalding University

\section{TEACHING EXPERIENCE}

Critical Thinking and Reflective Practice, Instructor, Summer 2015

University of Louisville, Kent School of Social Work

Human Behavior in the Social Environment II, Adjunct Instructor, Spring 2014

Macro Social Work Practice (Online), Adjunct Instructor, Spring 2014

Human Behavior in the Social Environment I, Adjunct Instructor, Fall 2013

Micro Social Work Practice (Online), Adjunct Instructor, Fall 2013

Advanced Research Practice I, Invited Lecturer, Qualitative Methods, Fall 2013

Intimate and Family Relationships, Invited Lecturer, Fall 2013

Introduction to Marriage \& Family Therapy (Online), Adjunct Instructor, Summer 2013

Human Behavior in the Social Environment II, Adjunct Instructor, Spring, 2012 
Family Relationships (Online), Teaching Assistant, Spring 2012

Human Behavior in the Social Environment I, Adjunct Instructor, Fall 2012

Micro Marital and Family Intervention Issues in the Profession and the

Community, Invited Lecturer, Love Notes, Fall 2012

\section{PUBLICATIONS}

Sterrett, E.M, Kincaid, C.K., Ness, E.E., Gonzolez, M., McKee, L.G., Jones, D.J. (2013)

Youth functioning in the co-parenting context: A mixed methods study of African American single mother families. Journal of Child and Family Studies, DOI: 10.1007/s10826-013-9857-4

Karam, E., Antle, B., Ness Roberts, E. (manuscript under review). Intergenerational Transmission of intimate partner violence and its impact on adolescent relationship attitudes: A qualitative study. Journal of Family Social Work.

Antle, B., Karam, E., Ness, E (manuscript in preparation). Best practices in relationship education, the recruitment and retention of low income individuals.

Antle, B.F., Ness Roberts, E. (manuscript in preparation). CAN YOU HEAR ME?!?!: Explorations in communication patterns in intimate partner violence perpetration and victimization.

Antle, B.F., Ness, E., Brown, J.H., \& Pulce, T. (manuscript in preparation) Empowering unmarried parents for success: Preliminary findings.

Antle, B.F., Ness Roberts, E.E, Owens, J., Barbee, A. (manuscript in preparation). Gender differences in satisfaction with and benefits from a healthy relationships program to prevent intimate partner violence.

\section{CONFERENCE ACTIVITY/PREPARATION}

2015 Ness Roberts, E.E \& Antle, B.F.: Controlled Parenting: Why Violent Control Makes a Difference in Intimate Partner Violence Relationships, Workshop, International Violence Abuse and Trauma Conference, San Diego, California,

2014 August 24, 2015.

Antle, B.F. \& Ness Roberts, E.E.: School of Hearts: Embedding Violence Prevention in the College Classroom, Workshop, $16^{\text {th }}$ Annual Ending Sexual

2014 Assault \& Domestic Violence Conference, Lexington, Kentucky, December 1012, 2014.

Antle, B.F., \& Ness Roberts, E.E.: It's Logistics! Creating Optimal Results for

2014 Relationship Education Programs in the Community. Workshop, International Violence, Abuse and Trauma Conference, San Diego, California, September 10, 2014.

2013 Collins, W.L. \& Ness Roberts, E.E.: The new cyber-face of practice: What's different about teaching online. The Association of Baccalaureate Social Work Program National Directors Conference, March 21, 2014.

2012 Antle, B.F, Ness Roberts, E., Barbee, A.: Relative effectiveness of communitybased violence prevention for different types of interpersonal violence. International Violence Abuse and Trauma Conference, Poster Presentation, San Diego, California, September 5-7, 2013

2012 Ness Roberts, E.E. \& Antle, B.: Can You Hear Me?!?!: Differentiating Communication Patterns and Communication Changes in Intimate 
Terrorism and Situational Violence after a Relationship Education Class, International Violence, Abuse and Trauma Conference, Poster Presentation, San Diego, California, September 10-13, 2012.

2012 Langley, C.H., Barbee, A.P. \& Ness, E.E.: A Cross-sectional Review of the Sexual Health Practices and Outcomes of Youth Participating in the CHAMPS! Teen Pregnancy Prevention Program, Kentucky HIV Fair, Presentation, Frankfort, Kentucky, August 15.

2012 Langley, C., Barbee, A. P., Antle, B. F., Dryden, A. A., \& Ness, E.: Prevention of MTV's Teen Mom 3: An Effective Method for Teaching Abstinence and Sexual Education to High-Risk Adolescents presented during the 140th American Public Health Association Annual Meeting, San Francisco, California, October $27-31,2012$.

\section{RESEARCH EXPERIENCE}

2011- Program Coordinator, CHAMPS! Teenage Pregnancy Prevention,

2013 University of Louisville, Kent School of Social Work.

Funded by: Department for Health and Human Services, Administration on Children and Families, Office of Adolescent Health, 5-yr, \$4.8 million research grant for 1,200 youth

Presented research findings at the 2013 Mid-Grant retreat

Responsible for insuring IRB compliance \& study logistics

2013 Program Coordinator, CHAMPS! The Effectiveness of Parenting on Teenage Pregnancy Prevention Study, University of Louisville, Kent School of Social Work

Appointed to implement of a smaller, 300-participant parent study on the Effect of Parenting on Teen Pregnancy Prevention as a part of the CHAMPS! grant.

2010- Program Coordinator, Relationship Education Across Louisville:

2011 Promoting Healthy Relationships for At-Risk Adults and Youth through Community-Based Training and Collaboration, University of Louisville, Kent School of Social Work

Funded by: Department for Health and Human Services, Administration on Children, Youth and Families, Office of Family Assistance, 5-year, \$2.5 million healthy relationships grant for adults and adolescents

Implemented Diary Study; a mixed-methods study on relationship decisionmaking

Collected data on 40 participants, created data codebooks

Organized details for healthy relationships classes and Training of Trainers

2008- Student Assistant, Relationship Education Across Louisville, University of

2010 Louisville, Kent School of Social Work

Instructor for the Love Notes Curriculum for 2009-2010

Assistant at Within My Reach, healthy relationships programs for adults Logistics for Love U2 healthy relationship program for teens/young adults Collected fidelity and data in accordance with University IRB 
Administered data collection for each program

Trained in the Love Notes \& Within My Reach curriculum

2010- Facilitator, Empowering Young Unmarried Parents for Success, University

2011 of Louisville, Louisville, KY

Facilitated court-ordered co-parenting program for young adults with children Co- created curriculum, power points, projects \& facilitated services for participants

Arranged for service providers in the community to speak to young parents

Conducted collaborative meetings with the Family Court team

Coordinated logistics for the project

\section{CLINICAL EXPERIENCE}

2015 Our Lady of Peace, Access Center, Clinician II, Louisville, KY

2015 Uspiritus, Contract Therapist, Louisville, KY

2013-2015 Willow Oak Counseling, Co-Founder and Therapist, Louisville, KY

2009-2010 Family \& Children's First, Intern Therapist, Louisville, KY

2009 Home of the Innocents, Contract Clinician, LaGrange, KY

2008-2009 Home of the Innocents, Clinical Intern, Louisville, KY

\section{PROGRAM DEVELOPMENT}

2014 Depression Disease Management Program, Coordinated Health Mutual, Ohio

2013- Mental Health Consultant \& Grant Writer, Coordinated Health Mutual,

Present Columbus, $\mathrm{OH}$

2013- $\quad$ Facilitator, LoveSmart, Healthy Marriage and Relationship Program,

Present Multi-Purpose Community Action Center, Shelbyville, KY

2010 Career Coach, SummerWorks, KentuckianaWorks, Louisville, KY

2008-2011 Relief Social Services Assistant, Home of the Innocents, Louisville, KY

2006-2008 Client Information Management Specialist, Home of the Innocents, Louisville, KY

2006

Social Services Assistant, Home of the Innocents, Louisville, KY

PROFESSIONAL ASSOCIATIONS

National Association of Social Workers, Active Member, 2008-Current

American Association of Marriage \& Family Therapists, Active Member, 2008-

Current

Kentucky Association of Marriage and Family Therapists, Active Member, 2008-

Current

The Association of Baccalaureate Social Work Program Directors, Previous Member, 2014

Lou. Independent Business Association (LIBA), Active Member, Business Owner, 2013-Current

National Public Radio, Active Member, 2013-2015 


\section{VOLUNTEER WORK}

St. Luke's Episcopal Church Youth Group, Youth Group Adult Leader, 2014-Current

St. Luke's Episcopal Church Pastoral Care Team, Volunteer, 2014-Current

\section{PERSONAL INTERESTS \& PURSUITS}

Zumba, dogs, antique \& flea market shopping, genealogy, house projects, books \& coffee. 